\title{
REORGANIZACIÓN DE LAS RESPUESTAS NEURONALES EN EL COLÍCULO INFERIOR DE LA RATA TRAS EXPOSICIÓN A UN AMBIENTE ACÚSTICO MODIFICADO Y TRAUMA ACÚSTICO
}

REORGANIZATION OF NEURONAL RESPONSES IN THE INFERIOR COLLICULUS OF THE RAT AFTER EXPOSURE TO A MODIFIED ACOUSTIC ENVIRONMENT AND ACOUSTIC TRAUMA

Memoria presentada por Marco Antonio Izquierdo Gómez para optar al grado de

Doctor Europeo por la Universidad de Salamanca

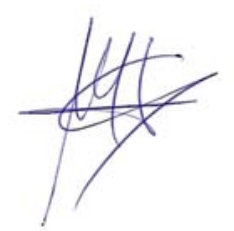

Directores:

Prof. Dr. D. Manuel Sánchez Malmierca Prof. Dr. D. Miguel Ángel Merchán Cifuentes

Salamanca, 2009

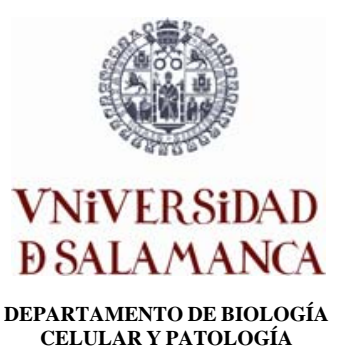



Este trabajo ha sido financiado por el MEC (BFI-2003-09147-02-01), el MICINN (BFU2006-00572) y la Junta de Castilla y León - Fondo Social Europeo (GR221 y SAN673/SA20/08). 

MANUEL SÁNCHEZ MALMIERCA, PROFESOR TITULAR DE UNIVERSIDAD DEL DEPARTAMENTO DE BIOLOGÍA CELULAR Y PATOLOGÍA DE LA UNIVERSIDAD DE SALAMANCA Y

MIGUEL MERCHÁN CIFUENTES, CATEDRÁTICO DEL DEPARTAMENTO DE BIOLOGÍA CELULAR Y PATOLOGÍA DE LA UNIVERSIDAD DE SALAMANCA

\section{CERTIFICAN}

Que la tesis doctoral titulada:

\section{REORGANIZACIÓN DE LAS RESPUESTAS NEURONALES EN EL COLÍCULO INFERIOR DE LA RATA TRAS EXPOSICIÓN A UN AMBIENTE ACÚSTICO MODIFICADO Y TRAUMA ACÚSTICO}

ha sido redactada en español, contiene un resumen en inglés, y describe el trabajo de investigación realizado por D. Marco Antonio Izquierdo Gómez bajo nuestra dirección durante los últimos 4 años.

La memoria de este estudio recoge un análisis exhaustivo y detallado de la organización tonotópica del colículo inferior de la rata. Además, la tesis demuestra como esta organización se modifica tras someter a los animales de experimentación ante diferentes medios acústicos, ya sean de tipo traumático o un medio acústico enriquecido.

Los datos presentados en esta memoria constituyen una aportación original y han permitido un avance significativo en el conocimiento de la organización funcional del colículo inferior.

Por todo ello, consideramos que esta tesis reúne la calidad y rigor científicos necesarios para que sea defendida en la Universidad de Salamanca como requisito para que D. Marco Antonio Izquierdo Gómez opte a los grados de 'Doctor' y 'Doctor Europeus' por la Universidad de Salamanca.

Y para que así conste, firmamos el presente certificado en Salamanca a 11 de Junio de 2009. 

Debo agradecer en primer lugar al Profesor Manuel Sánchez Malmierca su apoyo y dedicación durante este tiempo, además de sus valiosas enseñanzas y consejos.

También agradezco al Profesor Miguel A. Merchán la oportunidad que me brindó para incorporarme al Laboratorio de Neurobiología de la Audición y poder realizar este trabajo de Tesis.

Sin ellos no hubiera sido posible desarrollar este trabajo.

Al Profesor Douglas L. Oliver de la Universidad de Connecticut Health Center por darme la posibilidad de colaborar con él y por sus valiosas lecciones dentro y fuera del Laboratorio.

Al Profesor Manuel Gutiérrez Conde por su inestimable ayuda en la parte técnica del Proyecto, su paciencia y disposición en todo momento.

Al Profesor Alberto Recio-Spinoso por su amabilidad durante mi estancia en su laboratorio del Hospital Universitario de Leiden.

Al Profesor Alan R. Palmer del MRC Institute of Hearing Research de la Universidad de Nottingham por enseñarnos la técnica PAC y ayudarnos a ponerla a punto.

Al Profesor Charles Liberman de la Harvard Medical School de Boston, Massachussets, por sus consejos para el diseño y elaboración de la caja de estimulación utilizada en nuestros experimentos de trauma acústico.

Al resto de Profesores del Laboratorio de Neurobiología de la Audición: Profs. Ma Dolores E. López, Enrique A. López Poveda, Enrique Saldaña, Juan Carlos Arévalo, Orlando Castellanos.

A todos y cada uno de los miembros de dicho laboratorio: Almudena, Anchieta, Auxi, Cheryl, Med, Nacho, Patricia, Peter, les agradezco todo lo que hemos compartido y el tiempo que hemos pasado juntos, que les ha convertido en parte de mi familia. No quisiera olvidarme de aquellos que se han incorporado recientemente: Ana, Jorge, Tao y Verónica.

A David porque, aún en la distancia, nos proporciona su ayuda y nos ofrece su experiencia en todo momento.

A Flora, mi compañera de trabajo más directa durante este período.

Me gustaría agradecer de manera muy especial a Olga y a Richard por ser compañeros, pero sobre todo amigos.

A Virginia, con quien he compartido gran parte de este camino, con algunos momentos duros, pero con infinidad de momentos dulces.

A mi familia, a quienes va dedicado este trabajo, por su apoyo incondicional, su aliento en los momentos difíciles y por ser lo más importante en mi vida. 



\section{PUBLICACIONES ORIGINALES}

Esta tesis está basada en las siguientes publicaciones:

1.- Izquierdo M A, Gutiérrez-Conde P M, Merchán M A y Malmierca M S (2008).

Non-plastic reorganization of frequency coding in the inferior colliculus of the rat following noise-induced hearing loss.

Neuroscience. 154: 355-369.

2.- Malmierca MS, Izquierdo MA, Cristaudo S, Hernández O, Pérez-González D, Covey E y Oliver D L (2008).

A discontinuous tonotopic organization in the inferior colliculus of the rat.

Journal of Neuroscience. 28: 4767-4776.

3.- Izquierdo M A, Malmierca M S y Oliver D L (2009).

Functional and activity-dependent plasticity mechanisms in the adult and developing auditory brain.

Revista de Neurología. 48: 421-429. 

Estructura y función del sistema auditivo

Inicio y maduración de la actividad en respuesta al sonido ........................................................ 8

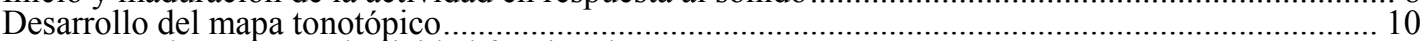

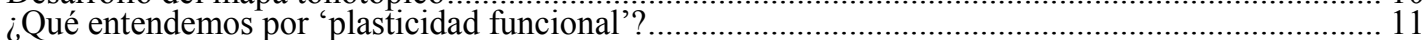

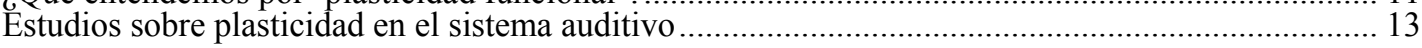

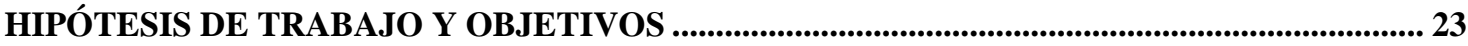

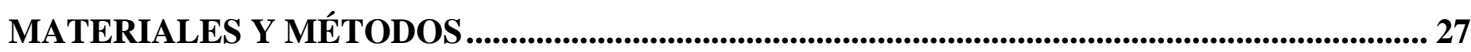

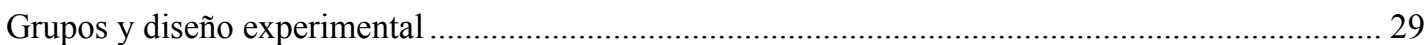

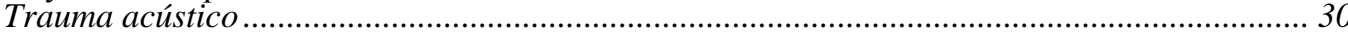

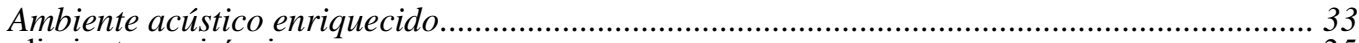

Procedimientos quirúrgicos ............................................................................................. 35

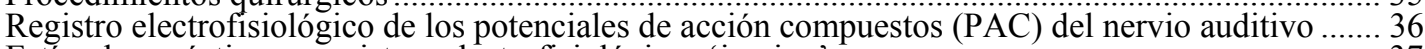

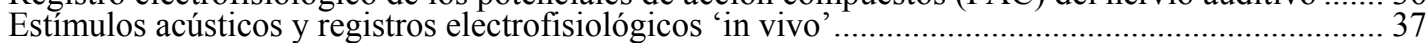

Verificación histológica de los lugares de registro .......................................................................... 43

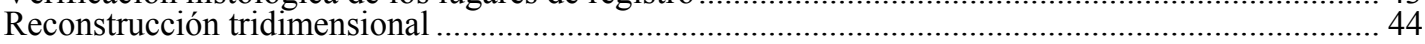

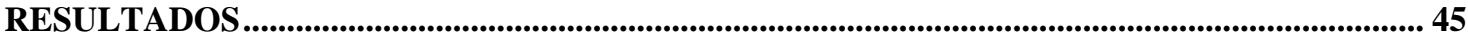

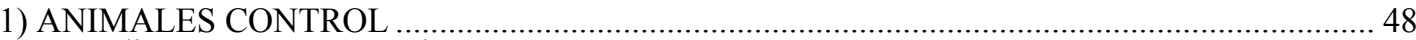

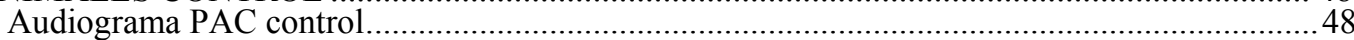

Mapa tonotópico del colículo inferior .........................................................................................5

Mapas de frecuencia de neuronas aisladas en el colículo inferior.................................................54

Análisis de la representación de frecuencias en el colículo inferior ............................................... 55

Reconstrucción tridimensional de las láminas de isofrecuencia del colículo inferior ................... 57

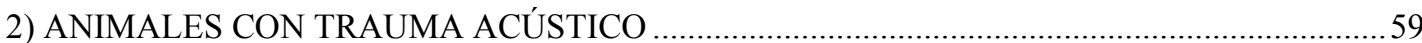

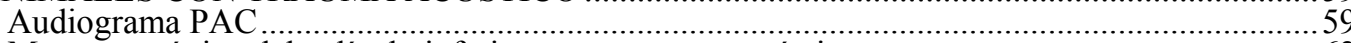

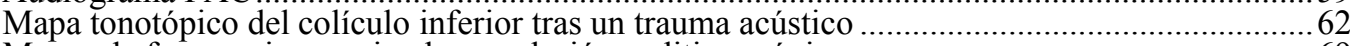

Mapas de frecuencia en animales con lesión auditiva crónica ................................................69

3) ANIMALES SOMETIDOS A UN AMBIENTE ACÚSTICO ENRIQUECIDO ......................... 75

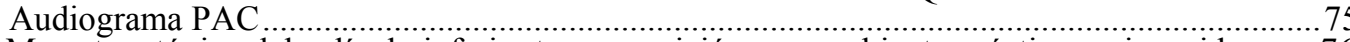

Mapa tonotópico del colículo inferior tras exposición a un ambiente acústico enriquecido .........7 76

Mapas de frecuencia tras exposición a un ambiente acústico enriquecido ................................ 81

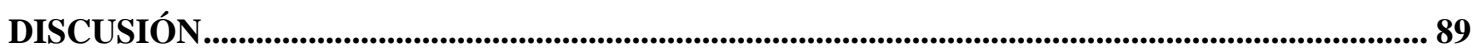

Limitaciones técnicas y consideraciones metodológicas .......................................................... 93

Organización tonotópica del colículo inferior: ¿cómo se relaciona la distribución discontinua de las frecuencias óptimas de neuronas con las láminas anatómicas del colículo inferior? ...... 98

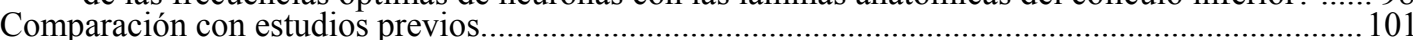

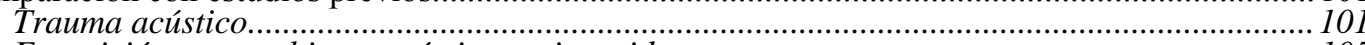

Exposición a un ambiente acústico enriquecido .............................................................................. 105

Reorganización del mapa tonotópico en el colículo inferior tras un trauma acústico........................ 108

Efectos de la exposición a un ambiente acústico enriquecido sobre la respuesta neuronal en el colículo inferior

Importancia funcional y posibles implicaciones clínicas de la reorganización

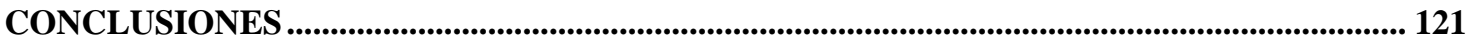

ABREVIATURAS ......................................................................................................................................... 125

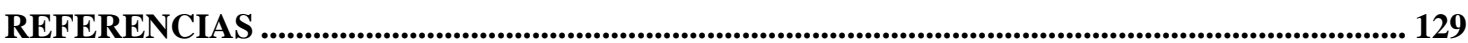

APÉNDICE I: Publicaciones originales

APÉNDICE II: Summary 

INTRODUCCIÓN 

Los sistemas sensoriales poseen una representación topográfica del epitelio sensorial en el sistema nervioso central. Esta característica fundamental también está presente en el sistema auditivo de la rata en forma de mapas tonotópicos de los receptores auditivos (Malmierca, 2003). Durante muchos años se ha pensado que estos mapas sensoriales sólo podían modificarse durante el desarrollo, especialmente a lo largo de determinados 'períodos críticos' que poseen una duración limitada, tal y como describieron hace casi 40 años Hubel y Wiesel (1970). Por aquel entonces se pensaba que esta capacidad de modificación de los mapas sensoriales se perdía en el cerebro adulto (Hubel y Wiesel, 1970; Blakemore y Van Sluyters, 1974). Sin embargo, en la actualidad sabemos que los mapas sensoriales tienen una gran capacidad de reorganización. Así pues, pueden cambiar su configuración si el sistema sensorial maduro se ve privado de sus aferencias normales de forma crónica, p. ej., como consecuencia de una lesión periférica (Merzenich et al., 1983a, b; Robertson e Irvine, 1989) o como resultado de las experiencias sensoriales adquiridas a lo largo de la vida del individuo (Recanzone et al., 1993).

Estos mapas sensoriales reflejan las respuestas de miles de neuronas individuales. Así pues, las propiedades de respuesta básicas de estas neuronas corticales se modifican como consecuencia de diferentes paradigmas de condicionamiento (Ryugo y Weinberger, 1978; Irvine y Wright, 2005; Weinberger, 2007). Esto se traduce en una modificación del mapa sensorial a consecuencia de cambios en las condiciones y estímulos ambientales.

En esta tesis doctoral hacemos un estudio de los cambios que se producen en los mapas sensoriales y en las propiedades de respuesta de las neuronas del colículo inferior (CI) de la rata en dos modelos bien diferentes pero complementarios. Por un lado estudiaremos los cambios que sufren las neuronas del CI tras la exposición a un ambiente acústico alterado y patológico, como es el trauma acústico en el animal adulto. Por otro, estudiaremos los cambios de estas mismas neuronas y mapas tras la exposición a un ambiente acústico modificado y enriquecido (pero no traumático) durante el desarrollo.

\section{ESTRUCTURA Y FUNCIÓN DEL SISTEMA AUDITIVO}

El sistema auditivo procesa la información acústica del entorno mediante el análisis de las propiedades temporales, espectrales y biaurales de los sonidos (Malmierca, 2003). Tras este análisis se obtiene una representación mental del espacio acústico que rodea al sujeto, separando unos sonidos de otros y localizando su origen. Las ondas de presión sonora atraviesan el oído externo hasta alcanzar la membrana timpánica, a la que transmiten su energía. Esta energía se propaga por la cadena de huesecillos del oído medio donde además se amplifica y se transmite al oído interno o cóclea a través de la ventana oval. En la cóclea se encuentra el órgano receptor auditivo u órgano de Corti, donde las ondas sonoras hacen vibrar la membrana basilar. Esta membrana posee unas características estructurales que determinan un comportamiento diferente a lo largo de su extensión, en función de la frecuencia del sonido. De esta forma, para cada frecuencia hay un punto en la membrana basilar que vibra con una amplitud máxima (von Békésy, 1960). Esta propiedad permite descomponer los sonidos complejos del medio en diferentes tonos puros, por lo 
que la membrana basilar se comporta como un analizador de frecuencias o de Fourier ${ }^{1}$. Posteriormente, las vibraciones de la membrana basilar se transforman en potenciales de acción (el lenguaje de las neuronas) gracias al órgano de Corti, que se localiza sobre la membrana basilar (para una revisión detallada del proceso ver Dallos, 1992a, b; Nobili et al., 1998 y más recientemente Malmierca, 2003; Malmierca y Merchán, 2004). El órgano de Corti posee células ciliadas internas y externas que junto con las membranas tectoria y basilar, son quienes dan lugar a la transducción de las ondas de presión en potenciales de acción (mecanismo de transducción mecanoeléctrica).

Así pues, a lo largo de la membrana basilar se produce una distribución espacial de las frecuencias que se conoce como cocleotopía. Esta organización espacial o topográfica se conserva, de forma separada y ordenada, en las fibras del nervio coclear y en todos los núcleos de la vía auditiva, donde se refiere como tonotopía. La mayoría de las neuronas, en todos los centros auditivos, responden mejor a sonidos de una frecuencia determinada, denominada frecuencia óptima (FO). La FO se define como la frecuencia del sonido capaz de provocar la respuesta de una neurona con la menor intensidad de estimulación. Las neuronas con un rango de FO similar se organizan en láminas de isofrecuencia, que determinan la organización tonotópica de los diferentes núcleos auditivos. El substrato morfológico de la tonotopía, en la mayoría de los núcleos de la vía auditiva central, son las láminas fibrodendríticas. Dichas láminas fueron descritas por primera vez en 1964 por Morest en el cuerpo geniculado medial y en el CI (Morest, 1964a, b).

La vía auditiva está constituida por dos componentes: una vía ascendente y otra descendente (para una revisión detallada de la vía auditiva en la rata ver Malmierca, 2003 y Malmierca y Merchán, 2004). La vía ascendente (Fig. 1A) transmite la información sensorial desde la cóclea hasta la corteza cerebral auditiva, situada en el lóbulo temporal superior, a través de una serie de núcleos bilaterales interconectados. A nivel bulbar se encuentran el complejo de los núcleos cocleares, el complejo olivar superior y los núcleos del lemnisco lateral. Desde los núcleos del lemnisco lateral la información se transmite al tronco del encéfalo, donde se localiza el CI. En el tálamo, el cuerpo geniculado medial y la porción auditiva del núcleo reticular del tálamo modulan la información y la transmiten a la corteza auditiva (para una revisión detallada ver Winer, 1992; Malmierca, 2003).

La vía auditiva descendente (Fig. 1B) transmite la información en sentido inverso, es decir, desde la corteza auditiva hasta el receptor auditivo. De forma muy general y simplificada podemos decir que cada núcleo de la vía auditiva modula la actividad de uno o varios núcleos inferiores.

El CI se localiza en la porción dorsal del mesencéfalo, inmediatamente caudal al colículo superior (Ramón y Cajal, 1902; Faye-Lund y Osen, 1985). El CI juega un papel clave en el sistema auditivo, ya que constituye un centro de análisis, integración y distribución de la información auditiva hacia el tálamo auditivo y los núcleos inferiores (Malmierca y Merchán, 2004).

El núcleo central del colículo inferior (NCCI) está rodeado por regiones corticales. En la rata se distinguen tres áreas corticales: la corteza dorsal del CI, la corteza lateral y la corteza rostral del CI (Fig. 2; Malmierca, 1991; Loftus et al., 2008). La corteza dorsal cubre las partes caudal y dorsomedial del CI. En la rata, la corteza lateral rodea las porciones lateral y ventral. La corteza rostral cubre la parte rostral del NCCI. La corteza lateral del CI no sólo responde a estímulos auditivos, sino también a estímulos somatosensoriales. El NCCI es el centro puramente auditivo del CI. En todas las especies estudiadas, el NCCI se caracteriza por presentar una organización tonotópica.

\footnotetext{
${ }^{1}$ El análisis de Fourier se basa en el hecho de que toda función periódica, sea cual sea su complejidad, se puede descomponer en una suma infinita de funciones básicas.
} 
A

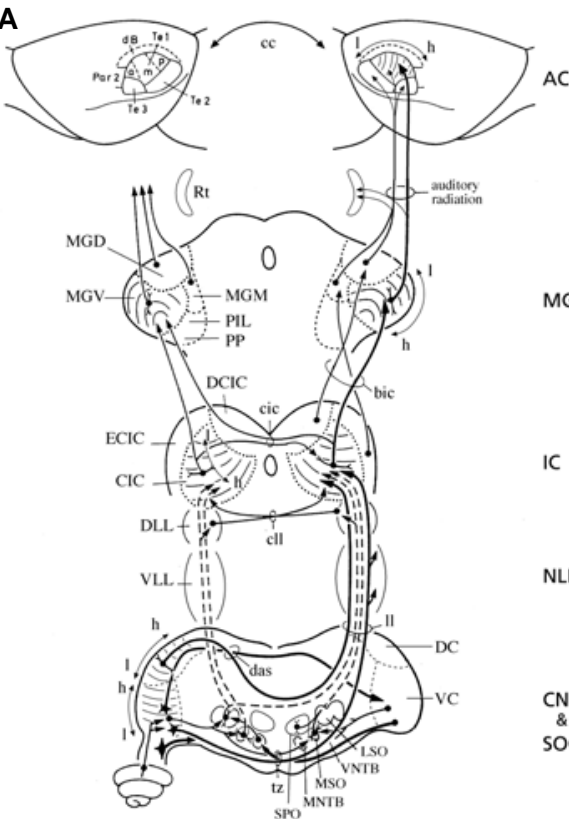

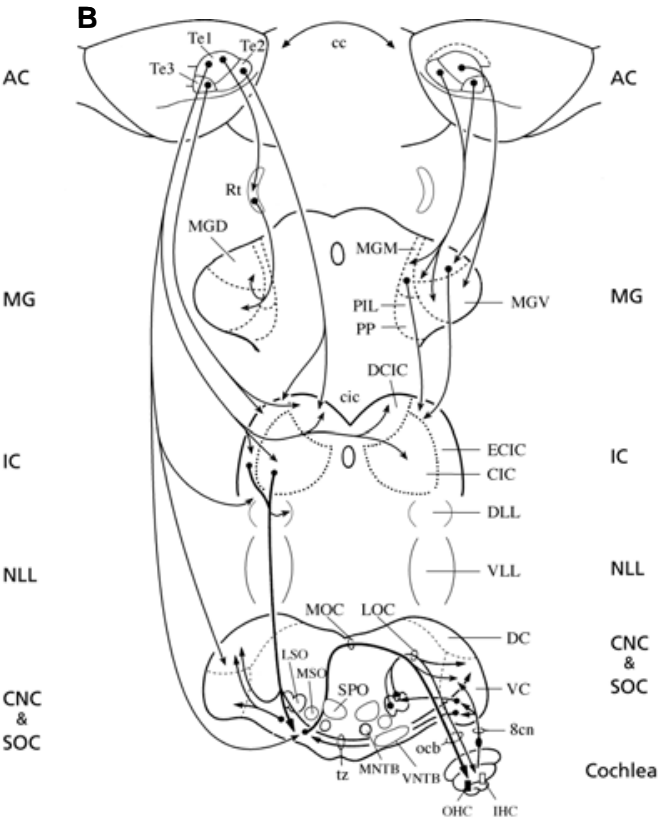

Figura 1. Esquema de la vía auditiva ascendente (A) y descendente (B) de la rata. Tomado de Mamierca, 2003.

El substrato morfológico de esta organización, como ya hemos visto, son las láminas fibrodendríticas (Morest, 1964b; Oliver y Morest, 1984; Malmierca, 1991; Malmierca et al., 1993, 1995), que están formadas por las fibras aferentes que inervan el CI y las neuronas planas (Malmierca, 1991; Malmierca et al., 1993, 1995, 2005).

Los estudios electrofisiológicos han puesto de manifiesto una clara correspondencia entre la tonotopía y la organización laminar del CI (Merzenich y Reid, 1974; Schreiner y Langner, 1997; Malmierca et al., 2008). Las neuronas de las láminas dorsolaterales responden a tonos puros de frecuencias bajas y las neuronas de las láminas ventromediales responden a tonos de frecuencias altas (Rose et al., 1963; Merzenich y Reid, 1974; Malmierca et al., 2008; ver Fig. 2). De esta forma se cubre todo el rango de audición en la rata $(0.25-70 \mathrm{kHz}$; Heffner et al., 1994), mediante las 8 a 10 láminas descritas en el NCCI (Malmierca et al., 1993). 

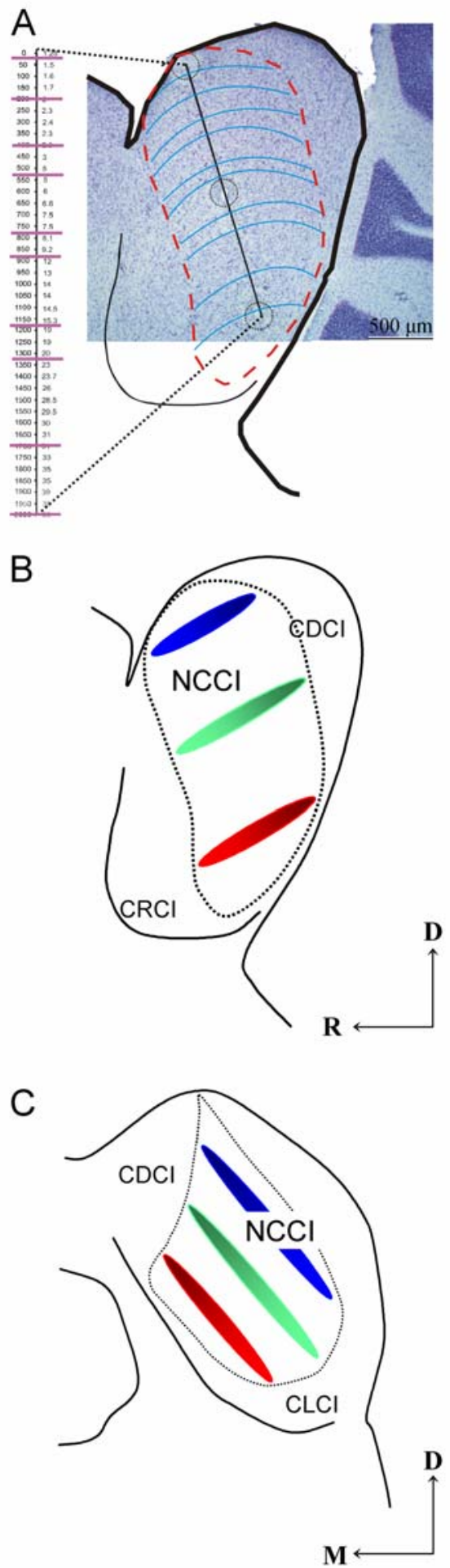

Figura 2. A) Sección parasagital del CI de la rata en la que se observan 3 lesiones electrolíticas (círculos) realizadas durante el recorrido de salida del electrodo (línea continua). El ángulo de penetración del electrodo es $10^{\circ}$ con respecto al plano vertical. A la izquierda se muestra la progresión de la frecuencia en función de la profundidad de registro. B y C) Esquemas de una sección parasagital (B) y coronal (C) del CI. En el CI de la rata se distinguen tres áreas corticales: la corteza dorsal (CDCI), la corteza rostral $(\mathrm{CRCI})$ y la corteza lateral del colículo inferior (CLCI). Las líneas de colores representan láminas de isofrecuencia: azul, frecuencias bajas; verde, frecuencias medias y rojo, frecuencias altas. Las líneas discontinuas delimitan el núcleo central del colículo inferior (NCCI). Podemos observar la disposición de las láminas de isofrecuencia en ambos planos. R, Rostral; D, dorsal; M, medial. 
Nuestra hipótesis de trabajo general parte de la base de que el tamaño y número de estas láminas podría alterarse de manera permanente en respuesta a modificaciones del ambiente acústico, tal y como se ha demostrado a nivel cortical (v.s.). Sin embargo, desconocemos los mecanismos funcionales de estas alteraciones y si son meramente pasivos o por el contrario dependen de un proceso activo que implique un mecanismo real de plasticidad.

\section{INICIO Y MADURACIÓN DE LA ACTIVIDAD EN RESPUESTA AL SONIDO}

El desarrollo de la cóclea tiene una enorme influencia sobre el desarrollo de la actividad provocada por el sonido y sobre la configuración del mapa tonotópico en el sistema auditivo central (Lippe y Rubel, 1983; Rubel y Ryals, 1983). En la cóclea inmadura sólamente la base responde al sonido y sólo lo hace en respuesta a frecuencias bajas (Lippe y Rubel, 1983; Rubel y Ryals, 1983; Harris y Dallos, 1984; Ryals y Rubel, 1985). Durante su maduración, el mismo punto de la cóclea responde a frecuencias progresivamente más altas, a medida que la actividad se mueve en una onda desde la base hacia el ápice, hasta que la cóclea responde al rango completo de frecuencias (Fig. 3; Lippe y Rubel, 1983; Rubel y Ryals, 1983). Durante el desarrollo, el punto de máxima sensibilidad a frecuencias bajas y medias se desplaza gradualmente hacia el ápice de la cóclea, a medida que el extremo basal comienza a responder a frecuencias más altas. Este efecto implica que las neuronas del sistema nervioso central pueden ser estimuladas por sonidos diferentes durante el desarrollo. Ello se traduce en una modificación de la organización tonotópica en los núcleos de la vía auditiva durante el desarrollo (Fig. 3).

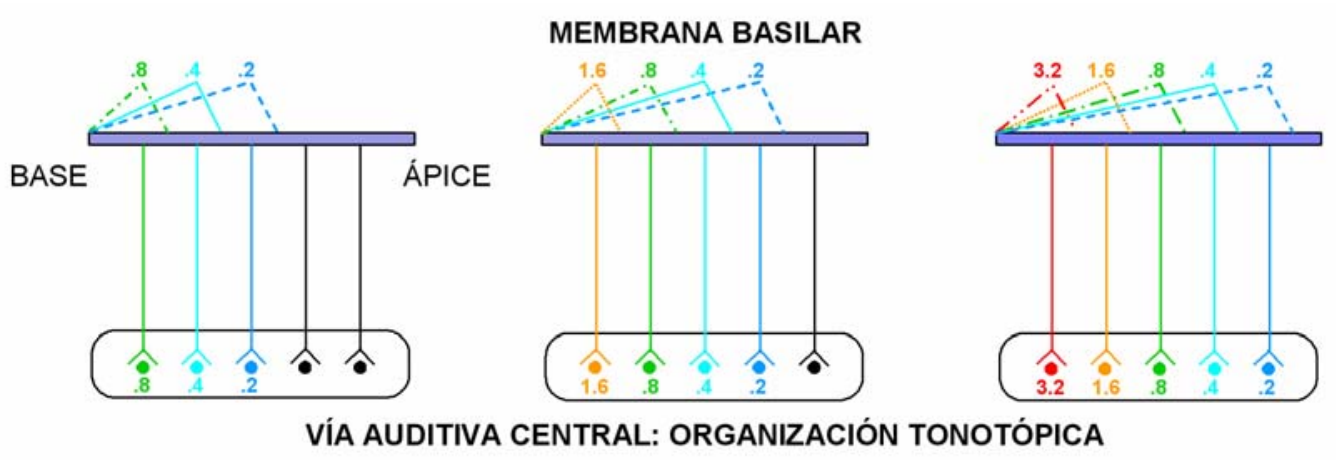

INMADURO

MADURO

DESARROLLO

Figura. 3. Inicio y desarrollo de la función auditiva. Modelo propuesto originalmente por Rubel y colaboradores para explicar el cambio que tiene lugar, durante el desarrollo, en el código de posición de la membrana basilar. Durante el desarrollo, el punto de máxima sensibilidad a frecuencias bajas de la membrana basilar se desplaza hacia el ápice de la cóclea de forma gradual, a medida que el extremo basal comienza a responder a frecuencias más altas. Este efecto implica que las neuronas de la vía auditiva central modifican su frecuencia de respuesta durante el desarrollo, lo cual se traduce en una modificación de la organización tonotópica en los núcleos de la vía. Modificado de Lippe y Rubel, 1985. 


\section{Desarrollo del mapa tonotópico}

Los componentes estructurales principales del mapa tonotópico central están presentes antes de la maduración de la cóclea y del inicio de la audición (Gabriele et al., 2000), que en la rata tiene lugar a P12 (Uziel et al., 1981; Blatchley et al., 1987; Puel y Uziel, 1987; Kelly, 1992). Al nacer (P0) ya se han formado las conexiones anatómicas básicas entre la cóclea, tronco del encéfalo y la corteza (incluyendo la llegada de las aferencias lemniscales al CI) y ya existen proyecciones topográficamente organizadas en los núcleos cocleares (Leake et al., 2002) y el complejo olivar superior (Sanes, 1993; Kandler y Gillespie, 2005). Además, los axones procedentes de los núcleos cocleares están ya presentes en el CI en la rata, pero los campos axonales estrechos típicos de las láminas maduras no pueden verse hasta P14 (Friauf y Kandler, 1990; Kandler y Friauf, 1993). De manera análoga, los axones que proyectan desde el núcleo dorsal del lemnisco lateral al CI en la rata también progresan a partir de un estado difusamente organizado a $\mathrm{P} 0$, hacia láminas segregadas a P8, hasta láminas similares a las adultas a P12 (Gabriele et al., 2000; Fathke y Gabriele, 2009). Los axones talamocorticales alcanzan la corteza antes del nacimiento (Wise y Jones, 1978; Catalano et al., 1991). Claramente, la organización tonotópica no está completamente definida al nacer, pero existe una organización morfológica y topográfica básica de las vías. Así pues, durante las 2-3 primeras semanas postnatales, cuando comienza la audición, se deben producir cambios rápidos en el desarrollo que determinen la organización funcional adulta del cerebro auditivo.

Por ello, parece que en el desarrollo de los circuitos cerebrales auditivos están implicados dos tipos de procesos, unos que son dependientes de actividad y otros que no (Friauf y Lohmann, 1999). Un ejemplo de proceso independiente de actividad es la anteriormente mencionada emergencia de la topografía 'básica' que, muy probablemente, está determinada por marcadores moleculares cuya expresión está sometida a un control genético (Friauf y Lohmann, 1999). Por otro lado, la actividad neuronal mantiene la supervivencia neuronal, afecta al crecimiento dendrítico y axonal e influye en la sintonización fina de los mapas. Existen varios tipos de actividad neuronal, a saber, espontánea frente a evocada acústicamente, bilateral frente a unilateral, descoordinada frente a organizada, que desempeñan un papel importante en diferentes aspectos del desarrollo y cooperan con los procesos independientes de actividad para asegurar la formación correcta de los circuitos neuronales (Friauf y Lohmann, 1999).

\section{¿QUÉ ENTENDEMOS POR 'PLASTICIDAD FUNCIONAL'?}

Antes de profundizar en el estudio de las alteraciones en los mapas tonotópicos y considerar un posible fenómeno plástico, es conveniente definir el término plasticidad. Este término es objeto de un abuso muy considerable en el lenguaje científico (Holloway, 2003; Parks y Rubel, 2004; Izquierdo et al., 2008, 2009) e implica numerosos procesos cuyo origen está aún por determinar. El término 'plasticidad' se aplica a una gran cantidad de fenómenos, tales como la recuperación funcional tras una lesión, la neurogénesis en adultos, la reorganización de mapas corticales en función de las distintas experiencias sensoriales, cambios sinápticos asociados al aprendizaje, etc. Todos estos fenómenos y muchos otros suponen una modificación de la respuesta neuronal, pero no todos implican un cambio persistente en las propiedades funcionales de las neuronas (Tsukahara, 1981). 
Para que un cambio sea considerado una manifestación de 'plasticidad funcional' debe expresar algún tipo de mecanismo o proceso activo, que se inicie por un cambio en las aferencias y que no refleje una mera pérdida de aferencias sensoriales (Rajan et al., 1993; Calford, 2002). Es decir, la plasticidad funcional debe expresar una readaptación activa frente a las condiciones cambiantes del medio (para una discusión detallada sobre la definición de plasticidad ver Calford et al., 1993; Rajan, 2001; Calford, 2002; Irvine y Wright, 2005; Izquierdo et al., 2008, 2009). Este proceso activo podría implicar cambios en el número o efícacia de las sinapsis o cambios en las características neuronales intrínsecas de una neurona/s de la vía a través de la que llegan las aferencias (Calford, 2002). Dichos cambios en la eficacia sináptica estabilizan las conexiones de una determinada vía aferente, una vez que éstas alcanzan su 'blanco' (revisado en Morales et al., 2003) y pueden constituir un substrato morfológico para el aprendizaje y la memoria. En concreto, existe un tipo de plasticidad sináptica asociativa o Hebbiana (Hebb, 1949) basada en correlaciones temporales de aferencias. Las conexiones sinápticas que presentan correlaciones positivas se potencian y estabilizan, mientras que aquellas que muestran una correlación negativa o nula se desestabilizan o se eliminan (Singer, 1995). Este fenómeno se fundamenta en que las aferencias procedentes de áreas sensoriales vecinas muestran, en general, más correlación entre sí de la que muestran con áreas no adyacentes. Por lo tanto, las áreas corticales adyacentes deberían representar regiones sensoriales vecinas, estableciendo de este modo un mapa topográfico (Merzenich et al., 1987).

\section{ESTUDIOS SOBRE PLASTICIDAD EN EL SISTEMA AUDITIVO}

Las cortezas sensoriales primarias muestran una gran capacidad plástica tras la alteración de sus patrones de aferencias por denervación periférica (Buonomano y Merzenich, 1998; Calford, 2002).

En la corteza somatosensorial del mono se describió por primera vez una reorganización plástica muy dramática del mapa somatotópico provocada por lesiones periféricas restringidas (Merzenich et al., 1983a). Como resultado de esta reorganización el área cortical que originalmente recibía aferencias de la zona alterada pasaba a representar zonas adyacentes. Asimismo, se produce una reorganización plástica en la corteza motora de animales adultos tras una lesión (Gilbert, 1998). Por ejemplo, si se secciona el nervio facial, el área de la corteza motora que originalmente controlaba la musculatura de la vibrisa pasa a controlar un miembro anterior o de forma alternativa, la musculatura ocular (Sanes et al., 1988; Donoghue et al, 1990).

En el sistema visual, tras lesiones restringidas de la retina, la corteza estriada que recibe aferencias de la zona lesionada se silencia inicialmente, pero tras un período de varios meses recupera su actividad en respuesta a estímulos visuales. Sin embargo, el campo receptivo que representaba las células de la retina lesionada pasa finalmente a representar el área retiniana que rodea a la lesión (Rosa et al., 1995; Schmid et al., 1996).

La corteza auditiva de mamíferos adultos también posee dicha capacidad plástica (Robertson e Irvine, 1989; Rajan et al., 1993, para una revisión detallada ver Irvine y Wright, 2005; Irvine, 2007). Tras una lesión mecánica restringida de la cóclea se produce una 'resintonización' o cambio en la FO de las neuronas corticales que representaban la zona lesionada de la cóclea (Fig. 4A). La corteza ipsilateral se utiliza como autocontrol (Fig. 4B) ya que los receptores que proyectan a esa corteza no han sufrido daño alguno, dado que la lesión es unilateral. Este tipo de lesiones también provocan una reorganización plástica similar a nivel talámico (Kamke et al., 2003). Sin embargo, no se han encontrado 
pruebas de la existencia de plasticidad funcional a nivel troncoencefálico (Rajan e Irvine, 1998a) o se ha puesto de manifiesto la existencia de dicho fenómeno en determinadas zonas o 'parches' en el CI (Irvine et al., 2003).

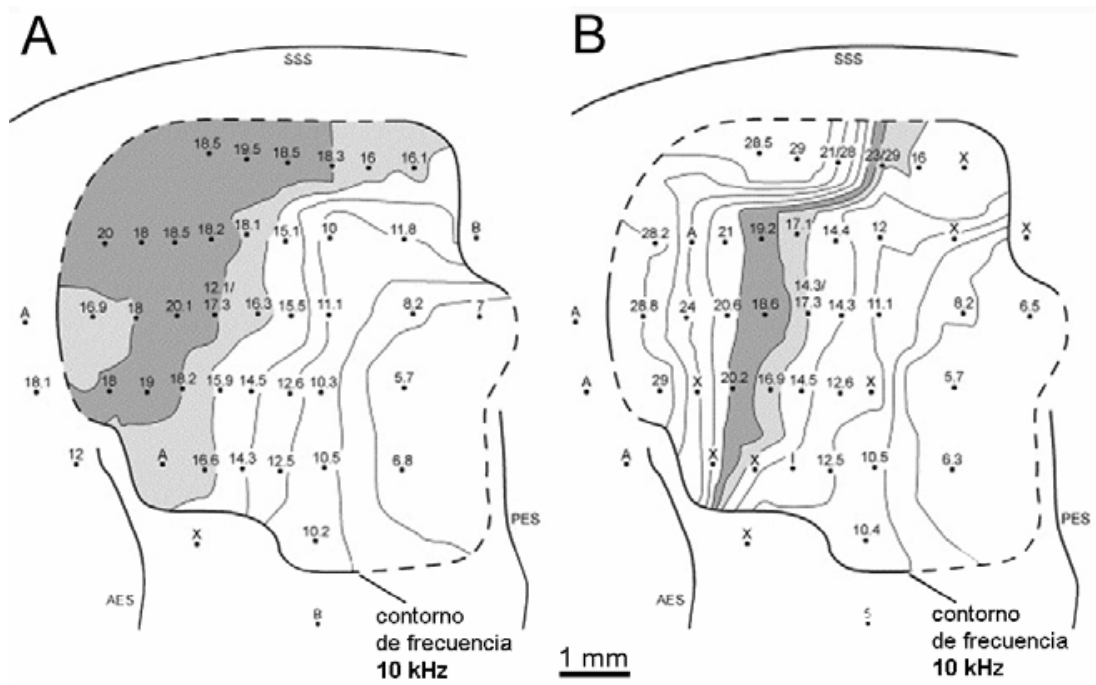

\section{Estimulación contralateral Estimulación ipsilateral}

Figura 4. Mapa tonotópico de la corteza auditiva primaria tras lesión mecánica restringida de la cóclea. Las líneas finas delimitan áreas de isofrecuencia (zonas que responden a la misma frecuencia). El área representada en gris claro corresponde a la frecuencia a la que se realizó la lesión coclear. B) Representación tonotópica de las frecuencias en la corteza control (ipsilateral a la lesión mecánica de la cóclea). A) Reorganización plástica sufrida en el mapa tonotópico de la corteza contralateral tras la lesión. Las frecuencias adyacentes a la lesión (representadas en gris oscuro) sufren una expansión, es decir, están más representadas que en la corteza auditiva control. Modificado de Kamke et al., 2005.

En los núcleos cocleares, en cambio, hay una ausencia de plasticidad funcional tras una lesión coclear restringida (Rajan e Irvine, 1998a) que limita el desarrollo de plasticidad en la representación sensorial de la vía auditiva al CI y núcleos superiores de la vía. Por ello, el CI constituye una pieza clave en investigaciones futuras sobre plasticidad en el sistema nervioso auditivo, ya que representa el primer núcleo de la vía en el que se han observado indicios de plasticidad como consecuencia de este tipo de lesiones periféricas.

Robertson e Irvine formularon una teoría que explica la reorganización de naturaleza 'no plástica' observada en los mapas sensoriales de los núcleos cocleares y determinadas porciones del CI (Robertson e Irvine, 1989; Rajan et al., 1993; Rajan e Irvine, 1998a). Dicha hipótesis, a la que denominaron hipótesis de la 'respuesta residual', plantea que las consecuencias de una lesión periférica sobre la representación central de los receptores son tales que los mapas sensoriales reflejan únicamente la pérdida de aferencias, sin dar lugar a ningún proceso activo de reorganización que pueda considerarse plasticidad. Aparecen FOs de respuesta 'nuevas', que corresponden a la porción del campo receptivo original cuyas aferencias no han sido eliminadas por la lesión periférica, es decir, son el 'residuo' de la respuesta previa a la lesión.

Esta hipótesis se ilustra en el esquema de la figura 5, donde podemos observar cómo tras una lesión periférica, la parte más sensible a la estimulación del mapa de 
frecuencias $^{2}(\mathrm{MdF})$ es la porción de la cola de bajas frecuencias (Fig. 5, línea continua), con umbrales más bajos que los correspondientes a la frecuencia de respuesta 'original' (la frecuencia que ha resultado lesionada; Fig. 5, línea discontinua). Además, el MdF tras la lesión tiene una frecuencia de respuesta más baja (por su posición en la cola), dando la 'falsa' impresión en el mapa tonotópico del núcleo auditivo de que la zona de repuesta a bajas frecuencias ha 'invadido' la zona de representación de la lesión periférica (o zona de proyección de la lesión, Kaltenbach et al., 1992). Lo que sucede en realidad es un incremento muy marcado de los umbrales de respuesta a la/s frecuencia/s lesionada/s. La similitud con la reorganización del mapa tonotópico que tiene lugar tras un cambio plástico (invasión de la zona de representación de la lesión por frecuencias adyacentes) ha provocado que este modelo se conozca también como modelo de 'pseudoplasticidad' (Kaltenbach et al., 1992).

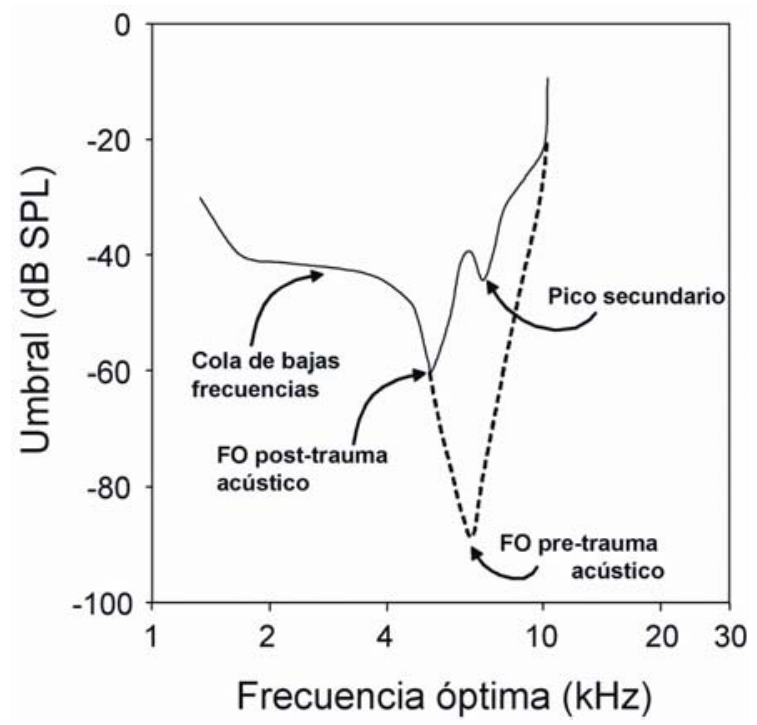

Figura 5. Esquema del mapa de frecuencias (campo receptivo) de una neurona antes (línea discontinua) y después (línea continua) de sufrir un trauma acústico. La zona más sensible frecuencia óptima (FO) - previa al trauma acústico desaparece a consecuencia de la eliminación de aferencias desde la zona lesionada de la cóclea. La 'nueva' FO de respuesta tras el trauma acústico se desplaza a la izquierda, hacia la cola de bajas frecuencias -FO post trauma acústico-, dando la impresión errónea de que se ha producido una 'resintonización' en la frecuencia de respuesta. En muchas neuronas se observa un pico secundario que representa un vestigio de la FO de respuesta previa a la lesión. SPL, nivel de presión sonora.

El trauma acústico (o daño acústico inducido por ruido) es una lesión del oído interno que causa una pérdida auditiva neurosensorial, como consecuencia de la exposición prolongada a un sonido de alta intensidad. Esta afección es cada día más frecuente debido a la sobre-exposición sonora típica de las sociedades modernas. Por ello, la probabilidad de sufrir una lesión acústica es mucho mayor que la probabilidad de sufrir una lesión mecánica de la cóclea. Aunque los trabajos basados en lesiones mecánicas de la cóclea han

\footnotetext{
${ }^{2}$ El mapa de frecuencias representa el campo receptivo de una neurona. Este MdF normalmente tiene forma de ' $\mathrm{V}$ ', con el pico indicando la frecuencia óptima y en ciertas ocasiones, una 'cola' de respuesta a frecuencias bajas.
} 
contribuido de manera significativa a esclarecer los mecanismos básicos de plasticidad que operan a nivel cortical tras una lesión periférica, creemos que es necesario el estudio detallado de los efectos de las lesiones producidas tras un trauma acústico.

El trauma acústico afecta a un área más amplia de frecuencias que la lesión mecánica, dependiendo de la intensidad y duración del estímulo utilizado (Bilak et al., 1997; Bohne et al., 1999; Yoshida et al., 2000; Wang et al., 2002b; Holme y Steel, 2004; Kim et al., 2004a, b; Izquierdo et al., 2008). Además, los efectos entre animales son muy variables (Cody y Robertson, 1983; Bohne et al., 1999; Yoshida et al., 2000; Wang et al., 2002b; Holme y Steel, 2004; Izquierdo et al., 2008). Todo ello dificulta, en gran medida, la interpretación de los resultados obtenidos tras un trauma acústico.

No se ha demostrado aún a ningún nivel de la vía auditiva que un trauma acústico provoque un fenómeno de plasticidad funcional. No obstante, estudios morfológicos tras lesiones por trauma acústico han demostrado que en los núcleos cocleares se puede observar crecimiento axonal y de botones sinápticos (Bilak et al., 1997; Kim et al., 2004a, b). Por otro lado, no existen estudios previos detallados sobre las consecuencias del trauma acústico en los mapas tonotópicos y MdFs neuronales a todos los niveles de la vía auditiva. Por lo tanto, nuestro estudio resulta de importancia vital a la hora de caracterizar las consecuencias del trauma acústico sobre las respuestas neuronales del CI.

Además de los estudios de plasticidad basados en lesiones mecánicas de la cóclea y trauma acústico, existe un tercer tipo de estudios desarrollados por el grupo del Prof. Merzenich y sus colaboradores (Zhang et al., 2001; Bao et al., 2003; Chang y Merzenich, 2003; de Villers-Sidani et al., 2007). Dichos estudios se basan en la exposición de animales de experimentación a un ambiente acústico enriquecido durante el desarrollo. Este modelo produce una modificación plástica de la representación auditiva cortical que depende del desarrollo de las aferencias sensoriales. Se ha llegado incluso a determinar de manera muy exquisita un breve período de tiempo ('período crítico'), durante el cual el desarrollo de dichas aferencias sensoriales determina la reorganización plástica cortical (Zhang et al., 2001; de Villers-Sidani et al., 2007). Aunque el aprendizaje a lo largo de la vida es posible, la plasticidad neuronal durante este período crítico es máxima, facilitando la adaptación del cerebro en desarrollo a su medio ambiente y proporcionándole una experiencia basal estable y duradera (Zhang et al., 2001; Bao et al., 2003; de Villers-Sidani et al., 2007). La actividad provocada por el sonido es, por consiguiente, importante para el desarrollo auditivo normal y para los cambios sinápticos dependientes de actividad que tienen lugar en el sistema auditivo durante el desarrollo (Kandler, 2004; Kandler y Gillespie; 2005; Seidl y Grothe, 2005).

Los mecanismos que originan este tipo de modificaciones plásticas son diferentes a los que aparecen en la plasticidad funcional y se refieren como mecanismos de 'plasticidad dependiente de actividad' (Muhlnickel et al., 1998; Zhang et al., 2001; Bao et al., 2003; Kandler, 2004; Kandler y Gillespie, 2005; Seidl y Grothe, 2005; de Villers-Sidani et al., 2007).

La figura 6 muestra un mapa tonotópico en la superficie de la corteza auditiva de animales control y de animales expuestos a un tono puro durante el período crítico. En este mapa podemos observar cómo la superficie de la corteza auditiva que responde a la frecuencia de exposición $(7 \mathrm{kHz})$, en animales estimulados a dicha frecuencia, aumenta su extensión abarcando un área más amplia de la corteza (en detrimento del área cortical dedicada a frecuencias adyacentes). Dicho de otro modo, se produce un aumento del número de neuronas que responden a la frecuencia de estimulación. Esta reorganización supone un fenómeno de plasticidad genuina y dependiente de actividad, ya que los umbrales de respuesta en el área expandida no difieren significativamente de los umbrales normales para esa frecuencia en lo que sería su ubicación normal y porque surge como 
consecuencia de una actividad aumentada por estimulación enriquecida (de Villers-Sidani et al., 2007). Sin embargo, tampoco está claro si este tipo de plasticidad se genera a nivel cortical y se transmite al CI o si por el contrario, la plasticidad se transmite a la corteza desde el CI (Oliver et al., 2006, 2007; Izquierdo et al., 2007), a través de un proceso de codificación jerárquico 'de abajo hacia arriba' desde centros subcorticales. También cabe la posibilidad de que la generación de plasticidad ocurra a ambos niveles de la vía (corteza auditiva y $\mathrm{CI})$.

\section{Control Expuestos a $7 \mathrm{kHz}$}

A
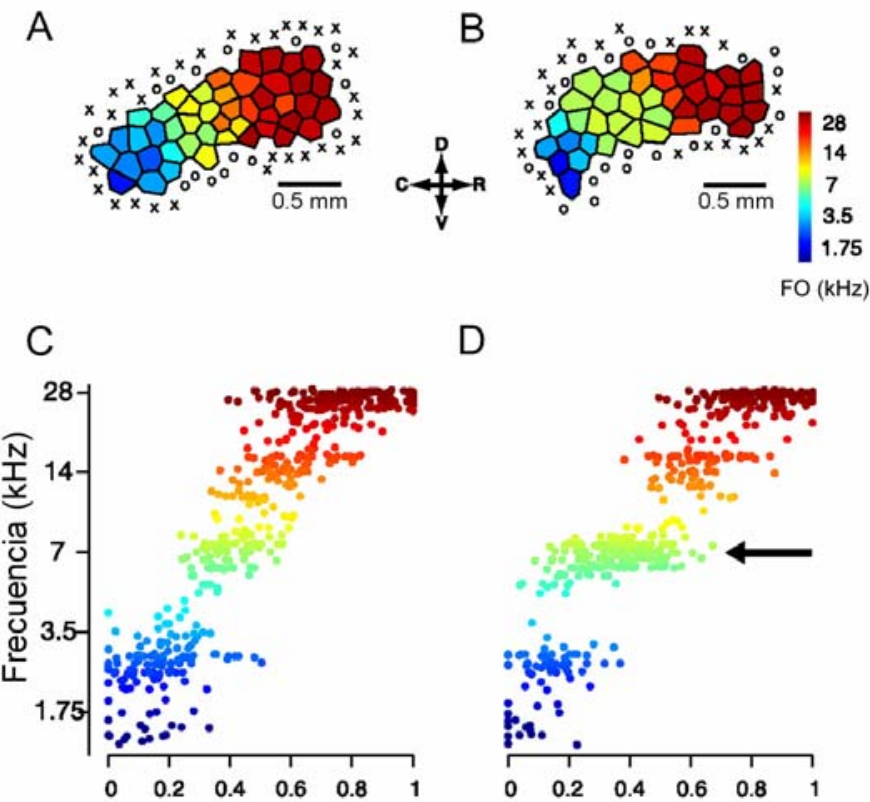

D

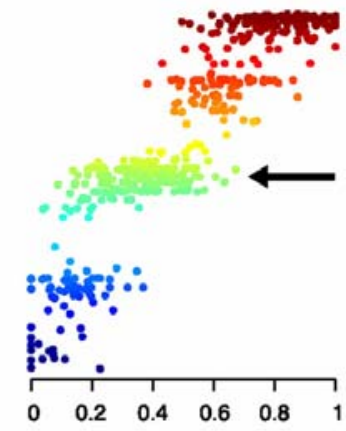

Eje tonotópico normalizado

Figura 6. Efectos de la exposición a un sonido, durante el período crítico, sobre los mapas tonotópicos de la corteza auditiva. A) Mapa tonotópico de la corteza auditiva de una rata control a P18. B) Mapa tonotópico de la corteza auditiva, a P18, de una rata sometida a estimulación con tonos puros de $7 \mathrm{kHz}$ durante el período crítico. Se observa un incremento en el área de respuesta a $7 \mathrm{kHz}$ en el mapa tonotópico de la corteza auditiva de animales estimulados. C, D) Distribución de las FOs de respuesta, en función de un eje tonotópico normalizado, en animales control (C) y en animales estimulados durante el período crítico (D); se aprecia un incremento del número de lugares de registro que responden a la frecuencia de estimulación $(7 \mathrm{kHz})$ en los animales del grupo experimental (flecha) y una disminución en la respuesta a las frecuencias adyacentes a dicha frecuencia de estimulación. Modificado de de Villers-Sidani et al., 2007.

Estudios similares mediante exposición a un ambiente sonoro con dos tonos de distinta frecuencia, han demostrado la existencia de cambios de naturaleza plástica en la organización tonotópica del CI en ratones. Dichos cambios se manifiestan como una alteración de la respuesta específica a las frecuencias de exposición, con aparición de un gran área del CI que responde a ambas frecuencias (Yu et al., 2007). Este estudio sitúa al CI como posible lugar de origen para la plasticidad dependiente de actividad. 
HIPÓTESIS Y OBJETIVOS 

Nuestro trabajo plantea el análisis de las consecuencias fisiológicas del trauma acústico, así como de los cambios inducidos por la exposición a un ambiente acústico enriquecido durante el desarrollo a nivel del colículo inferior. El colículo inferior es un centro de relevo obligatorio en la vía auditiva ascendente, por lo tanto la reorganización a cualquier nivel inferior del sistema auditivo, como consecuencia de la exposición a un ambiente acústico alterado (traumático o enriquecido), debería verse reflejada en este núcleo, mostrando mapas tonotópicos alterados y neuronas cuyas respuestas difieren de las normales.

El sistema nervioso auditivo proporciona un modelo excelente para examinar la plasticidad funcional y dependiente de actividad, ya que el nivel de actividad neuronal puede ser manipulado fácilmente, debido a la organización tonotópica de dichas neuronas en la vía auditiva. 
Esta hipótesis de trabajo nos conduce a plantear los siguientes objetivos:

1. Determinar la organización tonotópica normal del colículo inferior en la rata.

2. Estudiar los cambios producidos en dicha organización tonotópica como consecuencia de la exposición a un ambiente acústico alterado, ya sea por trauma acústico o por exposición a un ambiente acústico enriquecido.

3. Determinar los cambios provocados por la exposición a un ambiente acústico alterado a nivel celular.

4. Dilucidar si la sobre-exposición selectiva a un sonido particular, en el neonato, altera el desarrollo de la función auditiva. 
MATERIALES Y MÉTODOS 

Para los experimentos de nuestra tesis hemos empleado un total de 66 ratas (Rattus norvegicus, Rj: Long Evans) de ambos sexos. Los animales pesaban entre 130-430 g en el momento de los experimentos de registro y no presentaban ningún signo de patología del oído externo ni del oído medio. El cuidado y la utilización de los animales empleados en este trabajo fueron aprobados, previamente, por el Comité de Bioética de la Universidad de Salamanca y siguieron, en todo momento, las pautas indicadas en la Directiva Europea 2003/65/CE y la Legislación Española RD 1201/2005.

\section{GRUPOS Y DISEÑO EXPERIMENTAL}

Para la realización de los experimentos asignamos los animales de forma aleatoria a tres grupos experimentales distintos cuyos resultados describiremos de forma separada:

1) animales control $(n=32 ; 3-7$ meses) que utilizamos para realizar un estudio detallado de las condiciones de respuesta auditiva normales y del mapa tonotópico control a nivel del CI.

2) animales expuestos a estimulación con tonos puros de alta intensidad ( $\mathrm{n}=17$; ver tabla 1), en los que primero evaluamos el aumento permanente del umbral auditivo inducido y a continuación, registramos el mapa tonotópico y la respuesta neuronal del CI tras diferentes períodos de recuperación.

3) animales sometidos a un ambiente acústico enriquecido durante el período crítico $(\mathrm{n}=17$; tabla 2 ). Realizamos registros para elaborar el mapa tonotópico del CI y evaluamos la respuesta neuronal.

Además, los experimentos en los tres grupos se han realizado de forma aleatoria, para evitar posibles sesgos a la hora de hacer los registros.

\section{Trauma Acústico}

Para esta serie de experimentos, expusimos a los animales del grupo 2 a tonos puros continuos de frecuencia $5 \mathrm{u} 8 \mathrm{kHz}$, a intensidades entre 110-121 dB SPL. Con objeto de inducir diferentes grados de daño coclear, manipulamos la duración de la exposición de 3.3-16 h (tabla 1). Durante la exposición, los animales permanecieron despiertos y recluidos en jaulas individuales suspendidas dentro de una caja de estimulación con paredes antiparalelas (Fig. 7; Liberman y Gao, 1995; Yoshida et al., 2000; Izquierdo et al., 2008).

Para la generación del estímulo acústico utilizamos una fuente sonora hecha a medida, lo amplificamos utilizando un amplificador Magnat de 4 canales (Magnat AudioProdukte $\mathrm{GmbH}$, Alemania) con una potencia máxima de $600 \mathrm{~W}$, conectado a una batería Varta ${ }^{\circledR}$ (Johnson Controls, Inc. Milwaukee, WI, EE. UU.) de $12 \mathrm{~V}$ y lo reprodujimos a través de 4 altavoces Hifi (Mac Audio Electronic GmbH \& Co. KG, Alemania) con capacidad de potencia RMS/máx: 50/100 W, 42-23000 Hz de frecuencia de respuesta, una impedancia de $4 \Omega$ y $90 \mathrm{~dB}$ de sensibilidad. Los altavoces se montaron en la caja de estimulación a una altura diferente en cada una de las cuatro paredes laterales no simétricas, para evitar que se produjeran ondas estacionarias y posibles resonancias. 
Tabla 1. Resumen de los parámetros y animales sometidos a trauma acústico

\begin{tabular}{lcccccc}
\hline $\mathrm{N}^{\mathbf{o}}$ Animal & $\begin{array}{c}\text { Inicio } \\
\text { exposición } \\
\text { (días) }\end{array}$ & $\begin{array}{c}\text { Frecuencia } \\
\text { estimulación } \\
(\mathrm{kHz})\end{array}$ & $\begin{array}{c}\text { Intensidad } \\
\text { estímulo } \\
\text { (dB SPL) }\end{array}$ & $\begin{array}{c}\text { Duración } \\
\text { estímulo } \\
\text { (horas) }\end{array}$ & $\begin{array}{c}\text { Edad de } \\
\text { registro } \\
\text { (dias) }\end{array}$ & $\begin{array}{c}\text { Período de } \\
\text { recuperación } \\
\text { (dias) }\end{array}$ \\
\hline 107 & 53 & 8 & 114 & 10.6 & 181 & 128 \\
108 & 53 & 8 & 114 & 10.6 & 186 & 133 \\
147 & 46 & 8 & 115 & 12.5 & 169 & 123 \\
148 & 46 & 8 & 115 & 12.5 & 190 & 144 \\
150 & 46 & 8 & 115 & 12.5 & 290 & 244 \\
151 & 46 & 8 & 114.5 & 11.6 & 192 & 146 \\
152 & 46 & 8 & 114.5 & 11.6 & 193 & 147 \\
167 & 50 & 8 & 110 & 16 & 160 & 110 \\
168 & 50 & 8 & 110 & 16 & 208 & 158 \\
169 & 50 & 8 & 110 & 16 & 209 & 159 \\
170 & 50 & 8 & 110 & 16 & 288 & 238 \\
224 & 61 & 5 & 121 & 3.3 & 100 & 39 \\
225 & 61 & 5 & 121 & 3.3 & 96 & 35 \\
226 & 61 & 5 & 121 & 3.3 & 162 & 101 \\
227 & 61 & 5 & 121 & 3.3 & 190 & 129 \\
243 & 45 & 5 & 121 & 3.3 & 164 & 119 \\
244 & 45 & 5 & 121 & 3.3 & 341 & 296 \\
\hline
\end{tabular}
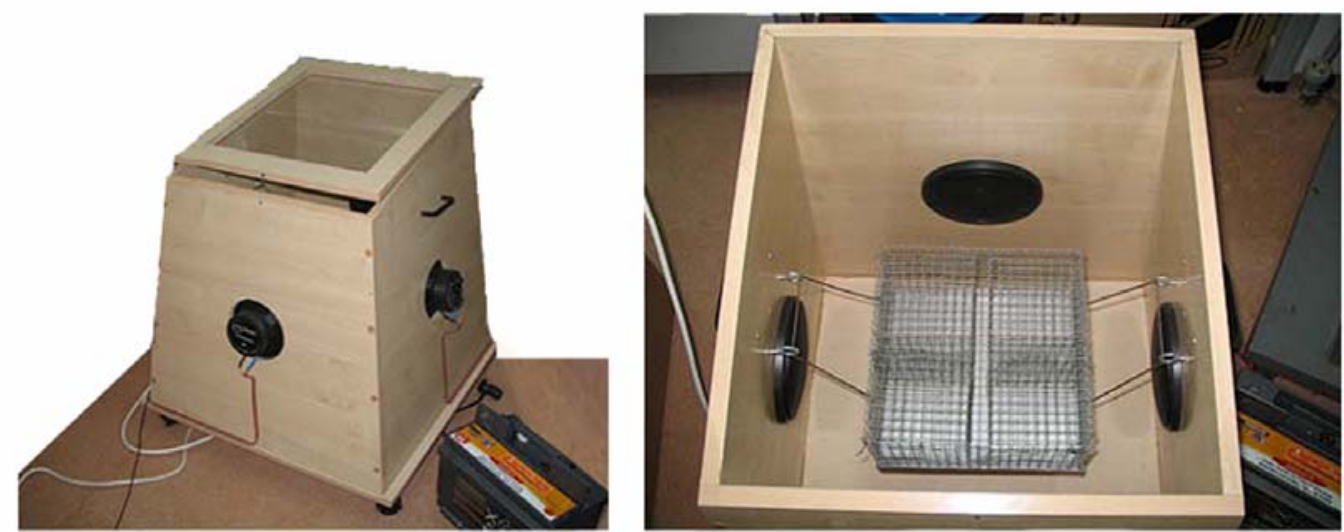

Figura 7. Caja de estimulación. Las paredes de la caja son antiparalelas y los altavoces están situados a diferente altura, de esta forma se evitan las ondas estacionarias y las resonancias. Los animales se disponen en jaulas de malla individuales, de tal forma que la atenuación del sonido sea la mínima posible. La calibración del estímulo traumático se realiza mediante un micrófono situado en una posición similar a la que se encuentra la cabeza de los animales.

La presión sonora se controló mediante un micrófono de campo abierto tipo 4133 de 1/2" (Brüel \& Kjaer. Nærum, Dinamarca) situado en una posición equivalente a la de la cabeza del animal y conectado a un analizador de espectro DI-2200 (Diagnostic Instruments Ltd. Livingston, Escocia, Reino Unido). Comprobamos que la presión sonora variaba $0.5-1 \mathrm{~dB}$ en dicha localización de la caja y antes o después de la exposición. Los animales se recuperaron durante un período $>35$ días, ya que tras ese período el aumento temporal del umbral es muy pequeño (si es que existe, Yoshida et al., 2000; Miller et al., 1963). 


\section{Ambiente Acústico Enriquecido}

Para este grupo de experimentos, expusimos dos camadas de ratas con sus madres a pulsos de tonos puros de $14 \mathrm{kHz}\left(25 \mathrm{~ms}\right.$ de duración cada $250 \mathrm{~ms}, 5 \mathrm{~ms}$ de rampa ${ }^{3}, 60-70$ dB SPL) durante 14-18 horas, desde P9 hasta P28 (tabla 2; a partir de métodos en Zhang et al., 2001). Situamos a los animales en jaulas estándar dentro de una cámara insonorizada. Para todos los animales sometidos a un ambiente acústico enriquecido se estableció un ciclo de $8 \mathrm{~h}$ luz $/ 16 \mathrm{~h}$ oscuridad. Los animales permanecieron despiertos en todo momento durante la estimulación, que se realizó durante el período de oscuridad. Para la generación del estímulo acústico utilizamos nuestra fuente sonora hecha a medida y 2 altavoces estándar (Realistic Fort Worth Texas 76102). La presión sonora se controló, durante toda la exposición, mediante el mismo micrófono de campo abierto tipo 4133 de B\&K. Comprobamos que la presión sonora variaba $<1 \mathrm{~dB}$ en todas las partes de la jaula, antes y después de la exposición. Los animales se recuperaron durante un período mínimo de 15 días y máximo de 342 días (ver tabla 2).

Sometimos a una segunda camada a estimulación con tonos puros de $4 \mathrm{kHz}$ y $14 \mathrm{~Hz}$ de modulación (para evitar la adaptación o habituación de las neuronas del CI al estímulo repetitivo), una duración de $1000 \mathrm{~ms}$ cada $2600 \mathrm{~ms}, 10 \mathrm{~ms}$ de rampa y 60-70 dB SPL, durante 14-15 horas diarias entre P9-P28. El período de recuperación osciló entre 15-39 días.

El tercer grupo de animales sometidos a un ambiente acústico enriquecido se expuso a tonos puros de $7 \mathrm{kHz}$, con una modulación de $40 \mathrm{~Hz}$. La duración del estímulo era $250 \mathrm{~ms}$ cada $750 \mathrm{~ms}$, con una rampa de $5 \mathrm{~ms}$ y una intensidad de 60-70 dB SPL, desde P9 a P17, durante 24 h/día. El período de recuperación en este grupo fue de 93-108 días.

Elegimos ese nivel de presión sonora (60-70 dB SPL) para asegurar que se evoque una respuesta significativa incluso en los animales más jóvenes, en los cuales los umbrales de respuesta son elevados.

Tabla 2. Resumen de los parámetros y animales sometidos a un ambiente acústico enriquecido

\begin{tabular}{cccccccc}
\hline $\mathbf{N}^{\circ}$ Animal & $\begin{array}{c}\text { Inicio } \\
\text { exposición } \\
\text { (días) }\end{array}$ & $\begin{array}{c}\text { Final } \\
\text { exposición } \\
\text { (días) }\end{array}$ & $\begin{array}{c}\text { Frecuencia } \\
\text { estimulación } \\
(\mathrm{kHz})\end{array}$ & $\begin{array}{c}\text { Intensidad } \\
\text { estímulo } \\
\text { (dB SPL) }\end{array}$ & $\begin{array}{c}\text { Duración } \\
\text { estímulo } \\
\text { (horas/día) }\end{array}$ & $\begin{array}{c}\text { Edad de } \\
\text { registro } \\
\text { (días) }\end{array}$ & $\begin{array}{c}\text { Período de } \\
\text { recuperación } \\
\text { (días) }\end{array}$ \\
\hline 081 & 9 & 28 & 14 & $60-70$ & $14-18$ & 43 & 15 \\
082 & 9 & 28 & 14 & $60-70$ & $14-18$ & 85 & 56 \\
083 & 9 & 28 & 14 & $60-70$ & $14-18$ & 232 & 203 \\
085 & 9 & 28 & 14 & $60-70$ & $14-18$ & 371 & 342 \\
091 & 9 & 28 & 14 control & $60-70$ & $14-18$ & 77 & 48 \\
092 & 9 & 28 & 14 & $60-70$ & $14-18$ & 50 & 21 \\
093 & 9 & 28 & 14 & $60-70$ & $14-18$ & 57 & 28 \\
094 & 9 & 28 & 14 & $60-70$ & $14-18$ & 67 & 38 \\
096 & 9 & 28 & 14 & $60-70$ & $14-18$ & 176 & 147 \\
097 & 9 & 28 & 14 & $60-70$ & $14-18$ & 205 & 176 \\
098 & 9 & 28 & 14 & $60-70$ & $14-18$ & 206 & 177 \\
099 & 9 & 28 & 14 & $60-70$ & $14-18$ & 234 & 205 \\
229 & 9 & 28 & $4,14 \mathrm{~Hz}$. mod. & $60-70$ & $14-15$ & 43 & 15 \\
230 & 9 & 28 & $4,14 \mathrm{~Hz}$. mod. & $60-70$ & $14-15$ & 67 & 39 \\
020 & 9 & 17 & $7,40 \mathrm{~Hz}$. mod. & 70 & 24 & 110 & 93 \\
021 & 9 & 17 & $7,40 \mathrm{~Hz}$. mod. & 70 & 24 & 123 & 106 \\
022 & 9 & 17 & $7,40 \mathrm{~Hz}$. mod. & 70 & 24 & 125 & 108 \\
\hline
\end{tabular}

\footnotetext{
${ }^{3}$ La rampa es una pendiente lineal al comienzo y al final del estímulo sonoro.
} 


\section{PROCEDIMIENTOS QUIRÚRGICOS}

Al inicio de cada experimento, anestesiamos a los animales con una inyección intraperitoneal de uretano (1.5 g/kg: Sigma-Aldrich Inc. St. Louis, MO, EE. UU., en una solución al 20\%) suministrando dosis suplementarias cuando era necesario $(0.5 \mathrm{~g} / \mathrm{kg}$, i.p.). Realizamos la cirugía y los experimentos en una cámara insonorizada y con aislamiento eléctrico. A continuación, practicamos una traqueotomía y canulamos la tráquea para facilitar la respiración del animal. Asimismo, procuramos un ambiente rico en oxígeno en las inmediaciones de la cánula, para favorecer la respiración y evitar la hipoxia. Administramos sulfato de atropina por vía subcutánea $(0.05 \mathrm{mg} / \mathrm{kg}$ : Braun Medical. Barcelona, España) para reducir la secreción bronquial. La temperatura corporal del animal se mantuvo a $38^{\circ} \mathrm{C} \pm 1{ }^{\circ} \mathrm{C}$, por medio de una manta eléctrica controlada por un termostato y una sonda rectal (Malmierca et al., 2003). Suministramos un anestésico local (lidocaína: Guinama. Valencia, España) por vía subcutánea en la región auricular. Seguidamente, extirpamos los cartílagos auriculares para permitir una mejor fijación del animal en el aparato estereotáxico. Colocamos al animal en un aparato estereotáxico con las barras de los oídos modificadas, para permitir la estimulación acústica a través de ellas (Rees et al., 1997; Malmierca et al., 2003, 2005, 2008). La diferencia con las barras tradicionales consiste en que nuestras barras son huecas y además, tienen la forma apropiada para acoplar en ellas los altavoces. Las barras están diseñadas de forma que encajan precisamente en el meato auditivo externo de la rata, sin provocar ningún daño a la membrana timpánica. Tras la colocación de las barras comprobamos, visualmente, la comunicación del meato auditivo con el exterior.

\section{REGISTRO ELECTROFISIOLÓGICO DE LOS POTENCIALES DE ACCIÓN COMPUESTOS (PAC) DEL NERVIO AUDITIVO}

Comprobamos la función auditiva midiendo los umbrales PAC. El audiograma PAC o electrococleograma (Dallos y Cheatham, 1976; Eggermont, 1976; Johnstone et al., 1979) es un método rápido y apropiado para verificar las condiciones de la cóclea, porque mide el umbral de la respuesta global del nervio auditivo en función de la frecuencia sonora (Rajan et al., 1991). Ello nos proporciona una idea de la cantidad y la calidad de información transducida por los receptores en el espectro de frecuencias audibles. Para ello, realizamos una incisión en la parte posterior del pabellón auditivo de la oreja izquierda, con la finalidad de exponer la bulla timpánica. Practicamos un orificio en la bulla con ayuda de un bisturí y unas pinzas, para poder colocar un alambre de plata con la punta redondeada en contacto con la membrana de la ventana redonda de la cóclea (Wise e Irvine, 1983; Rajan et al., 1991; Izquierdo et al., 2008). Utilizamos este alambre como electrodo para registrar los potenciales de acción compuestos del nervio auditivo. Para mantener el electrodo en su posición lo adherimos al hueso con pegamento instantáneo y sellamos el orificio de la bulla con vaselina. En nuestro caso, utilizamos el método de detección audio-visual (Johnstone et al., 1979) para medir los umbrales N1 frente a 20 frecuencias de estimulación distintas, en un rango entre 0.5 y $39 \mathrm{kHz}$. La onda $\mathrm{N} 1$ es la parte del PAC (onda compleja) que refleja la actividad del nervio auditivo como respuesta al estímulo. Medimos los umbrales N1 frente a tonos puros $(5 \mathrm{~ms}$ de duración y $1 \mathrm{~ms}$ de rampa), presentados con una frecuencia de 10/s, variando la intensidad del estímulo en 
pasos de $1 \mathrm{~dB}$. Definimos los umbrales como la presión sonora necesaria para producir una respuesta neural, pico-a-pico, de $1-2 \mu \mathrm{V}$ de amplitud a la latencia correspondiente a $\mathrm{N} 1$ (Rajan et al., 1991). La respuesta se amplificó (x100000), se filtró $(0.1-3 \mathrm{kHz}$ ) y se promedió fuera del programa de registro.

\section{ESTÍMULOS ACÚSTICOS Y REGISTROS ELECTROFISIOLÓGICOS 'IN VIVO’}

Una vez finalizado el registro electrofisiológico del audiograma PAC, realizamos una incisión longitudinal en la piel de la cabeza siguiendo la línea sagital y desinsertamos los músculos de la calota occipital y temporal. Después, realizamos una craneotomía a partir de dos trepanaciones efectuadas sobre la superficie cortical que cubre el CI (siguiendo coordenadas esterotáxicas según el atlas de Paxinos y Watson, 2005). La abertura del orificio se amplió con ayuda de una gubia, hasta que tenía un tamaño adecuado para poder acceder fácilmente, a través de los electrodos de registro, a cualquier parte del CI. Finalmente, retiramos la duramadre con unas pinzas y unas tijeras de iridectomía, para permitir el acceso de los electrodos de tungsteno recubiertos de vidrio (1$2 \mathrm{M} \Omega$, Merrill y Ainsworth, 1972). Utilizamos dichos electrodos para el registro electrofisiológico extracelular de la respuesta de unidades neuronales aisladas (relación señal-ruido normalmente $10 / 1$ o superior) y grupos multineuronales, en respuesta a estimulación con tonos puros. La corteza cerebral, que quedó expuesta, se irrigó regularmente con suero salino $(\mathrm{NaCl} 0.9 \%)$ para evitar su desecación.

Generamos los estímulos en un equipo TDT System 2 (Tucker-Davis Technologies. Gainesville, FL, EE. UU.), utilizando un programa informático hecho a medida (SpikeSpain, amablemente cedido por Brandon Warren, Univ. de Washington, Seattle y descrito en Faure et al., 2003) y los presentamos a través de un sistema acústico en campo cerrado (Rees et al., 1997; Malmierca et al., 2003, 2005), usando dos altavoces electroestáticos (TDT EC1) controlados por dos módulos TDT ED1. Calibramos la salida del sistema 'in situ', utilizando un micrófono de campo cerrado Brüel y Kjær tipo 4136 de 1/4" conectado al analizador de espectro DI-2200. La frecuencia más alta que puede producir el sistema es $40 \mathrm{kHz}$. La salida máxima del sistema es plana entre $0.5-3 \mathrm{kHz}$ $(\sim 100 \pm 10 \mathrm{~dB}$ SPL $)$ y entre $4-40 \mathrm{kHz}(\sim 80 \pm 10 \mathrm{~dB}$ SPL $)$. En nuestro estudio, medimos la intensidad de un determinado estímulo en $\mathrm{dB}$ de atenuación (relativos a la salida máxima de los altavoces para una determinada frecuencia) o en dB SPL (nivel de presión sonora, re $20 \mu \mathrm{Pa})$.

Para avanzar el electrodo hasta alcanzar el CI utilizamos un microposicionador piezoeléctrico con una resolución de $0.5 \mu \mathrm{m}$ (modelo Burleigh 6000, Burleigh Instruments Inc. Fishers, NY, EE. UU.), controlado de forma remota desde el exterior de la cabina. El ángulo de penetración del electrodo es $10^{\circ}$ con respecto al plano vertical (Fig. 2A). Este ángulo es aproximadamente ortogonal a la orientación predominante de las láminas de isofrecuencia (Malmierca et al., 1993). Una vez localizado el NCCI, realizamos registros extracelulares de las respuestas de grupos multineuronales y de unidades neuronales aisladas. La localización de las neuronas dentro del NCCI se basó en criterios electrofisiológicos de tonotopía y fidelidad de la respuesta (Palombi y Caspary, 1996; Rees et al., 1997; Nuding et al., 1999; Syka et al., 2000; Malmierca et al., 2003, 2008), así como en la verificación histológica (v. i.).

Registramos los potenciales de acción usando un amplificador BIOAMP (TDT). Estos potenciales de acción fueron amplificados (x10000-90000) y filtrados $(0.5-3 \mathrm{kHz}$, TDT DB4) antes de pasar por un discriminador de espigas (TDT SD1). Los tiempos de las 
espigas se enviaron a un ordenador, a través de un temporizador de eventos (TDT ET1) sincronizado con un generador de tiempos (TDT TG6). La generación de los estímulos y la visualización en línea de los datos se controlaron por nuestro programa específico hecho a medida (SpikeSpain). Los tiempos de las espigas se presentaron como gráficos de puntos, ordenados según el parámetro acústico que nos interesaba modificar durante el experimento.

Para localizar el CI empleamos ráfagas de ruido blanco (ya que el ruido blanco estimula todas las regiones del CI) y para realizar los mapas tonotópicos y los MdFs utilizamos tonos puros.

Para la elaboración de un mapa tonotópico, registramos la FO de respuesta de grupos multineuronales en un tracto, de forma sistemática y detallada cada $25-50 \mu \mathrm{m}$ a lo largo del eje dorsoventral del CI. Los estímulos utilizados son tonos puros monoaurales (presentados en un solo oído) de $75 \mathrm{~ms}$ de duración, con una rampa de $5 \mathrm{~ms}$. Modificamos la frecuencia e intensidad de los estímulos utilizando una matriz de dos dimensiones que controlamos con el ratón del ordenador. Determinamos la FO en cada punto del tracto tonotópico de manera audio-visual, como aquella frecuencia que provoca la respuesta del grupo multineuronal con el mínimo umbral (mínima intensidad de estimulación) y representamos el mapa tonotópico de forma gráfica utilizando Microsoft Excel. Analizamos la distribución de FOs en función de la profundidad a lo largo del tracto de forma automática, utilizando una hoja de cálculo de Microsoft Excel. Calculamos la distancia en $\mu \mathrm{m}$ y los cambios de frecuencia en octavas para todos los cambios de FO que se producían en el tracto (y para cualquier cambio de la $\mathrm{FO}>0.1$ octavas) con respecto a la FO previamente registrada. Consideramos incluidos dentro del mismo escalón de frecuencias a aquellos grupos multineuronales cuya FO cambiaba $<0.1$ octavas con respecto a la FO del grupo multineuronal previo. Si el cambio es $>0.1$ octavas lo consideramos un nuevo escalón o lámina de isofrecuencia.

Para generar los MdFs de neuronas aisladas utilizamos estímulos que consisten en tonos puros monoaurales de $75 \mathrm{~ms}$, con una pendiente lineal de $5 \mathrm{~ms}$, que se presentan con una frecuencia de repetición de 4 estímulos por segundo. La frecuencia de cada estímulo varía de forma aleatoria $(0.5-40 \mathrm{kHz}$, en 25 pasos logarítmicos). Presentamos cada uno de estos estímulos entre 2-5 veces en bloques de intensidad fija, realizando un total de 10 bloques a intensidades en progresivo aumento (100-10 dB de atenuación, Fig. 8).

En algunas neuronas realizamos un mapa de frecuencias con dos tonos (MdF 2T). Estos MdF 2T se utilizan para evocar una ligera actividad en todo el campo receptivo neuronal, emulando actividad espontánea, lo que nos permitirá revelar posibles zonas de inhibición o supresión de la respuesta. Para ello, presentamos dos tonos puros de manera simultánea, uno de los tonos a la FO de respuesta de la neurona, con un nivel de intensidad justo por encima del umbral de respuesta. El propósito de este tono es hacer responder a la neurona de forma constante a la menor intensidad posible (normalmente 10-20 dB SPL por encima del umbral). El segundo componente (tono 'variable') tiene una frecuencia e intensidad que varían de la misma forma que en el estímulo utilizado para generar un MdF normal. Este segundo tono nos permite determinar los rangos de frecuencia-intensidad que suprimen la respuesta a tonos de FO (Sutter et al., 1999). 


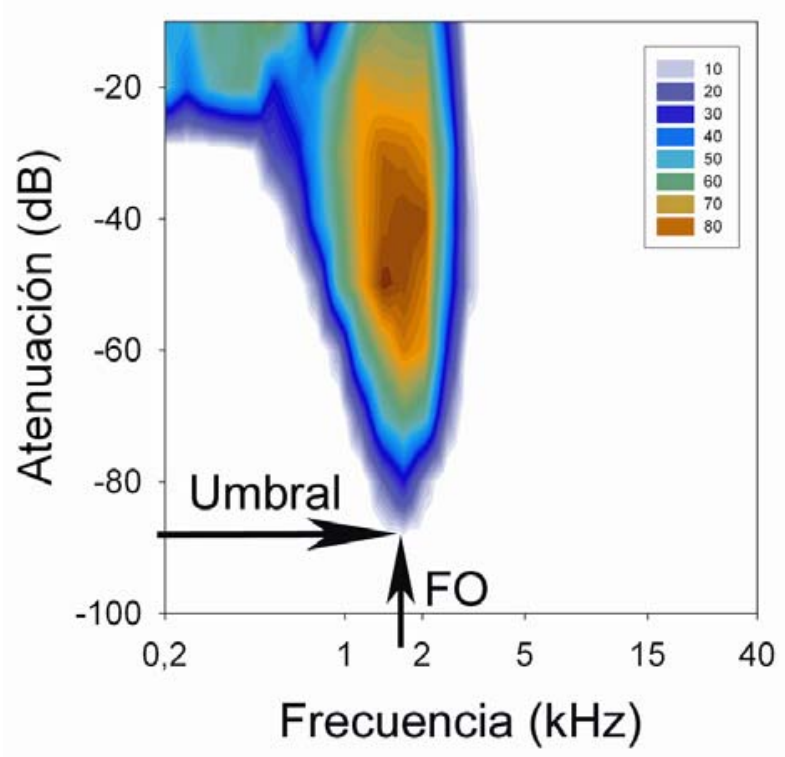

Figura 8. Ejemplo de mapa de frecuencia (MdF) de una neurona del CI de la rata. Para generar el MdF presentamos una serie de estímulos de frecuencia e intensidad variables. La escala de colores representa el número de potenciales de acción que la neurona dispara, en respuesta a cada uno de esos estímulos. Las flechas indican el umbral (intensidad mínima del estímulo que provoca respuesta) y la frecuencia óptima (FO) que es aquella frecuencia capaz de provocar la respuesta de una neurona con la menor intensidad de estimulación. En nuestros MdFs medimos la intensidad del estímulo en decibelios de atenuación.

Analizamos y representamos los datos obtenidos usando programas informáticos comerciales (Microsoft Excel, SigmaPlot y SPSS) y construimos una representación visual del área de respuesta $(\mathrm{MdF})$, basada en el recuento de los potenciales de acción para cada combinación de frecuencia e intensidad (Fig. 8).

\section{VERIFICACIÓN HISTOLÓGICA DE LOS LUGARES DE REGISTRO}

Al final de cada experimento realizamos lesiones electrolíticas $(5-10 \mu \mathrm{A}$, durante 5-10 s) en los lugares de registro utilizando el electrodo de tungsteno. A continuación, administramos al animal una dosis letal de pentobarbital sódico $(60 \mathrm{mg} / \mathrm{kg}$, disuelto en suero salino) y lo prefundimos transcardialmente, utilizando como fijador una mezcla de paraformaldehído (Panreac Química S.A. Barcelona, España) al 1\% y glutaraldehído (Sigma-Aldrich Inc. St. Louis. MO, EE. UU.) al $1 \%$ en tampón fosfato salino $0.1 \mathrm{M}$, previo lavado del árbol vascular con solución Ringer $(8.5 \mathrm{~g} \mathrm{NaCl}, 0.25 \mathrm{~g} \mathrm{KCl}, 0.2 \mathrm{~g}$ $\mathrm{NaHCO} 3$, por litro de agua destilada + Heparina al $1 \%$ a pH 6.9 y $\left.37^{\circ} \mathrm{C}\right)$.

Posteriormente, extrajimos el cerebro y lo crioprotegimos mediante inmersión en sacarosa al 30\% (Panreac Química S.A. Barcelona, España) en tampón fosfato $0.1 \mathrm{M}$ a 4 ${ }^{\circ} \mathrm{C}$, durante 2-3 días. Finalmente, cortamos secciones parasagitales o transversales de 40 $\mu \mathrm{m}$ con un micrótomo de congelación (MICROM HM 400, Heidelberg, Alemania) y las teñimos con una solución de Violeta de Cresilo al 1\% (Sigma-Aldrich Inc. St. Louis. MO, 
EE. UU.) para facilitar la identificación de los límites citoarquitectónicos. Estos datos histológicos, junto con las pruebas electrofisiológicas de progresión tonotópica y latencia de la respuesta, confirmaron que la mayoría de los lugares de registro se localizan en el NCCI.

\section{RECONSTRUCCIÓN TRIDIMENSIONAL}

En dos de los animales utilizados para los registros de unidades multineuronales (casos \# 259 y 260; Fig. 13) realizamos reconstrucciones tridimensionales de ocho tractos con lesiones electrolíticas utilizando Neurolucida (MicroBrightField. Colchester, VT. EE. UU.). Hicimos registros avanzando el electrodo a través del NCCI y determinando la FO cada $50 \mu \mathrm{m}$. A medida que retirábamos el electrodo, registramos la FO nuevamente y realizamos lesiones a determinadas frecuencias. Las lesiones tenían un diámetro de $\sim 100$ $\mu \mathrm{m}$, así que utilizamos el centro de la lesión como referencia. Realizamos la reconstrucción uniendo los puntos con idéntica FO de diferentes tractos. 
RESULTADOS 

Hemos dividido la exposición de los resultados en tres partes, cada una de las cuales se refiere a uno de los tres grupos de animales utilizados:

1) animales control.

2) animales con trauma acústico.

3) animales sometidos a un ambiente acústico enriquecido.

Para valorar los efectos de la exposición al sonido sobre la organización funcional del CI, realizamos varias pruebas en cada uno de los tres grupos: presentaremos primero los audiogramas PAC, después los mapas tonotópicos detallados del CI, realizados a partir de la respuesta de grupos multineuronales y finalmente MdFs de neuronas aisladas en animales control. A continuación, compararemos esos datos control con los obtenidos en animales expuestos a sonido (trauma acústico y ambiente acústico enriquecido).

\section{1) ANIMALES CONTROL}

\section{Audiograma PAC control}

Para elaborar un audiograma PAC que nos sirva de referencia a la hora de evaluar el daño acústico que provocamos, hemos empleado 7 animales control, ya que existen muy pocos estudios similares en rata (Fechter et al., 1998, 2000). Además, las ratas empleadas por el grupo de Fechter son de diferente estirpe a las que usamos en nuestros experimentos.

De forma aleatoria, hemos registrado 2-3 medidas de los umbrales PAC para cada una de las 20 frecuencias en el rango $0.5-39 \mathrm{kHz}$. A continuación hemos calculado la media y la desviación típica (SD) de los umbrales para cada una de las frecuencias a partir de los 7 casos control y finalmente hemos establecido la función resultante (Fig.9A, línea roja) como audiograma PAC control. Estos datos nos servirán para compararlos con el PAC obtenido de animales tras un trauma acústico (Figs. 15 y 16) y tras exposición a un ambiente acústico enriquecido (Fig. 21).

Para la frecuencia más baja que registramos, el umbral es de $\sim 80 \mathrm{~dB}$ SPL. Progresivamente, los umbrales descienden a frecuencias mayores y forman una muesca (que representa un descenso en la sensibilidad) en torno a $15 \mathrm{kHz}$. La zona de máxima sensibilidad del audiograma control está en torno a $20-30 \mathrm{kHz}$, coincidiendo con las frecuencias de mayor sensibilidad en nuestro conjunto de unidades aisladas control (v.i.) y con la zona más sensible del audiograma conductual de la rata pigmentada (Heffner et al., 1994). A partir de $30 \mathrm{kHz}$, los umbrales aumentan gradualmente hasta la frecuencia más alta que registramos $(39 \mathrm{kHz})$. 

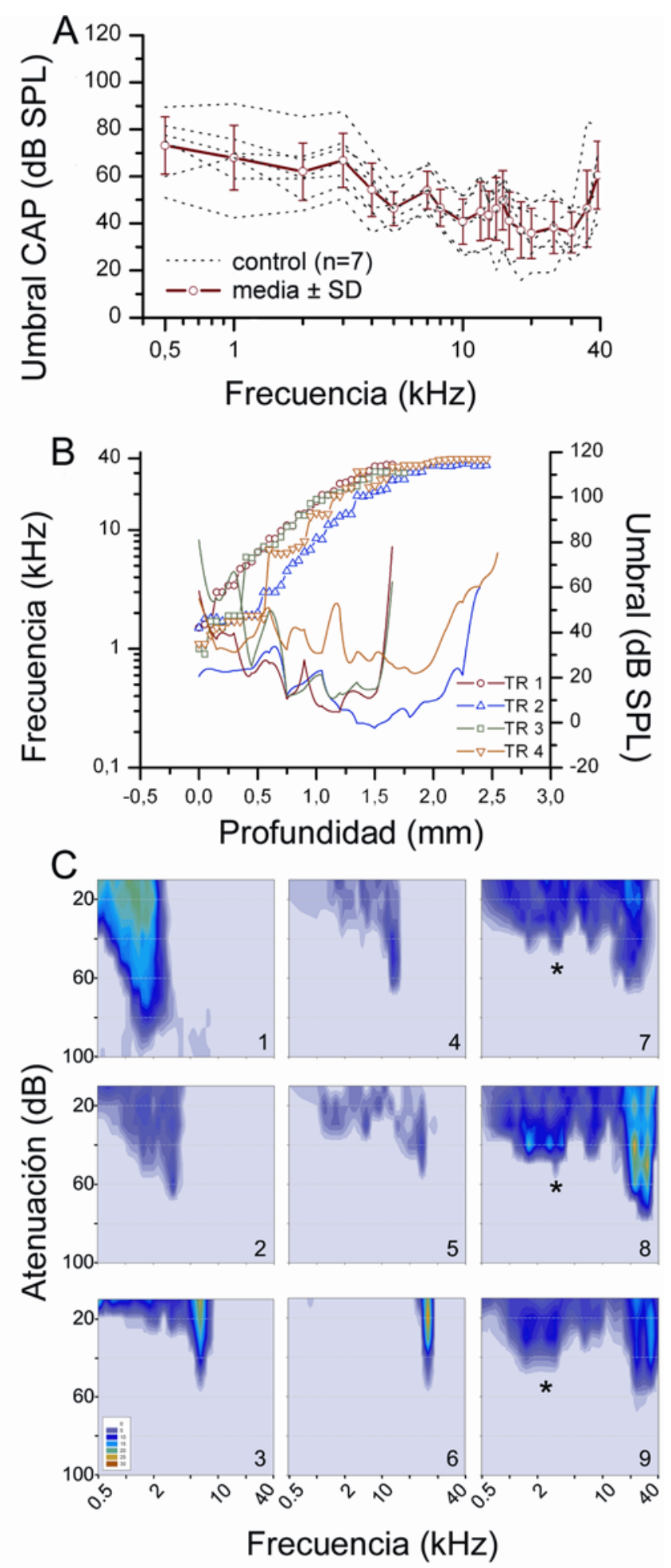

Figura 9. Datos control. A) Audiogramas PAC para 7 animales control (líneas discontinuas) y su correspondiente audiograma PAC promedio (media $\pm \mathrm{SD}$, círculos abiertos y línea roja). B) Mapas tonotópicos de la respuesta de grupos multineuronales, a través del NCCI, en cuatro tractos diferentes de un mismo animal (símbolos abiertos) y sus correspondientes umbrales (líneas continuas) en función de la profundidad de registro. Todos los tractos muestran un patrón en 'escalera' para la progresión de FOs. C) Representación de nueve MdFs de unidades neuronales aisladas (1-9), registradas en tres tractos diferentes a través del NCCI, ordenados por profundidad de registro. La escala de colores indica el número de potenciales de acción disparados en respuesta a dos presentaciones de cada estímulo. Los asteriscos señalan las colas de bajas frecuencias en neuronas con FO elevada. SPL, nivel de presión sonora. TR, Tracto. Tomado de Izquierdo et al., 2008. 


\section{Mapa tonotópico del colículo inferior}

Para estudiar la representación de frecuencias en el NCCI, hemos realizado mapas tonotópicos registrando la FO de respuesta de grupos multineuronales en distintas penetraciones a lo largo del eje dorsoventral del CI de forma sistemática y detallada. Si medíamos la respuesta de grupos multineuronales cada 100-150 $\mu \mathrm{m}$, el mapa que obteníamos seguía una progresión más o menos lineal y suavizada, dando lugar a una función monotónica en la que aumentaba la FO a medida que aumentaba la profundidad (Fig. 10).

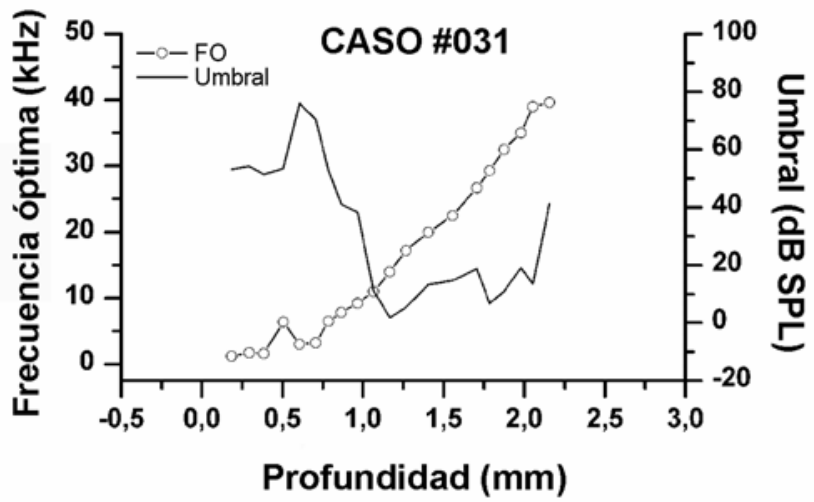

Figura 10. Progresión lineal de FOs en un mapa tonotópico control. La FO de grupos multineuronales (círculos abiertos) se ha medido en pasos de 100-150 $\mu \mathrm{m}$ a lo largo del eje dorsoventral del CI. Adviértase que el caso \# 031 no muestra una progresión en escalones, ya que la resolución del mapa es $>100 \mu \mathrm{m}$. La línea continua muestra los umbrales en los mismos sitios de registro. Tomado de Malmierca et al., 2008.

Por otro lado, si registrábamos la respuesta de forma muy detallada cada 25-50 $\mu \mathrm{m}$ (Figs. 9B y 11), en todos los casos los mapas también presentaban un cambio en la FO de respuesta de grupos multineuronales en función de la profundidad (Merzenich y Reid, 1974). Sin embargo, hemos comprobado que este cambio de frecuencia no era continuo, sino que presentaba una serie de discontinuidades similares a los peldaños de una escalera (Figs. 9B y 11). Por lo tanto, establecimos en $50 \mu \mathrm{m}$ el límite ideal de resolución a la hora de realizar los mapas tonotópicos. Estos saltos en la progresión de las frecuencias afectan a todo el rango de frecuencias. En la figura 11D pueden apreciarse con mayor claridad los escalones de bajas frecuencias $(1-10 \mathrm{kHz}$ ), al representar dichas frecuencias en una escala logarítmica.

En total, hemos analizado 45 tractos tonotópicos obtenidos a partir de 16 animales distintos. En 12 de esos tractos no encontramos una organización tonotópica clara (p. ej., Fig. 11C, símbolos negros) o la progresión tonotópica era incompleta (carecía de algunas frecuencias, normalmente de las representadas en los extremos del mapa). La localización histológica de esos tractos mostró que se encontraban fuera del NCCI, por lo cual, los excluimos de nuestro estudio. El análisis detallado de los 33 tractos que consideramos localizados en el NCCI mostró los siguientes resultados: 

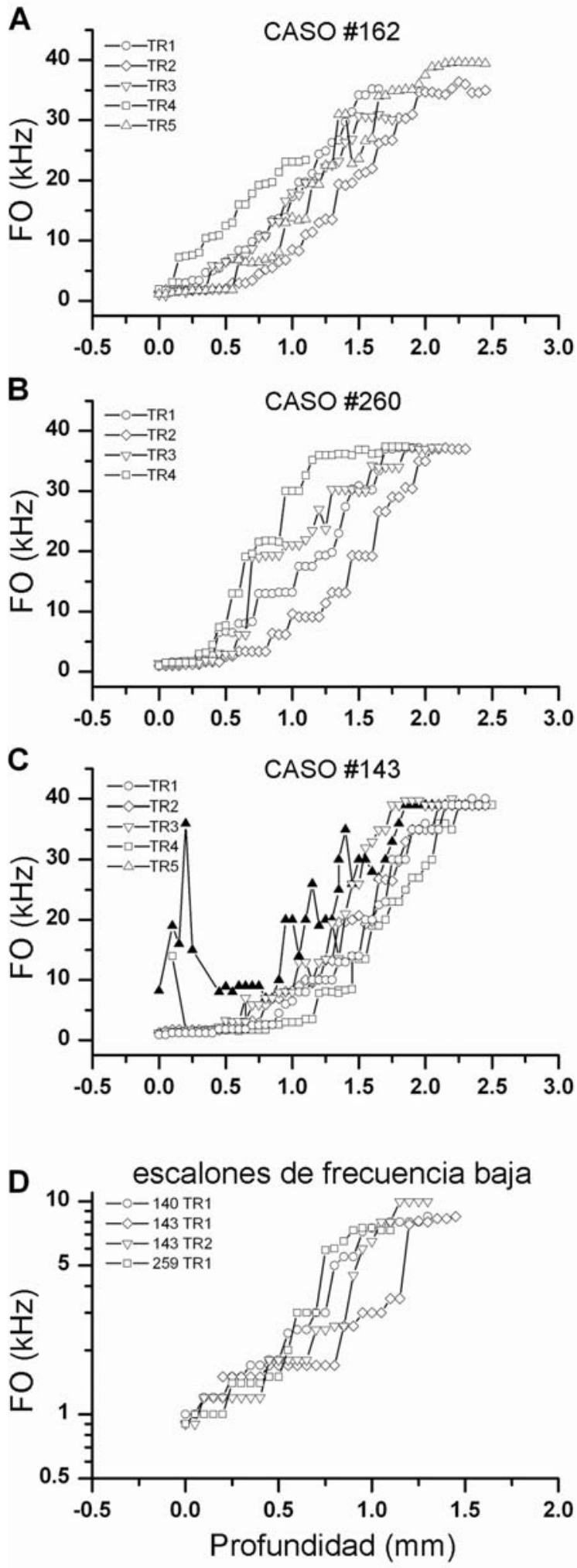

Figura 11. Mapas tonotópicos control. A-C) La FO de grupos multineuronales se ha medido en pasos de 25-50 $\mu \mathrm{m}$ en cuatro tractos (B) y cinco tractos (A, C) a lo largo del eje dorsoventral del CI. Todos los casos presentan una progresión de FOs discontinua. C) El tracto 5 del caso \# 143 no mostró una progresión tonotópica clara. Posteriormente, confirmamos su localización fuera del NCCI. D) Detalle, en escala logarítmica, de los escalones de bajas frecuencias en cuatro tractos pertenecientes a tres animales distintos. TR, Tracto. Tomado de Malmierca et al., 2008. 
La longitud media de los tractos que registramos es $2180 \pm 460 \mu \mathrm{m}$ (media \pm SD). Esta longitud se corresponde con las dimensiones del CI en la rata (Faye-Lund y Osen, 1985; Malmierca, 1991, 2003; Malmierca et al., 1993). La FO registrada varía entre 0.5 y $40 \mathrm{kHz}$. En todos los tractos, la FO permanece casi constante (varía $<0.1$ octavas) durante una media de $151 \pm 41 \mu \mathrm{m}$ (media \pm SD) y luego cambia $0.34 \pm 0.11$ octavas, formando un total de 460 escalones de frecuencia en los 33 tractos analizados. De media, existen $14 \pm 3.7$ escalones de frecuencia por tracto.

Para evaluar la variabilidad de la FO dentro de cada escalón registramos la actividad con el mismo electrodo cuando avanzamos y retrocedemos. En la mayoría de casos la diferencia de FO entre ambos tractos es $<0.05$ octavas. Sin embargo, en algunos tractos observamos una diferencia $\sim 0.13$ octavas. Para tener en cuenta esta variabilidad establecimos el umbral para considerar un escalón de FO diferente cuando se produce una variación de 0.1 octavas o superior en la FO.

En cada sitio de registro, medimos también los umbrales de respuesta correspondientes a cada uno de los grupos multineuronales (Fig. 9B, líneas de colores). La curva de umbrales resultante tiene forma de ' $U$ ' y presenta un umbral mínimo (0-20 $\mathrm{dB}$ SPL) en torno a la zona central del tracto, que corresponde a la región de frecuencias de $10-35 \mathrm{kHz}$.

\section{Mapas de frecuencia de neuronas aisladas en el colículo inferior}

Hemos registrado $120 \mathrm{MdFs}$ a partir de 32 ratas adultas con audición normal. La figura 9C muestra una composición de $9 \mathrm{MdFs}$ representativos. Dichos MdFs muestran la respuesta de neuronas aisladas en el NCCI de tres animales diferentes. Como cabe esperar, la FO de respuesta de los MdFs individuales aumenta progresivamente con la profundidad de registro en el CI (Fig. 9C, 1-9). La mayoría de los MdFs de este grupo control tienen forma de ' $\mathrm{V}$ ' $(\mathrm{n}=91,75.83 \%)$, coincidiendo con el porcentaje de MdFs de tipo ' $V$ ' encontrado en estudios previos (Le Beau et al., 2001; Hernández et al., 2005). Los MdFs tipo ' $V$ ' varían en función de su FO, de tal forma que la mayoría de las neuronas con $\mathrm{FO}>4-5 \mathrm{kHz}$ presentan un pico sintonizado a un rango estrecho de frecuencias y una región sintonizada a un rango más amplio de frecuencias, que conocemos como 'cola de bajas frecuencias' (p. ej., Fig. 9C, asteriscos; Hernández et al., 2005). Nuestra muestra también contiene algunos MdFs de tipo 'no V' $(n=29$, 24.17\%; p. ej., Fig. 9C 6, que es un MdF de tipo 'estrecho'), pero son menos abundantes. La mayoría de neuronas en este grupo control (66.7\%) carece de actividad espontánea.

\section{Análisis de la representación de frecuencias en el colículo inferior}

Para estudiar la representación de FOs en el CI hemos analizado dos conjuntos de datos independientes. Por una parte hemos utilizado las FOs de una población de neuronas aisladas y por otra las FOs de los grupos multineuronales que hemos registrado al realizar los mapas tonotópicos en el CI.

Hemos empleado una colección de unidades neuronales de experimentos previos realizados en el laboratorio de neurofisiología auditiva (Malmierca et al., 2003; Hernández et al., 2005; Pérez-González et al., 2006), además de nuestros $120 \mathrm{MdFs}$ 

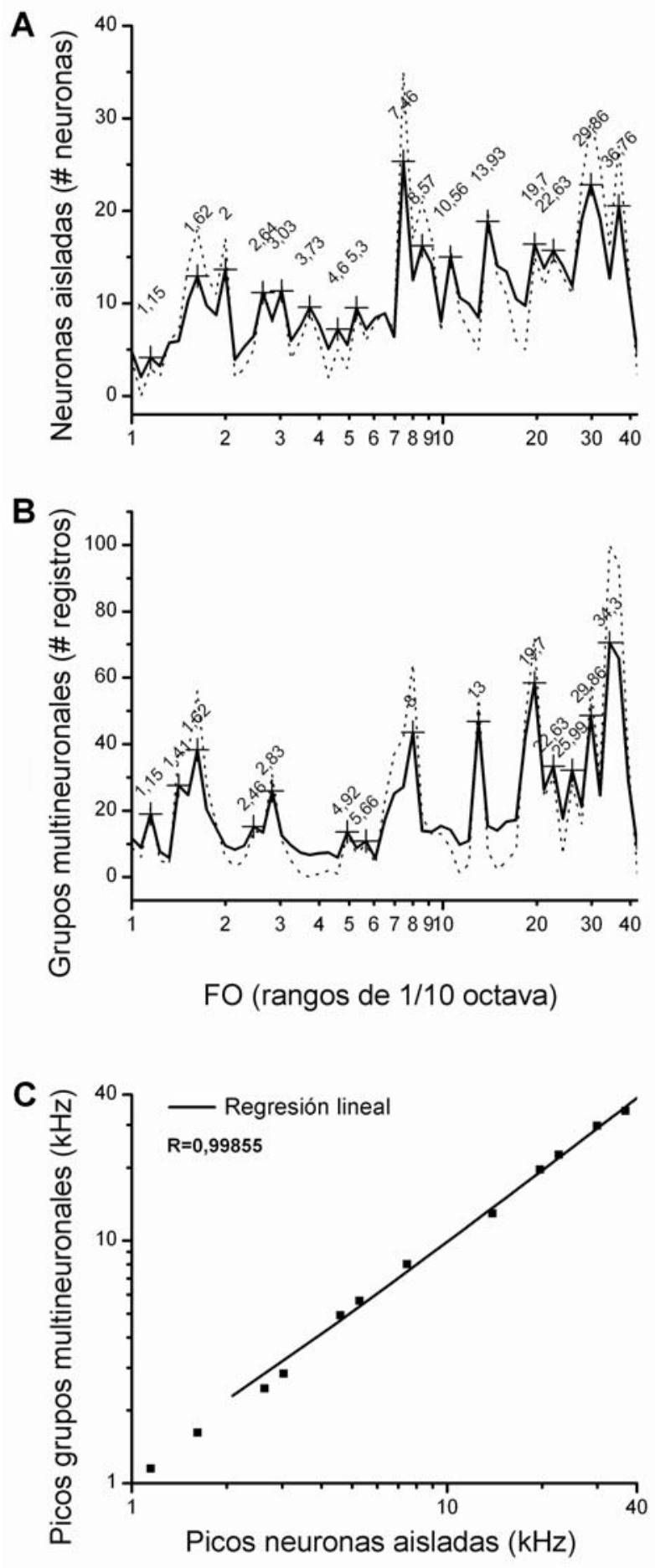

Figura 12. Histogramas de las FOs de poblaciones neuronales (línea discontinua). Suavizamos la distribución aplicando un análisis basado en la transformada de Fourier (línea continua) y representamos las frecuencias en escala logarítmica, en rangos de 1/10 octavas. A) Las FOs en la muestra de unidades neuronales aisladas muestran una distribución multimodal, con 16 picos en intervalos de $0.32 \pm 0.11$ octavas. B) Las FOs en la muestra de grupos multineuronales también muestran una distribución multimodal, con 14 picos a $0.34 \pm 0.11$ octavas, 12 de los cuales se ajustan a picos similares observados en la distribución de FOs de neuronas aisladas. C) Los dos conjuntos de datos independientes (grupos multineuronales y neuronas aisladas) están significativamente correlacionados $(\mathrm{r}=0.99855)$. Tomado de Malmierca et al., 2008. 
control. Entre las dos colecciones suman un total de $604 \mathrm{MdFs}$ de neuronas aisladas, elaborados con ayuda de dos programas informáticos diferentes que utilizan presentaciones aleatorias de tonos puros (Malmierca et al., 2003, 2005, 2008; Hernández et al., 2005; Pérez-González et al., 2005, 2006). Las FOs y umbrales de las neuronas incluidas en dicha muestra cubren el rango auditivo de frecuencias de la rata hasta $40 \mathrm{kHz}$. La FO de estas neuronas (al igual que en nuestra muestra control de 120 neuronas) aumenta con la profundidad de registro. Cuando representamos las FOs de las 604 neuronas totales en forma de histograma, agrupadas en rangos de frecuencia de 0.1 octavas, vemos una distribución multimodal con 16 picos que aparecen en intervalos de $0.32 \pm 0.11$ octavas (Fig. 12A; Malmierca et al., 2008).

En una distribución similar, realizada a partir de los registros de grupos multineuronales, aparecen 14 picos de frecuencia (Fig. 12B), 12 de los cuales coinciden con los observados en la distribución de neuronas aisladas (Fig. 12C). Los 12 picos que coinciden, procedentes de los dos grupos de datos independientes, están significativamente correlacionados $(r=0.99855)$ en un análisis de regresión lineal. La secuencia combinada de picos de ambas distribuciones sugiere que existen 18 picos que aparecen en intervalos de $0.29 \pm 0.1$ octavas. Por ello, las dos poblaciones de neuronas registradas en el NCCI con diferentes metodologías (en diferentes laboratorios y usando distintos equipos de registro), sugieren un aumento en la representación de FOs en intervalos de aproximadamente un tercio de octava (las frecuencias situadas en intervalos de 1/3 octava están más representadas que el resto). Estos estudios indican que las FOs en el CI están distribuidas de una manera discontinua.

\section{Reconstrucción tridimensional de las láminas de isofrecuencia del colículo inferior}

Para estudiar la extensión, forma y orientación de diferentes láminas de isofrecuencia dentro del CI, hemos realizado lesiones electrolíticas en determinadas FOs del mismo CI en varios tractos. La figura 13 muestra la orientación de dichas láminas en dos de los casos (\# 259 y 260) que utilizamos para el registro de mapas tonotópicos de grupos multineuronales.

Tras registrar cuatro tractos tonotópicos y utilizando las lesiones electrolíticas como referencia, realizamos la reconstrucción 3-D del CI, uniendo los puntos con la misma FO y delimitando así una lámina de isofrecuencia. El caso \# 259 (Fig. 13, columna izquierda) muestra láminas de isofrecuencia a 3 y $30 \mathrm{kHz}$, mientras que el caso \# 260 (Fig. 13, columna derecha) muestra láminas de isofrecuencia a 8 y $30 \mathrm{kHz}$. En ambos casos las láminas de $30 \mathrm{kHz}$ son más oblicuas, mientras que las láminas de frecuencia menor están más orientadas en el plano horizontal. Esto explica que en algunos de los mapas tonotópicos las frecuencias altas estén representadas durante un trayecto mayor del electrodo de registro. Al estar las láminas más inclinadas, el electrodo las atraviesa de forma oblicua y no de forma perpendicular, como lo hace en el caso de las láminas de frecuencias bajas. 
Caso \#259

Caso \#260
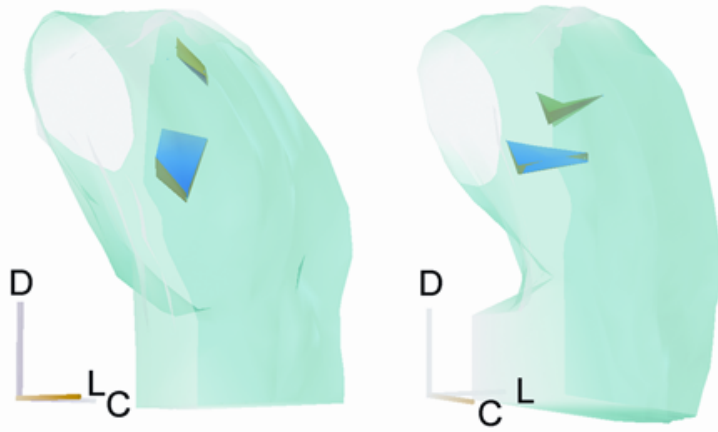

Vista lateral
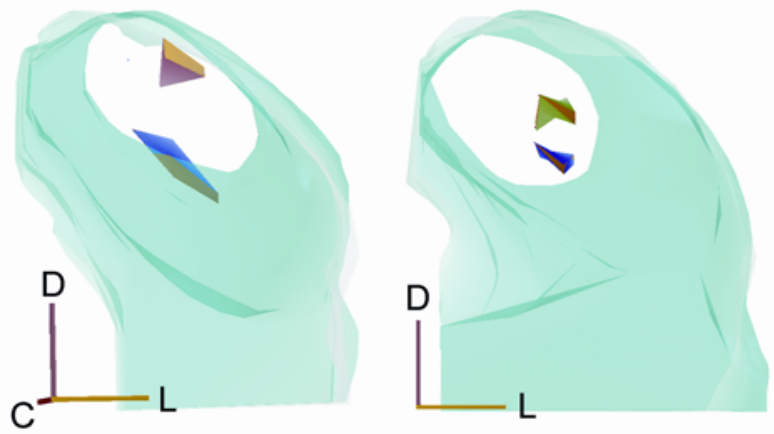

Vista caudal
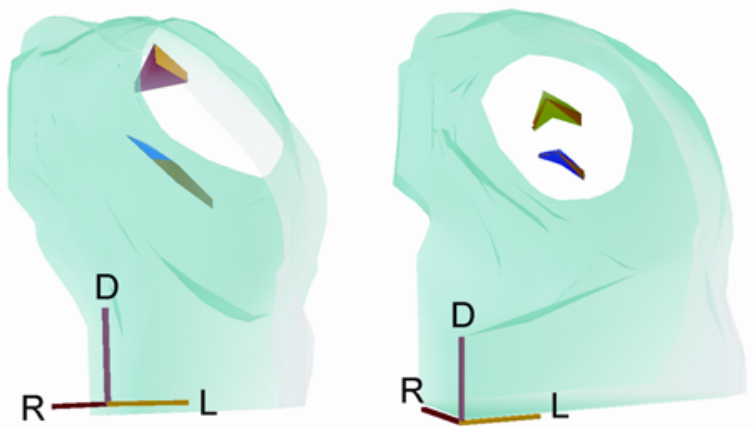

Vista medial

Figura 13. Reconstrucción tridimensional de las láminas de isofrecuencia del CI. Esta reconstrucción 3-D muestra la relación mutua y la orientación de las láminas de isofrecuencia a $3 \mathrm{kHz}$ (rojo), $8 \mathrm{kHz}$ (verde), y $30 \mathrm{kHz}$ (azul), obtenidas a partir de los tractos tonotópicos y las lesiones electrolíticas realizados en dos casos diferentes. Cada lámina se ha reconstruido partiendo de cuatro lesiones equidistantes. R, Rostral; D, dorsal; L, lateral, C; caudal. Tomado de Malmierca et al., 2008. 


\section{Audiograma PAC}

Para caracterizar el grado de pérdida auditiva en animales con lesión crónica por trauma acústico hemos realizado audiogramas PAC. Para asegurar un aumento permanente del umbral auditivo hicimos los registros 35-296 días tras la exposición al tono traumatizante. La figura 14 muestra el audiograma PAC para cada animal sometido a trauma acústico expresado como aumento permanente del umbral relativo a la media del PAC control (0 dB, línea basal). Varios estudios previos han demostrado que es necesario un aumento de al menos $20 \mathrm{~dB}$ en los umbrales de respuesta normales para que se produzca una reorganización plástica del mapa tonotópico cortical (Rajan, 1998, 2001; Rajan e Irvine, 1998b). Por lo tanto, adoptamos ese valor como referencia.

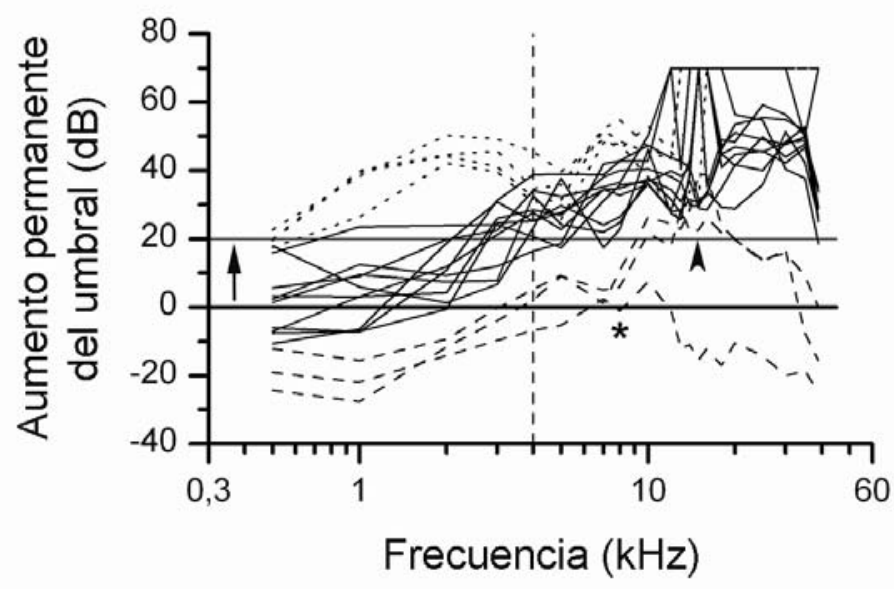

Figura 14. Caracterización de la pérdida auditiva. Aumento permanente del umbral auditivo en los diecisiete animales con trauma acústico, en relación a los umbrales control (línea base, $0 \mathrm{~dB}$ ). La línea fina horizontal indica un aumento permanente del umbral de $20 \mathrm{~dB}$ (flecha). La mayoría de casos presentaron un aumento permanente del umbral $>20 \mathrm{~dB}$ a frecuencias superiores a 4 $\mathrm{kHz}$ (línea vertical discontinua). Cuatro casos también mostraron aumento permanente del umbral $>20 \mathrm{~dB}$ a frecuencias bajas $(<4 \mathrm{kHz})$, afectando así todo el rango de frecuencias (líneas de puntos). Los tres últimos casos (líneas discontinuas) resultaron ser más sensibles tras la lesión acústica que los animales control, pero sufrieron un aumento permanente del umbral a frecuencias medias $(5-12 \mathrm{kHz}$, asterisco) o medias-altas $(5-30 \mathrm{kHz}$, cabeza de flecha). Tomado de Izquierdo et al., 2008.

Independientemente del paradigma de trauma acústico al que se sometieron (tabla 1), 10/17 casos mostraron un aumento permanente del umbral $>20 \mathrm{~dB}$ (Fig. 14, flecha) en torno a 3-4 kHz (Fig. 14, línea discontinua vertical) y por encima de estas frecuencias. De los 7 casos restantes, 4 (casos \# 107, 147, 148 y 150) también mostraron un aumento permanente del umbral a frecuencias bajas (Fig. 14, líneas de puntos). Esto es, un aumento permanente del umbral incluso más extenso que afectaba prácticamente 
a todas las frecuencias que examinamos. Los 3 casos restantes (casos \# 224, 226 y 244) mostraron un audiograma PAC que parecía más sensible que el audiograma PAC control (Fig. 14, líneas discontinuas). Sin embargo, 2 de esos casos presentaban un aumento permanente del umbral de tipo 'muesca' en el rango de frecuencias $5-20 \mathrm{kHz}$ (Fig. 14, cabeza de flecha). El último caso (\# 224) quedaba dentro del área de respuesta normal, pero mostraba un descenso en la sensibilidad $\sim 5-12 \mathrm{kHz}$ (Fig. 14, asterisco).

En resumen, los datos del audiograma PAC descritos demuestran una pérdida auditiva muy severa en todos los casos exceptuando uno (caso \# 224), independientemente de la frecuencia o intensidad del tono empleado para generar el trauma acústico y del tiempo de exposición.

\section{Mapa tonotópico del colículo inferior tras un trauma acústico}

Hemos elaborado mapas de la FO de grupos multineuronales en 17 ratas, previamente sometidas a un trauma acústico a $5 \mathrm{kHz}(\mathrm{n}=6$, tabla 1$)$ y también a $8 \mathrm{kHz}$ $(\mathrm{n}=11$, tabla 1), realizando un total de 29 tractos a través del NCCI (10 en animales expuestos a un tono traumático de $5 \mathrm{kHz}$ y 19 tractos en animales sometidos a $8 \mathrm{kHz}$ ). Las figuras 15 y 16 muestran 12 de los tractos. En estas figuras podemos observar los mapas tonotópicos obtenidos de 6 animales tras un trauma acústico (Figs. 15 y 16 A2C2, símbolos abiertos) y sus correspondientes audiogramas PAC (Figs. 15 y 16 A1-C1, círculos cerrados). Debemos subrayar que los casos ilustrados en dichas figuras son totalmente representativos de todo el grupo de animales con trauma acústico.

La inspección visual de los tractos en las figuras 15 y 16 nos muestra que la pérdida auditiva inducida por ruido produce una reorganización en el mapa tonotópico del CI. El patrón en 'escalera' observado en los mapas tonotópicos normales (Figs. 9B y 11) resulta ligeramente alterado (Fig. 15) y distorsionado de forma muy significativa (Fig. 16). En estos animales la FO permanece constante durante una media de $218.5 \pm$ $113 \mu \mathrm{m}$ (frente a los $151 \pm 41 \mu \mathrm{m}$ observados en animales control; t-test, $\mathrm{P}<0.01$ ) у a continuación, cambia $0.49 \pm 0.40$ octavas (frente a las $0.34 \pm 0.11$ octavas en animales control). Por ello, el número de escalones se reduce significativamente $(\mathrm{n}=287$ escalones, $9.9 \pm 4.4$ de media por tracto, frente a los $14 \pm 3.7$ observados en animales control; t-test, $\mathrm{P}<0.05$ ), como puede apreciarse en la figura 16 (Izquierdo et al., 2008).

En todos los tractos del grupo experimental la secuencia de FOs y umbrales es normal hasta $\sim 1.5-1.7 \mathrm{kHz}$ (Figs. 15 y 16 A2-C2, flechas). Sin embargo, a partir de esa frecuencia en adelante la secuencia de FOs se desorganiza. Todos los casos individuales de reorganización en los mapas tonotópicos tras un trauma acústico pueden clasificarse en dos grupos, atendiendo al grado de reorganización que experimentan: A2-C2).

1) el primer grupo muestra una alteración mínima del mapa tonotópico (Fig. 15

La mayoría de los escalones de frecuencia que aparecen son similares a los observados en los animales control (Figs. 9B y 11). Las frecuencias ausentes se corresponden con la pérdida auditiva observada en el audiograma PAC (Fig. 15 A2 y C2, asteriscos) y se sustituyen por expansiones de frecuencias adyacentes.

2) el segundo grupo muestra una reorganización profunda en todo el NCCI (Fig. 16 A2-C2). 

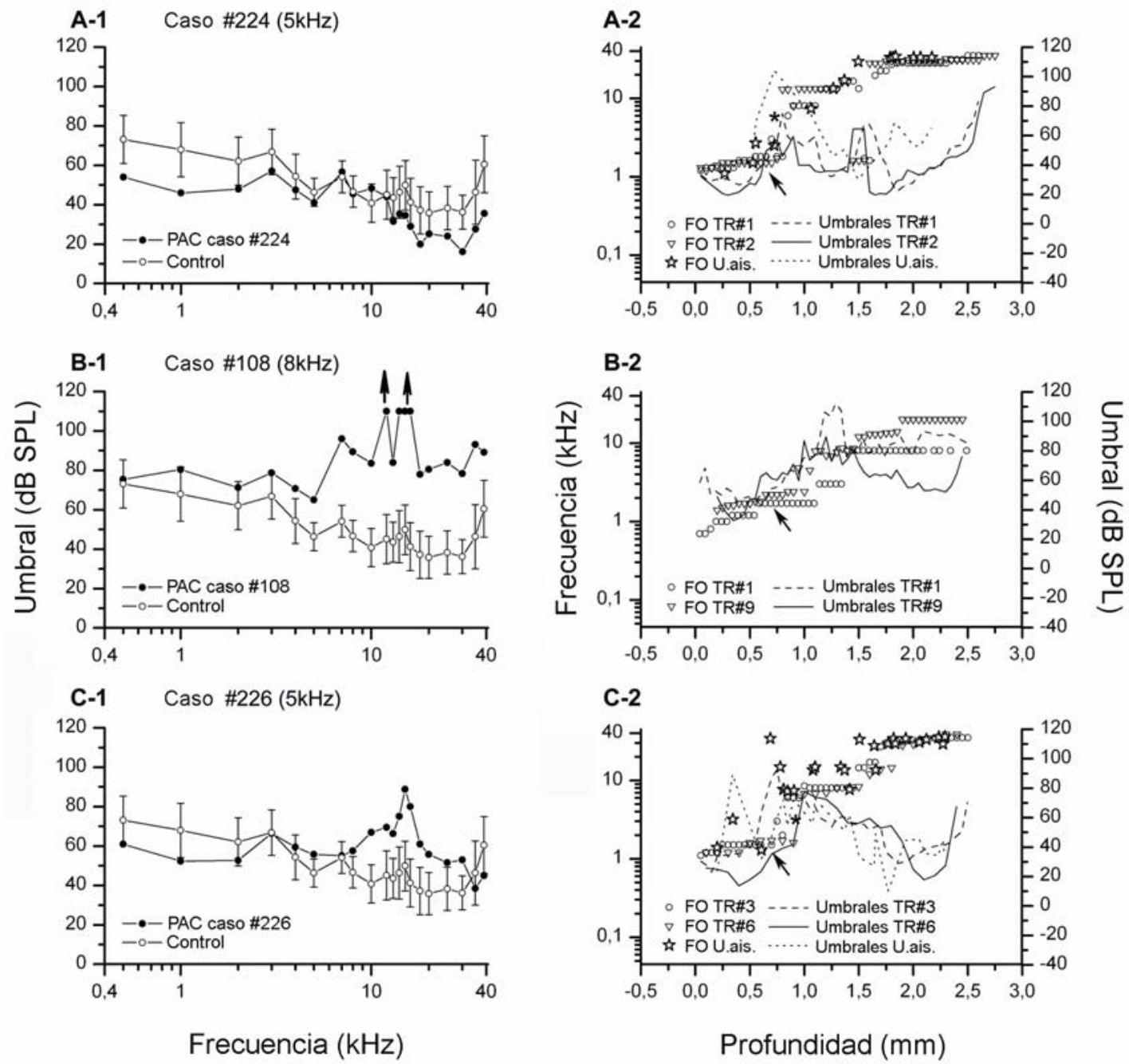

Figura 15. Audiogramas PAC y mapas tonotópicos de grupos multineuronales tras un trauma acústico. A1-C1) Audiogramas PAC de tres animales con lesión acústica (círculos cerrados) en comparación con audiogramas PAC control (círculos abiertos). La exposición sonora provocó una pérdida auditiva muy amplia en cuanto a rango de frecuencias afectadas. En algunos casos (p. ej., B1) registramos una pérdida completa en la sensibilidad a algunas frecuencias (flechas verticales). A2-C2) Mapas tonotópicos basados en registros de la FO de grupos multineuronales en función de la profundidad a través del NCCI (círculos y triángulos invertidos) y sus respectivos umbrales (líneas continuas y discontinuas, respectivamente), medidos en los mismos animales que A1-C1. La progresión tonotópica de FOs se rompe a consecuencia del trauma acústico (asteriscos), afectando a la región central del NCCI. Esta alteración comienza $\sim 700 \mu \mathrm{m}$ (A2-C2, flechas) y origina expansiones de las frecuencias bajas adyacentes a la lesión. En algunos sitios de registro, pudimos registrar neuronas aisladas (estrellas), demostrando que el aumento de los umbrales también afecta a las neuronas aisladas (líneas de puntos). TR, Tracto; U. ais., neuronas aisladas. Tomado de Izquierdo et al., 2008.

La progresión normal de la frecuencia en escalones se altera. Esta alteración conduce a una expansión significativa en el tamaño de uno o dos escalones, correspondientes a las frecuencias representadas en el borde de la pérdida de sensibilidad coclear a juzgar por el PAC (Fig. 16 A1-C1). 

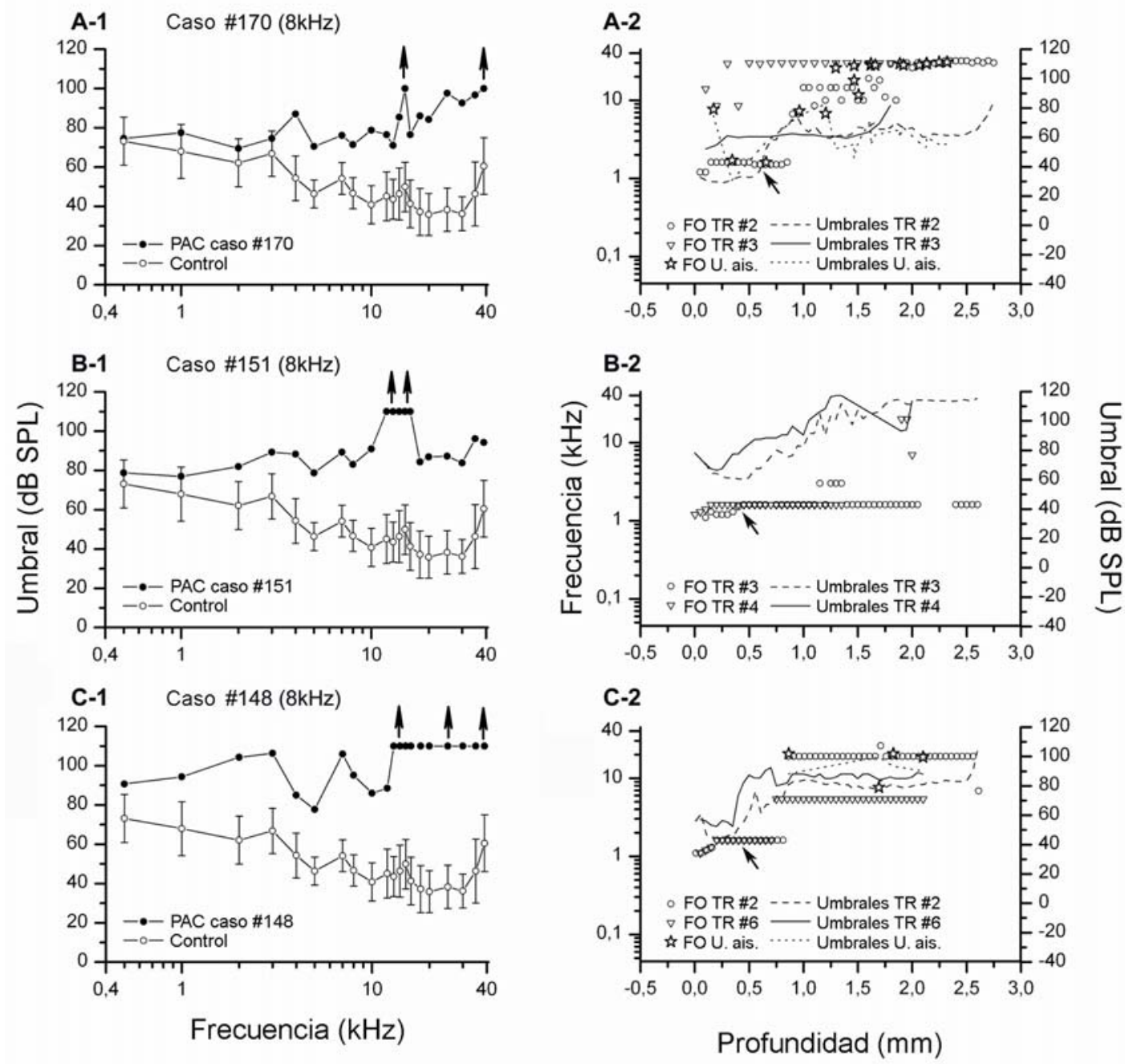

Figura 16. Audiogramas PAC y mapas tonotópicos de grupos multineuronales tras un trauma acústico. A1-C1) Los audiograma PAC de animales con trauma acústico (círculos cerrados) muestran una pérdida auditiva severa, que afecta a la mayoría de frecuencias analizadas, con una pérdida de sensibilidad completa para algunas frecuencias (flechas verticales). Este patrón de pérdida auditiva provoca mapas tonotópicos con una profunda alteración de la progresión normal de las frecuencias (A2-C2, símbolos abiertos). En torno a 1.5-1.7 kHz, que corresponde a una profundidad $\sim 700 \mu \mathrm{m}$ (A2-C2, flechas) se producen expansiones de las frecuencias localizadas en el borde la lesión y un aumento marcado de los umbrales (A2-C2, líneas continuas y discontinuas). También pudimos determinar la FO y umbral de unidades neuronales aisladas (estrellas y líneas de puntos, respectivamente) en algunas profundidades de registro. Vemos como estas FOs y umbrales siguen la tendencia mostrada por las FOs y umbrales de grupos multineuronales. TR, Tracto; U. ais., neuronas aisladas. Tomado de Izquierdo et al., 2008.

Ambos grupos muestran un fuerte incremento en los umbrales de respuesta (Figs. 15 y 16 A2-C2, líneas continuas y discontinuas).

El patrón de efectos observados en la respuesta de grupos multineuronales también aparece en los registros de neuronas aisladas que conseguimos realizar en algunos tractos. En cada caso, la FO y umbrales determinados a partir de la respuesta de neuronas individuales (Figs. 15 y 16 A2-C2, estrellas y líneas de puntos, 
respectivamente) son muy similares a la FO y umbrales determinados a partir de la respuesta de grupos multineuronales a través del NCCI (Figs. 15 y 16 A2-C2, símbolos abiertos y líneas continuas y discontinuas, respectivamente).

A pesar de la gran variabilidad en el nivel de pérdida auditiva observado en los 17 animales con trauma acústico (como hemos comprobado por sus audiogramas PAC), parece que existe una correlación entre el audiograma PAC y el grado de reorganización que experimenta el mapa tonotópico del NCCI. Aquellos casos que presentan la menor alteración en el mapa tonotópico (casos \# 108, 224, 225, 226 y 244) se corresponden con aquellos cuyo audiograma PAC presenta la menor pérdida de sensibilidad coclear. La mayoría de audiogramas PAC en dichos casos (menor grado de reorganización del mapa tonotópico) corresponden al de tipo 'muesca', salvo el caso \# 151 (Fig. 16B), que a pesar de presentar un audiograma PAC de tipo 'muesca' ha sufrido una profunda reorganización de su mapa tonotópico.

Hasta aquí, hemos descrito la organización tonotópica del CI, basada en la FO medida a profundidades diferentes de manera progresiva. Por definición, la FO es aquella frecuencia a la que la neurona es más sensible, es decir, la que posee un umbral de respuesta más bajo. Sin embargo, podemos realizar un análisis (o mapa) complementario representando los umbrales de respuesta a una frecuencia determinada en función de la profundidad de registro en el CI. De esta forma generamos una 'curva de sintonía espacial'. La figura 17 muestra la curva de sintonía espacial control para 1.6 $\mathrm{kHz}$ (la primera frecuencia a la que se produce un aumento en el tamaño de los escalones del mapa tonotópico alterado en animales con trauma acústico).

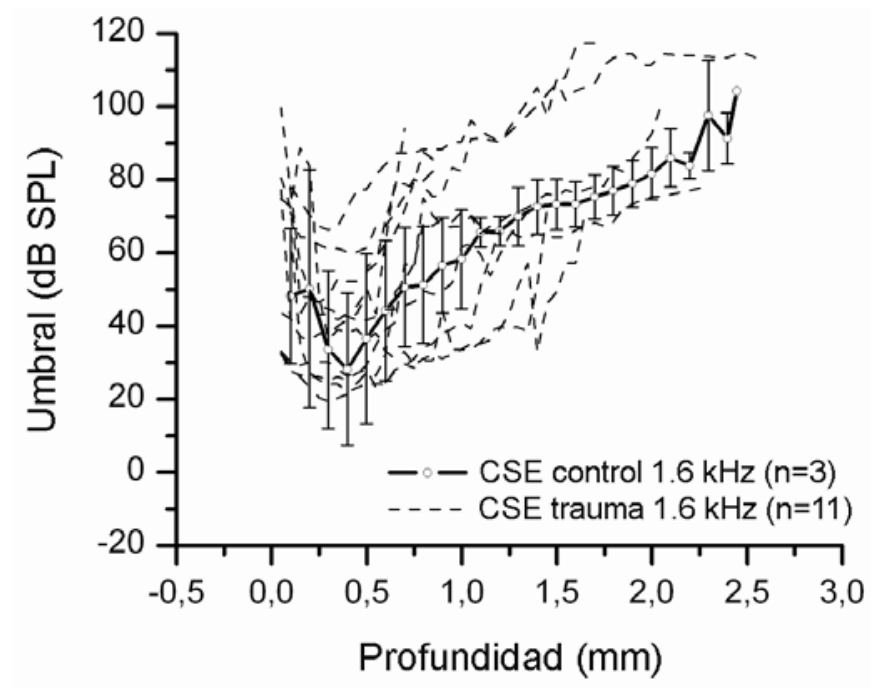

Figura 17. Curvas de sintonía espacial. Determinamos la curva de sintonía espacial control \pm SD (línea continua, $\mathrm{n}=3$ ) para $1.6 \mathrm{kHz}$. Esta curva representa los umbrales de respuesta del grupo multineuronal a $1.6 \mathrm{kHz}$, cada $25-50 \mu \mathrm{m}$ a través del NCCI. El pico de la curva indica la profundidad y grosor de la zona del CI más sensible a esta frecuencia (lámina de isofrecuencia $1.6 \mathrm{kHz}$ ). Las líneas discontinuas corresponden a curvas de sintonía espacial a la misma frecuencia $(1.6 \mathrm{kHz})$ registradas en animales con trauma acústico $(\mathrm{n}=11)$. La mayoría de esas curvas de sintonía espacial siguen la progresión normal de la curva de sintonía espacial control, demostrando un componente de respuesta residual tras la lesión y no una resintonización o cambio plástico en la representación de las frecuencias (ver Discusión). CSE, curva de sintonía espacial. Tomado de Izquierdo et al., 2008. 
Esta curva de sintonía espacial tiene forma de ' $\mathrm{V}$ ' y es asimétrica, con una pendiente más pronunciada en la región de frecuencias bajas del CI y una pendiente menos pronunciada en la zona de frecuencias altas. El pico de la ' $\mathrm{V}$ ' indica la zona del CI más sensible a esa frecuencia determinada, es decir, la lámina de isofrecuencia. Las diferentes líneas discontinuas de la figura 17 representan 11 curvas de sintonía espacial individuales para $1.6 \mathrm{kHz}$ en animales con trauma acústico. La mayoría de dichas curvas de sintonía espacial tienen una forma de ' $\mathrm{V}$ ' tan aguda como la curva de sintonía espacial control (ver Discusión). Sólo dos o tres de esas curvas de sintonía espacial muestran cierto ensanchamiento de su vértice, de tal forma que el umbral mínimo es más o menos similar al de la curva de sintonía espacial control durante una mayor distancia en el CI. Este hecho podría indicarnos una expansión de tipo plástico en la lámina de isofrecuencia (fruto de la resintonización de la respuesta de neuronas situadas en láminas adyacentes). De una forma similar, medimos la curva de sintonía espacial para $7 \mathrm{kHz}$ en animales lesionados, pero ninguna de dichas curva de sintonía espacial mostró un ensanchamiento significativo de su vértice.

Estos resultados indican que los mapas tonotópicos del CI sufren un proceso de reorganización no plástico tras un trauma acústico.

\section{Mapas de frecuencia en animales con lesión auditiva crónica}

Además de los mapas o tractos tonotópicos basados en el registro de grupos multineuronales, hemos examinado $142 \mathrm{MdFs}$ de unidades neuronales aisladas registradas en animales con un trauma acústico a $5 \mathrm{kHz}(\mathrm{n}=84)$ u $8 \mathrm{kHz}(\mathrm{n}=58)$. La figura 18A muestra los lugares de registro dentro del NCCI para 16 neuronas aisladas en 4 animales diferentes, así como sus correspondientes MdFs (Fig. 18B, cada columna corresponde a un caso individual). Las neuronas situadas al inicio de los tractos, es decir, superficialmente dentro del NCCI $(0-1000 \mu \mathrm{m})$, poseen MdFs con forma de ' $\mathrm{V}$ ' en la mayoría de casos (p. ej., Fig. 18B, unidades \# 223, 235, 236 y 185), con un pico que indica claramente su FO (1.5-2.9 kHz) y umbrales en torno a 20-40 dB SPL. Estos MdFs son muy similares a los registrados en animales control para ese mismo rango de frecuencias. A medida que el electrodo avanza ventralmente $(>1000 \mu \mathrm{m})$ dentro del NCCI, observamos MdFs más anchos (Fig. 18B, unidades \# 224, 237, 191 y 192) con un incremento muy marcado en sus umbrales de respuesta. Los MdFs en esta región normalmente poseen uno o más picos de respuesta a frecuencias por encima de la FO ( $p$. ej., Fig. 18B, flechas verticales). La frecuencia de estos picos aumenta, de manera gradual, en función de la profundidad de registro (p. ej., Fig. 18, columna derecha-caso \# 170-, flechas verticales).

Las neuronas localizadas en la zona más ventral muestran MdFs complejos de tipo 'no-V', con dos o tres picos de frecuencia y umbrales elevados (40-60 dB SPL; p. ej., Fig. 18B, unidades \# 238, 186, 187, 188 y 194). Una gran proporción de los MdFs registrados tras un trauma acústico muestran un incremento en la tasa de actividad espontánea (55.6\% del total de neuronas frente al 33.3\% de neuronas control, p. ej., Fig. 18B, unidades \# 224, 225 y 238).

Con objeto de evaluar los umbrales de respuesta neuronal tras un trauma acústico hicimos una determinación de los umbrales a partir de los MdFs de neuronas aisladas, teniendo en cuenta la profundidad de registro de las mismas. La figura 19A 

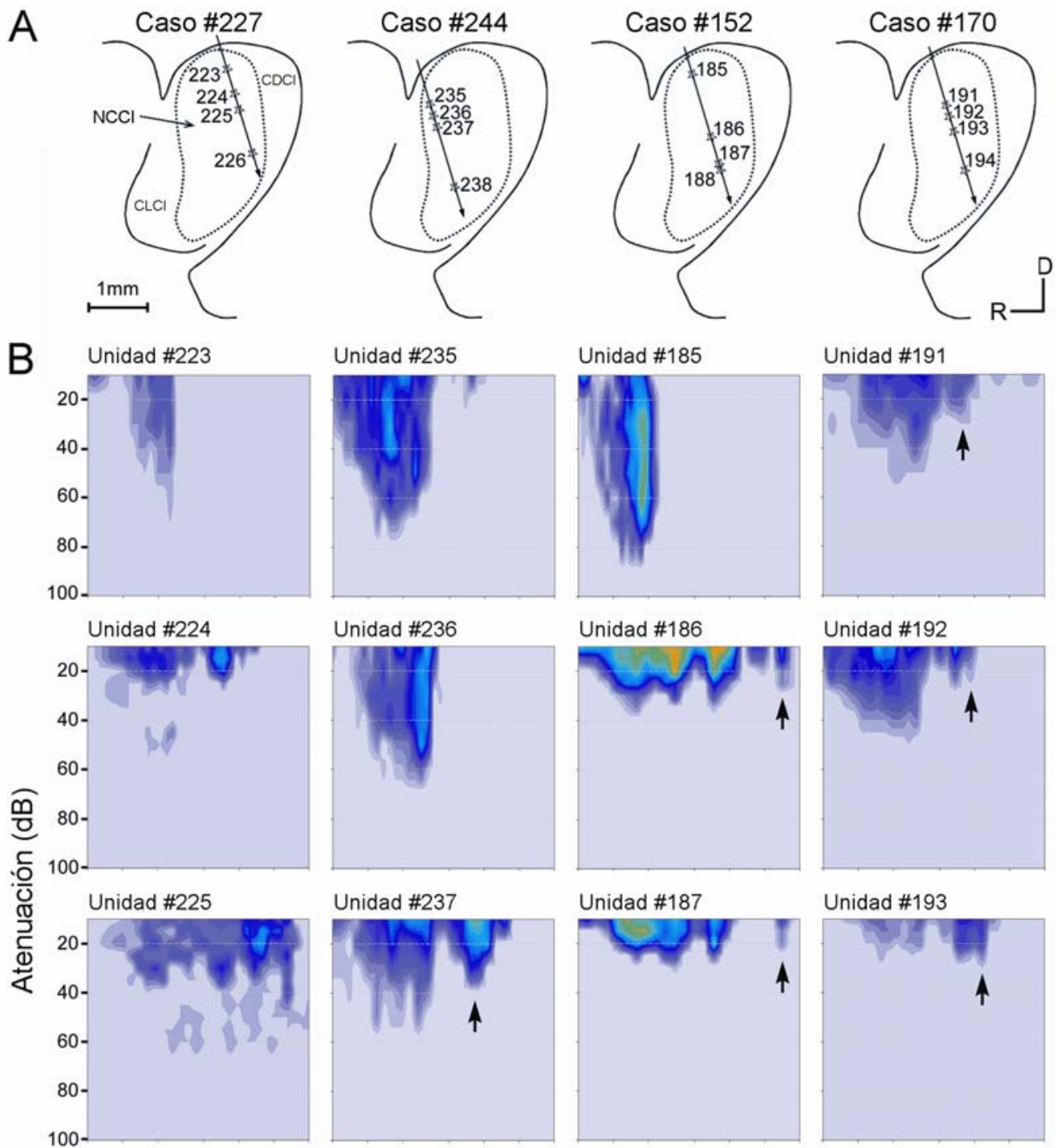

Unidad \#186

Unidad \#192
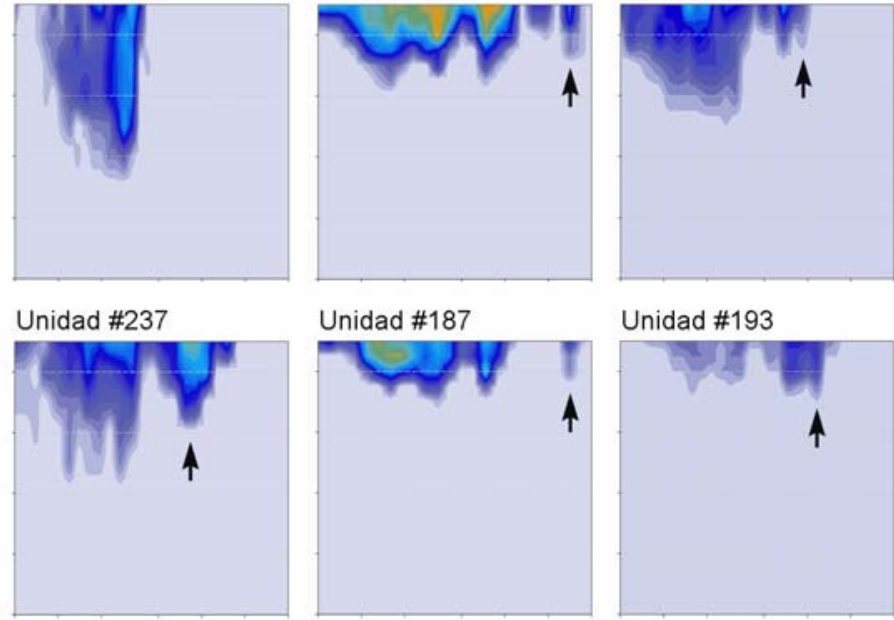

Unidad \#187
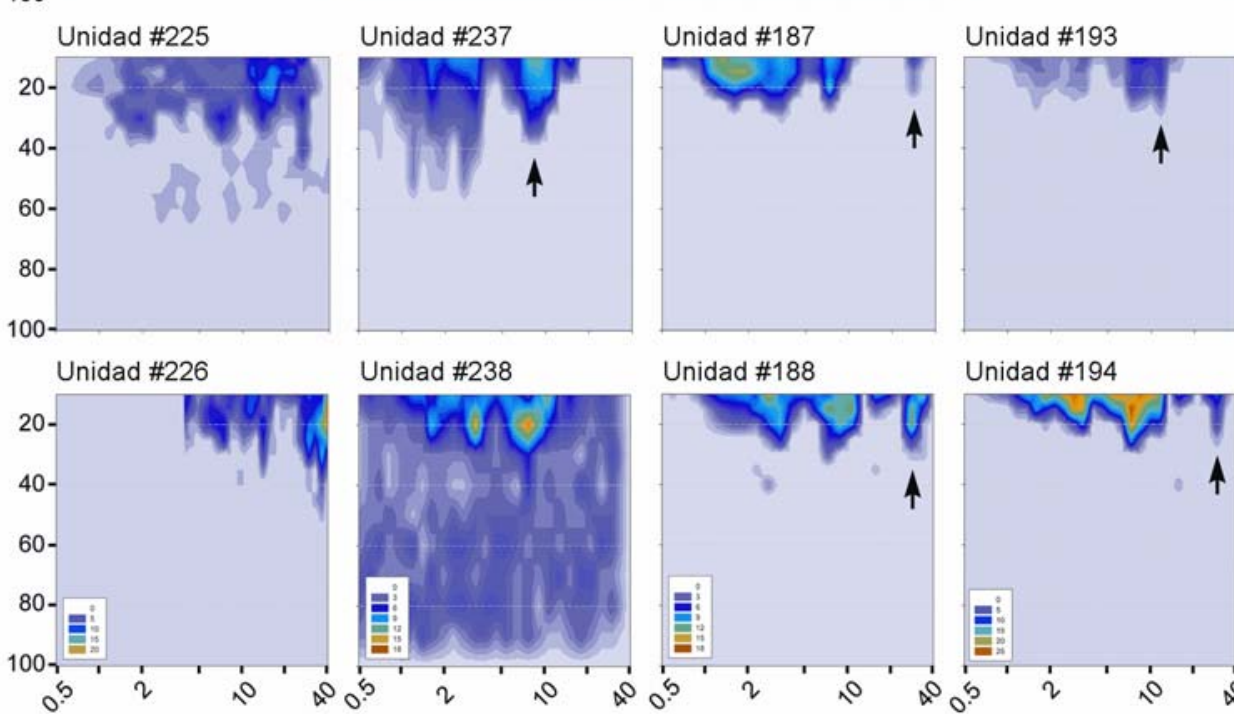

Unidad \#188

Unidad \#194
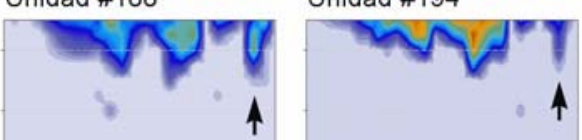

Frecuencia $(\mathrm{kHz})$

Figura 18. Respuesta de unidades neuronales aisladas tras un trauma acústico. A) Localización del electrodo en cuatro tractos, a través del NCCI, de cuatro animales con trauma acústico. El ángulo de penetración es el mismo en todos los casos $\left(10^{\circ}\right)$. Las estrellas indican la profundidad relativa a la que registramos cada neurona aislada. B) Ejemplo de MdFs de 16 neuronas aisladas en los mismos cuatro animales. Los umbrales de respuesta a la FO aumentan a medida que el electrodo avanza a través del NCCI. Tras el trauma acústico, la mayoría de MdFs de neuronas con frecuencias medias-altas muestran un pico secundario (flechas) que representa un vestigio de la FO original. Los MdFs en la zona lesionada también muestran un aumento en la actividad espontánea a consecuencia de la lesión acústica. La escala de color indica el número de potenciales de acción en respuesta a dos presentaciones de cada estímulo. Tomado de Izquierdo et al., 2008 . 
muestra un diagrama de dispersión de los umbrales en función de la FO para el grupo control (círculos abiertos, $\mathrm{n}=120$ ) y para animales con trauma acústico (círculos cerrados, $\mathrm{n}=142$ ). La distribución de umbrales de las dos poblaciones difiere significativamente en el rango de $5-30 \mathrm{kHz}$, mientras que los umbrales obtenidos de frecuencias mayores y menores a ese rango se solapan. La figura 19B muestra un histograma de los umbrales medios, correspondientes a FOs de repuesta para neuronas aisladas control y con trauma acústico, agrupados en rangos de 1/2 octava. El rango de frecuencias comprendido entre $8.1-32 \mathrm{kHz}$ muestra los umbrales más sensibles en animales control (Fig. 19B, barras blancas). Observamos un incremento significativo en los umbrales en el rango de frecuencias $5.71-32 \mathrm{kHz}$ como consecuencia de la lesión acústica (Fig. 19B, barras negras). Desde $32 \mathrm{kHz}$ en adelante, hasta la frecuencia más alta que examinamos $(40 \mathrm{kHz})$, los umbrales de las neuronas aisladas no experimentaron un aumento significativo. Por último, las neuronas aisladas en la región de 1.1-2 kHz mostraron umbrales más bajos después del trauma acústico que los observados en neuronas control, aunque esta diferencia no es significativa.
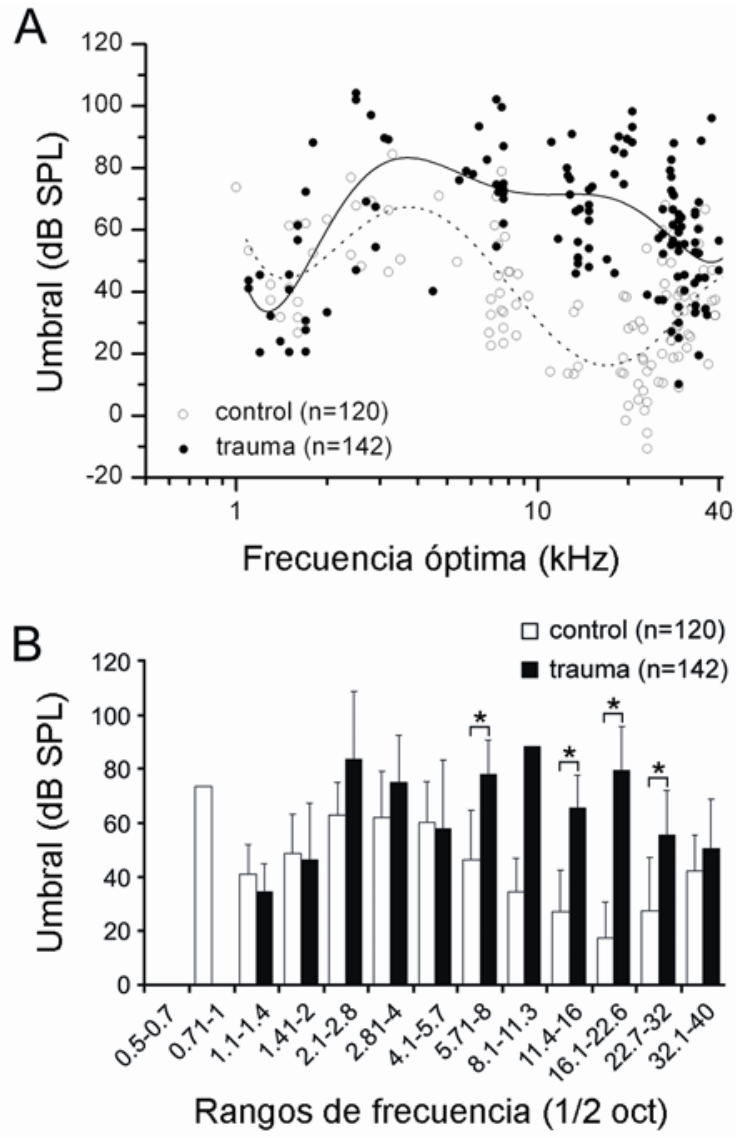

Figura 19. Distribución de umbrales de neuronas aisladas, en función de sus FOs, en animales control y traumatizados. A) Umbrales en una población de 120 unidades neuronales aisladas control (círculos abiertos) y sus valores medios (línea discontinua) en comparación con una población de 142 valores de umbrales de neuronas aisladas tras un trauma acústico (círculos cerrados) y su correspondiente media (línea discontinua). B) Histograma para los umbrales de respuesta de neuronas aisladas en animales lesionados (barras negras), comparados con los umbrales en animales control (barras blancas), en rangos de 1/2 octava. Los umbrales de respuesta neuronal para las frecuencias comprendidas en el rango 5.71-32 kHz, aumentan significativamente a consecuencia del trauma acústico ( $\mathrm{t}$-test, $\mathrm{P}<0.01$ ). Tomado de Izquierdo et al., 2008. 
Para determinar si el trauma acústico daña principalmente la región más sensible del MdF (es decir, la región de la FO), hemos agrupado un conjunto de $20 \mathrm{MdFs}$ de neuronas control con una FO de respuesta alta $(>20 \mathrm{kHz}$; Fig. 20A). De la misma forma, la figura 20B muestra el MdF resultante del promedio de $31 \mathrm{MdFs}$ registrados tras un trauma acústico (10 MdFs de 2 animales expuestos a $5 \mathrm{kHz}$ y $21 \mathrm{MdFs}$ de 4 animales expuestos a $8 \mathrm{kHz}$ ). A continuación, hicimos una substracción del MdF del grupo patológico del $\mathrm{MdF}$ promedio control, para obtener un $\mathrm{MdF}$ que refleje las diferencias en la respuesta tras el trauma acústico (Fig. 20C). Las líneas de puntos en la figura 20C delimitan las diferencias significativas en la respuesta de neuronas tras un trauma acústico. De esta forma se demuestra que la región de la FO desaparece tras el trauma acústico. Sin embargo, la cola de bajas frecuencias no parece alterarse.
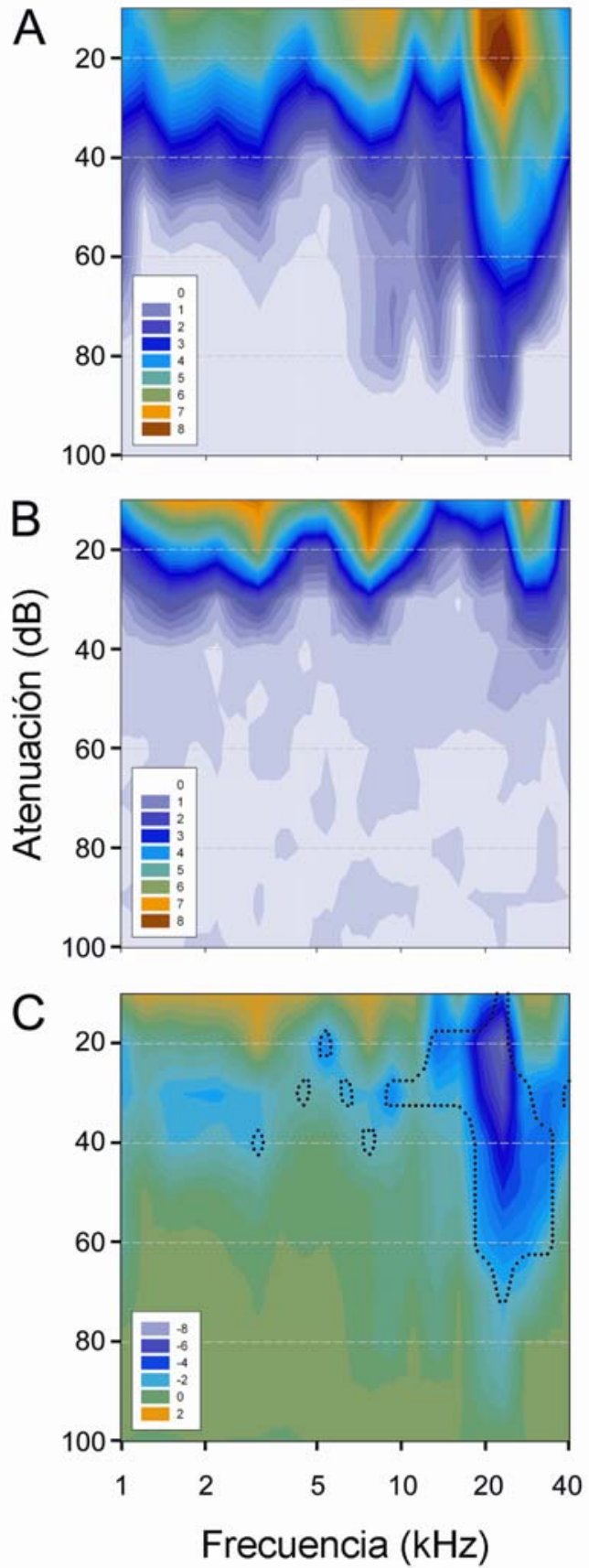

Figura 20. Efectos del trauma acústico sobre los MdFs de neuronas aisladas. Promedio de MdFs con $\mathrm{FO}$ alta $(>20 \mathrm{kHz})$ del grupo de animales control $(\mathrm{A} ; \mathrm{n}=20)$ y del grupo de animales con trauma acústico $(\mathrm{B} ; \mathrm{n}=31)$. La escala de color indica el número de potenciales de acción en respuesta a dos presentaciones de cada estímulo. C) Representación gráfica de las diferencias entre los grupos control y trauma acústico, en términos de tasa de descarga media por rangos de frecuencia-intensidad. La línea de puntos delimita las áreas en las cuales las respuestas son significativamente diferentes (Mann-Whitney test, $\mathrm{P}<0.01)$. Tomado de Izquierdo et al., 2008. 


\section{Audiograma PAC}

El audiograma PAC en estos animales no debería alterarse, ya que la intensidad del tono utilizado para la estimulación ( $\sim 60-70 \mathrm{~dB}$ SPL) en ningún momento superó los niveles necesarios para provocar un trauma acústico. No obstante, medimos el audiograma PAC en uno de los animales sometidos a un ambiente acústico enriquecido (caso \# 093), previo a realizar los registros electrofisiológicos pertinentes, para asegurarnos de que no se ha producido daño alguno en el receptor auditivo a consecuencia de la exposición sonora. El resultado de esta medición se muestra en la figura 21. En esta figura podemos observar cómo los umbrales para el audiograma PAC son normales (Fig. 21, círculos cerrados). Sin embargo, el PAC de este animal presenta una mayor sensibilidad en el rango de frecuencias comprendido entre $16-25 \mathrm{kHz}$.

Figura 21. Audiograma PAC de un animal tras exposición a un ambiente acústico enriquecido (círculos cerrados) en comparación con el audiograma PAC control (círculos abiertos). Los umbrales de respuesta del nervio auditivo son normales, es decir, el animal no ha sufrido pérdida auditiva como consecuencia de la exposición sonora.

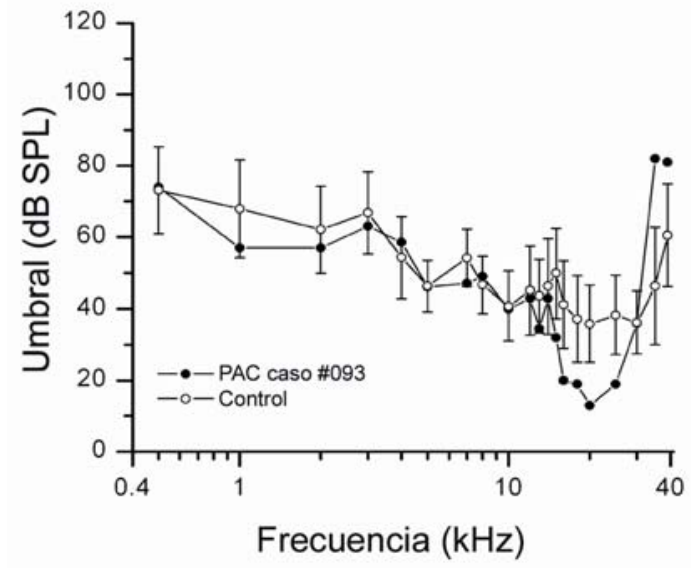

\section{Mapa tonotópico del colículo inferior tras exposición a un ambiente acústico enriquecido}

Para evaluar una posible alteración en la codificación de frecuencias en el CI provocada por la exposición postnatal a un ambiente acústico enriquecido, realizamos mapas tonotópicos del CI de una forma similar a la anteriormente descrita para animales control y con trauma acústico. En concreto, hemos estudiado 31 mapas tonotópicos procedentes de 9 animales sometidos a estimulación con tonos de $14 \mathrm{kHz}$ durante P9P28 (tabla 2).

Nuestros resultados muestran que la exposición acústica temprana (P9-P28) altera el tamaño de la lámina de isofrecuencia sintonizada a $14 \mathrm{kHz}$ (frecuencia de exposición). En la mayoría de animales expuestos al sonido registramos grupos de neuronas sintonizadas a la frecuencia de exposición acústica temprana $(14 \mathrm{kHz})$ durante un trayecto mayor del mapa que en los animales control. La figura 22A muestra los registros del mapa tonotópico en un animal expuesto a un tono de $14 \mathrm{kHz}$ en un estadio inmaduro, en comparación con los registros realizados en su madre, que utilizamos como control (animal expuesto en estadio adulto). La longitud del escalón de $14 \mathrm{kHz}$ 
también es mayor cuando la comparamos con escalones adyacentes en múltiples tractos del mismo animal (Fig. 22B, flechas). Además, comparamos la longitud media de los escalones de $\mathrm{FO}=14 \mathrm{kHz}$ en cada animal con la longitud media del escalón inmediatamente anterior en frecuencia y lo representamos en forma de diagrama de
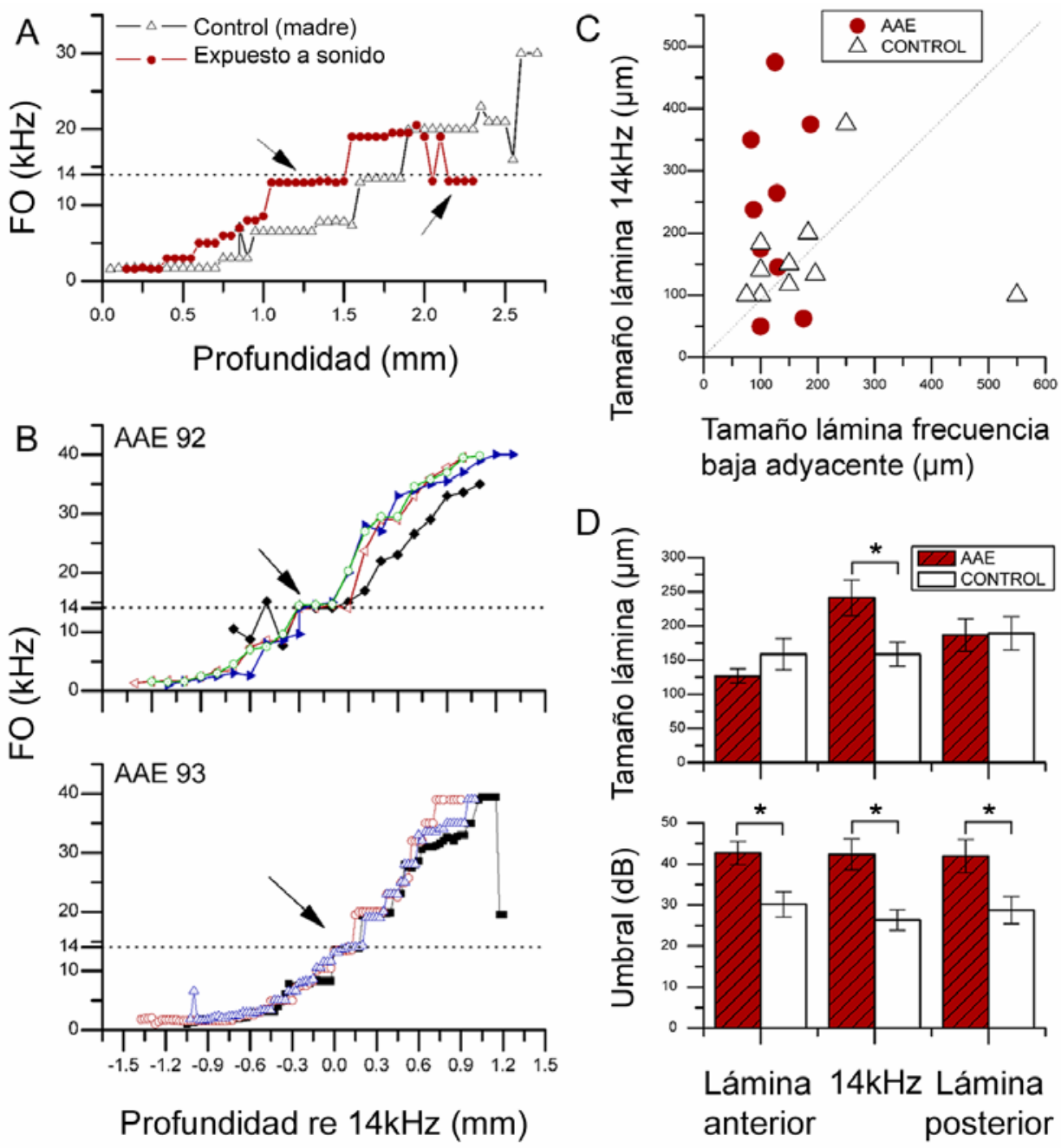

Figura 22. Tractos tonotópicos en el NCCI tras exposición a un ambiente acústico enriquecido. Las FOs de grupos multineuronales se midieron en pasos de $50 \mu \mathrm{m}$. A y B) En la mayoría de casos expuestos a sonido, la lámina de isofrecuencia correspondiente a $14 \mathrm{kHz}$ (líneas discontinuas y flechas) cubre una mayor cantidad de tejido del CI. Esto resulta muy evidente cuando comparamos el mapa tonotópico registrado en una de las madres (control adulto), con el de una de las crías de la camada (A). C) Diagrama de dispersión para el grosor medio de la lámina de isofrecuencia de $14 \mathrm{kHz}$ frente al grosor de la lámina de frecuencia baja adyacente. Para el grupo experimental la mayoría de los puntos (círculos) están desviados hacia el cuadrante superior izquierdo, lo cual indica que la lámina de isofrecuencia de $14 \mathrm{kHz}$ tiende a ser más ancha que la lámina de frecuencia menor adyacente. D, arriba) Histograma que muestra las diferencias significativas entre el tamaño de la lámina de $14 \mathrm{kHz}$ en animales control y estimulados $(\mathrm{P}<0.05)$. Sin embargo, el tamaño de las láminas de frecuencias adyacentes no varía. D, abajo) La estimulación acústica postnatal induce un aumento significativo en los umbrales de respuesta a frecuencias en torno a la frecuencia de estimulación $(\mathrm{P}<0.05)$. AAE, Ambiente acústico enriquecido. 
dispersión (Fig. 22C). La longitud del escalón de $14 \mathrm{kHz}$ en animales control (Fig. 22C, triángulos, $\mathrm{n}=11$ animales) sigue una regresión lineal con respecto a la longitud del escalón de frecuencia anterior, es decir, presenta un tamaño similar. Sin embargo, la longitud del escalón con $\mathrm{FO}=14 \mathrm{kHz}$ en la mayoría de animales expuestos a un ambiente acústico enriquecido $(7 / 9,77.8 \%)$ está por encima de la tendencia lineal. Esto quiere decir que tiende a ser mayor en longitud que el escalón adyacente de frecuencia más baja (Fig. 22C, círculos, $\mathrm{n}=9$ animales). Curiosamente, en 2 casos hay un descenso significativo en el tamaño de la lámina de $14 \mathrm{kHz}$, en lugar de un incremento.

Estos datos promediados por animal presentan una varianza demasiado elevada para apreciar diferencias significativas entre el grupo control y el experimental. Sin embargo, las medias de tractos tonotópicos individuales reflejan diferencias significativas. La longitud media del escalón de frecuencias que incluye $14 \mathrm{kHz}$ en el grupo experimental es significativamente mayor que en los individuos control (Fig. 22D, arriba). Sin embargo, no existen diferencias en el tamaño de los escalones situados a ambos lados de $14 \mathrm{kHz}$ entre los animales expuestos y controles (Fig. 22D, arriba).

Además del tamaño de la lámina de isofrecuencia, evaluamos los umbrales de respuesta de grupos multineuronales en los mismos rangos de frecuencias. Tanto en el escalón de $14 \mathrm{kHz}$ como en los adyacentes (anterior y posterior) los umbrales muestran un incremento significativo con respecto a los umbrales control (Fig. 22D, abajo). Este resultado indica que la exposición postnatal a un ambiente acústico enriquecido tiene un efecto general aumentando los umbrales del sistema. Dicho resultado (aumento de los umbrales) está en consonancia con los efectos observados en estudios previos (Chang y Merzenich, 2003).

El análisis de todos los grupos multineuronales, independientemente de si están localizados en el NCCI o en otra porción del CI, también muestra un efecto de la exposición acústica temprana. De esta forma, hemos realizado un histograma con rangos de frecuencia de $1 / 2$ octava, normalizado y promediado por grupo (control y

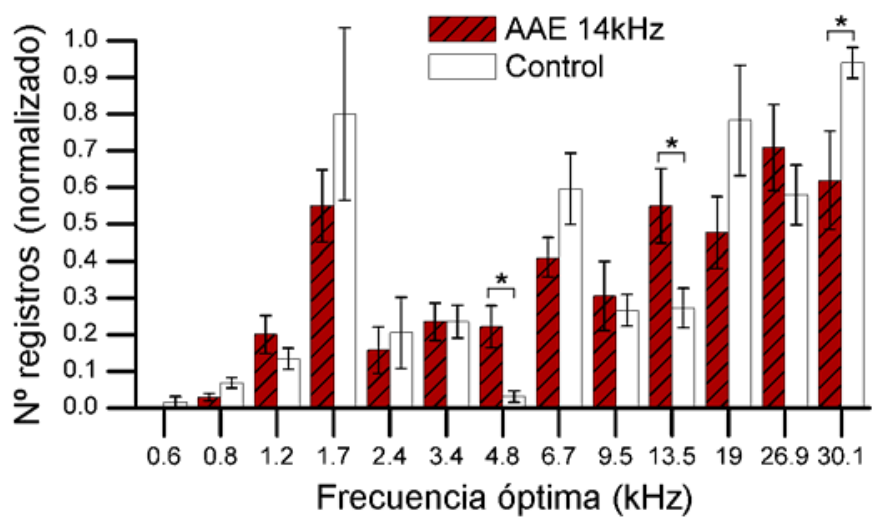

Figura 23. Histograma normalizado de los registros multineuronales realizados en todos los tractos tonotópicos del CI. La frecuencia está representada en rangos de 1/2 octava. Los registros realizados en animales tras exposición a un ambiente acústico enriquecido (barras rojas) muestran un aumento significativo en el número de grupos multineuronales que responden a frecuencias $\sim 14 \mathrm{kHz}(11.4-16 \mathrm{kHz}$ ), en comparación con animales control (barras blancas). El histograma también muestra un aumento significativo en el número de lugares de registro que responden a 4-5.7 kHz y un descenso en el número de respuestas al rango de frecuencias más altas $(32-40 \mathrm{kHz})$ en los animales del grupo experimental $(\mathrm{P}<0.05)$. AAE, Ambiente acústico enriquecido. 
experimental) de todos los registros de grupos multineuronales procedentes de todos los tractos, tanto de los localizados dentro del NCCI como en las cortezas del CI. El análisis de todos estos tractos muestra un ligero aumento en el número de grupos de neuronas que responden a la frecuencia de exposición (rango $11.4-16 \mathrm{kHz}$ ) en los animales sometidos a un ambiente acústico enriquecido durante el desarrollo (Fig. 23). Esto indica que las neuronas localizadas en las cortezas del CI también han resultado influenciadas por la exposición acústica temprana. Además, en los animales del grupo experimental se produce un incremento significativo del número de lugares que responden a frecuencias entre $4-5.7 \mathrm{kHz}$ y un descenso del número de lugares de registro en el rango de frecuencias más altas (32-40 kHz; Fig. 23).

En resumen, la exposición a un ambiente acústico enriquecido durante el desarrollo altera el mapa tonotópico en el NCCI. Esta alteración supone un incremento del tamaño de la lámina y del número de neuronas sintonizadas a la frecuencia de exposición. Es decir, supone un cambio plástico en el mapa tonotópico del CI.

\section{Mapas de frecuencia tras exposición a un ambiente acústico enriquecido}

Hemos registrado $51 \mathrm{MdFs}$ de unidades neuronales bien aisladas en animales expuestos en su etapa postnatal (P9-P28) a un tono de $14 \mathrm{kHz}$. La distribución por frecuencias de esos MdFs es la siguiente:

10 neuronas tienen una FO en el rango $11-16 \mathrm{kHz}$.

19 neuronas tienen $\mathrm{FO}<11 \mathrm{KHz}$ y 22 de ellas $>16 \mathrm{kHz}$.

4 neuronas presentan una $\mathrm{FO}=14 \mathrm{kHz}$ y son similares a las neuronas control en umbral y ancho de banda (Fig. 24A).

Sin embargo, el $68 \%$ de las neuronas $(19 / 28)$ con $\mathrm{FO}>14 \mathrm{kHz}$ mostraron un pico de mayor actividad en torno a $14 \mathrm{kHz}$. Este pico resulta especialmente evidente en 10 casos (35\%, p. ej., Figs. 24B y D, flechas rojas).

En 28/51 neuronas pudimos elaborar su correspondiente MdF 2T. Observándolos en detalle, vemos que el segundo pico de actividad en torno a $14 \mathrm{kHz}$ anteriormente mencionado, está rodeado por áreas de inhibición, tal y como puede apreciarse en su MdF 2T (comparar flechas negras y rojas en Figs. 24B y D). Este resultado sugiere que existe un cambio en el balance entre aferencias excitatorias e inhibitorias a esas neuronas del CI, con un predominio de excitación a $14 \mathrm{kHz}$. Por el contrario, observamos una isla de inhibición diferente a $14 \mathrm{kHz}$ cuando examinamos los MdF 2T (Fig. 24C, flecha negra) en $2 / 28$ casos con FO $>14 \mathrm{kHz}$. Estos dos casos sugieren un cambio en el balance hacia inhibición a $14 \mathrm{kHz}$.

En resumen, los resultados de los MdFs sencillos y los realizados con dos tonos sugieren que la exposición acústica temprana altera el balance neto entre excitación e inhibición sináptica en el NCCI.

Con objeto de estudiar un posible efecto global de la exposición a un ambiente acústico enriquecido sobre el campo receptivo neuronal en el CI, agrupamos los MdFs de un conjunto de neuronas aisladas con $\mathrm{FO}=14 \mathrm{kHz}$ tras estimulación temprana $(\mathrm{n}=$ 8) y de un conjunto de neuronas control $(\mathrm{n}=8)$, tal y como se muestra en las figuras 25A y B, respectivamente. Dichos MdFs se realizaron explorando un amplio rango de frecuencias (5-30 kHz). Los MdFs resultantes del promedio de ambos grupos por separado no difieren significativamente en su FO de respuesta $(13.09 \pm 0.66 \mathrm{kHz}$ para el grupo control y $14.21 \pm 0.39 \mathrm{kHz}$ para el grupo experimental). Sin embargo, entre 
ambos grupos se observan una serie de cambios complejos dentro del campo receptivo, cuyo resultado neto es una mayor actividad a frecuencias $>14 \mathrm{kHz}$ (Fig. 25C, flecha roja, MdF resultante de la diferencia entre 25A y 25B). También observamos inhibición (menor actividad tras la exposición acústica) en torno a la frecuencia de exposición (Fig. $25 \mathrm{C}$, flecha negra). Además, hemos agrupado los MdFs de un conjunto de neuronas
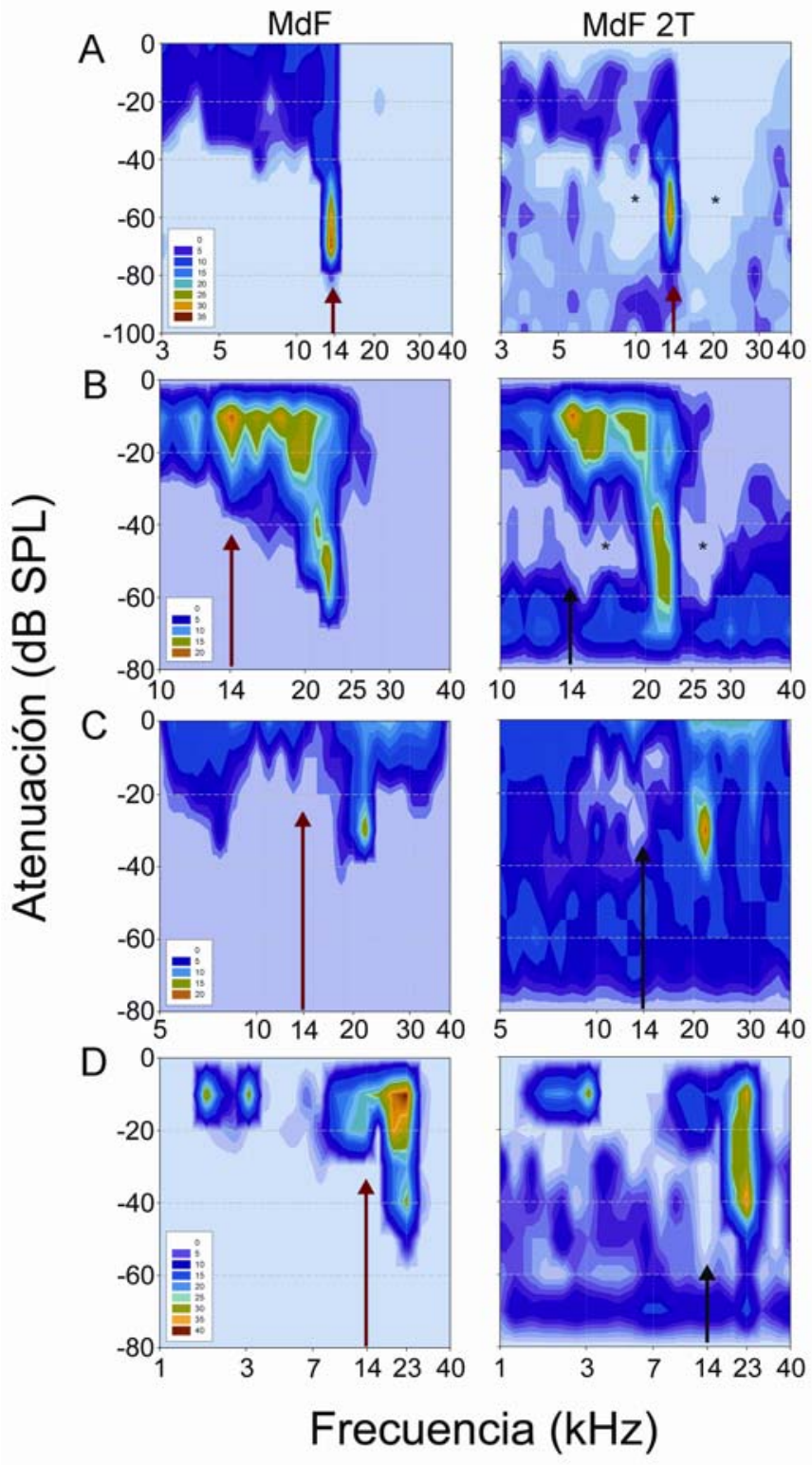

Figura 24. Mapas de frecuencia (MdFs) y sus correspondientes mapas de frecuencia con dos tonos (MdF 2T) de 4 neuronas aisladas en el CI de animales tras exposición acústica postnatal a $14 \mathrm{kHz}$. Los MdFs en A muestran un ejemplo de neurona con $\mathrm{FO}=14 \mathrm{kHz}$ y bandas de inhibición muy claras (asteriscos). B y D) ilustran 2 ejemplos de neuronas aisladas cuya FO es superior a $14 \mathrm{kHz}$ y cuyos MdFs $2 \mathrm{~T}$ indican que existe un área de inhibición con un umbral bajo a $14 \mathrm{kHz}$ (flechas negras). Los umbrales de las zonas inhibitorias son tan bajos como los correspondientes a la zona excitatoria de la FO. 
aisladas con $\mathrm{FO}>14 \mathrm{kHz}$ tras estimulación temprana $(\mathrm{n}=17)$ y controles $(\mathrm{n}=40$, Figs. $25 \mathrm{D}$ y $25 \mathrm{E}$, respectivamente). Los MdFs promedio de ambos grupos por separado tampoco difieren significativamente en su FO de respuesta $(24.94 \pm 5.47 \mathrm{kHz}$ para el grupo control y $22.91 \pm 4.19 \mathrm{kHz}$ para el grupo experimental). En el MdF diferencia (Fig. 25F) se observan cambios complejos similares a los anteriormente descritos dentro del campo receptivo, que también resultan en una mayor actividad a frecuencias $>14$ $\mathrm{kHz}$, aproximadamente entre $15-20 \mathrm{kHz}$ (Fig. 25F, flecha roja) y menor actividad o inhibición en la zona de respuesta a la frecuencia de estimulación (Fig. 25F, flecha negra) y a frecuencias $>20 \mathrm{kHz}$.

Por otro lado, sometimos un segundo grupo experimental $(\mathrm{n}=2)$ a un ambiente acústico modificado con un tono de $4 \mathrm{kHz}$ (P9-P28; ver sección de Materiales y Métodos, tabla 2). A continuación realizamos registros en el CI a los 15 y 39 días tras la estimulación y agrupamos varios MdFs de una manera similar a la anteriormente descrita para animales estimulados a $14 \mathrm{kHz}$. Examinamos un total de 7 neuronas de animales estimulados y 19 de animales control, con una $\mathrm{FO}>4 \mathrm{kHz}$, sobre un rango de frecuencias de respuesta entre $1-10 \mathrm{kHz}$. El resultado obtenido es muy similar al descrito con anterioridad y se muestra en la figura $25 \mathrm{G}$. El campo receptivo neuronal en el CI sufre un incremento claro en la actividad a frecuencias $>4 \mathrm{kHz}(6-7 \mathrm{kHz}$; Fig. $25 \mathrm{G}$, flecha roja) y un descenso en la actividad de las frecuencias bajas adyacentes (1.5$3 \mathrm{kHz}$; Fig. 25G, flecha negra) y de frecuencias $>7 \mathrm{kHz}$. Por último, realizamos una tercera prueba con animales sometidos a estimulación con tonos de $7 \mathrm{kHz}(\mathrm{n}=3$, tabla 2). El análisis de 26 neuronas con $\mathrm{FO}>7 \mathrm{kHz}$, a 93-108 días tras la estimulación, revela un aumento en la actividad del campo receptivo neuronal en el área comprendida entre 11-17 kHz (Fig. 25H, flecha roja) en comparación con una población de 32 neuronas control. Dicho análisis también muestra un descenso en la actividad de las frecuencias adyacentes $(4-10 \mathrm{kHz}$; Fig. $25 \mathrm{H}$, flecha negra) y frecuencias $>17 \mathrm{kHz}$.

En los tres grupos, la exposición a un ambiente acústico enriquecido durante el desarrollo produce una alteración de la respuesta dentro del campo receptivo de las neuronas del CI. Dicha alteración consiste en un aumento de la respuesta en un rango de frecuencias $0.10-1.28$ octavas por encima de la frecuencia utilizada para la estimulación temprana.

Hemos reducido la duración del protocolo utilizado para el tercer grupo experimental (animales expuestos a $7 \mathrm{kHz}$; P9-P17), en un intento de aproximarlo al período crítico (P11-P13). El resultado es un mayor ancho de banda de frecuencias afectadas por el incremento en la repuesta ( 0.63 octavas, vs. 0.23 octavas en animales estimulados con $4 \mathrm{kHz}$ y 0.40 octavas en los estimulados a $14 \mathrm{kHz}$ ). Además, se produce un mayor desplazamiento del rango de frecuencias afectado por la estimulación, con respecto a la frecuencia de estimulación ( 0.65 octavas, vs. 0.58 octavas en animales estimulados con $4 \mathrm{kHz}$ y 0.1 octavas en los estimulados a $14 \mathrm{kHz}$ ).

Los resultados descritos en este apartado indican que se produce una alteración en el balance excitación-inhibición fruto de la exposición a un ambiente acústico enriquecido. Dicha alteración supone un fenómeno de plasticidad dependiente de actividad que afecta a la lámina de isofrecuencia a nivel del mapa tonotópico y a la respuesta a frecuencias mayores que la frecuencia de exposición a nivel celular en el CI. Este último efecto es más acusado cuando la exposición acústica se realiza durante una ventana temporal más aproximada al período crítico. 


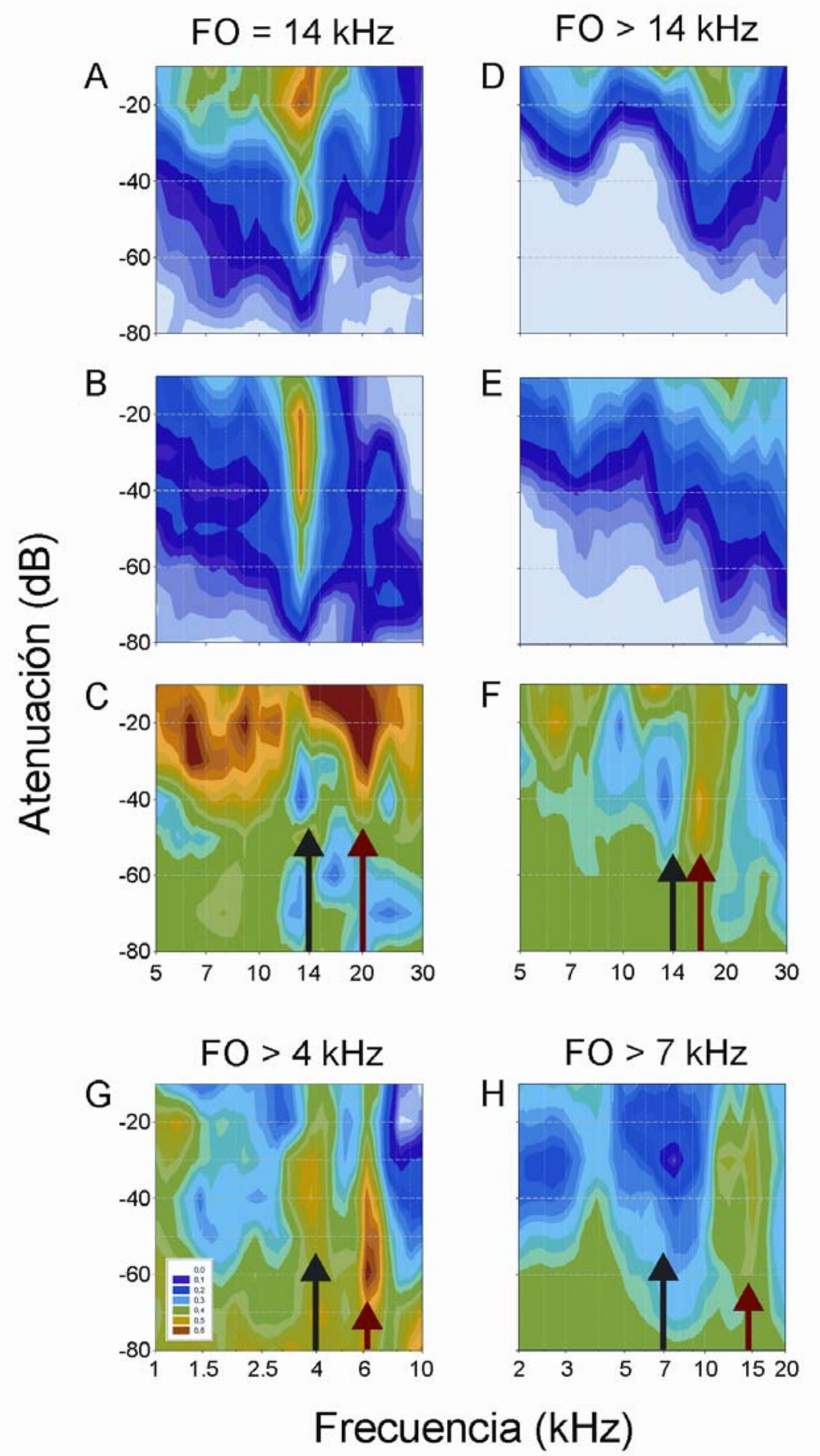

Figura 25. Efectos de la exposición a un ambiente acústico enriquecido sobre los MdFs de neuronas aisladas. A-B) Promedio de MdFs del grupo de animales tras exposición acústica postnatal $(\mathrm{A} ; \mathrm{n}=8)$ y del grupo de animales control $(\mathrm{B} ; \mathrm{n}=8)$. C representa el MdF diferencia entre los MdFs promedio de ambos grupos y muestra un incremento de la respuesta para intensidades $\sim 20 \mathrm{kHz}$ (flecha roja) y un descenso de la actividad a umbrales bajos a $14 \mathrm{kHz}$ (flecha negra). D-E) Promedio de MdFs del grupo experimental (D; $n=17)$ y control $(E ; n=40)$ con FO $>14 \mathrm{kHz}$. F representa el MdF diferencia y revela un aumento claro en la actividad $\sim 17$ $\mathrm{kHz}$ (flecha roja) y un descenso en la actividad a $14 \mathrm{kHz}$ (flecha negra). G-H) MdFs diferencia para dos frecuencias de estimulación distintas $(4 \mathrm{kHz}, 14 \mathrm{~Hz}$ de modulación, $\mathrm{G}$ y $7 \mathrm{kHz}, 40 \mathrm{~Hz}$ de modulación, $\mathrm{H})$. Se observa un patrón de excitación a frecuencias más altas ( $\sim 6$ y $15 \mathrm{kHz}$; G y $\mathrm{H}$, flechas rojas) e inhibición (a $1.5-3 \mathrm{kHz}$ y $4-10 \mathrm{kHz} ; \mathrm{G} \mathrm{y} \mathrm{H}$, flechas negras). La escala de color indica el número promedio de potenciales de acción en respuesta a dos presentaciones de cada estímulo. 


\section{DISCUSIÓN}



En este trabajo de tesis doctoral presentamos un estudio detallado de la organización tonotópica en el CI de la rata, demostrando cómo la codificación de frecuencias a nivel del CI se realiza de manera discontinua, en forma de láminas de isofrecuencia discretas. También estudiamos las consecuencias de un trauma acústico y de la exposición a un ambiente acústico enriquecido durante el desarrollo sobre dicha organización tonotópica.

Nuestros resultados demuestran que las láminas de isofrecuencia pueden sufrir alteraciones como consecuencia de un trauma acústico dando lugar a una reorganización de tipo no plástico. Por el contrario, la exposición a un ambiente acústico enriquecido provoca cambios de tipo plástico en el mapa tonotópico del CI. Creemos que estos hallazgos pueden tener un impacto muy significativo en el conocimiento de la organización funcional del CI y del sistema auditivo y que pueden contribuir al desarrollo de terapias para prevenir o tratar pérdidas auditivas de tipo neurosensorial.

De manera más especifica, nuestro estudio revela que la codificación de las frecuencias a nivel del CI no se realiza de manera continua, sino que se efectúa en forma de láminas discretas de neuronas, las cuales responden a un determinado rango de frecuencias (Malmierca et al., 2008). Así pues, las frecuencias del sonido están representadas en el mapa tonotónico del CI en intervalos de 1/3 de octava, formando 12-18 láminas de isofrecuencia. Estas láminas de isofrecuencia fisiológicas se corresponden con las láminas fibrodendríticas descritas en trabajos morfológicos previos (Morest, 1964b; Oliver y Morest, 1984; Faye-Lund y Osen, 1985; Malmierca et al., 1991, 2003, 2005).

Nuestro trabajo también demuestra que la pérdida auditiva inducida por ruido produce una reorganización persistente del mapa tonotópico en el CI de ratas adultas (Izquierdo et al., 2008). A nivel celular también se producen alteraciones en las respuestas neuronales, que experimentan un incremento significativo de sus umbrales y de su tasa de actividad espontánea tras el trauma acústico.

Además, en nuestra tesis también hemos explorado las consecuencias de la exposición a un ambiente acústico enriquecido, durante el período crítico, sobre el desarrollo de la función auditiva a nivel del CI. Nuestros resultados muestran cambios en la representación normal de las frecuencias, así como en la respuesta neuronal. Estas modificaciones implican una expansión de la lámina del CI destinada a la frecuencia de estimulación, así como una alteración en los MdFs de las neuronas del CI, con un incremento de la actividad a frecuencias por encima de la utilizada en la estimulación temprana. Además, el análisis de los umbrales muestra un descenso general en la sensibilidad a frecuencias en torno a la utilizada para la exposición acústica postnatal.

\section{LIMITACIONES TÉCNICAS Y CONSIDERACIONES METODOLÓGICAS}

Antes de discutir nuestros resultados en un contexto funcional conviene hacer algunas consideraciones técnicas de las limitaciones y ventajas de nuestros protocolos experimentales.

Un aspecto relevante y generalmente discutido es la forma de realizar los mapas tonotópicos. Para ello, introducimos en el cerebro del animal un electrodo controlado de manera remota con ayuda de un micromanipulador y avanzamos con él en pasos de $50 \mu \mathrm{m}$. 
El mayor problema podría ser que los escalones de frecuencia (láminas de isofrecuencia) que se observan en el CI fuesen un artefacto fruto del desplazamiento o empuje que sufre el tejido nervioso del CI al avanzar el electrodo. Ello determinaría erróneamente que durante cierta distancia registremos la misma FO. De esta forma, el inicio de un nuevo escalón de frecuencia se produciría cuando el electrodo avanza a través del CI liberando esa tensión acumulada al empujar el tejido sin atravesarlo. En nuestro estudio hemos descartado este artefacto realizando varios tractos tonotópicos pareados, de manera que registramos la actividad con el mismo electrodo cuando avanzamos y retrocedemos. El resultado de estos 3 experimentos son 4 pares de tractos tonotópicos muy similares entre sí, en los que la mayoría de los datos se solapan (Fig. 26). Esto demuestra inequívocamente que en cada uno de esos pares de tractos la mayor parte de los registros realizados a las mismas profundidades del $\mathrm{CI}$ coinciden en FO, con independencia de si el registro se realiza al introducir o sacar el electrodo.

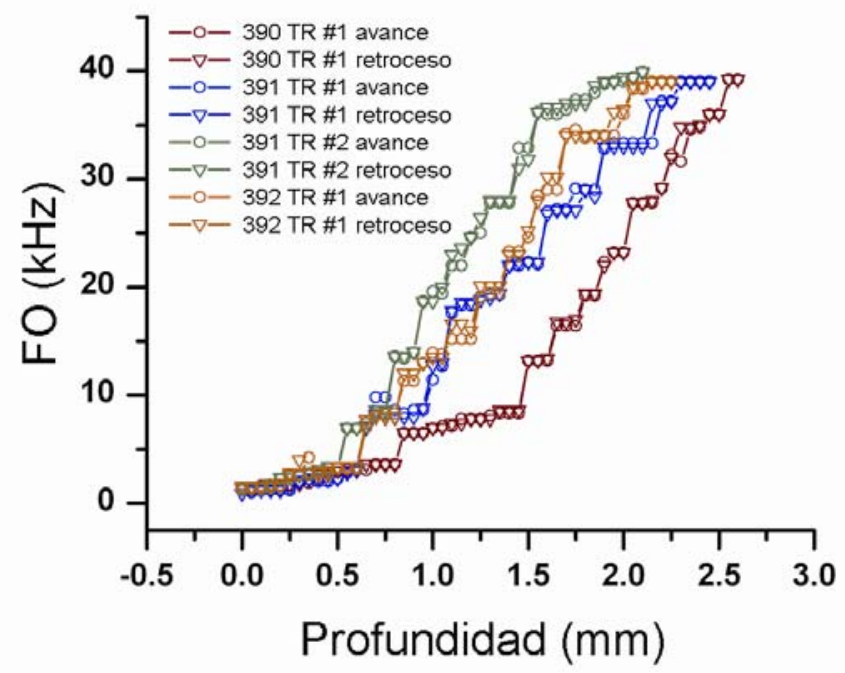

Figura 25. Ejemplos de varios tractos tonotópicos registrados en avance y retroceso. Como se puede apreciar, no existen prácticamente diferencias entre las FOs registradas en el CI cuando avanzamos el electrodo (círculos) o cuando retrocedemos (triángulos invertidos). Los registros se realizaron en grupos multineuronales. TR, Tracto. Tomado de Malmierca et al., 2008.

En lo referente a nuestros experimentos de trauma acústico, una de las limitaciones principales es que no hemos realizado exámenes histológicos de las cócleas para determinar el daño estructural de las células ciliadas y del tejido adyacente. Sin embargo, el paradigma de trauma acústico que utilizamos es muy similar (o incluso más prolongado) al utilizado en estudios previos (Liberman y Dodds, 1984a, b, 1987; Liberman y Kiang, 1984; Pettigrew et al., 1984; Heinz y Young, 2004) incluidos aquellos que han utilizado la rata como modelo experimental (Fechter et al., 1998, 2000; Milbrandt et al., 2000; Michler e Illing, 2002, 2003; Chen y Fechter, 2003; Kaltenbach y Zhang, 2007). Por lo tanto, es razonable sugerir que los daños morfológicos de las células ciliadas en nuestros experimentos deberían ser similares (o incluso más dramáticos) a los ocasionados en los casos anteriormente citados.

Otro aspecto importante que merece atención es que inicialmente pretendíamos producir lesiones localizadas en la cóclea similares a las provocadas por una lesión 
mecánica (Rajan e Irvine, 1998a; Snyder et al., 2000; Snyder y Sinex, 2002; Irvine et al., 2003). Sin embargo, el nivel de intensidad del tono que utilizamos para inducir el trauma acústico provocó un daño coclear mucho más amplio. Este daño afectaba a un área de frecuencias mucho mayor del que resulta afectada por una lesión mecánica. Además, este daño no se restringía a un rango de frecuencias de media octava por encima de la frecuencia del trauma (Cody y Johnstone, 1981). En la mayoría de casos también observamos una segunda lesión clara en la región de altas frecuencias, que debe estar localizada en la zona basal o 'gancho' de la cóclea. Este efecto es consistente con estudios histopatológicos previos realizados en otras especies, en los que se demuestra que la sobreexposición a una banda estrecha de ruido produce dos focos de lesión (Fried et al., 1976; Liberman y Kiang, 1978; Liberman y Dodds, 1987; Ou et al., 2000; Wang et al., 2002b) uno dependiente de la frecuencia del tono empleado para el trauma y otro en el gancho de la cóclea.

El resultado neto del trauma acústico es una lesión muy severa $(>30 \mathrm{~dB}$ de aumento permanente del umbral) y amplia en cuanto a rango de frecuencias afectadas en la mayoría de nuestros casos (Fig. 14). Por encima de un nivel crítico de presión sonora, la pérdida auditiva inducida por ruido incrementa muy rápidamente, por lo que controlar el grado de lesión resulta muy complicado, si no imposible. En un intento de provocar lesiones más restringidas, utilizamos un grupo adicional de cuatro animales que expusimos a un tono de relativamente 'baja' intensidad $(13 \mathrm{kHz}, \sim 100 \mathrm{~dB}$ SPL, durante un total de 24 $\mathrm{h}$ repartidas en 4 sesiones, o sea, 6 horas/día). Sin embargo, utilizando este protocolo no observamos ningún signo de aumento permanente del umbral (151 días tras la exposición al sonido). Asimismo, las respuestas neuronales que registramos en el CI de estos animales eran comparables a las respuestas en los casos control sin ningún daño funcional (como cabía esperar por sus audiogramas PAC normales). Por lo tanto decidimos excluir a este grupo experimental del análisis subsiguiente. Estos resultados, además, están en consonancia con un estudio reciente (Tan et al., 2007) que indica que un sonido intenso, pero no traumático (100 dB SPL), produce daños morfológicos en las células ciliadas pero no provoca aumento permanente del umbral.

Otro inconveniente importante es el enorme grado de variabilidad interanimal que observamos tras una exposición sonora idéntica (incluso entre animales de la misma camada). Esta variabilidad puede deberse a la diversidad genética normal que tiene lugar entre individuos (Bohne et al., 1999; Holme y Steel, 1999, 2004; Yoshida et al., 2000; Wang et al., 2002b) y podría ser la causa de las diferencias tan marcadas de susceptibilidad a la sobre-exposición sonora que hemos observado, tanto en nuestro grupo control (ver audiogramas PAC, Fig. 9A) como en los grupos experimentales (Figs. 14-16). A modo de ejemplo, creemos interesante mencionar un estudio reciente en el que los autores han demostrado que una única mutación en el receptor colinérgico nicotínico de las células ciliadas, prolonga la inhibición coclear e incrementa la protección frente al ruido intenso (Taranda et al., 2009). Este efecto está mediado por el haz olivococlear medial que proyecta de forma directa desde la porción medial del complejo olivar superior a las células ciliadas de la cóclea y puede constituir un mecanismo de protección natural frente al daño acústico (Rajan y Johnstone, 1988; Guinan, 1996).

Por último, también debemos mencionar que al realizar los mapas tonotópicos en los animales expuestos a un ambiente acústico enriquecido, no prestamos atención especial a las láminas del CI que incluyen la frecuencia de exposición, sino que simplemente determinamos la FO de respuesta en cada punto. Esto es muy importante, porque se podría pensar que cuando realizamos un registro de la respuesta de grupos multineuronales, el experimentador tiene tendencia a medir la respuesta a 14,7 o $4 \mathrm{kHz}$ (frecuencias de exposición) y determinarlas como FO de respuesta en ese lugar del CI, en detrimento de la 
respuesta a otra frecuencia con umbral más bajo (la verdadera FO en ese punto). Este sesgo en los registros podría explicar un incremento en los umbrales de respuesta a $14 \mathrm{kHz}$ como el observado en nuestros resultados. Sin embargo, descartamos este artefacto porque el incremento de umbrales es un efecto general real, ya que los umbrales de respuesta a $14 \mathrm{kHz}$ son similares a los umbrales de respuesta para los escalones adyacentes dentro del mismo tracto, pero nunca más elevados.

ORGANIZACIÓN TONOTÓPICA DEL COLÍCULO INFERIOR: ¿CÓMO SE RELACIONA LA DISTRIBUCIÓN DISCONTINUA DE LAS FRECUENCIAS ÓPTIMAS DE NEURONAS CON LAS LÁMINAS ANATÓMICAS DEL COLÍCULO INFERIOR?

Los datos en el CI demuestran agrupaciones de unidades neuronales en láminas de isofrecuencia que cubren 1/3 de octava. Así, a nivel del CI, las FOs pueden organizarse como filtros de paso de banda parcialmente solapados, con una separación de 1/3 octava entre sus regiones centrales. De este modo, cerca del umbral, las frecuencias situadas en el centro de los filtros se favorecen sobre aquellas situadas en las zonas solapadas. Esto da lugar al patrón multimodal con forma de 'dientes de sierra' de la distribución de frecuencias. Estos filtros de banda del mesencéfalo tienen anchos de banda más amplios que los filtros periféricos que se generan a nivel coclear (Moore, 1986; Moore et al., 1999; Moore y Glasberg, 2007). El ancho de banda del filtro auditivo representa la banda de frecuencias que deja pasar ese filtro. A partir de estudios realizados en humanos, los filtros auditivos se estiman generalmente como un $10-17 \%$ de la frecuencia central, es decir, un ancho de banda de $0.14-0.23$ octavas. Si el filtro auditivo en la rata es similar, los filtros del mesencéfalo deben ser aproximadamente el doble que los filtros periféricos. Se han postulado otros filtros, denominados 'bandas críticas', que se originan a nivel del mesencéfalo (Ehret y Merzenich, 1985, 1988; Ehret y Schreiner, 2005). Schreiner y Langner (1997) sugirieron que el CI del gato se compone de una serie de 30-40 bandas críticas, cada una de ellas con un tamaño idéntico al de la lámina de isofrecuencia definida por los escalones variables en el mapa tonotópico.

El número de bandas críticas en la rata no se conoce, pero se puede estimar de manera aproximada teniendo en cuenta que: 1) las membranas basilares de mamíferos son modelos a escala y las bandas críticas cubren distancias iguales en la membrana basilar (Greenwood, 1990); y 2) se piensa que una banda crítica cubre $\sim 1 \mathrm{~mm}(0.7-1.3 \mathrm{~mm}$ ) de la membrana basilar. Basándonos en los $8 \mathrm{~mm}$ de longitud de su membrana basilar, la rata posee $\sim 8-12$ bandas críticas (Ehret y Schreiner, 2005). Por otro lado, los estudios de reconstrucción tridimensional de las láminas fibrodendríticas del CI en la rata han demostrado que esta especie posee 8-10 láminas (Malmierca, 1991; Malmierca et al., 1993). Nuestros datos indican que deben existir 12-18 láminas de isofrecuencia y cada una de ellas debe cubrir $0.29-0.36$ octavas. Esta separación de aproximadamente 0.3 octavas en rata es similar a la descrita para las bandas críticas del ratón (0.333-0.375 octavas; Egorova et al., 2006). Asimismo, este agrupamiento también es compatible con estudios sobre la separación en frecuencia necesaria para activar poblaciones neuronales independientes en el CI (Yang et al., 2003, 2004; Oliver, 2005). Dos tonos puros separados por 0.5 octavas activan dos láminas de neuronas en el CI, mientras que tonos separados por 0.25 octavas activan una sola lámina.

Por todo ello, nuestros datos fisiológicos sugieren que el mapa tonotópico del NCCI en la rata se compone de láminas fisiológicas discretas que se corresponden con las láminas fibrodendríticas morfológicas (Malmierca et al., 1991; Malmierca et al., 1993, 
2008). Los agrupamientos de neuronas con $\sim 0.3$ octavas de separación representan grupos separados de neuronas con una representación de frecuencias discontinua en torno al umbral. Esta representación discontinua de frecuencias tiene implicaciones funcionales muy interesantes para la audición, porque permite umbrales desiguales para frecuencias muy cercanas, lo cual posibilita una discriminación muy fina entre sonidos parecidos.

Como consecuencia de la exposición a un ambiente acústico alterado, estas láminas de isofrecuencia pueden modificar su grosor (incrementando o disminuyendo el número de neuronas que responden a una frecuencia determinada).

\section{COMPARACIÓN CON ESTUDIOS PREVIOS}

\section{Trauma acústico}

Diversos estudios previos en busca de cambios plásticos en el CI se han basado en lesiones mecánicas de la cóclea (Irvine et al., 2003), lesiones de las células del ganglio espiral (Snyder et al., 2000; Snyder y Sinex, 2002), lesiones ototóxicas postnatales de la cóclea basal (Harrison et al., 1991) o en el efecto inmediato (agudo) de un trauma acústico (Salvi et al., 1990; Wang et al., 1996; Wang et al., 2002a). Sin embargo, no existe ningún trabajo similar al que hemos desarrollado, sobre los efectos crónicos del trauma acústico en las respuestas neuronales del CI.

Por tanto, resulta difícil realizar una comparación directa entre los estudios previos mencionados anteriormente y el nuestro, debido al uso de diferentes metodologías. Además, los resultados de esos estudios no están totalmente en acuerdo entre sí y muestran una gran controversia. Mientras que los estudios crónicos llevados a cabo por el profesor D. Irvine y sus colaboradores (Irvine et al., 2003) mostraron una capacidad limitada de plasticidad, con una reorganización plástica 'en parches' del mapa tonotópico en el CI del gato, las lesiones en las células del ganglio espiral demostraron que los MdFs en el CI sufren un proceso dinámico de reorganización muy rápido, poco después de la lesión (Snyder et al., 2000; Snyder y Sinex, 2002). Por el contrario, en nuestro trabajo no encontramos ningún indicio de reorganización plástica dinámica similar al observado en la corteza auditiva tras lesiones mecánicas de la cóclea, ni a nivel del mapa tonotópico general del CI, ni al nivel de los MdFs individuales.

Las diferencias entre todos estos estudios podrían explicarse por diversas causas, entre las que podemos destacar: 1) tamaño de la lesión, 2) naturaleza temporal del cambio plástico en el CI, 3) lugar de la vía auditiva en el que emerge, por primera vez, la codificación de frecuencias o la plasticidad funcional y/o 4) la existencia de un umbral mínimo de plasticidad. A continuación, comentamos cada una de estas posibilidades en detalle y de forma separada.

Primero, nuestras lesiones fueron masivas en comparación con las llevadas a cabo en otros estudios (Snyder et al., 2000; Snyder y Sinex, 2002; Irvine et al., 2003) que resultaron más limitadas o restringidas a un rango de frecuencias muy estrecho. Si el CI tiene una capacidad limitada para restaurar su maquinaria funcional después de un trauma acústico, es posible que sea necesario preservar un mínimo de tejido sano para compensar la región dañada y nuestra lesión masiva puede haber eliminado toda posibilidad de recuperación.

En segundo lugar, tal y como indicaron Snyder y colaboradores (2000), puede ser que los cambios plásticos que podrían compensar la lesión sean inmediatos y posean una 
duración muy limitada que oscilaría entre unos pocos minutos y una hora. Dado que ignoramos el curso temporal de cualquier posible reorganización dinámica en el CI, así como la posible existencia de una ventana temporal limitada o período sensible, es posible que nuestros registros y mapeo se hayan realizado fuera de la ventana temporal activa necesaria para el desarrollo de plasticidad.

En tercer lugar podría ocurrir que la plasticidad para la codificación de frecuencias se genere en centros jerárquicamente superiores de la vía auditiva (Harrison, 2001; Kamke et al., 2003; Kral y Tillein, 2006; Kral, 2007). La plasticidad de los mapas tonotópicos a nivel del tálamo auditivo y la corteza, como resultado de lesiones unilaterales restringidas de la cóclea, ha sido ampliamente descrita (Rajan et al., 1993; Rajan e Irvine, 1998b; Eggermont y Komiya, 2000; Kamke et al., 2003). Sin embargo, los cambios que nosotros observamos en el mapa tonotópico del CI, así como las respuestas neuronales observadas en los MdFs, podrían simplemente reflejar procesos pseudoplásticos explicables por la hipótesis de la respuesta residual (Robertson e Irvine, 1989; Rajan e Irvine, 1998a).

Cuarto, se ha sugerido que para generar plasticidad tiene que haber un aumento permanente del umbral con pérdidas auditivas de $20 \mathrm{~dB}$ o más (Rajan, 2001). Pero quizá aumentos permanentes del umbral muy por encima de este valor (20-60 o más dBs; Fig. 14), combinado con una lesión muy amplia en la mayoría de experimentos (ver sección de Resultados), impiden el desarrollo de plasticidad y limitan la recuperación de las respuestas neuronales en el $\mathrm{CI}$.

En resumen, el trauma acústico empleado en nuestros experimentos induce lesiones cocleares que provocan una reorganización muy evidente del mapa tonotópico, así como cambios en los MdFs individuales en el CI. Sin embargo, esta reorganización puede no ser debida a un proceso plástico. Si definimos plasticidad en términos de resintonización o desenmascaramiento de aferencias que conducen a una respuesta casi normal en el área dañada (Rajan, 1998, 2001), nuestros resultados revelan una ausencia de plasticidad en el mesencéfalo auditivo. Por el contrario, nuestros resultados son muy similares a los obtenidos tras un trauma acústico en el nervio auditivo (Liberman y Dodds, 1984b) y en los núcleos cocleares (Kaltenbach et al., 1992). Además, se comportan siguiendo la hipótesis de la 'respuesta residual' (Robertson e Irvine, 1989; Rajan et al., 1993; Rajan e Irvine, 1998a) o modelo de 'pseudoplasticidad' (Kaltenbach et al., 1992), es decir, son un mero reflejo de la lesión periférica y no constituyen un fenómeno plástico real.

Por todo ello, este fenómeno podría perderse en gran medida en animales maduros en comparación con animales en desarrollo, en los que la generación de plasticidad en el mapa tonotópico del CI resulta evidente (Harrison et al., 1998). Sin embargo, nuestros datos no pueden descartar otras formas de plasticidad, tales como la plasticidad sináptica o molecular (Potashner et al., 1997; Suneja et al., 1998a, b, 2005; Bauer et al., 2000; Milbrandt et al., 2000; Mossop et al., 2000; Brozoski et al., 2002; Kim et al., 2004a; D'Sa et al., 2007) y serán necesarios estudios futuros para determinar si la pérdida auditiva inducida por ruido provoca algún tipo de plasticidad no estudiada hasta ahora sobre las respuestas neuronales del CI. Es más, esos cambios plásticos moleculares podrían tener lugar inmediatamente tras la lesión y/o durante períodos de tiempo superiores a los examinados en este estudio (Snyder et al., 2000; Snyder y Sinex, 2002). 
Existen varios trabajos previos que demuestran la generación de cambios plásticos dependientes de actividad en el sistema auditivo como consecuencia de la exposición temprana al sonido. Todos estos trabajos se han realizado en la corteza auditiva (Zhang et al., 2001; Bao et al., 2003; Chang y Merzenich, 2003; Noreña et al., 2006; de VillersSidani et al., 2007), excepto uno reciente, en el que se ponen de manifiesto alteraciones de las regiones del CI que responden a la/s frecuencia/s de estimulación (Yu et al., 2007). En ambas estructuras (corteza auditiva y CI) se producen cambios en la representación de frecuencias que atienden a las características descritas para un cambio plástico dependiente de actividad. Los resultados mostrados en nuestro trabajo de tesis están en consonancia con los anteriormente mencionados, es decir, muestran un cambio plástico en la representación de frecuencias. En este caso, la metodología empleada permite una comparación más directa que en el caso de los experimentos de trauma acústico, discutidos anteriormente. Los trabajos de Merzenich y sus colaboradores se basan en mapas de la respuesta de neuronas de la corteza utilizando técnicas de registro electrofisiológico (al igual que en nuestro trabajo), mientras que el grupo de Sanes emplea un nuevo método de neuroimagen de alta resolución (NEMRI) para analizar la actividad neuronal en el CI. En ambos tipos de estudio, el resultado muestra un incremento en el área que responde a la frecuencia de estimulación, tanto en la corteza auditiva como en el CI, a consecuencia de la exposición acústica. Este resultado sugiere que los animales sometidos a estimulación postnatal presentan un mayor número de neuronas cuya FO de respuesta coincide con la frecuencia de exposición. Este cambio supone un fenómeno de plasticidad dependiente de actividad, puesto que los umbrales de respuesta en el área expandida (nuevas áreas de respuesta a la frecuencia de estimulación) no difieren significativamente de los umbrales para esa frecuencia en su ubicación normal. Estos efectos también están presentes en nuestros resultados en forma de incremento del área de respuesta a la frecuencia de estimulación, con umbrales similares a los de láminas adyacentes (esto es, no hay incremento de los umbrales de respuesta en la zona reorganizada).

Si el estímulo consiste en una exposición con dos tonos de distinta frecuencia, los cambios de naturaleza plástica originados provocan una alteración de la respuesta específica a las dos frecuencias de exposición. Esta alteración consiste en una respuesta neuronal combinada a dichas frecuencias, que en condiciones normales, muestran una clara separación en el espacio. Esto provoca la aparición de un gran área del CI que responde a ambas frecuencias ( $\mathrm{Yu}$ et al., 2007). En nuestro trabajo hemos observado que tras la exposición acústica temprana aparece un ensanchamiento en la lámina de isofrecuencia estimulada por el tono. Sin embargo, debemos ser cautelosos a la hora de realizar una comparación directa con el trabajo de $\mathrm{Yu}$ y colaboradores (Yu et al., 2007), ya que en nuestros experimentos hemos estimulado con una sola frecuencia y no con dos diferentes. La estimulación con dos frecuencias combinadas podría distorsionar los efectos que produce una única frecuencia, de forma individual, sobre la respuesta del CI.

De manera sorprendente, hemos comprobado que la frecuencia que resulta más afectada por la exposición dentro del campo receptivo neuronal no coincide con la frecuencia de estimulación, sino que está desplazada a frecuencias altas. Este efecto constituye una diferencia fundamental entre nuestro trabajo y el desarrollado por ( $\mathrm{Yu}$ et al., 2007).

Una conclusión clara de ambos trabajos (el realizado por el grupo de Sanes y el nuestro) es que sitúan al CI como posible lugar de origen para la plasticidad dependiente de actividad. Sin embargo, no está claro si este tipo de plasticidad se genera a nivel cortical y se refleja en el CI o se transmite a la corteza desde el CI (Oliver et al., 2006, 2007; 
Izquierdo et al., 2007) a través de un proceso de codificación jerárquico 'de abajo hacia arriba'. Por tanto, no podemos descartar que la plasticidad dependiente de actividad observada en los mapas tonotópicos a nivel de la corteza auditiva (Zhang et al., 2001; Bao et al., 2003; Chang y Merzenich, 2003; de Villers-Sidani et al., 2007) tenga su origen en el CI.

Resulta pues evidente que la plasticidad durante el desarrollo, a nivel del mesencéfalo auditivo, tiene lugar a una escala muchísimo mayor de lo que se pensaba originalmente.

\section{REORGANIZACIÓN DEL MAPA TONOTÓPICO EN EL COLÍCULO INFERIOR TRAS UN TRAUMA ACÚSTICO}

En este apartado discutiremos los principales cambios observados en el mapa tonotópico del CI tras sufrir un trauma acústico.

En general, podemos afirmar que en todos los animales sometidos a un trauma acústico se produce una reorganización del mapa tonotópico. Esta reorganización es más significativa en los casos que han sufrido una mayor pérdida auditiva. Dicha alteración afecta al tamaño de las láminas de isofrecuencia y a los umbrales de respuesta de las mismas. Por ello, es razonable concluir que esta reorganización no se corresponde con una resintonización real de la respuesta neuronal, sino que refleja la 'respuesta residual' tras el trauma acústico.

Las curvas de sintonía espacial nos han permitido examinar la posible presencia de un cambio plástico en el CI. Estas curvas miden la evolución de los umbrales de respuesta a una determinada frecuencia a lo largo de un tracto tonotópico. Como hemos visto en la primera parte de este trabajo de tesis, las FOs de respuesta aumentan en función de la profundidad en el CI. Así pues, registramos FOs progresivamente más elevadas a medida que avanzamos hacia la zona más ventral. Sin embargo, esas neuronas profundas con FO alta también responden a frecuencias bajas situadas en la cola de su MdF, pero con un umbral de respuesta más elevado. Por lo tanto, la evolución normal de los umbrales para una frecuencia determinada sigue una trayectoria con forma de ' $\mathrm{V}$ '. Antes de llegar a la lámina de isofrecuencia la respuesta posee umbrales elevados. Cuando llegamos a la lámina de isofrecuencia los umbrales son bajos, ya que la neurona es más sensible a esa frecuencia, que representa su FO y define el pico de la curva de sintonía espacial. A medida que atravesamos el CI y nos alejamos de la lámina de isofrecuencia los umbrales de respuesta vuelven a aumentar, puesto que nuestra frecuencia se encontraría en la cola del MdF de las neuronas situadas en esa zona. Para una frecuencia determinada, el pico de la curva de sintonía espacial es agudo e indica el grosor de la lámina de isofrecuencia. En nuestro estudio hemos calculado que el grosor de las láminas funcionales es $\sim 150 \mu \mathrm{m}$. Un ensanchamiento del pico de la curva de sintonía espacial, manteniendo umbrales normales, nos indicaría una resintonización de la $\mathrm{FO}$ de neuronas adyacentes a la lámina de isofrecuencia, lo cual supondría un cambio plástico genuino. En nuestros resultados podemos observar un ligero ensanchamiento en 2-3 de esas curvas de sintonía espacial, pero dicho ensanchamiento no resulta significativo. Este hallazgo, junto al hecho de que no hemos encontrado ningún tracto tonotópico con indicios de plasticidad, nos lleva a descartar que se produzca una reorganización plástica en el CI a consecuencia del trauma acústico.

A nivel celular, la FO de las neuronas aisladas registradas en los diferentes tractos tonotópicos se corresponde con la FO de los grupos multineuronales en los mismos tractos. Estos resultados para unidades neuronales aisladas se confirman gracias a los datos 
extraídos de los MdFs. Dichos datos muestran los cambios en la sensibilidad neuronal en función de su localización en el CI. Las neuronas situadas en la zona dorsal más superficial muestran MdFs con FOs bajas y una forma de ' $\mathrm{V}$ ' muy similar a los MdFs control sanos para ese rango de frecuencias $(\mathrm{FO}<5 \mathrm{kHz})$. De manera sorprendente, esas neuronas con FO en el rango 1.1-2 kHz mostraron umbrales más sensibles que las neuronas control (Fig. 19B). Aunque estas diferencias no son significativas, parece que existe cierta hipersensibilidad en la cola de bajas frecuencias de los MdFs tras un trauma acústico. Como hemos descrito en la Introducción, este hecho puede provocar la sensación de que el campo receptivo ha sufrido una resintonización real a una frecuencia más baja. Esta hipersensibilidad aparece tanto en el nervio auditivo (Liberman, 1984; Liberman y Dodds, 1984b) como a nivel cortical y talámico (Rajan et al., 1993; Kamke et al., 2003) y podría deberse a varias causas. Por un lado, los receptores de frecuencias bajas del órgano de Corti reciben una menor vibración de la membrana basilar como consecuencia de la onda de presión sonora (Le Page y Johnstone, 1980). Por lo cual, dichos receptores resultan menos afectados por el trauma acústico. Otros autores aluden a un desacoplamiento entre las células ciliadas y la membrana tectoria como una de las causas de esa hipersensibilidad (Liberman y Dodds, 1984b). Ese desacoplamiento provocaría que el sonido haga vibrar a la membrana con mayor amplitud, lo cual se traduciría en un descenso de los umbrales de respuesta a ese sonido. Por último, la hipersensibilidad de la cola de bajas frecuencias podría deberse al desenmascaramiento de aferencias latentes preexistentes (Rajan, 1998, 2001).

Las dos primeras causas (menor vibración y desacoplamiento de la membrana) explicarían el menor grado de lesión y el descenso en los umbrales de respuesta que hemos observado a frecuencias bajas, tanto en el audiograma PAC (Fig. 14) como en los mapas tonotópicos (Figs. 15 y 16) y en los MdFs (Figs. 18B y 19).

La tercera causa (desenmascaramiento de aferencias preexistentes) puede deberse a la alteración en el balance entre aferencias excitatorias e inhibitorias (Rajan, 1998, 2001). Hoy día se sabe que esta alteración no sólo puede afectar a diferentes porciones dentro del campo receptivo (Palombi y Caspary, 1996), sino que también afecta a las bandas laterales que esculpen el campo receptivo neuronal (LeBeau et al., 2001). La consecuencia final de los cambios en la inhibición es una expansión del campo receptivo (Yang et al., 1992; LeBeau et al., 2001; Scholl y Wehr, 2008) y en última instancia, un cambio plástico del mapa tonotópico en el núcleo afectado. Esta alteración puede persistir de manera crónica (Calford et al., 1993; Wang et al., 1996).

Para evaluar los efectos del trauma acústico sobre el campo receptivo neuronal hemos realizado un estudio de los MdFs de unidades aisladas control y sometidas a un trauma acústico (Fig. 20). En dicha prueba agrupamos MdFs correspondientes a ambos grupos por separado y realizamos una substracción con objeto de ver las diferencias entre los campos receptivos. Los resultados revelaron que el trauma acústico afecta principalmente a la zona más sensible del MdF (la zona del pico de respuesta o FO). La región de la FO de los MdFs tras un trauma acústico desaparece, dejando un pico secundario a frecuencias altas y una cola de bajas frecuencias intacta. Por lo tanto, la lesión acústica provoca una pérdida de aferencias procedentes de la zona lesionada. Esta pérdida de aferencias resulta más evidente en la zona con umbrales más bajos (FO), puesto que la respuesta en esa zona requiere el reclutamiento de un mayor número de fibras auditivas. El MdF tras un trauma acústico está compuesto por el residuo de la respuesta previa a la lesión, es decir, lo componen las aferencias sanas que llegan al CI. Estas aferencias dan lugar a un $\mathrm{MdF}$ alterado muy diferente del patrón en ' $\mathrm{V}$ ' normal, con un pico secundario que es el vestigio de la FO original. Estos resultados en el CI están en consonancia con la hipótesis de la respuesta residual (Robertson e Irvine, 1989; Rajan e Irvine, 1998a). 
Por todo ello, nuestros resultados sugieren muy claramente que los cambios podrían ser pasivos y no atribuibles a una reorganización dinámica de las frecuencias similar a la observada en la corteza auditiva (Robertson e Irvine, 1989). Estos resultados también indican que el CI (al menos en la rata) posee una capacidad limitada de recuperación de la codificación normal de las frecuencias a largo plazo, tras un trauma acústico severo. Sin embargo, otros cambios observados en las propiedades de la respuesta de neuronas del CI, tales como el incremento en la tasa de actividad espontánea, podrían reflejar algún tipo de cambio plástico debido a una alteración en el balance entre excitación-inhibición (Abbott et al., 1999; Milbrandt et al., 2000; Mossop et al., 2000) que no hemos podido estudiar en este trabajo, pero que resulta de importancia vital para la percepción auditiva tras una lesión acústica (v.i.).

\section{EFECTOS DE LA EXPOSICIÓN A UN AMBIENTE ACÚSTICO ENRIQUECIDO SOBRE LA RESPUESTA NEURONAL EN EL COLÍCULO INFERIOR}

Como hemos visto, la estimulación postnatal influye en el desarrollo de la función auditiva. Nuestros resultados muestran que la exposición a un ambiente acústico modificado durante el desarrollo altera el tamaño de la lámina sintonizada a la frecuencia de exposición. En la mayoría de animales dicha lámina incrementa su tamaño, posiblemente debido a un aumento del número de neuronas de láminas adyacentes que responden a la frecuencia de estimulación. Este fenómeno implica una resintonización de frecuencias, es decir, un cambio plástico dependiente de actividad que afecta a las células de láminas adyacentes.

Por tanto, los efectos de la exposición acústica temprana sobre el mapa tonotópico del CI se centran en la frecuencia de exposición, al igual que sucede en la corteza auditiva (Zhang et al., 2001; Bao et al., 2003; Chang y Merzenich, 2003; de Villers-Sidani et al., 2007).

Por otra parte, al estudiar la diferencia entre los MdFs de neuronas control y neuronas del grupo experimental comprobamos que la exposición acústica temprana también tiene un efecto sobre la frecuencia de estimulación postnatal, dentro del campo receptivo neuronal. El efecto sobre la frecuencia de exposición se manifiesta en los MdFs en forma de picos secundarios y áreas de inhibición o supresión (reveladas en los MdFs 2T). La estimulación temprana también afecta a los MdFs de neuronas alejadas de la lámina de isofrecuencia estimulada (neuronas con FO superior a la de estimulación). Dicho efecto consiste en un incremento de la actividad a frecuencias mayores que la utilizada en la estimulación.

La explicación a este fenómeno la podemos encontrar en el desarrollo de la función auditiva y la maduración coclear. Como ya hemos descrito en la sección de Introducción, durante la maduración de la cóclea un mismo punto responde a frecuencias progresivamente más altas (Fig. 3; Lippe y Rubel, 1983; Rubel y Ryals, 1983). Esto se traduce en una modificación de la organización tonotópica en los núcleos de la vía auditiva (Fig. 3). Si estimulamos a un animal en desarrollo con un tono de una frecuencia determinada, estimularemos a un grupo de neuronas cuya FO coincide con la frecuencia de ese tono. Ese grupo de neuronas va a recibir una mayor cantidad de estimulación que el resto de neuronas del núcleo auditivo. La estimulación repetitiva puede generar un fenómeno de potenciación a largo plazo que va a persistir hasta la edad adulta. Así, la actividad de este circuito neuronal constituido por los receptores y las fibras aferentes y neuronas del CI se potencia en respuesta a un estímulo sonoro. Sin embargo, la FO de 
respuesta de esas neuronas va a modificarse a lo largo del desarrollo, fruto de la maduración de la cóclea. Esa zona de la cóclea va a responder a frecuencias progresivamente más elevadas, por lo que ese circuito cuya actividad hemos potenciado durante el desarrollo terminará transduciendo una frecuencia más alta. Este mecanismo explicaría que la actividad que potenciamos durante el desarrollo (mediante la exposición a una frecuencia determinada) produzca su efecto a una frecuencia más alta en el adulto.

El análisis de los MdFs 2T revela áreas de inhibición que conducen a cambios complejos en el campo receptivo neuronal. Estas áreas de inhibición son el fruto de una alteración en el balance entre aferencias excitatorias e inhibitorias. Dicha alteración podría explicar que en dos de los animales del grupo experimental hayamos encontrado un estrechamiento de la lámina de isofrecuencia, en lugar de un ensanchamiento. Este hallazgo podría deberse a un cambio en el balance hacia inhibición en torno a la frecuencia de exposición, lo cual dificultaría el registro de la respuesta neuronal a esa frecuencia. Por lo tanto, se produciría un estrechamiento de la lámina debido a un menor número de neuronas que responden a esa frecuencia. No obstante, necesitaremos más estudios para confirmar esta hipótesis.

La exposición a un ambiente acústico enriquecido durante el desarrollo no provoca pérdida auditiva (Fig. 21). Sin embargo, hemos observado un incremento generalizado en los umbrales de respuesta a la frecuencia de exposición y a las frecuencias adyacentes. Este efecto también podría deberse a la inhibición que opera en la zona de la frecuencia de exposición del MdF. Como hemos visto, alrededor de dicha frecuencia de exposición se produce una banda de inhibición que podría reducir la respuesta en torno a su umbral y provocar un descenso en su sensibilidad.

\section{IMPORTANCIA FUNCIONAL Y POSIBLES IMPLICACIONES CLÍNICAS DE LA REORGANIZACIÓN EN LOS MAPAS TONOTÓPICOS}

La reorganización plástica de los mapas tonotópicos se ha relacionado con sensaciones anormales como los acúfenos (Muhlnickel et al., 1998; Eggermont, 2008). El acúfeno es una sensación auditiva 'fantasma' (Jastreboff et al., 1988) que acompaña con frecuencia a la pérdida auditiva, aunque también se manifiesta como consecuencia de la hipersensibilidad a determinadas drogas (salicilatos, quinina, antibióticos aminoglicósidos y cisplatino). Esta patología es más frecuente en la vejez, pero también puede darse en niños. Los acúfenos son cada vez más frecuentes debido al incremento de las pérdidas auditivas como consecuencia del ocio (p. ej., por escuchar música con un volumen muy elevado). La contaminación acústica medioambiental, combinada con un aumento en la esperanza de vida también favorecen la aparición de los acúfenos (Eggermont, 2005). Los mecanismos de plasticidad que producen este fenómeno han sido ampliamente estudiados (Eggermont, 2005, 2008). Es sabido que la exposición a un sonido de alta intensidad, así como la administración de fármacos, no afectan o disminuyen la tasa de actividad espontánea de las fibras del nervio auditivo. Por el contrario, los mismos tratamientos producen un incremento en la actividad espontánea en diversas estructuras del sistema nervioso central, incluyendo el núcleo coclear dorsal, el CI y la corteza auditiva. Este incremento de la actividad espontánea se atribuye a un descenso en los niveles de inhibición central (probablemente GABAérgica) en dichas estructuras auditivas, que se traduce en hiperactividad neuronal (Wang et al., 1996; Abbott et al., 1999; Bauer et al., 2000; Milbrandt et al., 2000; Eggermont, 2008). Por todo ello, la reorganización plástica de 
los mapas tonotópicos y el consiguiente aumento en la actividad espontánea de sus neuronas podrían resultar más perjudiciales que beneficiosos (Eggermont, 2005, 2008).

Sin embargo, el desarrollo de plasticidad en el sistema nervioso auditivo desempeña un papel muy importante en los pacientes con implantes cocleares. Las probabilidades de éxito de un implante coclear aumentan si la operación se realiza a una edad temprana. Asimismo, el rendimiento clínico de los usuarios de implantes mejora con la experiencia auditiva. Se producen determinados cambios en el sistema auditivo que inducen esas mejoras en la percepción del lenguaje con el uso de los implantes (plasticidad). En la actualidad, no sabemos si esas mejoras son el resultado, exclusivamente, de modificaciones a nivel cortical o involucran cambios en núcleos previos de la vía auditiva. Así pues, es evidente que son necesarios estudios futuros para esclarecer los detalles de estos mecanismos. No obstante, investigaciones preliminares sugieren que la mejoría observada en pacientes con implantes cocleares que han sido tratados con rehabilitación, así como el éxito de los implantes realizados en el CI, podrían deberse a una reorganización plástica de los mapas corticales. Esta reorganización sería una consecuencia de la estimulación 'artificial' de las fibras aferentes, por el implante o por el entrenamiento (Rauschecker y Shannon, 2002; Lenarz et al., 2007).

Por otra parte, la estimulación eléctrica mediante implantes cocleares tras una sordera a largo plazo, produce un incremento significativo de los umbrales y una degradación en la selectividad espacial en el CI. Esto podría explicar la baja discriminación del lenguaje en pacientes adultos a los que se ha realizado un implante coclear, tras sufrir una sordera congénita o adquirida de manera muy temprana (Vollmer et al., 2005, 2007).

Recientemente, se ha demostrado que la pérdida auditiva neurosensorial a largo plazo induce una pérdida severa de células del ganglio espiral y fibras del nervio auditivo. En consecuencia, se produce una alteración de la representación y procesamiento del sonido en el cerebro auditivo (Vollmer et al., 2007). El grupo de investigación del Prof. Rubel ha descubierto que a lo largo del desarrollo, los factores pro-apoptóticos disminuyen, mientras que los mecanismos de neuroprotección aumentan. Como resultado, las neuronas maduras se hacen menos dependientes de las aferencias que reciben para su supervivencia (Harris et al., 2005; Harris y Rubel, 2006). En estos trabajos, al igual que en nuestro trabajo de tesis, se han encontrado muchas neuronas que sobreviven, evitando una ruta apoptótica a pesar de haber sufrido una gran deaferentación. Así pues, en respuesta a un daño periférico, el cerebro adulto debe afrontar dos retos importantes pero paradójicos: estabilidad y plasticidad. Por un lado debe preservar los circuitos y la organización sináptica necesaria para mantener la conducta y la memoria a largo plazo. Por otro, debe permitir que dichos circuitos se adapten a los cambios ambientales, el aprendizaje o las lesiones. Así, mientras la plasticidad es claramente relevante, la estabilidad debe suponer una propiedad emergente por sus implicaciones conceptuales y clínicas (Turrigiano y Nelson, 2004; Harris et al., 2005; Harris y Rubel, 2006).

Por todo ello, creemos que para el desarrollo de futuros tratamientos de la sordera, puede ser más efectivo buscar terapias enfocadas a mantener la 'estabilidad' de las respuestas neuronales, en lugar de centrarse en inducir plasticidad como mecanismo de reparación de la lesión acústica. Como hemos visto, la plasticidad puede conducir a una alteración en el procesamiento de la información auditiva. Así pues, podemos concluir que el concepto de estabilidad neuronal emerge como una noción de importancia vital, a la hora de entender los mecanismos que operan tras una lesión periférica y sus posibles implicaciones clínicas. 
CONCLUSIONES 

1. El mapa tonotópico en el núcleo central del colículo inferior de la rata se compone de láminas fisiológicas con entidad propia. Estas láminas forman el substrato fisiológico de las láminas fibrodendríticas anatómicas.

2. La frecuencia óptima en el colículo inferior se representa de una manera discontinua en forma de 'escalones', compuestos de grupos de neuronas con una separación $\sim 0.3$ octavas.

3. El trauma acústico produce una reorganización persistente del mapa tonotópico del colículo inferior y altera el patrón de representación normal de las frecuencias.

4. La mayoría de los cambios observados en el colículo inferior tras un trauma acústico pueden explicarse por la hipótesis de la respuesta residual y no reflejan un fenómeno plástico real.

5. La exposición a un ambiente acústico enriquecido durante el desarrollo altera el mapa tonotópico del colículo inferior, aumentando el grosor de la lámina de isofrecuencia y el número de neuronas sintonizadas a la frecuencia de exposición. 

ABREVIATURAS 

CI, colículo inferior

$\mathrm{dB}$, decibelio

FO, frecuencia óptima

$\mathrm{MdF}$, mapa de frecuencias

MdF 2T, mapa de frecuencias con dos tonos

NCCI, núcleo central del colículo inferior

PAC, potencial de acción compuesto

SD, desviación estándar

SPL, nivel de presión sonora 

REFERENCIAS 

Abbott, S. D., Hughes, L. F., Bauer, C. A., Salvi, R. y Caspary, D. M., 1999. Detection of glutamate decarboxylase isoforms in rat inferior colliculus following acoustic exposure. Neuroscience. 93, 1375-1381.

Bao, S., Chang, E. F., Davis, J. D., Gobeske, K. T. y Merzenich, M. M., 2003. Progressive degradation and subsequent refinement of acoustic representations in the adult auditory cortex. $\mathrm{J}$ Neurosci. 23, 10765-10775.

Bauer, C. A., Brozoski, T. J., Holder, T. M. y Caspary, D. M., 2000. Effects of chronic salicylate on GABAergic activity in rat inferior colliculus. Hear Res. 147, 175-182.

Bilak, M., Kim, J., Potashner, S. J., Bohne, B. A. y Morest, D. K., 1997. New growth of axons in the cochlear nucleus of adult chinchillas after acoustic trauma. Exp Neurol. 147, 256-268.

Blakemore, C. y Van Sluyters, R. C., 1974. Reversal of the physiological effects of monocular deprivation in kittens: further evidence for a sensitive period. J Physiol. 237, 195-216.

Blatchley, B. J., Cooper, W. A. y Coleman, J. R., 1987. Development of auditory brainstem response to tone pip stimuli in the rat. Brain Res. 429, 75-84.

Bohne, B. A., Harding, G. W., Nordmann, A. S., Tseng, C. J., Liang, G. E. y Bahadori, R. S., 1999. Survival-fixation of the cochlea: a technique for following time-dependent degeneration and repair in noise-exposed chinchillas. Hear Res. 134, 163-178.

Brozoski, T. J., Bauer, C. A. y Caspary, D. M., 2002. Elevated fusiform cell activity in the dorsal cochlear nucleus of chinchillas with psychophysical evidence of tinnitus. J Neurosci. 22, 23832390.

Buonomano, D. V. y Merzenich, M. M., 1998. Cortical plasticity: from synapses to maps. Annu Rev Neurosci. 21, 149-186.

Calford, M. B., 2002. Dynamic representational plasticity in sensory cortex. Neuroscience. 111, 709-738.

Calford, M. B., Rajan, R. e Irvine, D. R., 1993. Rapid changes in the frequency tuning of neurons in cat auditory cortex resulting from pure-tone-induced temporary threshold shift. Neuroscience. 55, 953-964.

Catalano, S. M., Robertson, R. T. y Killackey, H. P., 1991. Early ingrowth of thalamocortical afferents to the neocortex of the prenatal rat. Proc Natl Acad Sci U S A. 88, 2999-3003.

Chang, E. F. y Merzenich, M. M., 2003. Environmental noise retards auditory cortical development. Science. 300, 498-502.

Chen, G. D. y Fechter, L. D., 2003. The relationship between noise-induced hearing loss and hair cell loss in rats. Hear Res. 177, 81-90.

Cody, A. R. y Johnstone, B. M., 1981. Acoustic trauma: single neuron basis for the "half-octave shift". J Acoust Soc Am. 70, 707-711.

Cody, A. R. y Robertson, D., 1983. Variability of noise-induced damage in the guinea pig cochlea: electrophysiological and morphological correlates after strictly controlled exposures. Hear Res. 9, 55-70.

Dallos, P., 1992a. The active cochlea. J Neurosci. 12, 4575-4585.

Dallos, P., 1992b. The cochlea. In: Springer Handbook of Auditory Research (Dallos, P., Popper, A. N. y Fay, R. R., eds). New York: Springer-Verlag.

Dallos, P. y Cheatham, M. A., 1976. Compound action potential (AP) tuning curves. J Acoust Soc Am. 59, 591-597.

de Villers-Sidani, E., Chang, E. F., Bao, S. y Merzenich, M. M., 2007. Critical period window for spectral tuning defined in the primary auditory cortex (A1) in the rat. J Neurosci. 27, 180-189.

Donoghue, J. P., Suner, S. y Sanes, J. N., 1990. Dynamic organization of primary motor cortex output to target muscles in adult rats. II. Rapid reorganization following motor nerve lesions. Exp Brain Res. 79, 492-503. 
D'Sa, C., Gross, J., Francone, V. P. y Morest, D. K., 2007. Plasticity of synaptic endings in the cochlear nucleus following noise-induced hearing loss is facilitated in the adult FGF2 overexpressor mouse. Eur J Neurosci. 26, 666-680.

Eggermont, J. J., 1976. Analysis of compound action potential responses to tone bursts in the human and guinea pig cochlea. J Acoust Soc Am. 60, 1132-1139.

Eggermont, J. J., 2005. Tinnitus: neurobiological substrates. Drug Discov Today. 10, 1283-1290.

Eggermont, J. J., 2008. The role of sound in adult and developmental auditory cortical plasticity. Ear Hear. 29, 819-829.

Eggermont, J. J. y Komiya, H., 2000. Moderate noise trauma in juvenile cats results in profound cortical topographic map changes in adulthood. Hear Res. 142, 89-101.

Egorova, M., Vartanyan, I. y Ehret, G., 2006. Frequency response areas of mouse inferior colliculus neurons: II. Critical bands. Neuroreport. 17, 1783-1786.

Ehret, G. y Merzenich, M. M., 1985. Auditory midbrain responses parallel spectral integration phenomena. Science. 227, 1245-1247.

Ehret, G. y Merzenich, M. M., 1988. Complex sound analysis (frequency resolution, filtering and spectral integration) by single units of the inferior colliculus of the cat. Brain Res. 472, 139-163.

Ehret, G. y Schreiner, C. E., 2005. Spectral and intensity coding in the auditory midbrain. In: The inferior colliculus (Winer, J.A. y Schreiner, C.E., eds), pp 312-345. New York: Springer.

Fathke, R. L. and Gabriele, M. L., 2009. Patterning of multiple layered projections to the auditory midbrain prior to experience. Hear Res. 249, 36-43.

Faure, P. A., Fremouw, T., Casseday, J. H. y Covey, E., 2003. Temporal masking reveals properties of sound-evoked inhibition in duration-tuned neurons of the inferior colliculus. J Neurosci. 23, 3052-3065.

Faye-Lund, H. y Osen, K. K., 1985. Anatomy of the inferior colliculus in rat. Anat Embryol (Berl). $171,1-20$

Fechter, L. D., Liu, Y., Herr, D. W. y Crofton, K. M., 1998. Trichloroethylene ototoxicity: evidence for a cochlear origin. Toxicol Sci. 42, 28-35.

Fechter, L. D., Chen, G. D., Rao, D. y Larabee, J., 2000. Predicting exposure conditions that facilitate the potentiation of noise-induced hearing loss by carbon monoxide. Toxicol Sci. 58, 315-323.

Friauf, E. y Kandler, K., 1990. Auditory projections to the inferior colliculus of the rat are present by birth. Neurosci Lett. 120, 58-61.

Friauf, E. y Lohmann, C., 1999. Development of auditory brainstem circuitry. Activity-dependent and activity-independent processes. Cell Tissue Res. 297, 187-195.

Fried, M. P., Dudek, S. E. y Bohne, B. A., 1976. Basal turn cochlear lesions following exposure to low-frequency noise. Trans Sect Otolaryngol Am Acad Ophthalmol Otolaryngol. 82, 285-298.

Gabriele, M. L., Brunso-Bechtold, J. K. y Henkel, C. K., 2000. Development of afferent patterns in the inferior colliculus of the rat: projection from the dorsal nucleus of the lateral lemniscus. $\mathrm{J}$ Comp Neurol. 416, 368-382.

Gilbert, C. D., 1998. Adult cortical dynamics. Physiol Rev. 78, 467-485.

Greenwood, D. D., 1990. A cochlear frequency-position function for several species--29 years later. J Acoust Soc Am. 87, 2592-2605.

Guinan, J.J., 1996. Physiology of olivocochlear efferents. In: The cochlea. (Dallos, P., Popper, A.N. y Fay, R.R., eds), pp 435-502. New York: Springer-Verlag.

Harris, D. M. y Dallos, P., 1984. Ontogenetic changes in frequency mapping of a mammalian ear. Science. 225, 741-743.

Harris, J. A., Hardie, N. A., Bermingham-McDonogh, O. y Rubel, E. W., 2005. Gene expression differences over a critical period of afferent-dependent neuron survival in the mouse auditory brainstem. J Comp Neurol. 493, 460-474.

Harris, J. A. y Rubel, E. W., 2006. Afferent regulation of neuron number in the cochlear nucleus: cellular and molecular analyses of a critical period. Hear Res. 216-217, 127-137.

Harrison, R. V., 2001. Age-related tonotopic map plasticity in the central auditory pathways. Scand Audiol Suppl, 8-14. 
Harrison, R. V., Shirane, M., Fukushima, N. y Mount, R. J., 1991. Morphological changes to the cochlea in an animal model of profound deafness. Acta Otolaryngol Suppl. 489, 5-11.

Harrison, R. V., Ibrahim, D. y Mount, R. J., 1998. Plasticity of tonotopic maps in auditory midbrain following partial cochlear damage in the developing chinchilla. Exp Brain Res. 123, 449-460.

Hebb, D. O., 1949. The organization of behavior (Wiley, J., ed). New York.

Heffner, H. E., Heffner, R. S., Contos, C. y Ott, T., 1994. Audiogram of the hooded Norway rat. Hear Res. 73, 244-247.

Heinz, M. G. y Young, E. D., 2004. Response growth with sound level in auditory-nerve fibers after noise-induced hearing loss. J Neurophysiol. 91, 784-795.

Hernández, O., Espinosa, N., Pérez-González, D. y Malmierca, M. S., 2005. The inferior colliculus of the rat: a quantitative analysis of monaural frequency response areas. Neuroscience. 132, 203217.

Holloway, M., 2003. The mutable brain. Sci Am. 289, 78-85.

Holme, R. H. y Steel, K. P., 1999. Genes involved in deafness. Curr Opin Genet Dev. 9, 309-314.

Holme, R. H. y Steel, K. P., 2004. Progressive hearing loss and increased susceptibility to noiseinduced hearing loss in mice carrying a Cdh23 but not a Myo7a mutation. J Assoc Res Otolaryngol. 5, 66-79.

Hubel, D. H. y Wiesel, T. N., 1970. The period of susceptibility to the physiological effects of unilateral eye closure in kittens. J Physiol. 206, 419-436.

Irvine, D. R., 2007. Auditory cortical plasticity: does it provide evidence for cognitive processing in the auditory cortex? Hear Res. 229, 158-170.

Irvine, D. R., Rajan, R. y Smith, S., 2003. Effects of restricted cochlear lesions in adult cats on the frequency organization of the inferior colliculus. J Comp Neurol. 467, 354-374.

Irvine, D. R. y Wright, B. A., 2005. Plasticity of spectral processing. Int Rev Neurobiol. 70, 435472.

Izquierdo, M. A., Malmierca, M. S. y Oliver, D. L., 2007. Early Sound Exposure alters frequency coding in the Inferior Colliculus (IC) of the Rat. Assoc Res Otolaryngol Abs. 30, 830.

Izquierdo, M. A., Gutiérrez-Conde, P. M., Merchán, M. A. y Malmierca, M. S., 2008. Non-plastic reorganization of frequency coding in the inferior colliculus of the rat following noise-induced hearing loss. Neuroscience. 154, 355-369.

Izquierdo, M. A., Malmierca, M. S. y Oliver, D. L., 2009. Functional and activity-dependent plasticity mechanisms in the adult and developing auditory brain. Rev Neurol. 48, 421-429.

Jastreboff, P. J., Brennan, J. F., Coleman, J. K. y Sasaki, C. T., 1988. Phantom auditory sensation in rats: an animal model for tinnitus. Behav Neurosci. 102, 811-822.

Johnstone, J. R., Alder, V. A., Johnstone, B. M., Robertson, D. y Yates, G. K., 1979. Cochlear action potential threshold and single unit thresholds. J Acoust Soc Am. 65, 254-257.

Kaltenbach, J. A., Czaja, J. M. y Kaplan, C. R., 1992. Changes in the tonotopic map of the dorsal cochlear nucleus following induction of cochlear lesions by exposure to intense sound. Hear Res. $59,213-223$.

Kaltenbach, J. A. y Zhang, J., 2007. Intense sound-induced plasticity in the dorsal cochlear nucleus of rats: evidence for cholinergic receptor upregulation. Hear Res. 226, 232-243.

Kamke, M. R., Brown, M. e Irvine, D. R., 2003. Plasticity in the tonotopic organization of the medial geniculate body in adult cats following restricted unilateral cochlear lesions. J Comp Neurol. 459, 355-367.

Kamke, M. R., Brown, M. e Irvine, D. R., 2005. Basal forebrain cholinergic input is not essential for lesion-induced plasticity in mature auditory cortex. Neuron. 48, 675-686.

Kandler, K., 2004. Activity-dependent organization of inhibitory circuits: lessons from the auditory system. Curr Opin Neurobiol. 14, 96-104.

Kandler, K. y Friauf, E., 1993. Pre- and postnatal development of efferent connections of the cochlear nucleus in the rat. J Comp Neurol. 328, 161-184.

Kandler, K. y Gillespie, D. C., 2005. Developmental refinement of inhibitory sound-localization circuits. Trends Neurosci. 28, 290-296. 
Kelly, J. B., 1992. Behavioral development of the auditory orientation response. In: Development of auditory and vestibular systems 2 (Romand, R., ed), pp 391-418. Amsterdam: Elsevier.

Kim, J. J., Gross, J., Morest, D. K. y Potashner, S. J., 2004a. Quantitative study of degeneration and new growth of axons and synaptic endings in the chinchilla cochlear nucleus after acoustic overstimulation. J Neurosci Res. 77, 829-842.

Kim, J. J., Gross, J., Potashner, S. J. y Morest, D. K., 2004b. Fine structure of long-term changes in the cochlear nucleus after acoustic overstimulation: chronic degeneration and new growth of synaptic endings. J Neurosci Res. 77, 817-828.

Kral, A., 2007. Unimodal and cross-modal plasticity in the 'deaf' auditory cortex. Int J Audiol. 46, 479-493.

Kral, A. y Tillein, J., 2006. Brain plasticity under cochlear implant stimulation. Adv Otorhinolaryngol. 64, 89-108.

Le Page, E. L. y Johnstone, B. M., 1980. Nonlinear mechanical behaviour of the basilar membrane in the basal turn of the guinea pig cochlea. Hear Res. 2, 183-189.

Leake, P. A., Snyder, R. L. y Hradek, G. T., 2002. Postnatal refinement of auditory nerve projections to the cochlear nucleus in cats. J Comp Neurol. 448, 6-27.

LeBeau, F. E., Malmierca, M. S. y Rees, A., 2001. Iontophoresis in vivo demonstrates a key role for GABA(A) and glycinergic inhibition in shaping frequency response areas in the inferior colliculus of guinea pig. J Neurosci. 21, 7303-7312.

Lenarz, M., Lim, H. H., Lenarz, T., Reich, U., Marquardt, N., Klingberg, M. N., Paasche, G., Reuter, G. y Stan, A. C., 2007. Auditory midbrain implant: histomorphologic effects of long-term implantation and electric stimulation of a new deep brain stimulation array. Otol Neurotol. 28, 1045-1052.

Liberman, M. C., 1984. Single-neuron labeling and chronic cochlear pathology. I. Threshold shift and characteristic-frequency shift. Hear Res. 16, 33-41.

Liberman, M. C. y Kiang, N. Y., 1978. Acoustic trauma in cats. Cochlear pathology and auditorynerve activity. Acta Otolaryngol Suppl. 358, 1-63.

Liberman, M. C. y Dodds, L. W., 1984a. Single-neuron labeling and chronic cochlear pathology. II. Stereocilia damage and alterations of spontaneous discharge rates. Hear Res. 16, 43-53.

Liberman, M. C. y Dodds, L. W., 1984b. Single-neuron labeling and chronic cochlear pathology. III. Stereocilia damage and alterations of threshold tuning curves. Hear Res. 16, 55-74.

Liberman, M. C. y Kiang, N. Y., 1984. Single-neuron labeling and chronic cochlear pathology. IV. Stereocilia damage and alterations in rate- and phase-level functions. Hear Res. 16, 75-90.

Liberman, M. C. y Dodds, L. W., 1987. Acute ultrastructural changes in acoustic trauma: serialsection reconstruction of stereocilia and cuticular plates. Hear Res. 26, 45-64.

Liberman, M. C. y Gao, W. Y., 1995. Chronic cochlear de-efferentation and susceptibility to permanent acoustic injury. Hear Res. 90, 158-168.

Lippe, W. y Rubel, E. W., 1983. Development of the place principle: tonotopic organization. Science. 219, 514-516.

Loftus, W. C., Malmierca, M. S., Bishop, D. C. y Oliver, D. L., 2008. The cytoarchitecture of the inferior colliculus revisited: a common organization of the lateral cortex in rat and cat. Neuroscience. 154, 196-205.

Malmierca, M. S., 1991. Computer-Assisted 3-D reconstructions of Golgi-impregnated cells in the rat interior colliculus. Tesis Doctoral, Universidad de Oslo y Universidad de Salamanca.

Malmierca, M. S., 2003. The structure and physiology of the rat auditory system: an overview. Int Rev Neurobiol. 56, 147-211.

Malmierca, M. S., Blackstad, T. W., Osen, K. K., Karagulle, T. y Molowny, R. L., 1993. The central nucleus of the inferior colliculus in rat: a Golgi and computer reconstruction study of neuronal and laminar structure. J Comp Neurol. 333, 1-27.

Malmierca, M. S., Rees, A., Le Beau, F. E. and Bjaalie, J. G., 1995. Laminar organization of frequency-defined local axons within and between the inferior colliculi of the guinea pig. J Comp Neurol. 357, 124-144. 
Malmierca, M. S., Hernández, O., Falconi, A., Lopez-Poveda, E. A., Merchán, M. y Rees, A., 2003. The commissure of the inferior colliculus shapes frequency response areas in rat: an in vivo study using reversible blockade with microinjection of kynurenic acid. Exp Brain Res. 153, 522-529.

Malmierca, M. S. y Merchán, M. A., 2004. The auditory system. In: The Rat Nervous System (Paxinos, G., ed). San Diego: Academic Press.

Malmierca, M. S., Hernández, O. y Rees, A., 2005. Intercollicular commissural projections modulate neuronal responses in the inferior colliculus. Eur J Neurosci. 21, 2701-2710.

Malmierca, M. S., Izquierdo, M. A., Cristaudo, S., Hernández, O., Pérez-González, D., Covey, E. y Oliver, D. L., 2008. A discontinuous tonotopic organization in the inferior colliculus of the rat. J Neurosci. 28, 4767-4776.

Merrill, E. G. y Ainsworth, A., 1972. Glass-coated platinum-plated tungsten microelectrodes. Med Biol Eng. 10, 662-672.

Merzenich, M. M. y Reid, M. D., 1974. Representation of the cochlea within the inferior colliculus of the cat. Brain Res. 77, 397-415.

Merzenich, M. M., Kaas, J. H., Wall, J., Nelson, R. J., Sur, M. y Felleman, D., 1983a. Topographic reorganization of somatosensory cortical areas $3 \mathrm{~b}$ and 1 in adult monkeys following restricted deafferentation. Neuroscience. 8, 33-55.

Merzenich, M. M., Kaas, J. H., Wall, J. T., Sur, M., Nelson, R. J. y Felleman, D. J., 1983b. Progression of change following median nerve section in the cortical representation of the hand in areas $3 \mathrm{~b}$ and 1 in adult owl and squirrel monkeys. Neuroscience. 10, 639-665.

Merzenich, M. M., Nelson, R. J., Kaas, J. H., Stryker, M. P., Jenkins, W. M., Zook, J. M., Cynader, M. S. y Schoppmann, A., 1987. Variability in hand surface representations in areas $3 \mathrm{~b}$ and 1 in adult owl and squirrel monkeys. J Comp Neurol. 258, 281-296.

Michler, S. A. e Illing, R. B., 2002. Acoustic trauma induces reemergence of the growth- and plasticity-associated protein GAP-43 in the rat auditory brainstem. J Comp Neurol. 451, 250-266.

Michler, S. A. e Illing, R. B., 2003. Molecular plasticity in the rat auditory brainstem: modulation of expression and distribution of phosphoserine, phospho-CREB and TrkB after noise trauma. Audiol Neurootol. 8, 190-206.

Milbrandt, J. C., Holder, T. M., Wilson, M. C., Salvi, R. J. y Caspary, D. M., 2000. GAD levels and muscimol binding in rat inferior colliculus following acoustic trauma. Hear Res. 147, 251-260.

Miller, J. D., Watson, C. S. y Covell, W. P., 1963. Deafening effects of noise on the cat. Acta Otolaryngol (Stockh). 176, 1-91.

Moore, B. C., 1986. Parallels between frequency selectivity measured psychophysically and in cochlear mechanics. Scand Audiol Suppl. 25, 139-152.

Moore, B. C., Vickers, D. A., Plack, C. J. y Oxenham, A. J., 1999. Inter-relationship between different psychoacoustic measures assumed to be related to the cochlear active mechanism. J Acoust Soc Am. 106, 2761-2778.

Moore, B. C. y Glasberg, B. R., 2007. Modeling binaural loudness. J Acoust Soc Am. 121, 16041612.

Morales, B., Rozas, C., Pancetti, F. y Kirkwood, A., 2003. Critical period of cortical plasticity. Rev Neurol. 37, 739-743.

Morest, D. K., 1964a. The Neuronal Architecture of the Medial Geniculate Body of the Cat. J Anat. 98, 611-630.

Morest, D. K., 1964b. The lamina structure of the inferior colliculus of the cat. Anat Rec. 148, 314.

Mossop, J. E., Wilson, M. J., Caspary, D. M. y Moore, D. R., 2000. Down-regulation of inhibition following unilateral deafening. Hear Res. 147, 183-187.

Muhlnickel, W., Elbert, T., Taub, E. y Flor, H., 1998. Reorganization of auditory cortex in tinnitus. Proc Natl Acad Sci U S A. 95, 10340-10343.

Nobili, R., Mammano, F. y Ashmore, J., 1998. How well do we understand the cochlea? Trends Neurosci. 21, 159-167.

Noreña, A. J., Gourevitch, B., Aizawa, N. y Eggermont, J. J., 2006. Spectrally enhanced acoustic environment disrupts frequency representation in cat auditory cortex. Nat Neurosci. 9, 932-939. 
Nuding, S. C., Chen, G. D. y Sinex, D. G., 1999. Monaural response properties of single neurons in the chinchilla inferior colliculus. Hear Res. 131, 89-106.

Oliver, D. L. y Morest, D. K., 1984. The central nucleus of the inferior colliculus in the cat. J Comp Neurol. 222, 237-264.

Oliver, D. L., 2005. Neuronal organization of the inferior colliculus. In: The inferior colliculus (Winer, J.A. y Schreiner, C.E., eds), pp 69-114. New York: Springer.

Oliver, D. L., Izquierdo, M. A. y Malmierca, M. S., 2006. Early Sound Exposure Modifies Function In The Inferior Colliculus (IC) Of The Rat. Soc for Neurosci Abstr. 32, 543.9.

Oliver, D. L., Izquierdo, M. A. y Malmierca, M. S., 2007. Early sound exposure alters frequency coding in the inferior colliculus. Proceedings of the The Auditory Brain - a Tribute to Dexter Irvine, Lorne, VIC, AUSTRALIA.

Ou, H. C., Bohne, B. A. y Harding, G. W., 2000. Noise damage in the C57BL/CBA mouse cochlea. Hear Res. 145, 111-122.

Palombi, P. S. y Caspary, D. M., 1996. GABA inputs control discharge rate primarily within frequency receptive fields of inferior colliculus neurons. J Neurophysiol. 75, 2211-2219.

Parks, T. N. y Rubel, E. W., 2004. Overview: development and plasticity of the central auditory system. In: Plasticity of the auditrory system (Parks, T.N., Rubel, E.W., Fay, R.R. y Popper, A.N., eds), pp 1-7. New York: Springer.

Paxinos, G. y Watson, C., 2005. The rat brain in stereotaxic coordinates. Elsevier Academic Press.

Pérez-González , D., Malmierca, M. S. y Covey, E., 2005. Novelty detector neurons in the mammalian auditory midbrain. Eur J Neurosci. 22, 2879-2885.

Pérez-González, D., Malmierca, M. S., Moore, J. M., Hernández, O. y Covey, E., 2006. Duration selective neurons in the inferior colliculus of the rat: topographic distribution and relation of duration sensitivity to other response properties. J Neurophysiol. 95, 823-836.

Pettigrew, A. M., Liberman, M. C. y Kiang, N. Y., 1984. Click-evoked gross potentials and singleunit thresholds in acoustically traumatized cats. Ann Otol Rhinol Laryngol Suppl. 112, 83-96.

Potashner, S. J., Suneja, S. K. y Benson, C. G., 1997. Regulation of D-aspartate release and uptake in adult brain stem auditory nuclei after unilateral middle ear ossicle removal and cochlear ablation. Exp Neurol. 148, 222-235.

Puel, J. L. y Uziel, A., 1987. Correlative development of cochlear action potential sensitivity, latency, and frequency selectivity. Brain Res. 465, 179-188.

Rajan, R., 1998. Receptor organ damage causes loss of cortical surround inhibition without topographic map plasticity. Nat Neurosci. 1, 138-143.

Rajan, R., 2001. Plasticity of excitation and inhibition in the receptive field of primary auditory cortical neurons after limited receptor organ damage. Cereb Cortex. 11, 171-182.

Rajan, R. and Johnstone, B. M., 1988. Binaural acoustic stimulation exercises protective effects at the cochlea that mimic the effects of electrical stimulation of an auditory efferent pathway. Brain Res. 459, 241-255.

Rajan, R., Irvine, D. R. y Cassell, J. F., 1991. Normative N1 audiogram data for the barbiturateanaesthetised domestic cat. Hear Res. 53, 153-158.

Rajan, R., Irvine, D. R., Wise, L. Z. y Heil, P., 1993. Effect of unilateral partial cochlear lesions in adult cats on the representation of lesioned and unlesioned cochleas in primary auditory cortex. $\mathrm{J}$ Comp Neurol. 338, 17-49.

Rajan, R. e Irvine, D. R., 1998a. Absence of plasticity of the frequency map in dorsal cochlear nucleus of adult cats after unilateral partial cochlear lesions. J Comp Neurol. 399, 35-46.

Rajan, R. e Irvine, D. R., 1998b. Neuronal responses across cortical field A1 in plasticity induced by peripheral auditory organ damage. Audiol Neurootol. 3, 123-144.

Ramón y Cajal, S., 1902. Estructura del tubérculo cuadrigémino posterior: Cuerpo geniculado interno y vías acústicas centrales. Trabajos del laboratorio de investigaciones biológicas. 1, 207227.

Rauschecker, J. P. y Shannon, R. V., 2002. Sending sound to the brain. Science. 295, 1025-1029. 
Recanzone, G. H., Schreiner, C. E. y Merzenich, M. M., 1993. Plasticity in the frequency representation of primary auditory cortex following discrimination training in adult owl monkeys. J Neurosci. 13, 87-103.

Rees, A., Sarbaz, A., Malmierca, M. S. y Le Beau, F. E., 1997. Regularity of firing of neurons in the inferior colliculus. J Neurophysiol. 77, 2945-2965.

Robertson, D. e Irvine, D. R., 1989. Plasticity of frequency organization in auditory cortex of guinea pigs with partial unilateral deafness. J Comp Neurol. 282, 456-471.

Rosa, M. G., Schmid, L. M. y Calford, M. B., 1995. Responsiveness of cat area 17 after monocular inactivation: limitation of topographic plasticity in adult cortex. J Physiol. 482 ( Pt 3), 589-608.

Rose, J. E., Greenwood, D. O., Goldberg, J. M. y Hind, J. E., 1963. Some discharge characteristic of single neurons in the inferior colliculus of the cat. I. Tonotopic organization, relation of spikecounts to tone intensity and firing of patterns of single elements. J. Neurophysiol. 26, 294-320.

Rubel, E. W. y Ryals, B. M., 1983. Development of the place principle: acoustic trauma. Science. 219, 512-514.

Ryals, B. M. y Rubel, E. W., 1985. Ontogenetic changes in the position of hair cell loss after acoustic overstimulation in avian basilar papilla. Hear Res. 19, 135-142.

Ryugo, D. K. y Weinberger, N. M., 1978. Differential plasticity of morphologically distinct neuron populations in the medical geniculate body of the cat during classical conditioning. Behav Biol. $22,275-301$.

Salvi, R. J., Saunders, S. S., Gratton, M. A., Arehole, S. y Powers, N., 1990. Enhanced evoked response amplitudes in the inferior colliculus of the chinchilla following acoustic trauma. Hear Res. 50, 245-257.

Sanes, J. N., Suner, S., Lando, J. F. y Donoghue, J. P., 1988. Rapid reorganization of adult rat motor cortex somatic representation patterns after motor nerve injury. Proc Natl Acad Sci USA. 85, 2003-2007.

Sanes, D. H., 1993. The development of synaptic function and integration in the central auditory system. J Neurosci. 13, 2627-2637.

Schmid, L. M., Rosa, M. G., Calford, M. B. y Ambler, J. S., 1996. Visuotopic reorganization in the primary visual cortex of adult cats following monocular and binocular retinal lesions. Cereb Cortex. 6, 388-405.

Scholl, B. y Wehr, M., 2008. Disruption of balanced cortical excitation and inhibition by acoustic trauma. J Neurophysiol. 100, 646-656.

Schreiner, C. E. y Langner, G., 1997. Laminar fine structure of frequency organization in auditory midbrain. Nature. 388, 383-386.

Seidl, A. H. y Grothe, B., 2005. Development of sound localization mechanisms in the mongolian gerbil is shaped by early acoustic experience. J Neurophysiol. 94, 1028-1036.

Singer, W., 1995. Development and plasticity of cortical processing architectures. Science. 270, 758-764.

Snyder, R. L., Sinex, D. G., McGee, J. D. y Walsh, E. W., 2000. Acute spiral ganglion lesions change the tuning and tonotopic organization of cat inferior colliculus neurons. Hear Res. 147, 200-220.

Snyder, R. L. y Sinex, D. G., 2002. Immediate changes in tuning of inferior colliculus neurons following acute lesions of cat spiral ganglion. J Neurophysiol. 87, 434-452.

Suneja, S. K., Benson, C. G. y Potashner, S. J., 1998a. Glycine receptors in adult guinea pig brain stem auditory nuclei: regulation after unilateral cochlear ablation. Exp Neurol. 154, 473-488.

Suneja, S. K., Potashner, S. J. y Benson, C. G., 1998b. Plastic changes in glycine and GABA release and uptake in adult brain stem auditory nuclei after unilateral middle ear ossicle removal and cochlear ablation. Exp Neurol. 151, 273-288.

Suneja, S. K., Yan, L. y Potashner, S. J., 2005. Regulation of NT-3 and BDNF levels in guinea pig auditory brain stem nuclei after unilateral cochlear ablation. J Neurosci Res. 80, 381-390.

Sutter, M. L., Schreiner, C. E., McLean, M., O'Connor K, N. y Loftus, W. C., 1999. Organization of inhibitory frequency receptive fields in cat primary auditory cortex. J Neurophysiol. 82, 23582371. 
Syka, J., Popelar, J., Kvasnak, E. y Astl, J., 2000. Response properties of neurons in the central nucleus and external and dorsal cortices of the inferior colliculus in guinea pig. Exp Brain Res. 133, 254-266.

Tan, J., Ruttiger, L., Panford-Walsh, R., Singer, W., Schulze, H., Kilian, S. B., Hadjab, S., Zimmermann, U., Kopschall, I., Rohbock, K. y Knipper, M., 2007. Tinnitus behavior and hearing function correlate with the reciprocal expression patterns of BDNF and Arg3.1/arc in auditory neurons following acoustic trauma. Neuroscience.

Taranda, J., Maison, S. F., Ballestero, J. A., Katz, E., Savino, J., Vetter, D. E., Boulter, J., Liberman, M. C., Fuchs, P. A. y Elgoyhen, A. B., 2009. A point mutation in the hair cell nicotinic cholinergic receptor prolongs cochlear inhibition and enhances noise protection. PLoS Biol. 7, e18.

Tsukahara, N., 1981. Synaptic plasticity in the mammalian central nervous system. Annu Rev Neurosci. 4, 351-379.

Turrigiano, G. G. y Nelson, S. B., 2004. Homeostatic plasticity in the developing nervous system. Nat Rev Neurosci. 5, 97-107.

Uziel, A., Romand, R. y Marot, M., 1981. Development of cochlear potentials in rats. Audiology. 20, 89-100.

Vollmer, M., Leake, P. A., Beitel, R. E., Rebscher, S. J. y Snyder, R. L., 2005. Degradation of temporal resolution in the auditory midbrain after prolonged deafness is reversed by electrical stimulation of the cochlea. J Neurophysiol. 93, 3339-3355.

Vollmer, M., Beitel, R. E., Snyder, R. L. y Leake, P. A., 2007. Spatial selectivity to intracochlear electrical stimulation in the inferior colliculus is degraded after long-term deafness in cats. $\mathrm{J}$ Neurophysiol. 98, 2588-2603.

Von Békésy, G., 1960. Experiments in Hearing. New York: McGraw-Hill.

Wang, J., Salvi, R. J. y Powers, N., 1996. Plasticity of response properties of inferior colliculus neurons following acute cochlear damage. J Neurophysiol. 75, 171-183.

Wang, J., Ding, D. y Salvi, R. J., 2002a. Functional reorganization in chinchilla inferior colliculus associated with chronic and acute cochlear damage. Hear Res. 168, 238-249.

Wang, Y., Hirose, K. y Liberman, M. C., 2002b. Dynamics of noise-induced cellular injury and repair in the mouse cochlea. J Assoc Res Otolaryngol. 3, 248-268.

Weinberger, N. M., 2007. Auditory associative memory and representational plasticity in the primary auditory cortex. Hear Res. 229, 54-68.

Winer, J. A., 1992. The functional architecture of the medial geniculate body and the primary auditory cortex. In: The mammalian auditory pathway. Neuroanatomy (Webster, D.B., Popper, A.N. y Fay, R.R., eds), pp 22-409. New York: Springer-Verlag.

Wise, L. Z. e Irvine, D. R., 1983. Auditory response properties of neurons in deep layers of cat superior colliculus. J Neurophysiol. 49, 674-685.

Wise, S. P. y Jones, E. G., 1978. Developmental studies of thalamocortical and commissural connections in the rat somatic sensory cortex. J Comp Neurol. 178, 187-208.

Yang, L., Pollak, G. D. and Resler, C., 1992. GABAergic circuits sharpen tuning curves and modify response properties in the mustache bat inferior colliculus. J Neurophysiol. 68, 1760-1774.

Yang, Y., Saint Marie, R. L. y Oliver, D. L., 2003. Frequency resolution in the auditory brainstem determined by sound-induced expression of Fos protein. Soc for Neurosci Abstr. 29, 592.11.

Yang, Y., Saint Marie, R. L. y Oliver, D. L., 2004. The effect of binaural stimulation on frequency resolution in the rat inferior colliculus (IC). Assoc Res Otolaryngol Abs. 27, 1565.

Yoshida, N., Hequembourg, S. J., Atencio, C. A., Rosowski, J. J. y Liberman, M. C., 2000. Acoustic injury in mice: $129 / \mathrm{SvEv}$ is exceptionally resistant to noise-induced hearing loss. Hear Res. 141, 97-106.

Yu, X., Sanes, D. H., Aristizabal, O., Wadghiri, Y. Z. y Turnbull, D. H., 2007. Large-scale reorganization of the tonotopic map in mouse auditory midbrain revealed by MRI. Proc Natl Acad Sci U S A. 104, 12193-12198.

Zhang, L. I., Bao, S. y Merzenich, M. M., 2001. Persistent and specific influences of early acoustic environments on primary auditory cortex. Nat Neurosci. 4, 1123-1130. 
APÉNDICE I:

Publicaciones originales 



\section{NON-PLASTIC REORGANIZATION OF FREQUENCY CODING IN THE INFERIOR COLLICULUS OF THE RAT FOLLOWING NOISE-INDUCED HEARING LOSS}

\author{
M. A. IZQUIERDO, ,c, P. M. GUTIÉRREZ-CONDE, ${ }^{\mathrm{b}, \mathrm{c}}$ \\ M. A. MERCHÁN ${ }^{\mathrm{a}, \mathrm{c}}$ AND M. S. MALMIERCA ${ }^{\mathrm{a}, \mathrm{c*}}$ \\ ${ }^{a}$ Auditory Neurophysiology Unit, Laboratory for the Neurobiology of \\ Hearing, Faculty of Medicine, University of Salamanca, Salamanca, \\ Spain \\ ${ }^{b}$ Department of Applied Physics, Faculty of Sciences, University of \\ Salamanca, Campus Miguel de Unamuno, s/n, 37007 Salamanca, Spain \\ 'Institute of Neuroscience of Castilla y León, University of Salamanca, \\ Salamanca, Spain
}

\begin{abstract}
It is well established that restricted mechanical lesions of the cochlea result in reorganization of the tonotopic map in the auditory thalamus and cortex, but it is unclear whether acoustic trauma produces similar effects at earlier stages of the auditory pathways. To test whether the tonotopic map is reorganized after acoustic trauma at the midbrain level, i.e. the inferior colliculus (IC), we exposed rats to an acoustic trauma and let them survive for at least 5 weeks to ensure that we produced a permanent threshold shift. Experiments were carried out in urethane-anesthetized animals 35-296 days after the traumatic exposure. The acoustic lesions were assessed by measuring the compound action potential. We mapped the frequency organization of the IC using multiunit recordings. In addition, we recorded frequency response areas (FRAs) when a single unit was isolated $(N=142)$. The results show that acoustic trauma produces a persistent reorganization of the tonotopic map and that the normal stepwise representation of sound frequency in the IC is profoundly disrupted. Although the reorganization in the IC is similar to that previously described in the cortex and thalamus in that the affected area appears to be invaded by the adjacent normal frequencies, changes in thresholds and FRAs in these regions are different from those in the forebrain. We conclude that most of the changes can be explained by the residual-response hypothesis [Irvine DR, Rajan R, Smith S (2003) Effects of restricted cochlear lesions in adult cats on the frequency organization of the inferior colliculus. J Comp Neurol 467:354-374]. Plastic reorganization of frequency response areas and tonotopic organization does not seem to occur at the midbrain level following acoustic trauma in adult animals in a manner similar to that previously shown in the auditory cortex. Maintaining the stability of the neuronal circuitry for frequency coding in the IC may be important for the treatment of noise-induced hearing loss. (c) 2008 IBRO. Published by Elsevier Ltd. All rights reserved.
\end{abstract}

${ }^{*}$ Correspondence to: M. S. Malmierca, Auditory Neurophysiology Unit, Laboratory for the Neurobiology of Hearing, Department of Cell Biology and Pathology, Faculty of Medicine, University of Salamanca, Campus Miguel de Unamuno, s/n, 37007 Salamanca, Spain. Tel: +34-923294500x1861; fax: +34-923294549.

E-mail address: msm@usal.es (M. S. Malmierca).

Abbreviation: $\mathrm{BF}$, best frequency; CAP, compound action potential; CNIC, central nucleus of the inferior colliculus; FRA, frequency response area; IC, inferior colliculus; MU, multiunit; PTS, permanent threshold shift; STC, spatial tuning curve; SU, single unit.
Key words: acoustic trauma, midbrain, spectral analysis, tonotopic organization, plasticity, stability.

A fundamental feature of sensory systems, including the auditory system, is the presence of a topographical representation or map of the sensory receptors in the CNS. For many years it was thought that topographic maps could be modified by experience only during development, notably during "sensitive" or "critical" periods of limited duration (de Villers-Sidani et al., 2007; Nakahara et al., 2004; Zhang et al., 2001), and that this organization was fixed in the adult brain. However, it is now well-established that topographical maps have the capacity to reorganize if the mature sensory system is chronically deprived of its normal input, for example, through damage of the sensory receptors.

The primary somatosensory and visual cortices of adult mammals exhibit a remarkable capacity for plastic change when patterns of input are altered by peripheral denervation (Buonomano and Merzenich, 1998; Gilbert, 1998; Kaas, 2000). In the auditory system, unilateral mechanical lesions of a restricted frequency region in the adult cochlea results in a reorganization of the normal frequency map in the contralateral cortex. Cortical neurons which would usually be tuned to the frequency corresponding to the lesioned section of the cochlea (termed lesion projection zone; Schmid et al., 1996) retune so that their new best frequencies correspond to the edge of the cochlear lesion (Robertson and Irvine, 1989; Rajan et al., 1993; Schwaber et al., 1993; Rajan, 1998). It is not clear to what extent, plastic changes occur within the excitatory response area following different forms of deafferentation.

Cortical plasticity is well-documented (Irvine and Wright, 2005; Irvine, 2007); however, it is unclear to what extent subcortical nuclei contribute to cortical reorganization. Studies carried out in the cochlear nucleus have failed to demonstrate plastic changes in frequency reorganization (Kaltenbach et al., 1992; Rajan and Irvine, 1998a); however, a single study of the auditory thalamus has shown evidence for genuine plastic reorganization of the tonotopic map similar to that seen in the auditory cortex (Kamke et al., 2003).

Since the inferior colliculus (IC) is an obligatory relay center for most input from lower auditory centers going to the thalamus (Anderson et al., 2006; Malmierca et al., 2002; Malmierca, 2003) understanding its contribution to thalamic and cortical plasticity in frequency coding is critical. The effects of partial ablation of the auditory periphery, including mechanical disruptions of the organ of Corti 
(Rajan et al., 1993; Rajan and Irvine, 1998b; Rajan, 1998, 2001; Robertson and Irvine, 1989), administration of ototoxic drugs (Harrison et al., 1993a,b, 1995; Harrison, 2001; Schwaber et al., 1993) or genetically induced progressive hearing loss (Willott, 1984; Willott et al., 1993; Willott and Bross, 1996), have been reported at the level of the auditory cortex in a wide variety of experimental models. However, fewer studies have described the effects at the level of the IC and the results are controversial. For example, while Harrison et al. (1998) reported some tonotopic map plasticity in the IC, Irvine et al. (2003) reported only a patchy reorganization in the central nucleus where most changes seem to be due to residual responses ("pseudoplastic").

The present study aimed to shed light on the issue of subcortical plasticity in the auditory system with special emphasis on the role of the midbrain in frequency coding. We exposed young adult rats to acoustic trauma in order to produce moderate to severe noise-induced hearing loss. This cochlear insult resulted in a profound reorganization of the tonotopic map in the IC. However, in most cases, the reorganization was accompanied by increases in neuronal thresholds. Preliminary reports have been presented elsewhere (Izquierdo et al., 2006, 2007).

\section{EXPERIMENTAL PROCEDURES}

Experiments were performed on a total of 51 healthy young-adult rats (Rattus norvegicus, Rj: Long Evans) of both sexes. Rats weighed between 170 and $430 \mathrm{~g}$, were between 96 and 341 days old and were free from any signs of external- or middle-ear pathology. The care and use of animals reported on in this study were approved by the University of Salamanca Animal Care and Use Committee and conformed to the guidelines of the EU directive 2003/65/CE and the Spanish RD 1201/2005. All efforts were made to minimize the number of animals used and their suffering.

\section{Experimental groups and experimental design}

Animals were randomly assigned to one of three groups: 1) seven control animals (3-7 months old) were used to establish a mean baseline compound action potential (CAP, Fig. 1A); 2) 32 animals in the same age range as the control group were used to obtain detailed tonotopic response maps from the "normal" IC (Fig. 1B) and to collect control frequency response areas (FRAs, Fig. 1C); and 3) 17 animals were exposed to intense pure tone stimuli (see Table 1 for parameters). The animals in the third group were first tested for permanent threshold shift (PTS) of the CAP audiogram. (In order to assess possible differences after longer recovery periods they were tested at variable periods after the exposure.) Following the CAP measurements, group 3 underwent a recording protocol similar to that described for group 2. The three groups of experiments were randomly conducted.

\section{Acoustic trauma}

Animals in group 3 were exposed to continuous pure tones of either 5 or $8 \mathrm{kHz}$, at intensities between 110-121 dB SPL. In order to induce different degrees of cochlear damage the duration of exposure ranged from 3.3-16 h (Table 1). Throughout the exposure, the animals were unanesthetized and unrestrained within individual cages which were suspended inside a small reverberant sound-exposure box with non-parallel sides (e.g. Liberman and Gao, 1995; Yoshida et al., 2000). The exposure stimulus was generated by a custom-made noise source, amplified (Magnat
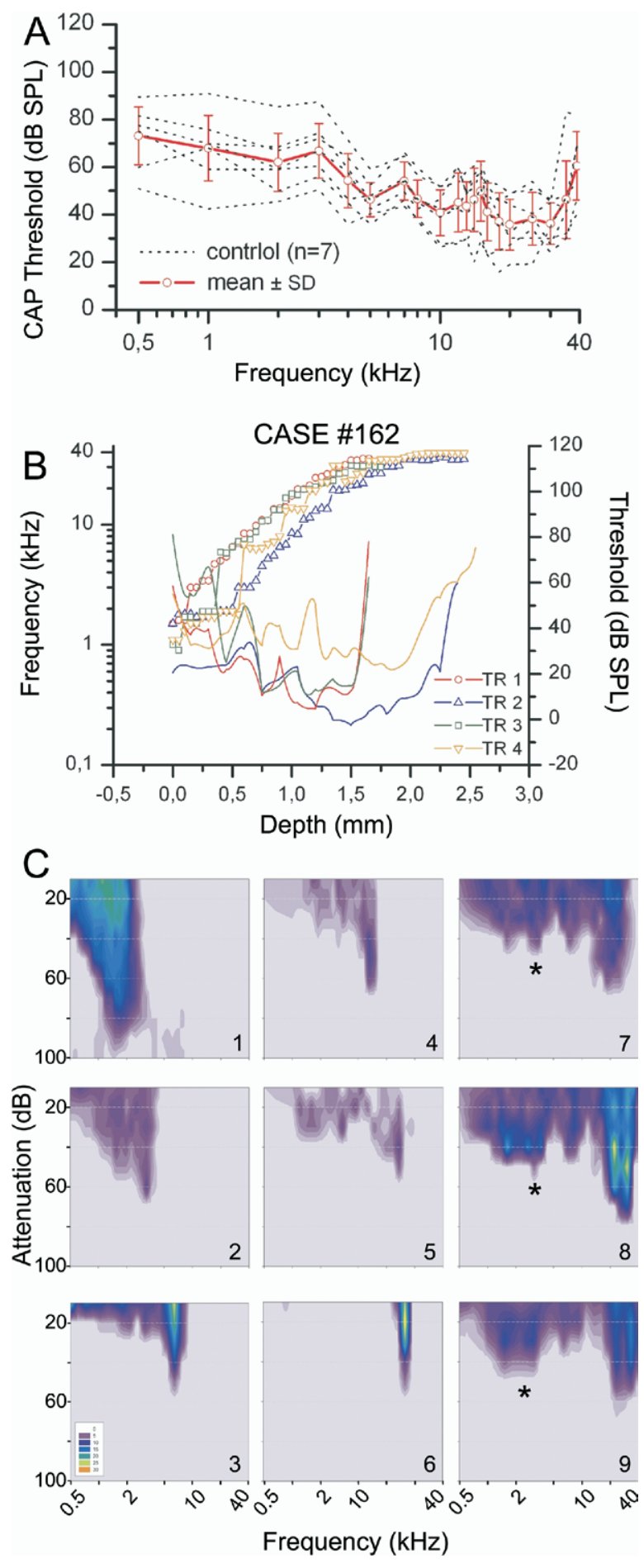

Fig. 1. Control data. (A) CAP audiograms for seven normal individual cases (dashed lines) and the corresponding mean CAP audiogram (mean \pm S.D.; open circles; red line). (B) Normal MU frequency organization from four penetrations across the CNIC for one normal animal (open symbols) and their corresponding thresholds (solid lines) as a function of recording depth. All tracks show a staircase pattern of progression of BFs. (C) Nine control FRAs from well isolated SUs (1-9) recorded from three different tracks across the CNIC. Asterisks indicate low frequency tails observed in high frequency FRAs. Color scale indicates number of spikes fired in response to two stimulus presentations. SPL, sound pressure level. 
Table 1. Summary of parameters and animals exposed to acoustic trauma

\begin{tabular}{|c|c|c|c|c|c|c|}
\hline Animal no. & $\begin{array}{l}\text { Age on day of } \\
\text { exposure (days) }\end{array}$ & $\begin{array}{l}\text { Stimulus } \\
\text { frequency }(\mathrm{kHz})\end{array}$ & $\begin{array}{l}\text { Stimulus } \\
\text { level (dB SPL) }\end{array}$ & $\begin{array}{l}\text { Stimulus } \\
\text { duration (hours) }\end{array}$ & $\begin{array}{l}\text { Age on day of } \\
\text { mapping (days) }\end{array}$ & $\begin{array}{l}\text { Postexposure recovery } \\
\text { period (days) }\end{array}$ \\
\hline 107 & 53 & 8 & 114 & 10.6 & 181 & 128 \\
\hline 108 & 53 & 8 & 114 & 10.6 & 186 & 133 \\
\hline 147 & 46 & 8 & 115 & 12.5 & 169 & 123 \\
\hline 148 & 46 & 8 & 115 & 12.5 & 190 & 144 \\
\hline 150 & 46 & 8 & 115 & 12.5 & 290 & 244 \\
\hline 151 & 46 & 8 & 114.5 & 11.6 & 192 & 146 \\
\hline 152 & 46 & 8 & 114.5 & 11.6 & 193 & 147 \\
\hline 167 & 50 & 8 & 110 & 16 & 160 & 110 \\
\hline 168 & 50 & 8 & 110 & 16 & 208 & 158 \\
\hline 169 & 50 & 8 & 110 & 16 & 209 & 159 \\
\hline 170 & 50 & 8 & 110 & 16 & 288 & 238 \\
\hline 224 & 61 & 5 & 121 & 3.3 & 100 & 39 \\
\hline 225 & 61 & 5 & 121 & 3.3 & 96 & 35 \\
\hline 226 & 61 & 5 & 121 & 3.3 & 162 & 101 \\
\hline 227 & 61 & 5 & 121 & 3.3 & 190 & 129 \\
\hline 243 & 45 & 5 & 121 & 3.3 & 164 & 119 \\
\hline 244 & 45 & 5 & 121 & 3.3 & 341 & 296 \\
\hline
\end{tabular}

Audio-Produkte $\mathrm{GmbH}$, Germany) and delivered to four free-field speakers (Mac Audio Electronic $\mathrm{GmbH}$ \& Co. KG, Germany) placed on the walls of the sound box. Sound exposure levels were measured at the position equivalent to the top of the rat's head before and after each exposure, using a [1/2]-inch condenser microphone (Brüel and Kjær 4191, Nærum, Denmark). Sound pressure was found to vary by $0.5-1 \mathrm{~dB}$ across these locations in the box and before or after the exposure. Animals were allowed to recover for $>35$ days since little if any temporary threshold shift occurs after this period (Yoshida et al., 2000; Miller et al., 1963).

\section{Surgical procedures}

On the day of recording, surgical anesthesia was induced with urethane $(1.5 \mathrm{~g} / \mathrm{kg}, 20 \%$ solution, i.p.) and maintained with supplementary doses $(0.5 \mathrm{~g} / \mathrm{kg}$, i.p.) to preserve an areflexive state. Surgical and experimental procedures were performed in an electrically shielded, sound-attenuating room. The trachea was cannulated, and atropine sulfate $(0.05 \mathrm{mg} / \mathrm{kg}$, s.c. $)$ was administered to reduce bronchial secretions. Body temperature was monitored with a rectal probe and maintained at $38 \pm 1{ }^{\circ} \mathrm{C}$ by a thermostatically-controlled electric-blanket. Details of surgical preparation were as described elsewhere (Hernandez et al., 2005; Malmierca et al., 2003, 2005; Perez-Gonzalez et al., 2005, 2006). The animal was placed in a stereotaxic frame in which the ear bars were replaced by hollow specula that accommodated a sound delivery system.

\section{Measuring the cochlear action potential audiogram}

Auditory function was assessed by measuring CAP thresholds. The tympanic bulla was exposed and the middle ear cavity was opened. A silver wire serving as the recording electrode was placed on the round window through a hole made in the bulla. The response was amplified $(10,000 \times)$, filtered $(0.1-3 \mathrm{kHz})$ and averaged offline. CAP thresholds were measured under computer control in response to tone pips $(5 \mathrm{~ms}$ duration with $1 \mathrm{~ms}$ rise-fall time), delivered at a $10 \mathrm{~Hz}$ repetition rate through a closed and calibrated sound system. The stimulus intensity was varied in $1 \mathrm{~dB}$ steps. CAP thresholds were determined for 20 frequencies between 0.5 and $39 \mathrm{kHz}$ and were defined as the sound pressure required to produce a peak-to-peak neural response of $1-2 \mu \mathrm{V}$ in amplitude at a latency corresponding to $\mathrm{N}_{1}$ (Rajan et al., 1991).

\section{Acoustic stimuli and electrophysiological recording}

A craniotomy was performed to expose the cerebral cortex and the cerebellum overlying the IC. A tungsten electrode (1-2 M $\Omega$ ) (Merryll and Ainswoth, 1972) was placed through the cortex and used to record extracellular single unit (SU, signal to noise ratio was usually $1 / 10$ or more) and multiunit (MU) responses in the IC in response to pure tone stimulation.

Stimuli were generated on a System II workstation (TuckerDavis Technologies; Gainesville, FL, USA) using custom software and delivered through a sealed acoustic system (Rees et al., 1997; Malmierca et al., 2003, 2005) using two electrostatic loudspeakers (TDT-EC1) driven by two TDT-ED1 modules. The output of the system was calibrated in situ using a Brüel and Kjær 4136 [1/4]-inch condenser microphone and a DI-2200 spectrum analyzer (Diagnostic Instruments Ltd., Livingston, Scotland, UK). The electrode was advanced using a microdrive (Burleigh 6000). Action potentials were amplified $(10,000 \times)$ with a Bioamp amplifier (TDT) and filtered $(0.5-3 \mathrm{kHz}$, TDT DB4) before being processed by a spike discriminator (TDT SD1). Spike times were logged by feeding the output of the spike discriminator into an event timer (TDT ET1) synchronized to a timing generator (TDT TG6). Stimulus generation and on-line data visualization were controlled with custom software. Monaural stimuli were used to generate FRAs from well-isolated SUs using pure tones $(75 \mathrm{~ms}, 5 \mathrm{~ms}$ rise/fall time, $4 \mathrm{~Hz}$ repetition rate). The frequency $(0.5-40 \mathrm{kHz}$ in 25 logarithmically steps) and intensity $(0-100 \mathrm{~dB}$ SPL in 5-10 dB steps) of each stimulus were varied randomly and presented two to five times. The data obtained were analyzed and plotted using commercial software (Microsoft Excel, SigmaPlot and SPSS).

\section{Histological verification of recording sites}

At the end of each experiment, electrolytic lesions ( $5 \mu \mathrm{A}, 5 \mathrm{~s})$ were made using the tungsten recording electrode. The animal was given a lethal dose of sodium pentobarbitone (Nembutal) and perfused intracardially with Ringer's solution followed by fixative (1\% paraformaldehyde and $1 \%$ glutaraldehyde in $0.1 \mathrm{M}$ phosphate buffer, $\mathrm{pH}: 7.4)$. The brains were immersed in a $30 \%$ sucrose solution for $2-3$ days. Sagittal sections $(40 \mu \mathrm{m})$ were cut on a freezing microtome and stained with Cresyl Violet to facilitate identification of cytoarchitectural boundaries. All sites from which we recorded single and $\mathrm{MU}$ activity were in the central nucleus of 
the IC as defined in the rat by Malmierca et al. (Malmierca et al., 1993, 1995; Loftus et al., 2008).

\section{RESULTS}

To assess the effects of noise-exposure on the functional organization of the IC we will first present 1) CAP audiograms, 2) detailed tonotopic maps of the IC derived from MU responses and 3) SU FRAs recorded from normal control animals. We will then compare these normal data with data recorded from noise-exposed animals.

\section{Normal CAP audiogram}

The CAP audiogram was measured from seven control animals (Fig. 1A). In all cases, the threshold at the lowest frequency tested $(0.5 \mathrm{kHz})$ was $80 \mathrm{~dB}$ SPL. The threshold decreased progressively on moving to higher frequencies with a notch of decreased sensitivity at around $15 \mathrm{kHz}$. The most sensitive region occurred around $20-30 \mathrm{kHz}$. From $30 \mathrm{kHz}$, thresholds increased gradually up to the highest frequency tested $(39 \mathrm{kHz})$. Our CAP data conform with previously described CAPs recorded from the rat (Fechter et al., 1998, 2000). We calculated the mean and S.D. from these seven control cases, and used the derived function (Fig. 1A; red line) as the control CAP audiogram for comparison with noise exposed animals (cf., Figs. 3 and 4).

\section{Normal MU tonotopic maps of the IC}

Dorsoventrally oriented microelectrode penetrations were made across the central nucleus of the inferior colliculus (CNIC) of 12 normal hearing adult rats. Recordings of best frequency (BF) were made from neuronal clusters every 25-50 $\mu \mathrm{m}$ (Fig. 1B) to reveal the tonotopic organization of the IC. This mapping demonstrated a systematic shift in the BF of the MU activity as a function of depth along the dorsoventral axis (Merzenich and Reid, 1974); this shift was not smooth but had a distinct staircase pattern (Schreiner and Langner, 1997; Malmierca et al., 2006, 2008). Average track length was $2180 \pm 460 \mu \mathrm{m}$ (mean \pm S.D.) and the $\mathrm{BF}$ recorded ranged from $0.5 \mathrm{kHz}$ to $40 \mathrm{kHz}$. In all tracks, the BF remained constant for an average of $151 \pm 41 \mu \mathrm{m}$ (mean \pm S.D.), then jumped by $0.34 \pm 0.11$ octave, creating 460 steps from 33 tracks $(14 \pm 3.7$ on average/track; Malmierca et al., in press).

Corresponding thresholds for each MU were also determined at every recording site (Fig. 1B; colored lines). The resulting threshold curves were $U$-shaped and showed a minimum threshold (0-20 dB SPL) around the middle of the track, corresponding to $10-35 \mathrm{kHz}$ frequency region.

\section{Normal FRAs of the IC (SU)}

We recorded 120 FRAs from 32 normally hearing adult rats. Fig. $1 \mathrm{C}$ shows a composition of nine representative FRAs recorded from SUs across the CNIC of three different animals. As expected, the BF of the individual FRAs progressively increases with recording depth within the IC (Fig. 1C, 1-9). A detailed analysis of the different FRA

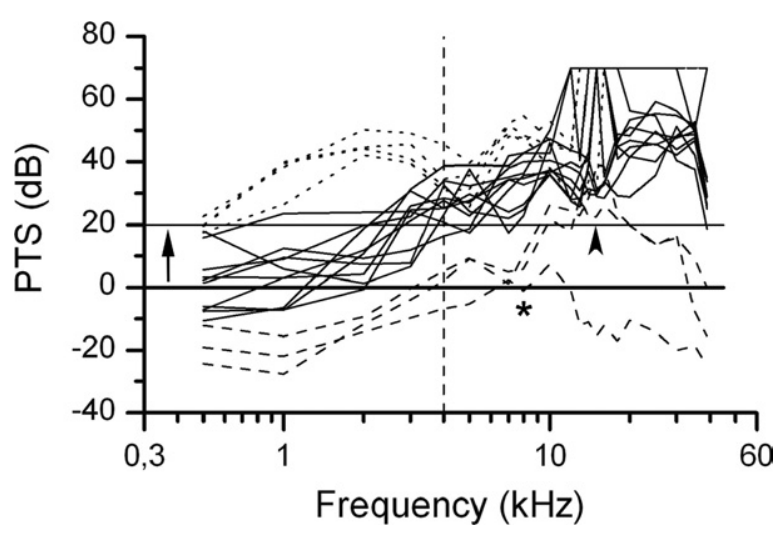

Fig. 2. PTS in the 17 exposed animals relative to control thresholds (0 dB baseline). Solid line illustrates PTS of $20 \mathrm{~dB}$ (arrow). Most cases show a PTS $>20 \mathrm{~dB}$ above $4 \mathrm{kHz}$ (vertical dashed line). Four cases also showed PTS $>20 \mathrm{~dB}$ at low frequencies $(<4 \mathrm{kHz})$, thus affecting the whole frequency range (dotted lines). The last three cases (dashed lines) were more sensitive after the acoustic insult than control animals, but suffered a PTS at mid (5-12 kHz; asterisk) or mid-high frequencies (5-30 kHz; arrowhead).

types is beyond the scope of this manuscript; however, most of the FRAs recorded from this group of control animals were of the V-shape type. The V-shaped FRA varies as a function of $B F$, so that neurons with a $B F>4-5$ $\mathrm{kHz}$ had a sharply tuned, sensitive region or tip, and a more broadly tuned, insensitive region ("low frequency tail") (e.g. Fig. 1C; asterisks, Hernandez et al., 2005). Our sample also contained some non-V-shaped FRAs (e.g. Fig. 1C-6), but they were less abundant. The majority of units in this control group lacked spontaneous activity.

\section{Characterization of hearing loss in chronically lesioned animals}

To ensure a PTS, we waited 35-296 days after the exposure before recording physiological responses from the noise-exposed animals. The extent of the trauma was assessed by measuring the CAP audiogram. Fig. 2 shows the CAP audiograms for each individual animal exposed to acoustic trauma expressed as PTS relative to the normal CAP mean ( $0 \mathrm{~dB}$ baseline). Previously, it had been shown that at least a $20 \mathrm{~dB}$ shift in normal thresholds was necessary to initiate cortical reorganization (Rajan and Irvine, 1998b; Rajan, 1998, 2001); therefore we have adopted this value for convenience and for the sake of description.

Regardless of the acoustic trauma experienced (Table 1), 10/17 cases showed a PTS of $>20 \mathrm{~dB}$ (Fig. 2, arrow) at 3-4 kHz (Fig. 2, vertical dashed line) and above. Of the remaining seven cases, four (cases \# 107, 147, 148 and 150) also exhibited a PTS at lower frequencies (Fig. 2, dotted lines), i.e. an even broader PTS including virtually all frequencies tested. The remaining three cases (cases \# 224, 226 and 244) showed a CAP that appeared to be more sensitive than the control CAP audiogram (Fig. 2, dashed lines), however, two of these cases (cases \# 226 and 244) also exhibited a notch PTS at the $5-20 \mathrm{kHz}$ 

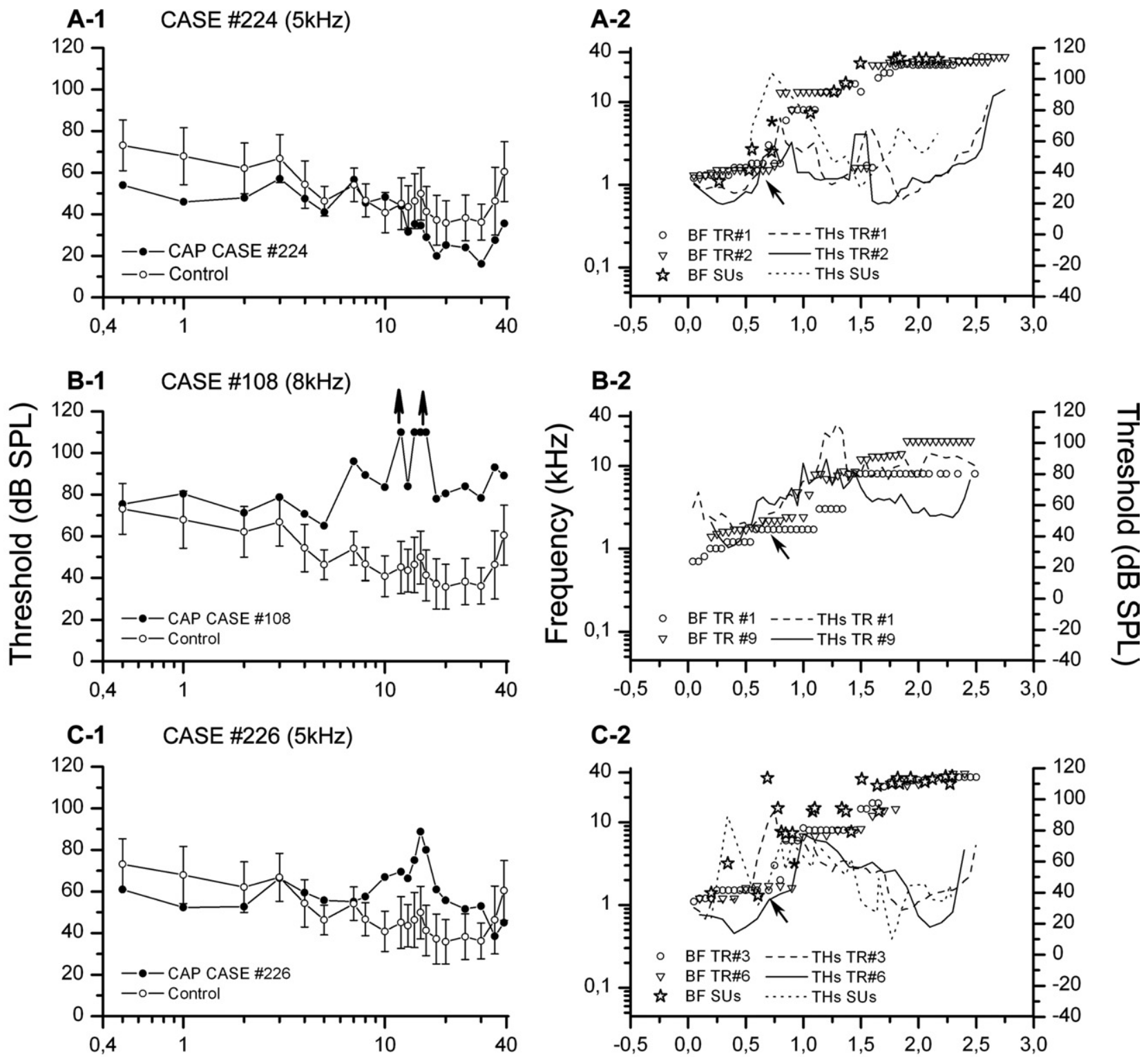

$$
\text { Frequency }(\mathrm{kHz})
$$

Depth $(\mathrm{mm})$

Fig. 3. CAP audiograms and MU maps after acoustic trauma. (A1-C1) Control CAP audiogram (open circles) compared with CAP audiograms from three exposed animals (filled circles). A broad hearing loss was induced after the sound exposure. Complete loss of sensitivity to some frequencies at the maximum intensity tested (arrows) was found in some cases (e.g. B-1). (A2-C2) Tonotopic maps based on MU recordings of BF across the CNIC as a function of depth (circles and triangles) and their respective thresholds (continuous dashed and dotted lines) were determined in the same exposed animals as in $\mathrm{A} 1-\mathrm{C} 1$. Tonotopic progression of BFs and thresholds was disrupted as a consequence of the acoustic trauma (asterisks), affecting a limited central portion of the CNIC. This alteration commenced around $700 \mu \mathrm{m}$ (arrows), leading to expansions of the low frequencies adjacent to the lesion. At some recording sites SUs could be isolated (stars), showing that the increase in thresholds also affects the SU thresholds (dotted lines).

frequency range (Fig. 2, arrowhead). The remaining case (\# 224) was confined to the normal region, but showed the least sensitivity at 8-10 kHz (Fig. 2, asterisk).

In summary, the CAP data described above demonstrate a severe hearing loss in all but one (\# 224) case, regardless of the frequency or intensity of the tone employed to generate the acoustic insult or the duration of the exposure time.

\section{Mapping of the tonotopic organization in chronically lesioned animals}

MU BF maps were obtained from the 17 rats that had been exposed to an acoustic trauma at $5 \mathrm{kHz}(n=6)$ and $8 \mathrm{kHz}$ $(n=11$; Table 1). We examined a total of 29 tracks across the CNIC (10 from animals exposed to $5 \mathrm{kHz}$ traumatic tone and 19 tracks to $8 \mathrm{kHz}$ ). Figs. 3 and 4 show 12 of the 

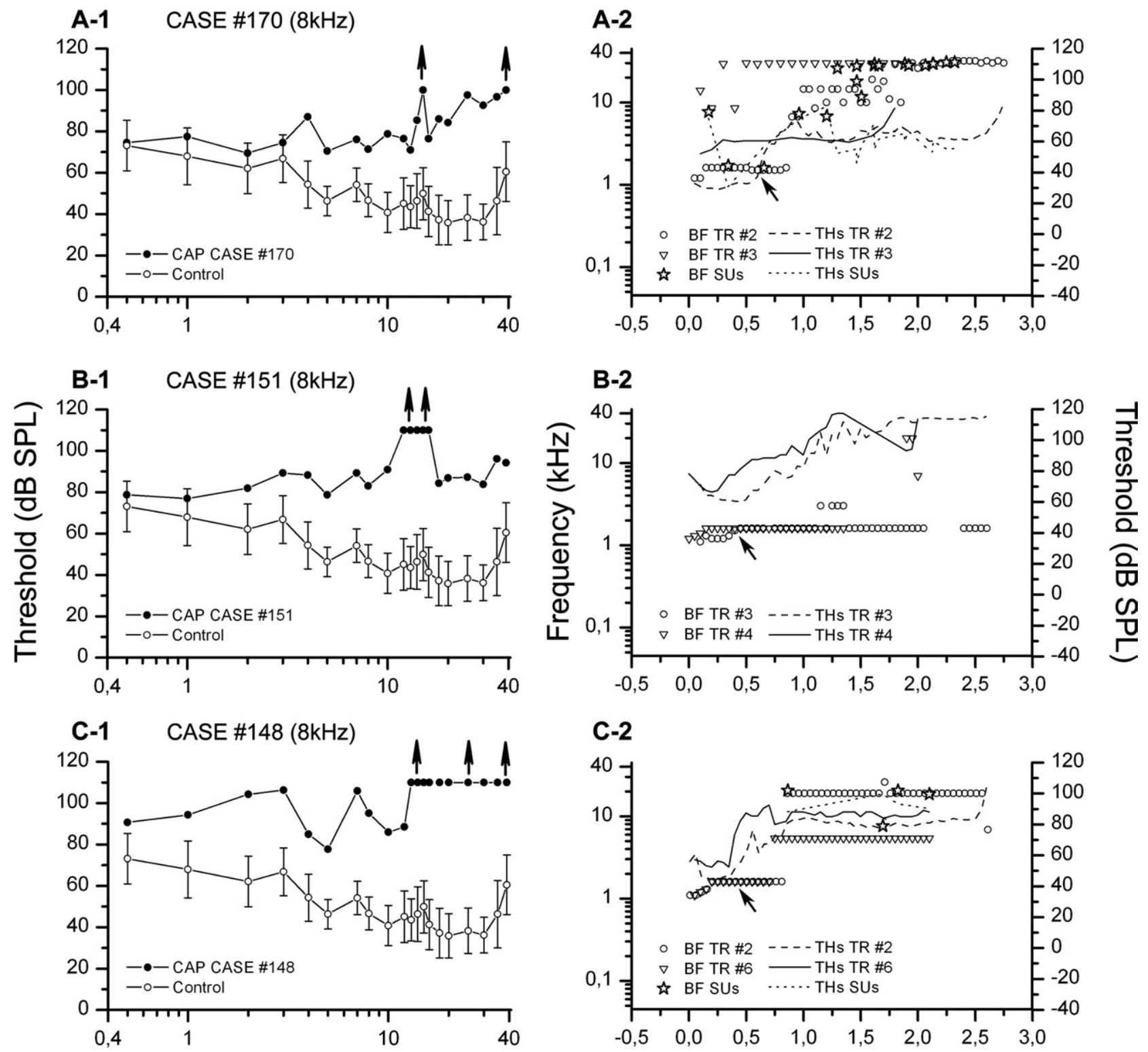

\section{Frequency $(\mathrm{kHz})$}

\section{Depth (mm)}

Fig. 4. CAP audiogram and MU maps in three cases (\# 170, 151 and 148) after acoustic trauma. (A1-C1) CAP audiogram in control (open circles) and exposed animals (filled circles) reveal a profound hearing loss affecting most of the frequencies tested, with complete loss of sensitivity at some frequencies (arrows). This pattern of hearing loss led to MU tonotopic maps with a profound alteration of the normal BF progression (A2-C2; open symbols). Expansions of the lesion edge frequencies and a marked increase in thresholds (A2-C2; continuous, dashed and dotted lines) started around $1.5-1.7 \mathrm{kHz}$, corresponding to $\sim 700 \mu \mathrm{m}$ depth (arrows). SU BFs and thresholds could also be determined at some recording depths (stars and dotted lines).

tracks, i.e. the tonotopic maps obtained from six animals following acoustic trauma and their corresponding CAP audiograms. They are fully representative of the entire sample.

Visual inspection of these tracks showed that noiseinduced hearing loss resulted in a reorganization of the normal tonotopic organization map of the IC. The distinct staircase pattern observed in normal cases (Fig. 1B) was clearly altered and became more or less blurred (Fig. 3) or significantly distorted (Fig. 4). In these experimental cases the BF remained constant for an average of $218.5 \pm$ $113 \mu \mathrm{m}$ (vs. $151 \pm 41$ observed in the control cases; $t$-test, $P<0.01$ ) and then jumped by $0.49 \pm 0.40$ octave (vs. $0.34 \pm 0.11$ in the control cases). Thus, the number of steps was significantly reduced ( $n=287$ steps, $9.9 \pm 4.4$ on average/track; $t$-test, $P<0.05$ ) as can be seen from Fig. 4 . In addition, we made a step analysis separately for the lowand high-frequency regions. In low-frequency regions (defined as $<4 \mathrm{kHz}$, control average $2.05 \mathrm{kHz}$ (Malmierca et al., in press)), the mean BF was $1.6 \mathrm{kHz}$ and BF steps 
were on average $221 \pm 166 \mu \mathrm{m}$ thick (vs. $142 \pm 69 \mu \mathrm{m}$ in the control). BF jumps were $0.27 \pm 0.19$ octaves (vs. $0.27 \pm$ 0.15 octaves in control cases), with 4.1 vs. 4.7 steps per track on average. In high frequency regions (defined as 8 $\mathrm{kHz}<\mathrm{BF}<35 \mathrm{kHz}$; control average $21.1 \mathrm{kHz}$ ), the BF steps were $244 \pm 231 \mu \mathrm{m}$ (vs. $140 \pm 48 \mu \mathrm{m}$; Mann-Whitney tests, $P<0.05)$ and jumped by $0.21 \pm 0.18$ octaves with an average of 5.6 steps per track (vs. $0.26 \pm 0.06$ octaves and 7.4 steps per track). The absence of statistically significant differences between low- or high- frequency step sizes and their corresponding control sizes is most probably due to the large variability observed in the number and size of the steps seen after acoustic trauma (Figs. 3 and 4). In all of the experimental tracks, the sequence of BFs and thresholds started in a normal fashion up to frequencies of $\sim 1.5$ $1.7 \mathrm{kHz}$ (Fig. 3 and 4, arrows), but from there on the $\mathrm{BF}$ sequence became disrupted.

Although the individual cases of tonotopic map reorganization following noise-induced hearing loss seem to form a continuum, for descriptive purposes we have divided them into two main patterns: 1) the first pattern showed minimal alteration of the tonotopic map. Most of the frequency steps that occurred in normal animals were present (Fig. 3), the missing frequencies corresponded to the hearing loss seen in the CAP audiogram (Fig. 3; asterisks) and were flanked by expansions of adjacent frequencies. 2) The second pattern showed a profound reorganization across the whole CNIC (Fig. 4) and an absence of the characteristic normal stepwise frequency progression. This alteration led to a significant expansion in the size of one or two steps corresponding to the frequencies represented at the edge of the loss in cochlear sensitivity as judged from the CAPs (Fig. $4 \mathrm{~A} 1-\mathrm{C} 1$ ). Both patterns showed a marked increase in the response thresholds (Fig. 3 and 4 A2-C2, continuous and dotted lines). The pattern of effects observed at the level of MU responses was also apparent in SU recordings which were made occasionally in some penetrations. In each case, the BFs determined from the individual SU responses (Fig. 3 and 4 A2-C2, stars) were very similar to those determined from the $\mathrm{MU}$ responses across the CNIC.

Although a great deal of variability in the level of hearing loss was observed in the 17 CAPs, there appeared to be a correlation between the CAP audiogram and the degree of reorganization exhibited in the CNIC. Those cases (\# 108, 224, 225, 226 and 244) that showed the least alteration in tonotopic mapping corresponded to those whose CAPs exhibited the least loss in cochlear sensitivity, most of which were notch-like except for case \# 151 (Fig. 4 B).

Thus far, we have described the tonotopic organization of the IC based on the BF measured at progressively different depths. By definition, BF is the frequency to which a neuron is most sensitive, i.e. at the lowest threshold, but a complementary mapping analysis can be obtained by plotting the threshold of any given frequency as a function of recording depth within the IC, to generate a spatial tuning curve (STC). Fig. 5 illustrates the normal STC for $1.6 \mathrm{kHz}(1.6 \mathrm{kHz}$ is the first frequency at which there is an

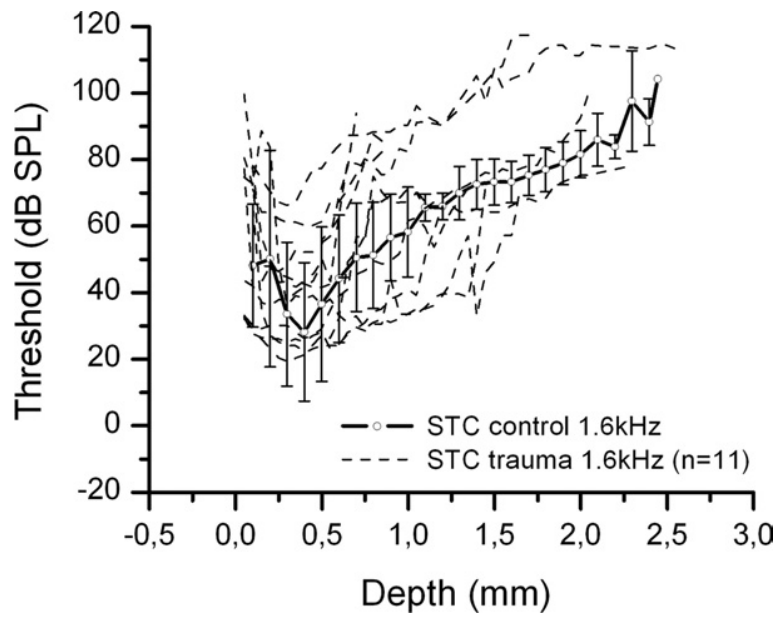

Fig. 5. STCs. Control \pm S.D. STC (solid line) at $1.6 \mathrm{kHz}$ was determined. This curve represents MU thresholds at $1.6 \mathrm{kHz}$ every $25-$ $50 \mu \mathrm{m}$ across the CNIC. The tip of the curve indicates the most sensitive area of the IC tuned to this frequency $(1.6 \mathrm{kHz})$. Dashed lines correspond to STCs at the same frequency $(1.6 \mathrm{kHz})$ recorded from animals with acoustic trauma $(n=11)$. Most of these STCs follow the normal progression of the control STC, suggesting a residual response component after the lesion.

expansion in the step size of the altered tonotopic maps from the exposed animals). This STC curve is V-shaped and asymmetric, with the steeper slope in the low-frequency region of the $I C$ and the shallower slope in the high-frequency region of the IC. The different dashed lines show 11 individual STCs for $1.6 \mathrm{kHz}$, (see Fig. 4). Most of these STCs are as sharply V-shaped as the normal STC (see Discussion). Only two to three of these STC curves show some broadening so that the minimal threshold is more or less similar to the tip of the normal STC for some distance. We also constructed STCs for both normal and lesioned animals at $7 \mathrm{kHz}$, but in these cases, none of the STCs showed any broadening.

\section{FRAs in chronically lesioned animals}

We examined 142 SU FRAs from animals with an acoustic trauma at $5 \mathrm{kHz}(n=84)$ or $8 \mathrm{kHz}(n=58)$. Fig. $6 \mathrm{~A}$ shows the recording sites in the CNIC for 16 SUs in four different animals and their corresponding FRAs (Fig. 6B). SUs located at the beginning of the tracks, i.e. superficially within the IC $(0-1000 \mu \mathrm{m})$, possessed V-shaped FRAs in most cases (e.g. Fig. 6; units \# 223, 235, 236, 185) with a clear peak indicating their BF $(1.5-2.9 \mathrm{kHz})$ and thresholds around $45-65 \mathrm{~dB}$ SPL. These FRAs were similar to those found in control animals for this frequency range. As the recording electrode progresses ventrally, i.e. recording depth increases $(>1000 \mu \mathrm{m})$ broader SU FRAs were observed (Fig. 6; units \# 224, 237, 191 and 192) and response thresholds were markedly increased. FRAs in this region usually had one or more additional frequency peaks at frequencies above BF (e.g. Fig. 6, arrows). The frequency of these peaks gradually increased as a function of depth (e.g. Fig. 6; case \# 170, arrows). The most ventrally located neurons showed complex, non-V-shaped FRAs, with two or three frequency peaks and high thresholds 
A
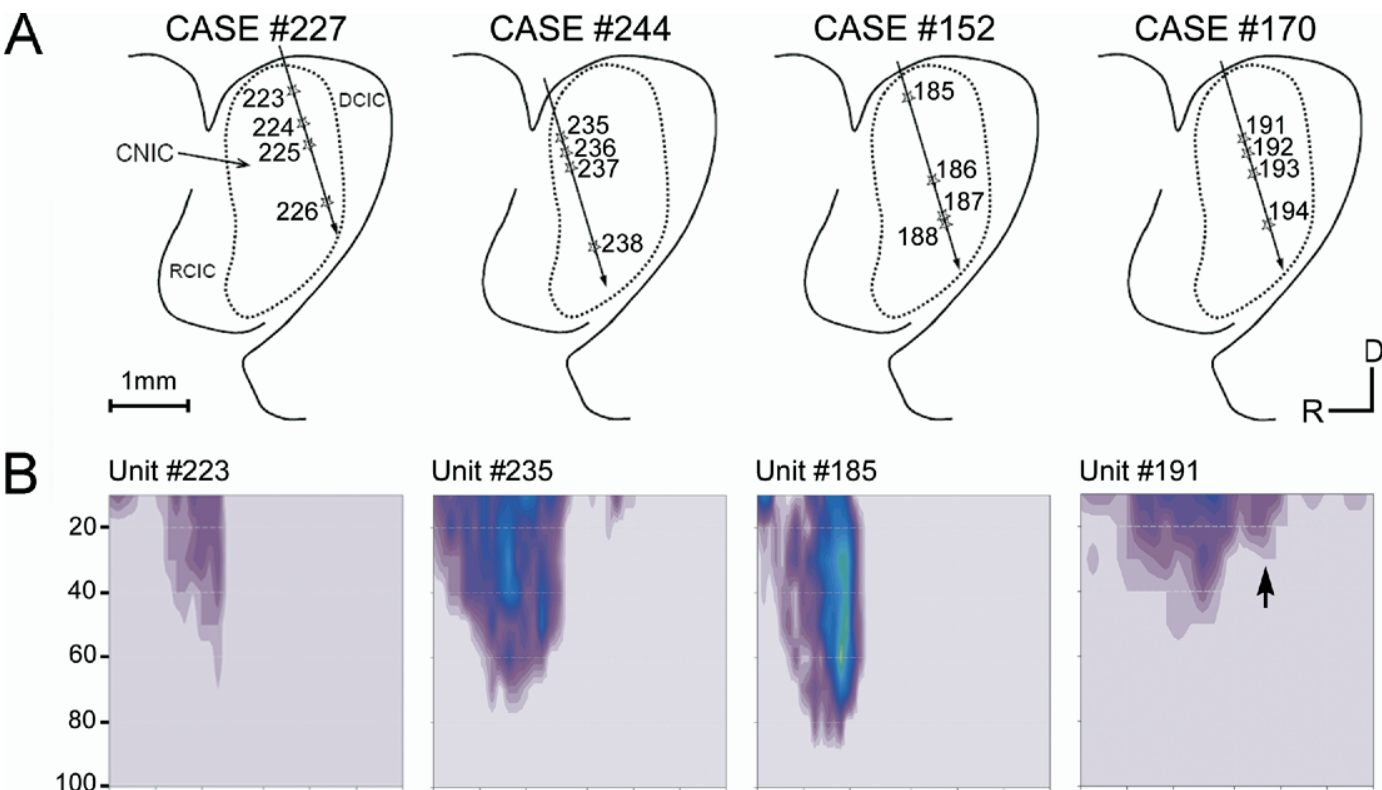

Unit \#191
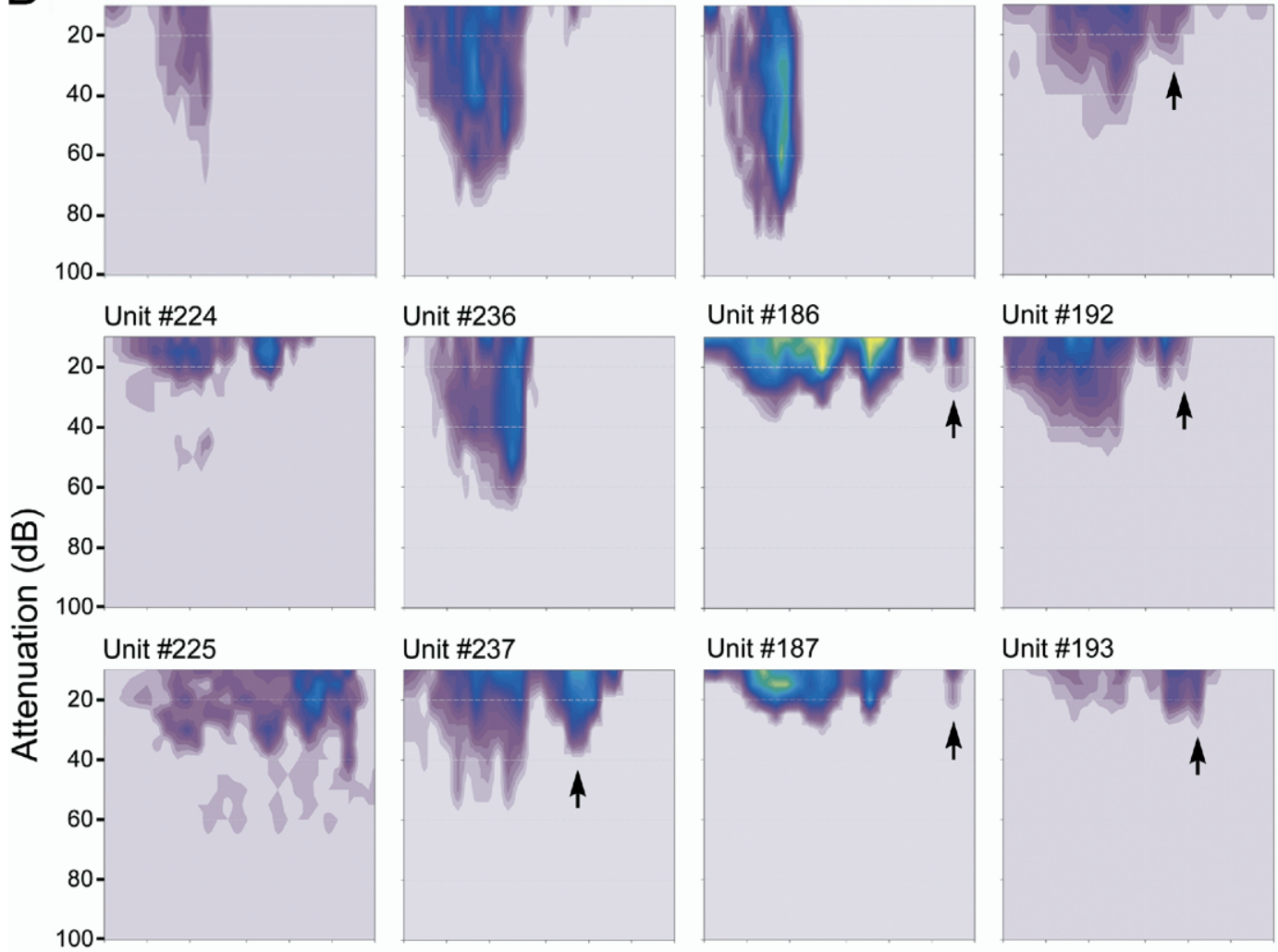

Unit \#192

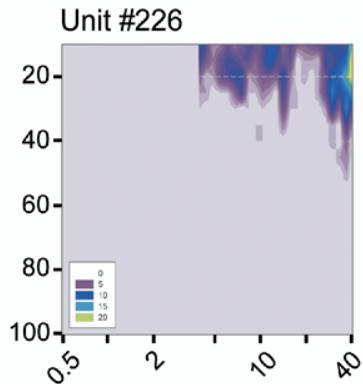

Unit \#238

Unit \#188

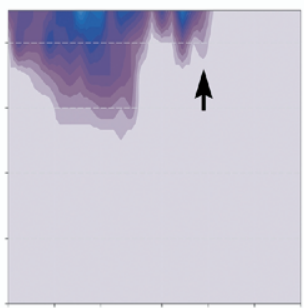

Unit \#193
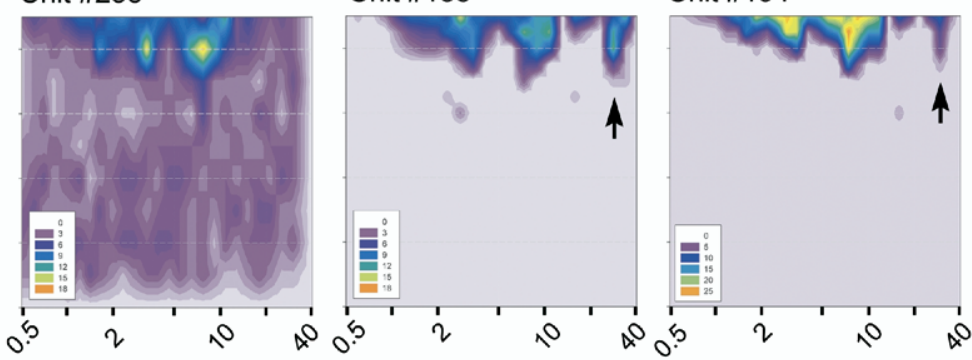

Frequency $(\mathrm{kHz})$

Fig. 6. SU responses after acoustic trauma. (A) Electrode location in four tracks across the CNIC of four exposed animals. The angle of penetration is the same in all cases $\left(10^{\circ}\right)$. Stars indicate the relative depth at which each SU was recorded. Scale bar $=1 \mathrm{~mm}$. (B) Example SU FRAs of 16 neurons recorded in the same four exposed animals. BF thresholds increase as the electrode advances through the CNIC. Most of the FRAs from mid-high frequency neurons exhibit a secondary peak (arrows) that represents the original BF remaining after the acoustic trauma. FRAs in the lesioned area also show an increase in spontaneous activity as a consequence of the acoustic insult.

(60-70 dB SPL. e.g. Fig. 6; units \# 238, 186, 187, 188 and 194). A large proportion of FRAs recorded after an acous- tic trauma showed an increase in spontaneous activity rate (55.6\%, e.g. Fig. 6; units \# 224, 225 and 238). 

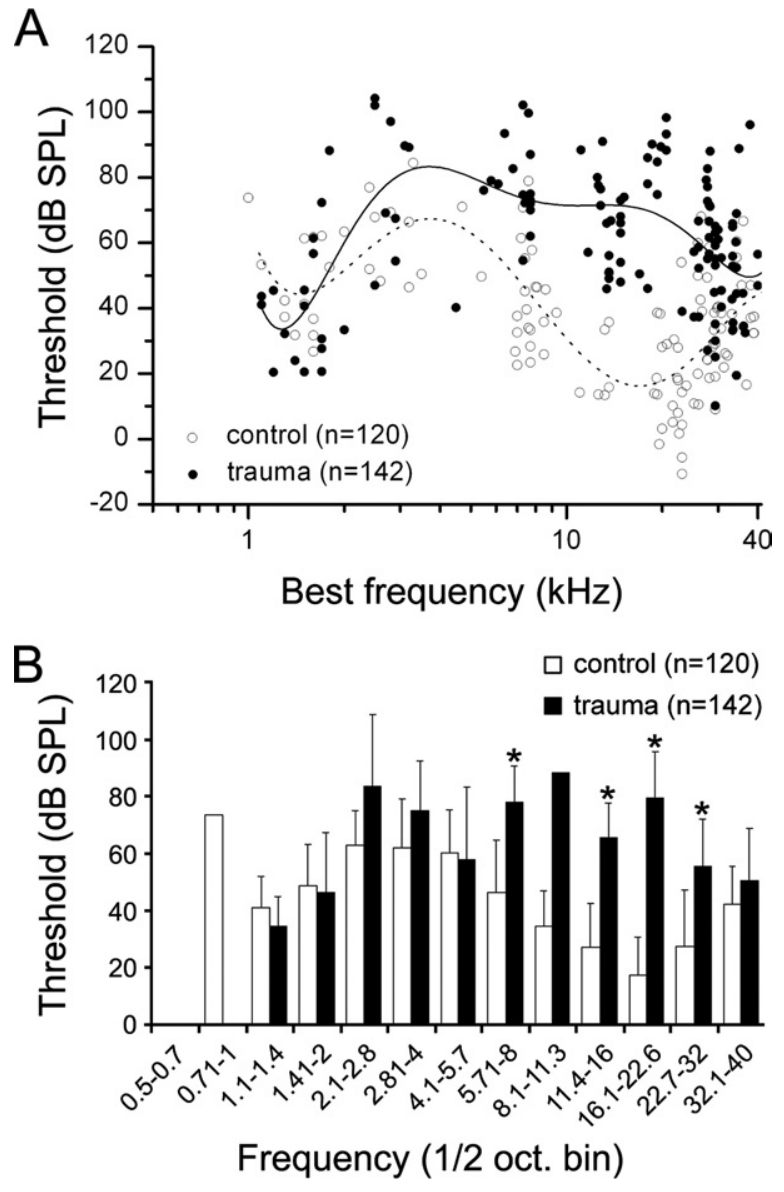

Fig. 7. Distribution of SU thresholds in control and traumatized animals as a function of their BFs. (A) Thresholds in a population of 120 control SUs (open circles) and their mean values (discontinuous line) are compared with a population of $142 \mathrm{SU}$ threshold values after acoustic trauma (filled circles) and their mean (solid line). (B) Histogram for SU response thresholds in lesioned animals (black bars), compared with thresholds in normal animals (white bars) in [1/2] octave frequency bins. Asterisks indicate significance level of those cases in which trauma values were shown by $t$-tests to be significantly different from normal values ( ${ }^{*} P<0.01$ )

The neuronal response thresholds can be obtained from the SU FRAs. Fig. 7A shows a plot of thresholds vs. BF for the control (open circles, $n=120$ ) and traumatized (filled circles, $n=142$ ) animals. The distribution of thresholds from these two populations significantly differs over the range $4-25 \mathrm{kHz}$, while thresholds obtained from lower and higher frequencies overlap. Fig. 7B shows a histogram of mean thresholds at BF in [1/2] octave bins for the control and traumatized SUs. The range of frequencies between 8.1-32 kHz exhibits the most sensitive thresholds (Fig. 7B; white bars). We observed a statistically significant increase in thresholds ( $t$-test, $P<0.01$ ) from the $5.71-8 \mathrm{kHz}$ bin to $32 \mathrm{kHz}$ as a consequence of the acoustic insult (Fig. 7B; black bars). From $32 \mathrm{kHz}$ up to the highest frequency tested $(40 \mathrm{kHz}) \mathrm{SU}$ thresholds did not show a significant increase. Following the acoustic trauma, SUs showed lower thresholds than the control in the $1.1-2 \mathrm{kHz}$ region although this difference was not statistically significant.
Comparison with the previous description of the FRA shapes demonstrates that they differ significantly from the normal FRA shapes in many respects. One hypothesis is that the additional frequency peaks observed above BF may reflect the original tuning sensitivity of the neuron prior to the acoustic damage, and that the resulting FRA observed after noise exposure may simply reflect the remainder of the low frequency tail of units with higher BF, as expected from their location deep in the IC. In order to determine whether the acoustic trauma mainly damages the most sensitive region of the FRA, i.e. the $B F$ region with low threshold, we pooled a group of normal high frequency $(>20 \mathrm{kHz}$ ) FRAs. The resulting normalized FRA interpolation, based on a sum of 20 control FRAs is shown in Fig. 8A. Fig. 8B shows the normalized FRA interpolation of 31 FRAs recorded after acoustic trauma (10 FRAs from two animals exposed to $5 \mathrm{kHz}$ and 21 FRAs from four animals exposed $8 \mathrm{kHz}$ ). The pathologic group of FRAs was subtracted from the control FRA pool (Fig. 8C). The dotted lines in Fig. 8C delimit significant differences (Mann-Whitney tests, $P<0.01$ ) in the response between acoustic trauma and controls, and demonstrate that the most sensitive $V$-shaped region (the $B F$ region) of the normal FRAs disappears, so only the less sensitive region of the "low frequency tails" are maintained. Furthermore, the subtraction shows an irregular area with one or more frequency peaks, which resemble the individual shapes seen in the traumatized FRAs shown in Fig. 6B.

\section{DISCUSSION}

The present account demonstrates that noise-induced hearing loss produces a persistent reorganization of the tonotopic map in the IC of adult rats. This reorganization shows expansions of frequency representations across the IC. At the single cell level, FRAs also show a significant increase in their threshold and spontaneous activity following acoustic trauma. These results suggest that the changes may be passive and not attributable to a dynamic frequency reorganization similar to that seen in A1. Furthermore, our results suggest that the IC machinery (at least in the rat) has a limited capability for long-term recovery of normal frequency coding function after severe acoustic trauma. Other changes observed in the response properties of the IC neurons following acoustic trauma, such as the increase in spontaneous activity, could reflect some forms of plastic changes due to an altered balance in the excitation-inhibition ratio not explored here (Abbott et al., 1999; Milbrandt et al., 2000; Mossop et al., 2000).

\section{Definition of plasticity}

Before we discuss the limitations of our data and relate them to a functional context, it is important to define "plasticity" as this term is one of the most abused words in neuroscience (Holloway, 2003; Parks and Rubel, 2004). It has been applied to a broad range of phenomena such as recovery of function after injury, adult neurogenesis, experience-dependent reorganization of cortical sensory maps, synaptic changes associated with learning, etc. Used 

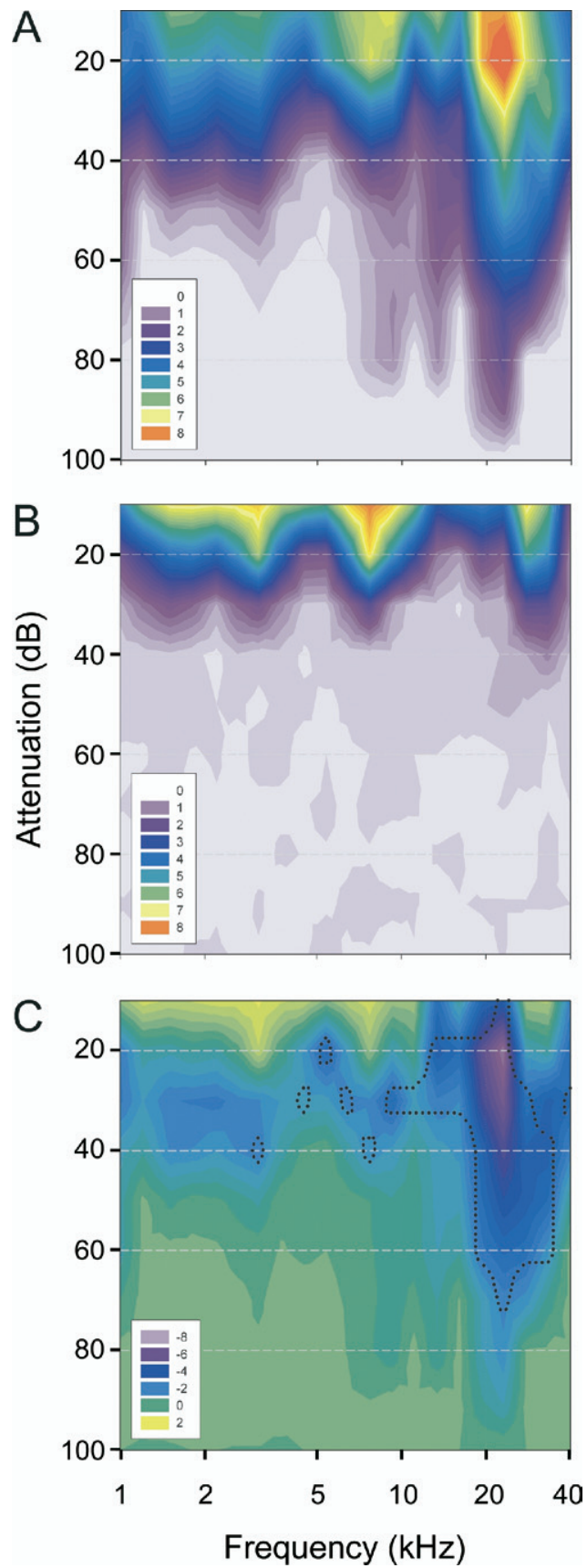

Fig. 8. Effect of acoustic trauma in SU FRAs. (A, B) Averaged high frequency $(>20 \mathrm{kHz})$ FRAs across control $(n=20)$ and acoustic trauma group $(n=31)$. Color scale indicates mean number of spikes fired in response to two stimulus presentations. (C) Graphical representation of differences between exposed and control groups in terms of mean firing rate per frequency-intensity bin. Dotted line delimits the areas in which the responses are significantly different $(P<0.01$, Mann-Whitney test).

alone, plasticity is a purely descriptive term and often rather vague (Calford, 2002). Tsukahara (1981) defined synaptic plasticity as "any persistent change in the functional properties of single neurons or neuronal aggregates." The use of the term "functional properties" serves to indicate that not all changes in neuronal responsiveness constitute cases of plasticity. For example, the response of a cortical or subcortical neuron in any sensory system might change (increase or decrease in magnitude) as a function of an arousal state or of other variables having a general influence on brain excitability (Irvine and Wright, 2005). These types of generalized changes are not evidence of plasticity without any change in the neuron's stimulus selectivity. For a change to be considered a manifestation of plasticity it must involve some kind of active mechanism or process that is initiated or triggered by the change in input, and not be explicable as a direct reflection of the altered input. Such active processes might involve, e.g. changes in the number or the efficacy of synapses or changes in intrinsic neuronal characteristics, either at the level of the neuron from which recordings are made or in neuron(s) in the pathways from which its input is derived. However, the distinction between active and passive processes is not a simple matter as discussed in detail elsewhere (see Calford, 2002; Irvine and Wright, 2005). In this manuscript, we adopt the definition of physiological plasticity as changes in neuronal stimulus selectivity and/or in the associated functional organization of populations of neurons, which are not explicable in terms of general changes in excitability or as passive reflections of changes in input (Irvine and Wright, 2005).

\section{Methodological considerations and limitations}

We exposed adult rats to pure tones at 110-121 dB SPL for durations ranging from 3 to $16 \mathrm{~h}$ and evaluated the resulting hearing losses by means of CAP audiograms. We did not perform histological examinations of the cochleae to assess the resulting structural damage of the hair cells and adjacent tissues. However, the acoustic trauma that we employed is very similar (or longer) to that used in previous studies (Heinz and Young, 2004; Liberman and Dodds, 1984a,b, 1987; Liberman and Kiang, 1984; Pettigrew et al., 1984; Heinz and Young, 2004) including those using rats as experimental model (Chen and Fechter, 2003; Fechter et al., 1998, 2000; Michler and Illing, 2002, 2003; Milbrandt et al., 2000; Kaltenbach and Zhang, 2007); therefore, it is reasonable to suggest that the levels of structural hair cell damage resulting from this study would be similar (or even more dramatic) to previously reported cases.

Originally, we intended to produce punctate lesions similar to those produced by mechanical lesions of the cochlea (Irvine et al., 2003; Rajan and Irvine, 1998b; Snyder et al., 2000; Snyder and Sinex, 2002). However, the intensity level of the traumatizing tone used here almost always resulted in much more profound damage over a wider frequency area than in the case of the mechanical lesions. This damage was not restricted to a frequency range of approximately half octave above the frequency of the trauma (Cody and Johnstone, 1981). In most cases, we also observed a second clear lesion in the high-frequency region which must be located at or near the hook of the cochlea. This is consistent with previous histopathological studies in other species which showed narrowband exposures led to two lesion foci (Fried et al., 1976; Liber- 
man and Kiang, 1978; Liberman and Dodds, 1987; Ou et al., 2000; Wang et al., 2002b). The net result was that we obtained a very severe ( $>30 \mathrm{~dB}$ PTS) and broadband frequency lesion in most of our cases (Fig. 2). Above a given critical sound pressure level, noise-induced hearing loss increased very rapidly. To attempt to create more restricted lesions, we exposed a group of four additional animals to a relatively low intensity $(13 \mathrm{kHz}$ at about 100 $\mathrm{dB}$ SPL for $24 \mathrm{~h}$ ). However, using this protocol, we did not observe any sign of PTS and the IC responses recorded (151 days postexposure) were comparable to those found in the control cases with any functional damage (as expected from their normal CAP). These animals were therefore excluded from the subsequent analysis. This result is in agreement with a recent study (Tan et al., 2007) whose authors found that the effect of loud, but not traumatic sound (100 dB SPL) did not cause PTS or morphological damage of the hair cells. However these authors also showed a significant upregulation of the activity-dependent cytoskeletal protein (Arg3.1/arc) in the auditory cortex confirming recent findings (Mahlke and Wallhausser-Franke, 2004) and indicating a reciprocal expression of Arg3.1/arc following physiological and/or traumatic acoustic stimulation. Arg3.1/arc expression has been directly correlated with BDNF-induced plasticity changes (Yin et al., 1998; Ying et al., 2005) and is selectively altered during formation of activitydriven neuronal networks (Ramirez-Amaya et al., 2005). Thus, animals exposed to "non-traumatic" noise may develop some forms of neurochemical plasticity in the central auditory pathway (Tan et al., 2007). This is not surprising as tonotopic plasticity also takes place at the auditory cortex.

With identical animal exposures we observed a high degree of interanimal variability (even within the same litter). Unpredictable functional and structural changes of the cochlea after acoustic overexposures have also been noted in previous studies (Bohne et al., 1999; Holme and Steel, 1999, 2004; Wang et al., 2002b; Yoshida et al., 2000). This variability may be due to the normal genetic diversity that occurs across individuals, and could result in the markedly different susceptibility among animals observed in the control and experimental groups (Bohne et al., 1999; Holme and Steel, 1999, 2004; Wang et al., 2002b; Yoshida et al., 2000) (cf., CAP audiograms Figs. 1 and 2).

Another potential issue that may be considered and may have affected our results is the age of the animals we used. The inhibitory neurotransmitter GABA has been shown to be critically involved in shaping neuronal responses to simple and complex acoustic stimuli in the IC (Le Beau et al., 1996, 2001). Studies in the rat and human IC have suggested significant changes in functions related to GABA neurotransmission in the aged, including decreases in GABA content, GABA $A_{A}$ release, GABAergic neurons, glutamate decarboxylase enzymatic activity, and $\mathrm{GABA}_{\mathrm{B}}$ receptor binding (Bledsoe et al., 1995; Milbrandt et al., 2000; Suneja et al., 1998b, 2005). Such changes within the IC may affect the general response of IC neurons following acoustic trauma (Milbrandt et al., 2000) and further studies on the modification on GABA would help to better understand the physiological changes that we observed.

\section{Comparison with previous studies}

To our knowledge, there are no similar studies regarding the chronic effect of acoustic trauma on the neuronal responses of the IC. Previous studies seeking plasticity in the IC have been based on mechanical lesions of the cochlea (Irvine et al., 2003), lesions of the spiral ganglion cells (Snyder et al., 2000; Snyder and Sinex, 2002), neonatal ototoxic lesions of the basal cochlea (Harrison et al., 1996) or the immediate (acute) effect after acoustic trauma (Salvi et al., 1990; Wang et al., 1996, 2002a). A direct comparison between these previous studies and ours is hampered by the use of different methodologies. In addition, the results of these previous studies are not totally in agreement. While the chronic studies carried out by Irvine et al. (2003) showed a limited capacity for plasticity with a patchy reorganization of the tonotopic map of the IC in cat, lesions of the spiral ganglion cells demonstrated that the FRAs in the IC undergo a rapid dynamic reorganization shortly after the lesion was produced (Snyder et al., 2000; Snyder and Sinex, 2002). We failed to find any sign of a dynamic plastic reorganization (in a way analogous to that seen in A1) in either the general tonotopic map of the IC or at the level of the individual FRAs. The differences between the studies might be accounted for in several ways, i.e. 1) lesion size, 2) temporary nature of the plastic changes in the $\mathrm{IC}, 3$ ) the locus in the auditory pathway where frequency coding or tonotopic plasticity will first emergence of and/or 4) the existence of a minimum plasticity threshold. First, our lesions were massive compared with those described above which were more limited or restricted to a very narrow frequency range (Irvine et al., 2003; Snyder et al., 2000; Snyder and Sinex, 2002). If the IC has a limited capability for restoring its functional machinery after noise trauma, there may be a critical amount of normally functioning IC tissue which needs to remain to compensate for the damaged region, and our massive lesions may have knocked out any possibility for recovery. Second, as pointed out by Snyder et al. (2000) it may be that the plastic changes that would compensate for the insult are immediate but temporary. Since we ignored the time course of any possible dynamic reorganization within the IC including the presence of a limited time-window or sensitive period it is possible our mapping and recordings were made outside of the temporal framework potentially needed for plasticity. Third, it may simply be that frequency coding plasticity emerges at higher centers in the auditory pathway (Harrison, 2001; Kamke et al., 2003; Kral, 2007; Kral and Tillein, 2006). Frequency map plasticity at the level of the auditory thalamus and cortex resulting from restricted unilateral cochlear lesions is well documented (Eggermont and Komiya, 2000; Kamke et al., 2003; Rajan et al., 1993; Rajan and Irvine, 1998b); the changes we observed in the tonotopic map of the IC and neuronal responses seen in the FRAs may simply reveal pseudoplastic processes explicable by the residual response hypothesis (Harris et al., 2005; Rajan and Irvine, 1998a). Our responses in the $\mathrm{IC}$ reveal changes in thresholds and tuning properties of multi- and SUs in the affected region; 
thresholds at BF are significantly higher than those expected for neurons at the same location in the normal IC. No clear evidence of BF retuning with normal thresholds was observed in the STC analysis (Fig. 5) or at the single cell level that would be compatible with the development of a dynamic reorganization. Instead, the responses seen at progressively more ventral (populated by mid- and high frequency neurons) regions of the IC seemed to reveal the remaining low frequency tails of these neurons (shown by the FRAs recorded in these areas; cf., Fig. 1C, asterisks and Fig. 6). Fourth, it has been suggested that to generate plasticity there must a PTS with hearing losses of $20 \mathrm{~dB}$ or more (Rajan, 2001), but perhaps, PTS far beyond this value (20-60 or more dBs, Fig. 2) combined with a very broad frequency lesion in most of the experiments (see above), impedes the development of plasticity and prevents the recovery of neuronal responses in the IC.

In summary, the acoustic trauma employed in our experiments induces cochlear lesions that result in a distinct reorganization of the tonotopic map and changes of the individual FRAs in the IC. However, this reorganization may not be due to a dynamic process. If we define plasticity in terms of retuning or the unmasking of inputs leading to a near normal response in the damaged area (for a detailed discussion on the definition of plasticity see (Calford et al., 1993; Irvine and Wright, 2005; Rajan, 2001), our results reveal the absence of plasticity in the auditory midbrain. Thus, this phenomenon may be largely lost in the mature animal compared with developing animals (Harrison et al., 1998). However, our data cannot rule out other forms of plasticity such as synaptic or molecular plasticity (Bauer et al., 2000; Brozoski et al., 2002; D'Sa et al., 2007; Kim et al., 2004; Milbrandt et al., 2000; Mossop et al., 2000; Potashner et al., 1997; Suneja et al., 1998a,b, 2005) and further studies will be necessary to fully address the effect of noise-induced hearing loss on IC responses. Furthermore, other molecular plastic changes may occur immediately after the lesion and/or for longer periods than those examined in our study (Snyder et al., 2000; Snyder and Sinex, 2002).

\section{Functional significance and speculations on clinical implications}

It has been recently demonstrated that long-term profound sensorineural hearing loss leads to severe loss of spiral ganglion cells and auditory nerve fibers which in turn effectively alters the representation and processing of sound in the auditory brain (Vollmer et al., 2007). Electrical stimulation using cochlear implants after long-term deafness results in significant increases in thresholds and marked degradation in spatial selectivity in the IC. This may explain the poor speech discrimination performance in cochlear implant users with congenital or very early-acquired deafness that are implanted as adults (Vollmer et al., 2005, 2007). These data are in general agreement with our findings.

Over the course of development, pro-apoptotic factors decrease and multiple neuroprotective mechanisms increase to protect mature neurons from stressful insults, making them less dependent on afferent input for survival
(Harris et al., 2005; Harris and Rubel, 2006). These authors have found many neurons that survived avoiding an apoptotic route despite suffering a great deafferentation. The adult brain faces two ostensibly paradoxical challenges: stability and plasticity. It must preserve the circuitry and synaptic organization necessary to maintain behavior and long-term memories while allowing circuits to adapt to environmental changes, learning and injury. As discussed very elegantly by Harris and Rubel (2006), the study of structural and functional plasticity has captivated and even obsessed the attention of neurobiologists over the past 50 years. It is now clear that an entire group of genes that promote neuronal stability is upregulated and occurs during the initial development of hearing (Harris et al., 2005). Thus, while behavioral plasticity is clearly important, stability may be an emerging property important for both conceptual and clinical reasons (Harris and Rubel, 2006; Mizrahi and Katz, 2003; Turrigiano and Nelson, 2004).

The results we present here also suggest that it may be important to maintain the stability of the neuronal circuitry in the IC since plasticity for frequency coding seems to be limited at the midbrain level. In fact, it is not clear what perceptual advantages are provided by plasticity. Plastic reorganization of the tonotopic map in cortex has been related to abnormal sensations (Eggermont and Komiya, 2000) including tinnitus (Muhlnickel et al., 1998) and has been suggested to be more problematic than beneficial (Eggermont, 2005). In the future, it may be more effective to look for a treatment of noise-induced hearing loss that emphasizes stability rather than focusing solely on plasticity.

Acknowledgments-We thank Dr. Alan Palmer for teaching us the CAP technique and Dr. Charlie Liberman for the details provided on the construction of the small reverberant sound-exposure box with non-parallel sides. We also thank Drs. Lucy Anderson, Nell Cant and Alan Palmer for their critical comments and suggestions on a previous version of the manuscript.

Financial support was provided by the Spanish MEC (BFU200600572) to M.S.M. and JCYL (SA 007C05) to M.A.M. M.A.I. was supported by a JCYL predoctoral fellowship.

\section{REFERENCES}

Abbott SD, Hughes LF, Bauer CA, Salvi R, Caspary DM (1999) Detection of glutamate decarboxylase isoforms in rat inferior colliculus following acoustic exposure. Neuroscience 93:1375-1381.

Anderson LA, Malmierca MS, Wallace MN, Palmer AR (2006) Evidence for a direct, short latency projection from the dorsal cochlear nucleus to the auditory thalamus in the guinea pig. Eur $\mathrm{J}$ Neurosci 24:491-498.

Bauer CA, Brozoski TJ, Holder TM, Caspary DM (2000) Effects of chronic salicylate on GABAergic activity in rat inferior colliculus. Hear Res 147:175-182.

Bledsoe SC Jr, Nagase S, Miller JM, Altschuler RA (1995) Deafnessinduced plasticity in the mature central auditory system. Neuroreport 7:225-229.

Bohne BA, Harding GW, Nordmann AS, Tseng CJ, Liang GE, Bahadori RS (1999) Survival-fixation of the cochlea: a technique for following time-dependent degeneration and repair in noise-exposed chinchillas. Hear Res 134:163-178.

Brozoski TJ, Bauer CA, Caspary DM (2002) Elevated fusiform cell activity in the dorsal cochlear nucleus of chinchillas with psychophysical evidence of tinnitus. J Neurosci 22:2383-2390. 
Buonomano DV, Merzenich MM (1998) Cortical plasticity: from synapses to maps. Annu Rev Neurosci 21:149-186.

Calford MB (2002) Dynamic representational plasticity in sensory cortex. Neuroscience 111:709-738.

Calford MB, Rajan R, Irvine DR (1993) Rapid changes in the frequency tuning of neurons in cat auditory cortex resulting from pure-toneinduced temporary threshold shift. Neuroscience 55:953-964.

Chen GD, Fechter LD (2003) The relationship between noise-induced hearing loss and hair cell loss in rats. Hear Res 177:81-90.

Cody AR, Johnstone BM (1981) Acoustic trauma: single neuron basis for the "half-octave shift". J Acoust Soc Am 70:707-711.

D'Sa C, Gross J, Francone VP, Morest DK (2007) Plasticity of synaptic endings in the cochlear nucleus following noise-induced hearing loss is facilitated in the adult FGF2 overexpressor mouse. Eur J Neurosci 26:666-680.

de Villers-Sidani E, Chang EF, Bao S, Merzenich MM (2007) Critical period window for spectral tuning defined in the primary auditory cortex (A1) in the rat. J Neurosci 27:180-189.

Eggermont JJ (2005) Tinnitus: neurobiological substrates. Drug Discov Today 10:1283-1290.

Eggermont JJ, Komiya $H$ (2000) Moderate noise trauma in juvenile cats results in profound cortical topographic map changes in adulthood. Hear Res 142:89-101.

Fechter LD, Chen GD, Rao D, Larabee J (2000) Predicting exposure conditions that facilitate the potentiation of noise-induced hearing loss by carbon monoxide. Toxicol Sci 58:315-323.

Fechter LD, Liu Y, Herr DW, Crofton KM (1998) Trichloroethylene ototoxicity: evidence for a cochlear origin. Toxicol Sci 42:28-35.

Fried MP, Dudek SE, Bohne BA (1976) Basal turn cochlear lesions following exposure to low-frequency noise. Trans Sect Otolaryngol Am Acad Ophthalmol Otolaryngol 82:285-298.

Gilbert CD (1998) Adult cortical dynamics. Physiol Rev 78:467-485.

Harris JA, Hardie NA, Bermingham-McDonogh O, Rubel EW (2005) Gene expression differences over a critical period of afferentdependent neuron survival in the mouse auditory brainstem. J Comp Neurol 493:460-474.

Harris JA, Rubel EW (2006) Afferent regulation of neuron number in the cochlear nucleus: cellular and molecular analyses of a critical period. Hear Res 216-217:127-137.

Harrison RV (2001) Age-related tonotopic map plasticity in the central auditory pathways. Scand Audiol Suppl (53):8-14.

Harrison RV, Ibrahim D, Mount RJ (1998) Plasticity of tonotopic maps in auditory midbrain following partial cochlear damage in the developing chinchilla. Exp Brain Res 123:449-460.

Harrison RV, Kakigi A, Hirakawa H, Harel N, Mount RJ (1996) Tonotopic mapping in auditory cortex of the chinchilla. Hear Res 100:157-163.

Harrison RV, Stanton SG, Ibrahim D, Nagasawa A, Mount RJ (1993a) Neonatal cochlear hearing loss results in developmental abnormalities of the central auditory pathways. Acta Otolaryngol 113: 296-302.

Harrison RV, Stanton SG, Nagasawa A, Ibrahim D, Mount RJ (1993b) The effects of long-term cochlear hearing loss on the functional organization of central auditory pathways. J Otolaryngol 22:4-11.

Harrison RV, Stanton SG, Mount RJ (1995) Effects of chronic cochlear damage on threshold and frequency tuning of neurons in Al auditory cortex. Acta Otolaryngol Suppl 519:30-35.

Heinz MG, Young ED (2004) Response growth with sound level in auditory-nerve fibers after noise-induced hearing loss. J Neurophysiol 91:784-795.

Hernandez O, Espinosa N, Perez-Gonzalez D, Malmierca MS (2005) The inferior colliculus of the rat: a quantitative analysis of monaural frequency response areas. Neuroscience 132:203-217.

Holloway M (2003) The mutable brain. Sci Am 289:79-85.

Holme RH, Steel KP (2004) Progressive hearing loss and increased susceptibility to noise-induced hearing loss in mice carrying a Cdh23 but not a Myo7a mutation. J Assoc Res Otolaryngol 5:66-79.
Holme RH, Steel KP (1999) Genes involved in deafness. Curr Opin Genet Dev 9:309-314.

Irvine DR (2007) Auditory cortical plasticity: does it provide evidence for cognitive processing in the auditory cortex? Hear Res 229: $158-170$.

Irvine DR, Rajan R, Smith S (2003) Effects of restricted cochlear lesions in adult cats on the frequency organization of the inferior colliculus. J Comp Neurol 467:354-374.

Irvine DR, Wright BA (2005) Plasticity of spectral processing. Int Rev Neurobiol 70:435-472.

Izquierdo MA, Cristaudo S, Merchan M, Malmierca MS (2006) Noiseinduced reorganization of the tonotopic map in the inferior colliculus of the rat. ARO abstract: pp 701.

Izquierdo MA, Merchan M, Malmierca MS (2007) Changes in the tonotopic map of the inferior colliculus of the rat following an acoustic trauma. IBRO abstract: pp 209.

Kaas JH (2000) The reorganization of somatosensory and motor cortex after peripheral nerve or spinal cord injury in primates. Prog Brain Res 128:173-179.

Kaltenbach JA, Czaja JM, Kaplan CR (1992) Changes in the tonotopic map of the dorsal cochlear nucleus following induction of cochlear lesions by exposure to intense sound. Hear Res 59:213-223.

Kaltenbach JA, Zhang J (2007) Intense sound-induced plasticity in the dorsal cochlear nucleus of rats: evidence for cholinergic receptor upregulation. Hear Res 226:232-243.

Kamke MR, Brown M, Irvine DR (2003) Plasticity in the tonotopic organization of the medial geniculate body in adult cats following restricted unilateral cochlear lesions. J Comp Neurol 459:355-367.

Kim JJ, Gross J, Morest DK, Potashner SJ (2004) Quantitative study of degeneration and new growth of axons and synaptic endings in the chinchilla cochlear nucleus after acoustic overstimulation. J Neurosci Res 77:829-842.

Kral A (2007) Unimodal and cross-modal plasticity in the "deaf" auditory cortex. Int J Audiol 46:479-493.

Kral A, Tillein J (2006) Brain plasticity under cochlear implant stimulation. Adv Otorhinolaryngol 64:89-108.

Le Beau FE, Rees A, Malmierca MS (1996) Contribution of GABA- and glycine-mediated inhibition to the monaural temporal response properties of neurons in the inferior colliculus. J Neurophysiol 75:902-919.

LeBeau FE, Malmierca MS, Rees A (2001) lontophoresis in vivo demonstrates a key role for $\mathrm{GABA}(\mathrm{A})$ and glycinergic inhibition in shaping frequency response areas in the inferior colliculus of guinea pig. J Neurosci 21:7303-7312.

Liberman MC, Dodds LW (1987) Acute ultrastructural changes in acoustic trauma: serial-section reconstruction of stereocilia and cuticular plates. Hear Res 26:45-64.

Liberman MC, Dodds LW (1984a) Single-neuron labeling and chronic cochlear pathology. II. Stereocilia damage and alterations of spontaneous discharge rates. Hear Res 16:43-53.

Liberman MC, Dodds LW (1984b) Single-neuron labeling and chronic cochlear pathology. III. Stereocilia damage and alterations of threshold tuning curves. Hear Res 16:55-74.

Liberman MC, Gao WY (1995) Chronic cochlear de-efferentation and susceptibility to permanent acoustic injury. Hear Res 90:158-168.

Liberman MC, Kiang NY (1978) Acoustic trauma in cats. Cochlear pathology and auditory-nerve activity. Acta Otolaryngol Suppl 358:1-63.

Liberman MC, Kiang NY (1984) Single-neuron labeling and chronic cochlear pathology. IV. Stereocilia damage and alterations in rateand phase-level functions. Hear Res 16:75-90.

Loftus WC, Malmierca MS, Bishop DC, Oliver DL (2008) The cytoarchitecture of the inferior colliculus revisited: a common organization of the lateral cortex in rat and cat. Neuroscience 154:196-205.

Mahlke C, Wallhausser-Franke E (2004) Evidence for tinnitus-related plasticity in the auditory and limbic system, demonstrated by arg3.1 and c-fos immunocytochemistry. Hear Res 195:17-34. 
Malmierca MS (2003) The structure and physiology of the rat auditory system: an overview. Int Rev Neurobiol 56:147-211.

Malmierca MS, Blackstad TW, Osen KK, Karagulle T, Molowny RL (1993) The central nucleus of the inferior colliculus in rat: a Golgi and computer reconstruction study of neuronal and laminar structure. J Comp Neurol 333:1-27.

Malmierca MS, Cristaudo S, Perez-Gonzalez D, Hernandez O, Covey E, Oliver DL (2006) Stepwise organization of tonotopy in the inferior colliculus of the rat: Electrophysiological evidence. ARO Abstr 29:146.

Malmierca MS, Hernandez O, Falconi A, Lopez-Poveda EA, Merchan M, Rees A (2003) The commissure of the inferior colliculus shapes frequency response areas in rat: an in vivo study using reversible blockade with microinjection of kynurenic acid. Exp Brain Res 153:522-529.

Malmierca MS, Hernandez O, Rees A (2005) Intercollicular commissural projections modulate neuronal responses in the inferior colliculus. Eur J Neurosci 21:2701-2710.

Malmierca MS, Izquierdo MA, Cristaudo S, Perez-Gonzalez D, Hernandez O, Covey E, Oliver DL (2008) A discontinuous tonotopic organization in the inferior colliculus of the rat. J Neurosci 28:4767-4776.

Malmierca MS, Merchan MA, Henkel CK, Oliver DL (2002) Direct projections from cochlear nuclear complex to auditory thalamus in the rat. J Neurosci 22:10891-10897.

Malmierca MS, Seip KL, Osen KK (1995) Morphological classification and identification of neurons in the inferior colliculus: a multivariate analysis. Anat Embryol (Berl) 191:343-350.

Merryll EG, Ainswoth A (1972) Glass-coated platinum coated tungsten microelectrodes. Med Biol Eng 10:662-672.

Merzenich MM, Reid MD (1974) Representation of the cochlea within the inferior colliculus of the cat. Brain Res 77:397-415.

Michler SA, Illing RB (2002) Acoustic trauma induces reemergence of the growth- and plasticity-associated protein GAP-43 in the rat auditory brainstem. J Comp Neurol 451:250-266.

Michler SA, Illing RB (2003) Molecular plasticity in the rat auditory brainstem: modulation of expression and distribution of phosphoserine, phospho-CREB and TrkB after noise trauma. Audiol Neurootol 8:190-206.

Milbrandt JC, Holder TM, Wilson MC, Salvi RJ, Caspary DM (2000) GAD levels and muscimol binding in rat inferior colliculus following acoustic trauma. Hear Res 147:251-260.

Miller JD, Watson CS, Covell WP (1963) Deafening effects of noise on the cat. Acta Otolaryngol (Stockh) 176:1-91.

Mizrahi A, Katz LC (2003) Dendritic stability in the adult olfactory bulb. Nat Neurosci 6:1201-1207.

Mossop JE, Wilson MJ, Caspary DM, Moore DR (2000) Down-regulation of inhibition following unilateral deafening. Hear Res 147: 183-187.

Muhlnickel W, Elbert T, Taub E, Flor H (1998) Reorganization of auditory cortex in tinnitus. Proc Natl Acad Sci U S A 95: 10340-10343

Nakahara H, Zhang LI, Merzenich MM (2004) Specialization of primary auditory cortex processing by sound exposure in the "critical period." Proc Natl Acad Sci U S A 101:7170-7174.

Ou HC, Bohne BA, Harding GW (2000) Noise damage in the C57BL/ CBA mouse cochlea. Hear Res 145:111-122.

Parks TN, Rubel EW (2004) Overview: development and plasticity of the central auditory system. In: Plasticity of the auditrory system (Parks TN, Rubel EW, Fay RR, Popper AN, eds), pp 1-7. New York: Springer.

Perez-Gonzalez D, Malmierca MS, Covey E (2005) Novelty detector neurons in the mammalian auditory midbrain. Eur $\mathrm{J}$ Neurosci 22:2879-2885.

Perez-Gonzalez D, Malmierca MS, Moore JM, Hernandez O, Covey E (2006) Duration selective neurons in the inferior colliculus of the rat: topographic distribution and relation of duration sensitivity to other response properties. J Neurophysiol 95:823-836.
Pettigrew AM, Liberman MC, Kiang NY (1984) Click-evoked gross potentials and single-unit thresholds in acoustically traumatized cats. Ann Otol Rhinol Laryngol Suppl 112:83-96.

Potashner SJ, Suneja SK, Benson CG (1997) Regulation of D-aspartate release and uptake in adult brain stem auditory nuclei after unilateral middle ear ossicle removal and cochlear ablation. Exp Neurol 148:222-235.

Rajan R (1998) Receptor organ damage causes loss of cortical surround inhibition without topographic map plasticity. Nat Neurosci 1:138-143.

Rajan R (2001) Plasticity of excitation and inhibition in the receptive field of primary auditory cortical neurons after limited receptor organ damage. Cereb Cortex 11:171-182.

Rajan R, Irvine DR (1998a) Absence of plasticity of the frequency map in dorsal cochlear nucleus of adult cats after unilateral partial cochlear lesions. J Comp Neurol 399:35-46.

Rajan R, Irvine DR (1998b) Neuronal responses across cortical field A1 in plasticity induced by peripheral auditory organ damage. Audiol Neurootol 3:123-144.

Rajan R, Irvine DR, Cassell JF (1991) Normative N1 audiogram data for the barbiturate-anaesthetised domestic cat. Hear Res 53: 153-158.

Rajan R, Irvine DR, Wise LZ, Heil P (1993) Effect of unilateral partial cochlear lesions in adult cats on the representation of lesioned and unlesioned cochleas in primary auditory cortex. J Comp Neurol 338:17-49.

Ramirez-Amaya V, Vazdarjanova A, Mikhael D, Rosi S, Worley PF, Barnes CA (2005) Spatial exploration-induced Arc mRNA and protein expression: evidence for selective, network-specific reactivation. J Neurosci 25:1761-1768.

Rees A, Sarbaz A, Malmierca MS, Le Beau FE (1997) Regularity of firing of neurons in the inferior colliculus. J Neurophysiol 77: 2945-2965.

Robertson D, Irvine DR (1989) Plasticity of frequency organization in auditory cortex of guinea pigs with partial unilateral deafness. J Comp Neurol 282:456-471.

Salvi RJ, Saunders SS, Gratton MA, Arehole S, Powers N (1990) Enhanced evoked response amplitudes in the inferior colliculus of the chinchilla following acoustic trauma. Hear Res 50:245-257.

Schmid LM, Rosa MG, Calford MB, Ambler JS (1996) Visuotopic reorganization in the primary visual cortex of adult cats following monocular and binocular retinal lesions. Cereb Cortex 6:388-405.

Schreiner CE, Langner G (1997) Laminar fine structure of frequency organization in auditory midbrain. Nature 388:383-386.

Schwaber MK, Garraghty PE, Kaas JH (1993) Neuroplasticity of the adult primate auditory cortex following cochlear hearing loss. Am J Otol 14:252-258.

Snyder RL, Sinex DG (2002) Immediate changes in tuning of inferior colliculus neurons following acute lesions of cat spiral ganglion. J Neurophysiol 87:434-452.

Snyder RL, Sinex DG, McGee JD, Walsh EW (2000) Acute spiral ganglion lesions change the tuning and tonotopic organization of cat inferior colliculus neurons. Hear Res 147:200-220.

Suneja SK, Benson CG, Potashner SJ (1998a) Glycine receptors in adult guinea pig brain stem auditory nuclei: regulation after unilateral cochlear ablation. Exp Neurol 154:473-488.

Suneja SK, Potashner SJ, Benson CG (1998b) Plastic changes in glycine and GABA release and uptake in adult brain stem auditory nuclei after unilateral middle ear ossicle removal and cochlear ablation. Exp Neurol 151:273-288.

Suneja SK, Yan L, Potashner SJ (2005) Regulation of NT-3 and BDNF levels in guinea pig auditory brain stem nuclei after unilateral cochlear ablation. J Neurosci Res 80:381-390.

Tan J, Ruttiger L, Panford-Walsh R, Singer W, Schulze H, Kilian SB, Hadjab S, Zimmermann U, Kopschall I, Rohbock K, Knipper M (2007) Tinnitus behavior and hearing function correlate with the reciprocal expression patterns of BDNF and Arg3.1/arc in auditory neurons following acoustic trauma. Neuroscience 145:715-726. 
Tsukahara N (1981) Synaptic plasticity in the mammalian central nervous system. Annu Rev Neurosci 4:351-379.

Turrigiano GG, Nelson SB (2004) Homeostatic plasticity in the developing nervous system. Nat Rev Neurosci 5:97-107.

Vollmer M, Beitel RE, Snyder RL, Leake PA (2007) Spatial selectivity to intracochlear electrical stimulation in the inferior colliculus is degraded following long-term deafness in cats. J Neurophysiol, in press.

Vollmer M, Leake PA, Beitel RE, Rebscher SJ, Snyder RL (2005) Degradation of temporal resolution in the auditory midbrain after prolonged deafness is reversed by electrical stimulation of the cochlea. J Neurophysiol 93:3339-3355.

Wang J, Ding D, Salvi RJ (2002a) Functional reorganization in chinchilla inferior colliculus associated with chronic and acute cochlear damage. Hear Res 168:238-249.

Wang Y, Hirose K, Liberman MC (2002b) Dynamics of noise-induced cellular injury and repair in the mouse cochlea. J Assoc Res Otolaryngol 3:248-268.

Wang J, Salvi RJ, Powers N (1996) Plasticity of response properties of inferior colliculus neurons following acute cochlear damage. J Neurophysiol 75:171-183.
Willott JF (1984) Changes in frequency representation in the auditory system of mice with age-related hearing impairment. Brain Res 309:159-162.

Willott JF, Aitkin LM, McFadden SL (1993) Plasticity of auditory cortex associated with sensorineural hearing loss in adult C57BL/6J mice. J Comp Neurol 329:402-411.

Willott JF, Bross LS (1996) Morphological changes in the anteroventral cochlear nucleus that accompany sensorineural hearing loss in DBA/2J and C57BL/6J mice. Brain Res Dev Brain Res 91: 218-226.

Yin Q, Kemp GJ, Frostick SP (1998) Neurotrophins, neurones and peripheral nerve regeneration. J Hand Surg [Br] 23:433-437.

Ying Z, Roy RR, Edgerton VR, Gomez-Pinilla F (2005) Exercise restores levels of neurotrophins and synaptic plasticity following spinal cord injury. Exp Neurol 193:411-419.

Yoshida N, Hequembourg SJ, Atencio CA, Rosowski JJ, Liberman MC (2000) Acoustic injury in mice: $129 / \mathrm{SvEv}$ is exceptionally resistant to noise-induced hearing loss. Hear Res 141:97-106.

Zhang LI, Bao S, Merzenich MM (2001) Persistent and specific influences of early acoustic environments on primary auditory cortex. Nat Neurosci 4:1123-1130. 


\title{
A Discontinuous Tonotopic Organization in the Inferior Colliculus of the Rat
}

\author{
Manuel S. Malmierca, ${ }^{1,2}$ Marco A. Izquierdo, ${ }^{1,2}$ Salvatore Cristaudo, ${ }^{1,2}$ Olga Hernández, ${ }^{1,2}$ David Pérez-González, ${ }^{1,2}$ \\ Ellen Covey, ${ }^{2,3}$ and Douglas L. Oliver ${ }^{2,4}$ \\ ${ }^{1}$ Auditory Neurophysiology Unit, Laboratory for the Neurobiology of Hearing, Faculty of Medicine and 2Institute of Neuroscience of Castilla y León, \\ University of Salamanca, 37007 Salamanca, Spain, ${ }^{3}$ Department of Psychology, University of Washington, Seattle, Washington 98195, and ${ }^{4}$ Department of \\ Neuroscience, University of Connecticut Health Center, Farmington, Connecticut 06030-3401
}

Audible frequencies of sound are encoded in a continuous manner along the length of the cochlea, and frequency is transmitted to the brain as a representation of place on the basilar membrane. The resulting tonotopic map has been assumed to be a continuous smooth progression from low to high frequency throughout the central auditory system. Here, physiological and anatomical data show that best frequency is represented in a discontinuous manner in the inferior colliculus, the major auditory structure of the midbrain. Multiunit maps demonstrate a distinct stepwise organization in the order of best frequency progression. Furthermore, independent data from single neurons show that best frequencies at octave intervals of approximately one-third are more prevalent than others. These data suggest that, in the inferior colliculus, there is a defined space of tissue devoted to a given frequency, and input within this frequency band may be pooled for higher-level processing.

Key words: auditory; inferior colliculus; tonotopic organization; laminar organization; 3-D reconstruction; critical bands

\section{Introduction}

A distinct feature of sensory systems is the topographical representation of the sensory epithelium in the CNS. In the auditory system, the sensory epithelium in the cochlea is organized according to frequency. Receptor cells are maximally stimulated by different frequencies of sound depending on their position along the basilar membrane. The resulting gradient in frequency tuning gives rise to a topographic representation of sound frequency, or tonotopic organization, a representation that is maintained in a point-to-point manner from the first auditory relay center, the cochlear nucleus, up to the cortex (Ehret and Schreiner, 2005).

The inferior colliculus (IC) is the major processing center in the auditory midbrain (Irvine, 1992). Anatomically, the central nucleus of the IC (CNIC) is composed of fibrodendritic laminae (Oliver and Morest, 1984; Malmierca et al., 1993). This laminar organization is made up of flat, disk-shaped neurons and axonal afferents that originate in lower auditory centers (Malmierca et al., 2005). The afferent axons parallel the dendritic fields of the disk-shaped neurons (Semple and Aitkin, 1979; Oliver and Mo-

Received 0ct. 6, 2007; revised March 11, 2008; accepted March 26, 2008.

This work was supported by Spanish Ministerio de Educación y Ciencia (MEC) Grant BFU2006-00572 and Junta de Castilla y León (JCYL) Grant SA 007 C05 (M.S.M.), MEC Grant SAB2004-0076 (M.S.M., D.L.0.), and National Institutes of Health Grants R01 DC00189 (D.L.0.) and DC-00607 and DC-00287 (E.C.). 0.H. was supported by MEC Postdoctoral Contract BFU2006-00572. M.A.I. was supported by a JCYL fellowship and S.C. by MEC Fellowship AP2005-5166. We thank Dr. Mal Semple for sharing his single-unit data from the auditory cortex in the study by Doron et al. (2002). We also thank three anonymous reviewers and Drs. Shig Kuwada, Alan Palmer, and Adrian Rees for their critical comments and suggestions on a previous version of this manuscript.

Correspondence should be addressed to Dr. Manuel S. Malmierca, Auditory Neurophysiology Unit, Laboratory for the Neurobiology of Hearing, Faculty of Medicine, University of Salamanca, Campus Miguel Unamuno, Alfonso X el Sabio s/n, 37007 Salamanca, Spain. E-mail:msm@usal.es.

DOI:10.1523/JNEUROSCI.0238-08.2008

Copyright $\odot 2008$ Society for Neuroscience $\quad$ 0270-6474/08/284767-10\$15.00/0 rest, 1984; Malmierca et al., 1993, 1995). These anatomical laminae are thought to be the morphological substrate for the tonotopic organization described in electrophysiological studies (Rose et al., 1966; Clopton and Winfield, 1973; Merzenich and Reid, 1974), but the relationship between frequency representation and laminar structure is not fully understood.

The tonotopic organization in the CNIC is often assumed to be a continuous progression from low to high frequency (Rose et al., 1966; Clopton and Winfield, 1973; Merzenich and Reid, 1974). However, multiunit recordings of best frequency (BF) at threshold from the CNIC in the cat have described a stepwise progression in the tonotopic organization of the IC (Schreiner and Langner, 1997). These findings are consistent with a fine structure in which each anatomical lamina also represents a functional module in which a specific frequency range is represented. It is not known how this tonotopic pattern corresponds with the BF of single neurons, nor is it known how the stepwise progression seen by Schreiner and Langner (1997) relates to the anatomical laminae within the IC. These details are important because they can provide insights into how the auditory system extracts and transmits spectral information from the cochlea to higher centers. Furthermore, understanding this spectral coding will help to further develop promising new auditory prosthetic devices that use electrodes implanted in the IC and are now in clinical trials (Lenarz et al., 2006; Lim and Anderson, 2006, 2007; Lim et al., 2007).

To investigate this relationship, we conducted three series of complementary experiments in anesthetized rats to obtain details about the fine-grained tonotopic progression in the CNIC. We used multiunit recordings to demonstrate that the rat IC shows a stepwise progression of $\mathrm{BF}$, and single-unit recordings of fre- 
quency response areas (FRAs) to determine whether the BF of individual neurons in the IC is correlated with the frequency steps seen in the multiunit mapping. Finally, we used computerassisted three-dimensional (3-D) reconstructions to show the relationship between anatomical and physiologically defined laminae.

\section{Materials and Methods}

This study is based on three sets of complementary experiments that included (1) multiunit tonotopic mapping, (2) single-unit recording and measurement of FRAs, and (3) anatomical tracing combined with computer-assisted 3-D reconstructions. The procedures for the physiological and morphological experiments are described separately.

The use of experimental animals in this study followed the National Institutes of Health Guidelines and the Society for Neuroscience Policy on the Use of Animals in Neuroscience Research under the supervision of the Institutional Animal Care and Use Committee. All experiments were conducted in Salamanca, and procedures were approved by The University of Salamanca Animal Care Committee and were in accord with $\mathrm{Na}-$ tional Institutes of Health guidelines.

Anesthesia and surgical preparation for single-unit and multiunit recording. Extracellular single-unit or multiunit activity was recorded from the IC in 137 pigmented rats (Rattus norvergicus, Rj:Long-Evans; body weight, 109-420 g) of both sexes. The methods have been described in previous studies (Hernández et al., 2005; Pérez-González et al., 2005, 2006), so only the essential details are given here. Animals were anesthetized with urethane $(1.5 \mathrm{~g} / \mathrm{kg}, 20 \%$ solution, i.p.), and anesthesia was maintained with supplementary doses of urethane $(0.5 \mathrm{~g} / \mathrm{kg}$, i.p.) to preserve an areflexive state.

The trachea was cannulated, and atropine sulfate $(0.05 \mathrm{mg} / \mathrm{kg}$, s.c. $)$ was used to reduce bronchial secretions. The animal was placed inside a double-walled sound attenuation room. A local anesthetic (lidocaine) was applied to the ears, and the rat's head was immobilized and placed in a stereotaxic frame with the ear bars replaced by hollow specula that accommodated a sound delivery system (Rees et al., 1997; Hernández et al., 2005). The animal's body temperature was monitored with a rectal probe and maintained at $38^{\circ} \mathrm{C}$ by a thermostatically controlled electric blanket. A midsagittal scalp incision was made, the muscle and underlying periosteum were scraped away, and a small hole was made in the skull over the occipital cortex. The dura was reflected, and the exposed cortex was covered with $2 \%$ agar to prevent desiccation. Neuronal responses were recorded in the IC contralateral to the stimulated ear using tungsten-in-glass electrodes (Merryll and Ainswoth, 1972). The electrode depth was remotely controlled using a microdrive (Burleigh 6000; Burleigh Instruments, Fishers, NY) with a resolution of $1 \mu \mathrm{m}$.

Stimulus presentation, electrophysiological recording of single units, and FRA generation. A total of 604 FRAs were obtained from 125 rats. Some $(n=400)$ of the units were used for other studies $(n=237$ from Hernández et al., 2005; $n=163$ from Pérez-González et al., 2005, 2006). Of the 604, 237 units were recorded from 67 rats in a laboratory where stimuli were generated with a waveform generator (8904A multifunction synthesizer; Hewlett Packard, Palo Alto, CA) controlled by a computer (Hernández et al., 2005). Stimuli were delivered monaurally through a closed acoustic system based on Sony (Tokyo, Japan) MDR 868 earphones. The output of the system at each ear was calibrated in situ using a $1 / 4$ inch condenser microphone (model 4136; Brüel and Kjær, Nærum, Denmark) and a DI-2200 spectrum analyzer (Diagnostic Instruments, Livingston, Scotland, UK). The maximum output was flat from 0.3 to 8 $\mathrm{kHz}[\approx 100 \pm 5 \mathrm{~dB}$ sound pressure level (SPL)] and then fell off with a slope of $\sim 10 \mathrm{~dB}$ /octave. The highest frequency produced by this system was limited to $25 \mathrm{kHz}$. Extracellularly recorded action potentials were amplified (10,000×; BAK MDA-4I; BAK Electronics, Germantown, $\mathrm{MD})$, filtered $(0.3-3 \mathrm{kHz})$, discriminated (BAK DIS-I; BAK Electronics), and time-stamped with an accuracy of $10 \mu$ s by a CED-1401plus Laboratory Interface (Cambridge Electronic Design, Cambridge, UK).

Complete excitatory FRAs were obtained using contralateral monaural stimulation in an automated procedure according to the method of Evans (1979). This method has been widely used in other studies (Sutter and Schreiner, 1991; Snyder et al., 2000; LeBeau et al., 2001; Snyder and Sinex, 2002). Stimuli were 969 presentations of $50 \mathrm{~ms}$ pure tones $(5 \mathrm{~ms}$ rise/fall time) at a rate of $4 / \mathrm{s}$. Sound level was varied between 0 and $90 \mathrm{~dB}$ of attenuation in $5 \mathrm{~dB}$ steps, and frequency was changed in 51 logarithmically spaced steps, 2 octaves around the BF of the unit. Stimuli were presented in a random sequence. FRA plots show response magnitude as a grid of vertical bars positioned at the frequency/intensity coordinates of the stimuli eliciting the responses. Bar length is proportional to the spike count for each set of stimulus conditions (Hernández et al., 2005). Threshold was identified as the lowest sound level to elicit a response, and $\mathrm{BF}$ was defined as the frequency with the lowest threshold.

The remaining 367 single units (from 58 rats) were recorded using stimuli synthesized on a System II workstation [Tucker-Davis Technologies (TDT), Gainesville, FL] using custom software and delivered by two electrostatic speakers (TDT EC1) controlled by an electrostatic speaker driver (TDT ED1). Action potentials were amplified $(10,000 \times)$ with a Bioamp amplifier (TDT) and filtered $(0.5-3 \mathrm{kHz}$; TDT DB4) before being processed in a spike discriminator (TDT SD1). The spike times were then stored on a computer. The maximum output of the TDT system was flat from 0.3 to $5 \mathrm{kHz}(\approx 100 \pm 7 \mathrm{~dB} \mathrm{SPL})$ and from 5 to 40 $\mathrm{kHz}(90 \pm 5 \mathrm{~dB} \mathrm{SPL})$. The highest frequency produced by this system was limited to $40 \mathrm{kHz}$. In this and the above system, the second and third harmonic components in the signal were $40 \mathrm{~dB}$ or more below the level of the fundamental at the highest output level. The monaural stimuli used to generate FRAs in single units were pure tones with a duration of $75 \mathrm{~ms}$. Frequency and intensity of the stimulus were varied randomly $(0-100 \mathrm{~dB}$ attenuation and 2 octaves above and below the BF). Each stimulus was presented two to five times.

The FRA data were analyzed and plotted using commercial software [Excel (Microsoft, Redmond, WA), Quattro Pro (Corel, Ottawa, Ontario, Canada), SigmaPlot (SPSS, Chicago, IL), Matlab (MathWorks, Natick, MA), Origin (OriginLab, Northampton, MA), and SPSS]. Log histograms were generated with Excel and plotted with Origin. The latter program was used to smooth and pick the peaks.

Multiunit mapping of tonotopic organization. For the mapping studies, we used 16 rats. These recordings were made using the TDT lab configuration. The anesthesia and surgical preparation was similar to that described above for the single-unit recordings. Penetrations were from anterodorsal to posteroventral through the IC at an angle $10^{\circ}$ from the frontal plane (see Fig. $8 C$ ). This angle is approximately orthogonal to the predominant orientation of isofrequency laminae (Malmierca et al., 1993). The electrode was advanced in steps of 25 or $50 \mu \mathrm{m}$, and recordings were made at each site. At most recording sites, multiunit activity was observed, but less frequently the responses of well isolated single neurons could be studied. Entry of the microelectrode into the CNIC was established by the presence of a robust response to low-frequency tones. Moreover, there was a low-to-high progression of BF as the electrode traversed a dorsoventral direction. At each recording site, the multiunit responses were monitored on the oscilloscope and with an acoustic monitor while we varied the frequency and sound level for contralateral monaural stimulation by manually sweeping a mouse-driven cursor over a two-dimensional matrix in our custom software. This process quickly determines the point on the matrix with a response at the lowest sound level, and we defined the frequency of this point as BF and the level as the threshold. It is unlikely that experimenter expectations could have compromised the data obtained in these experiments, because the experiments were conducted by six different experimenters in the same and different animals. Furthermore, in selected cases, complete automatic multiunit FRAs were also recorded (see Fig. 2).

The BF distribution was analyzed as a function of depth along the electrode track using an automated Microsoft Excel spread sheet. The distance in micrometers and frequency change in octaves was calculated for any change in $\mathrm{BF}$ with respect to the previous $\mathrm{BF}$ recorded and for any change in $\mathrm{BF}>0.1$ octaves.

Histological verification. At the end of each experiment, electrolytic lesions ( $5 \mu \mathrm{A}, 5 \mathrm{~s})$ were made with the tungsten recording electrode, and the animal was given a lethal dose of sodium pentobarbitone (Nembutal) (for details, see Malmierca et al., 1993; LeBeau et al., 2001; Hernández et al., 2005). Animals were perfused intracardially with Ringer's solution, 
followed by fixative ( $1 \%$ paraformaldehyde and $1 \%$ glutaraldehyde in 0.1 м phosphate buffer, $\mathrm{pH} 7.4$ ). The brains were immersed in a $30 \%$ sucrose solution for $2-3 \mathrm{~d}$. Transverse sections ( $40 \mu \mathrm{m}$ thick) were cut on a freezing microtome and stained with cresyl violet. The majority of units were localized within the CNIC.

3-D reconstructions of IC laminae. In multiunit recording cases, we reconstructed eight electrode tracks with electrolytic lesions from two cases (cases 259 and 260) using Neurolucida (MicroBrightField, Colchester, VT). Recordings were done as described above, while the electrode was advanced along a track, with BFs being determined at $50 \mu \mathrm{m}$ intervals. Then, while the electrode was retracted, the BFs were recorded again and lesions were made at selected frequencies. The lesions were $\sim 100 \mu \mathrm{m}$ in diameter, so we used the center of the lesion as a reference. The laminae were visualized in 3-D after connecting lesions or points along the track with identical BFs.

Three-dimensional reconstructions of IC laminae were also made after injections of anatomical tracers in physiologically defined regions in the dorsal cochlear nucleus (DCN) in eight additional cases used previously (Oliver et al., 1997; Malmierca et al., 2002). These provided information on the relationship of the thickness of the axonal laminae in the IC to the size of the injection site in the DCN. These methods have been published previously and are summarized below. For these experiments, an areflexive, anesthetic state was induced by intramuscular administration of ketamine $(57 \mathrm{mg} / \mathrm{kg})$ and xylazine $(8.6 \mathrm{mg} / \mathrm{kg})$ and maintained with the same compounds. The acoustic and experimental systems were the same as described above. Extracellular recordings in response to acoustic stimulation allowed the determination of $\mathrm{BF}$ at the injection sites in the right DCN. Recordings were made with glass micropipettes (tips, 10-40 $\mu \mathrm{m}$ ) filled with injection solutions for anterograde transport. The injection electrode contained either 10\% tetramethylrhodamine dextran (TDR; D-1817; Invitrogen, Carlsbad, CA) dissolved in saline or a mixture of $10 \%$ biotinylated dextran amine (BDA; D-1956; Invitrogen) and 10\% FITC-dextran (FD; D-1820; Invitrogen) in saline. Once the desired site was found, the dextrans were injected by iontophoresis (2-6 $\mu$ A for 5-24 $\mathrm{min})$. Seven to $10 \mathrm{~d}$ after the injections, the animals were perfused transcardially under deep surgical anesthesia to fix the brain tissue with a buffered washout solution ( $2 \%$ sucrose in $0.12 \mathrm{~m}$ phosphate buffer, $\mathrm{pH}$ 7.4 , containing $0.05 \%$ lidocaine and $0.004 \% \mathrm{CaCl}_{2}$ ) and then a buffered (0.12 M phosphate buffer, $\mathrm{pH} 7.4$ ) 4\% paraformaldehyde fixative solution. After fixation, decapitation, and dissection, the brain tissue was cryoprotected in $30 \%$ sucrose and sectioned in the transverse plane into $40-\mu \mathrm{m}$-thick slices on a freezing microtome. Adjacent sections underwent avidin-biotin complex histochemistry for BDA (black reaction), followed by immunohistochemistry with antisera to rhodamine, biotinylated secondary antisera, and avidin-biotin histochemistry (red reaction). Every third or fourth section was used for Nissl counterstain.

Data analysis. Terminal fields in the IC were observed with a Leica DMRB microscope and digitized with Neurolucida software (MicroBrightField). Axonal laminae were measured in a random sample of sections that consisted of evenly spaced sections in each case (every third or fourth $40-\mu \mathrm{m}$-thick section). The labeled laminar axonal plexus was plotted in five to eight sections per case (Malmierca et al., 2005) with a Neurolucida system (MBF Bioscience, Burlington, VT). The width of the plexus in each section was defined as the narrowest dimension of the lamina, usually perpendicular to the long axis of the lamina that runs from ventrolateral to dorsomedial. Each plexus was measured at five to six sites in each section of the eight cases. Measurements are presented without correction for shrinkage. In a previous study (Malmierca et al., 1998), we found that histological processing resulted in up to $12 \%$ shrinkage.

\section{Results}

\section{Mapping of tonotopic organization}

To study the fine-grained tonotopic progression in the CNIC, we systematically mapped the BF of neuronal clusters along dorsoventrally oriented microelectrode penetrations. Recorded tracks had an average length of $2180 \pm 460 \mu \mathrm{m}$ (mean $\pm \mathrm{SD}$ ), which corresponds well with the dimensions of the IC in the rat (Faye-

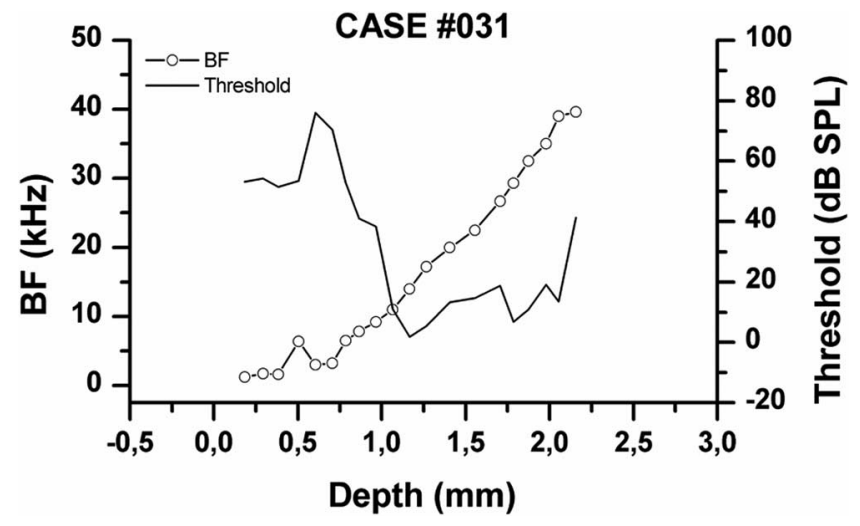

Figure 1. BFs of multiunit clusters measured in 100-150 $\mu \mathrm{m}$ steps along the main dorsoventral axis of the inferior colliculus. Note that case 031 does not show a stepwise progression because the mapping resolution was $>100 \mu \mathrm{m}$. BF is shown by the open circles and the left $y$-axis. The continuous line shows threshold measurements at the same location. Data were obtained from multiunit clusters.

Lund and Osen, 1985; Malmierca, 2003). When multiunit clusters were mapped in steps of $100 \mu \mathrm{m}$, the BF increased monotonically and smoothly as a function of depth (Fig. 1). However, when the BF was recorded every 25-50 $\mu \mathrm{m}$ (Fig. 2), we found a distinct stair-step pattern in every penetration ( $n=16$ animals, 45 penetrations). In 12 penetrations, no clear tonotopic organization was found (Fig. 2C, black symbols) or the tonotopic progression was incomplete. Histological location of these tracks showed that they were outside the central nucleus. These penetrations were excluded from subsequent analysis.

For the 33 penetrations that were considered complete and located within the central nucleus, we plotted BF versus recording depth. The frequency of these penetrations ranged from 0.5 to $40 \mathrm{kHz}$. Each showed a distinct staircase pattern (Fig. 2). The BF remained nearly constant (changing $<0.1$ octaves) for an average of $151 \pm 41 \mu \mathrm{m}$ (mean $\pm \mathrm{SD}$ ) and then jumped $0.34 \pm 0.11$ octaves ( $n=460$ steps). On average, there were $14 \pm 3.7$ steps per track.

At any one recording site, the BF remained virtually constant over time. We repeatedly recorded the FRA of a single unit three to seven times $(n=21)$ without moving the electrode to check the variability of the BF over $23-80 \mathrm{~min}$. BF changed $0.006 \pm 0.0002$ octaves on average. This is 50 times smaller than the jump in frequency at a staircase step.

Along a step, the frequency changed little between recording sites. Figure 3 illustrates four representative steps and multiunit FRAs recorded every $50 \mu \mathrm{m}$ along the track. The recordings were first made as the electrode moved downward along the track (Fig. $4 A$, circles) and were repeated as it was retracted from the IC (Fig. $3 A$, inverted triangles). At steps $\mathrm{B}-\mathrm{D}$, the $\mathrm{BF}$ changed from 0 to 0.05 octaves; however, at step A, the BFs changed 0.13 octaves. To take this variability into account, we set the threshold for our analysis of the step change in BF to be changes of 0.1 octaves or more.

Along a penetration, similar steps were obtained regardless of whether the recording electrode was being advanced into the IC or retracted as illustrated in Figures 3 and 4. The eight tracks in Figure 4 are from three different animals (circles show downward tracks, and inverted triangles show the corresponding upward tracks). A fourth animal is shown in Figure 3. The overlap of the symbols in Figures $3 A$ and 4 show that the same frequency was recorded at the same depth in most cases, regardless of whether it was an upward or downward penetration. 

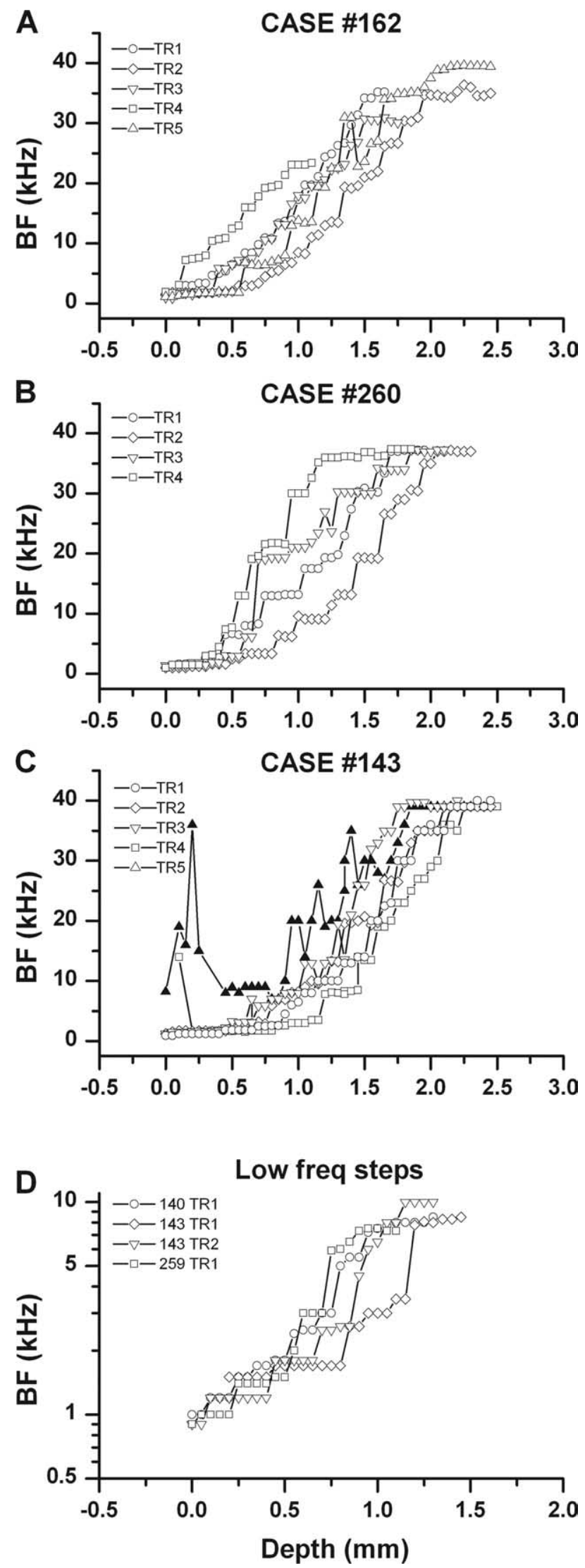

Figure 2. $A-C$, BF of multiunit clusters measured in $25-50 \mu \mathrm{m}$ steps along the main dorsoventral axis of the inferior colliculus in four tracks $(B)$ and five tracks $(\boldsymbol{A}, \boldsymbol{C})$. All cases show a stepwise progression. C, Track 5 in case 143 was found outside the CNIC and shows no clear tonotopic organization. $\boldsymbol{D}$, Details, in a logarithmic scale, of the low-frequency steps for four tracks from three animals. Data were obtained from multiunit clusters. TR, Track.
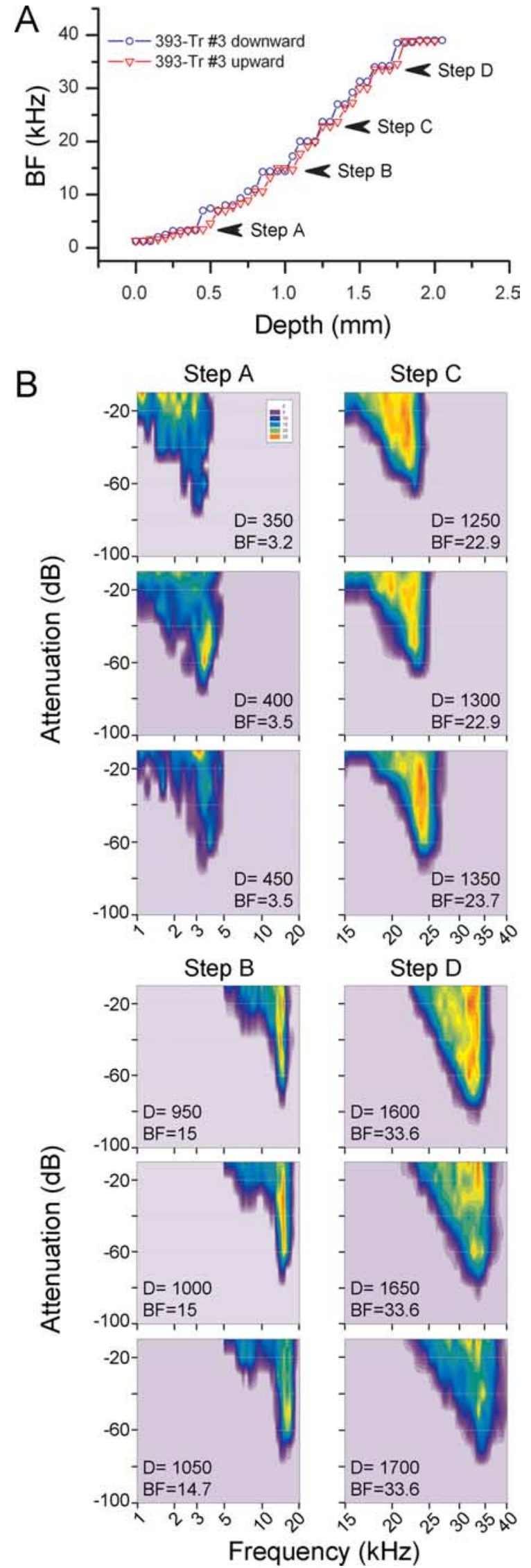

Figure 3. $\quad A$, A single electrode penetration downward (blue trace) and upward (red trace) along the same electrode track (Tr) in which we recorded FRA at every $50 \mu \mathrm{m}$. B, FRAs recorded at every $50 \mu \mathrm{m}$ at four different steps (step A-step D) along the downward penetration through ICC. Data were obtained from multiunit clusters. D, Depth. 


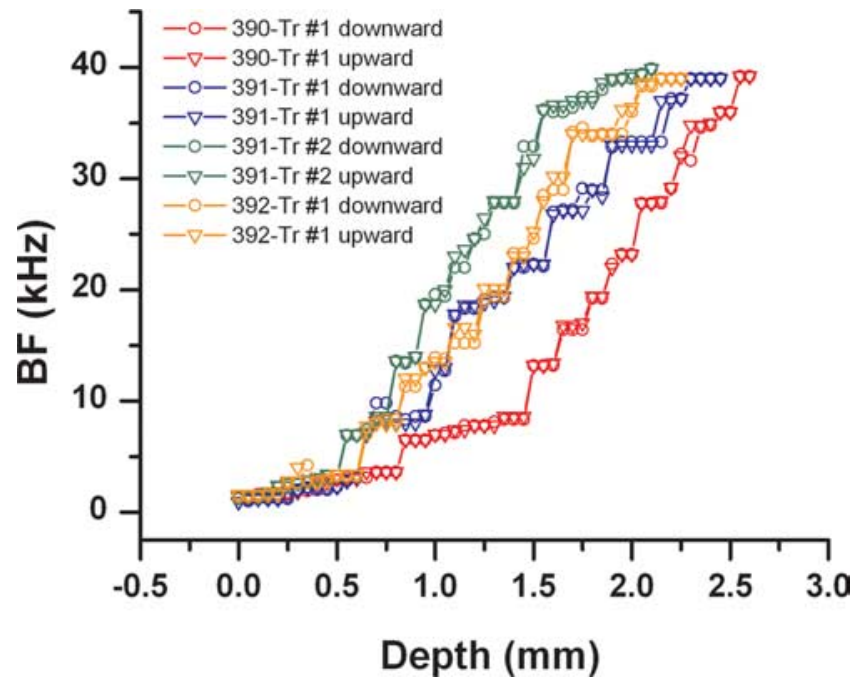

Figure 4. Examples of several electrode penetrations downward (circles) and upward (inverted triangles) along the same electrode track (Tr). Note that there is virtually no difference between the BF recorded downward and upward. Data were obtained from multiunit clusters.

We also performed a step analysis separately for the low- and high-frequency regions (multiunit clusters). In low-frequency regions (defined as $<4 \mathrm{kHz}$, average of $2.05 \mathrm{kHz}$ ), the BF steps were on average $142 \pm 69 \mu \mathrm{m}$ thick. BF jumps were $0.27 \pm 0.15$ octaves, with 4.7 steps per track on average $(n=143)$. In highfrequency regions (defined as $8 \mathrm{kHz}<\mathrm{BF}<35 \mathrm{kHz}$; average of $21.1 \mathrm{kHz}$ ), the BF steps were $140 \pm 48 \mu \mathrm{m}$ and jumped by $0.26 \pm$ 0.06 octaves with an average of 7.4 steps per track $(n=236)$. When we compared low-frequency versus high-frequency regions, neither the thickness of the constant pattern nor the change in BF at the steps were significantly different (MannWhitney tests, $p>0.05)$. This finding suggests that the laminae are similar in thickness and in the frequency range represented regardless of their location within the central nucleus.

\section{Single-unit frequency response areas}

In a separate set of experiments, we collected 604 FRAs from well isolated single units using automated software and pseudorandom presentations of pure tones (Hernández et al., 2005; PérezGonzález et al., 2006). The BFs and thresholds of the neurons in this sample cover the audible frequency range of the rat up to 40 $\mathrm{kHz}$. Figure 5 illustrates a track through the center of the CNIC in which we recorded six FRAs. The BF of the individual FRAs increased with depth. When the BFs of all 604 units in this sample were pooled and displayed as a histogram with 0.1 octave bins, we observed a multimodal distribution with 16 peaks occurring at $0.32 \pm 0.11$ octave intervals (Fig. $6 A$ ). In the distribution of the multiunit recordings, 14 peaks match 12 of the single-unit peaks (Fig. 6B). The 12 matched peaks from these two independent datasets are strongly correlated $(r=0.99855)$ in a linear regression analysis (Fig. 6C). The combined sequence of peaks from the two distributions suggests that there are 18 peaks that occur at $0.29 \pm 0.1$ octave intervals. Thus, the two samples collected from the CNIC with very different methodologies suggest an increased representation of BFs at octave intervals of approximately one-third.

3-D organization of the physiological and anatomical laminae The orientation of the frequency-band laminae is shown in two of the cases (cases 259 and 260) used for multiunit mapping. After

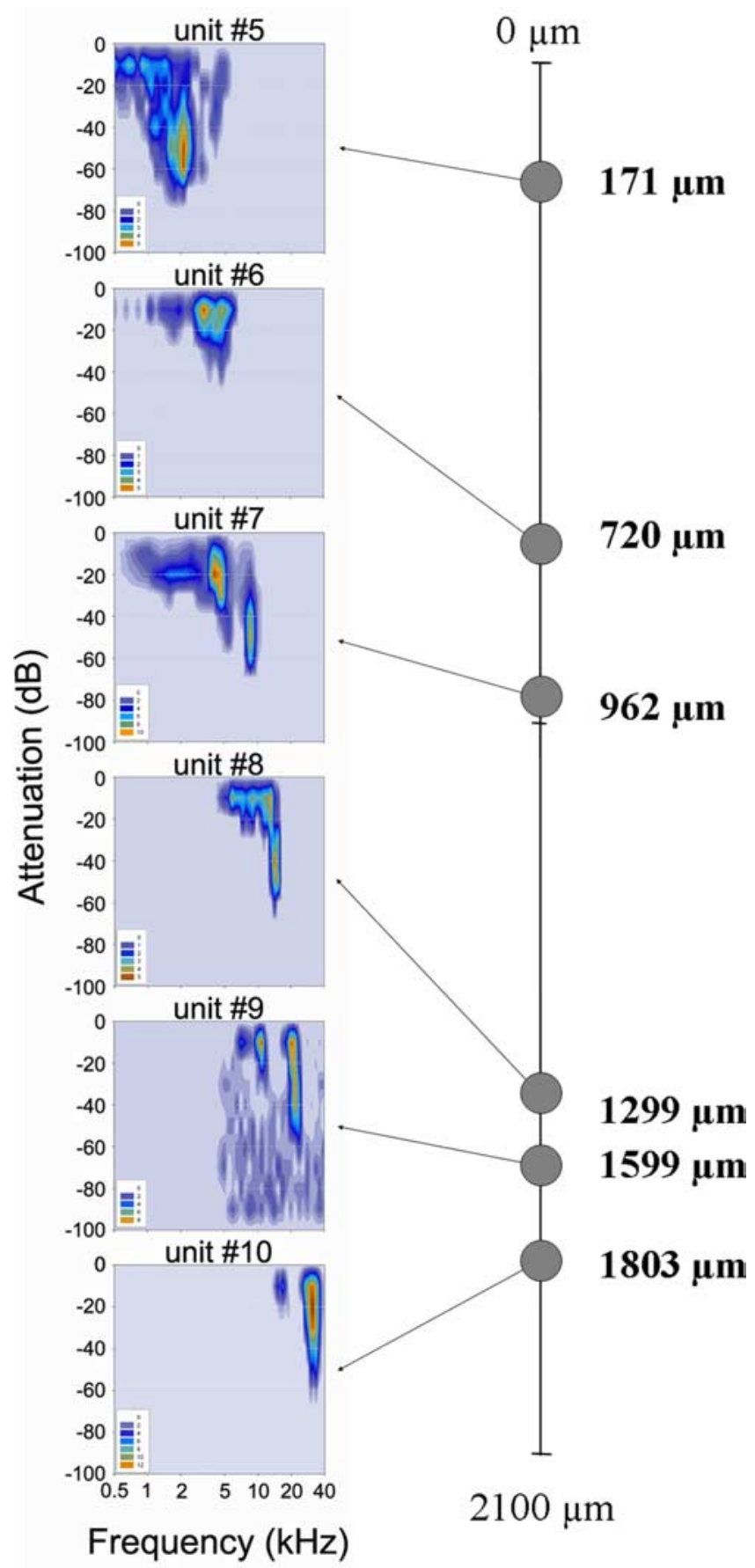

Figure 5. Six FRAs from single-unit recordings obtained from a single track through the CNIC. Note the increase of BF of the FRAs as a function of the depth in the CNIC.

recording along four tracks, the locations with the same BFs were connected. Case 260 (Fig. 7, right column) shows isofrequency bands at 8 and $30 \mathrm{kHz}$, whereas case 259 (Fig. 7, left column) shows isofrequency bands at 3 and $30 \mathrm{kHz}$. In both, the $30 \mathrm{kHz}$ laminae were more oblique to the frontal and sagittal planes and seen on edge from a caudal and medial view when rotated $26^{\circ}$ from caudal. The lower-frequency laminae were oriented more in the horizontal plane and seen on edge for a lateral view rotated $60^{\circ}$ from caudal.

For comparison, we examined the axonal lamina in CNIC that resulted from injections of anatomical tracers in the DCN. Two adjacent laminae are seen in the CNIC (Fig. 8A) after injections 

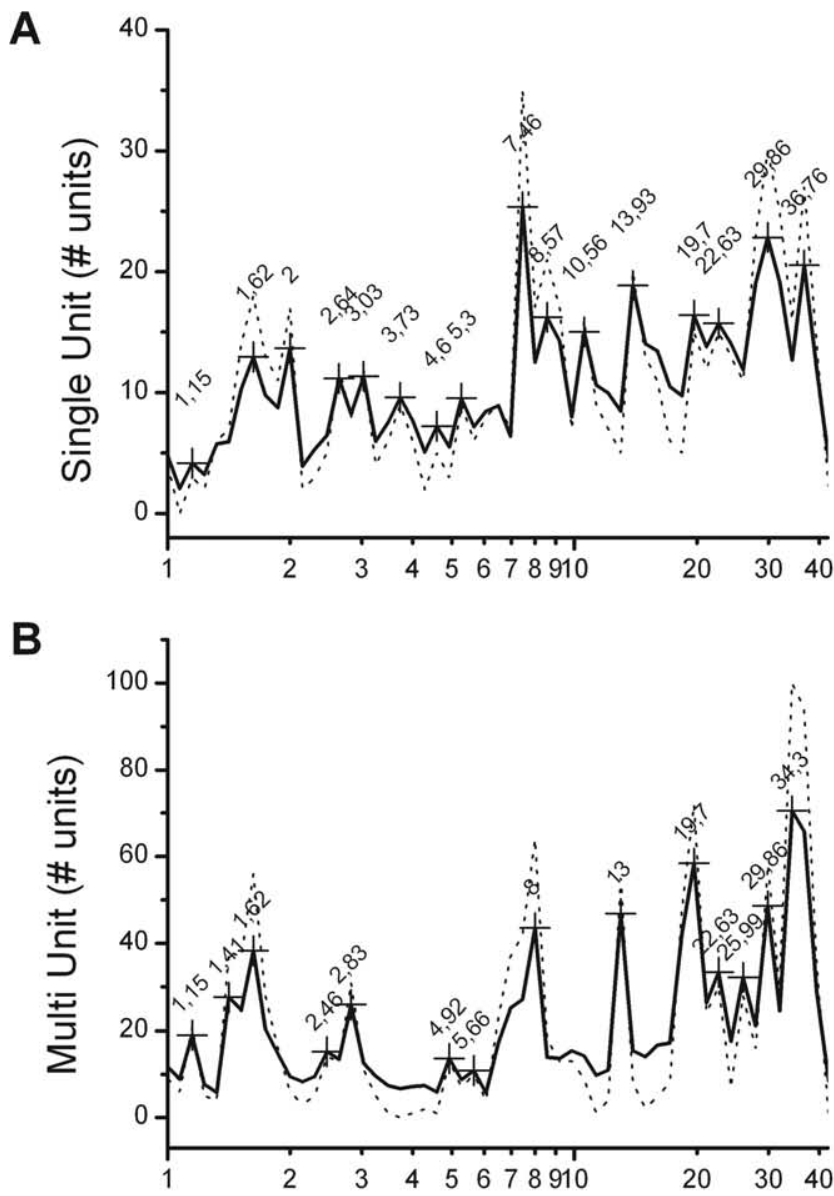

BF in $1 / 10$ Octave Bins

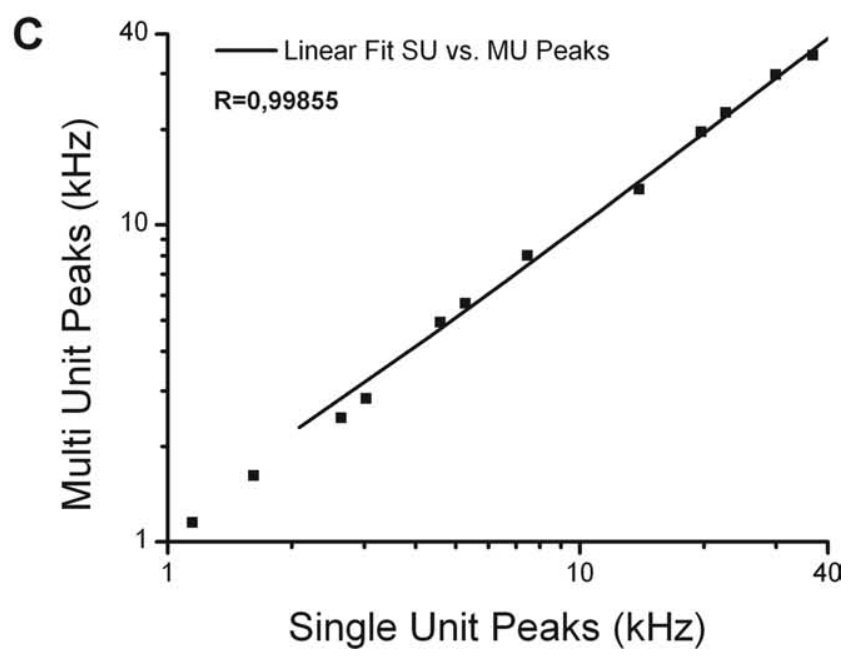

Figure 6. Logarithmic histogram of the pooled BF data (discontinuous line) with fast Fourier transform smoothing (continuous line) in $1 / 10$ octave bins. $A$, BFs of single-unit sample show a multimodal distribution with $10-12$ peaks occurring at $0.32 \pm 0.11$ octave intervals. $\boldsymbol{B}, \mathrm{BF}$ of multiunit clusters $(n=16)$ sample also show a multimodal distribution at $0.34 \pm 0.11$ and matches similar peaks $(n=14)$ seen in the distribution of the BFs of the single unit. C, The two independent datasets [single unit (SU) and multiunit (MU)] are strongly correlated $(r=$ 0.99855).

in DCN at $1.7 \mathrm{kHz}$ using TDR (red) and at $1.8 \mathrm{kHz}$ using FD-BDA (black) (Fig. $8 A$, inset). A second case (Fig. $8 B$ ) shows two different laminae, in which the injections in DCN were 3 octaves apart

\section{Case \#259}
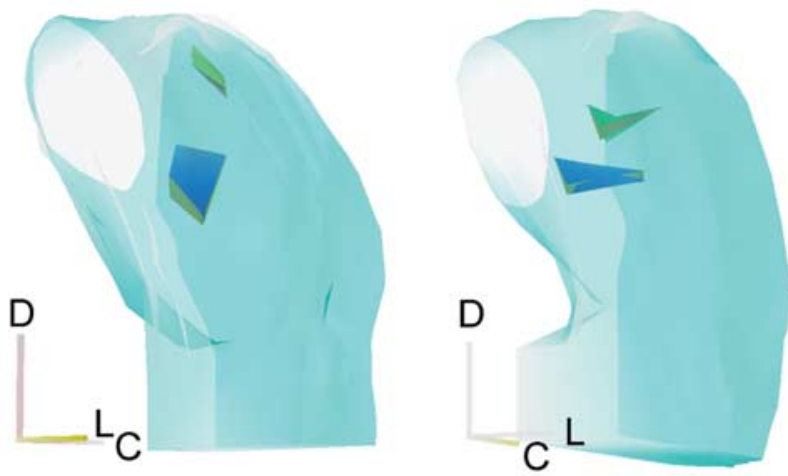

Lateral view
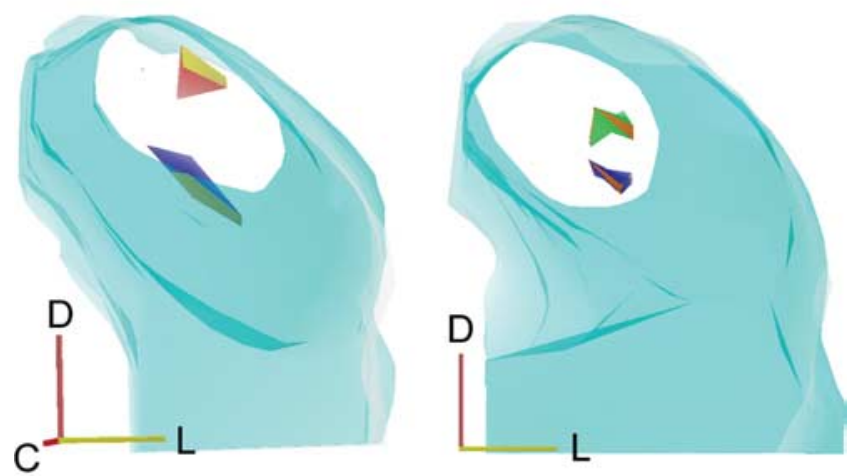

\section{Caudal view}
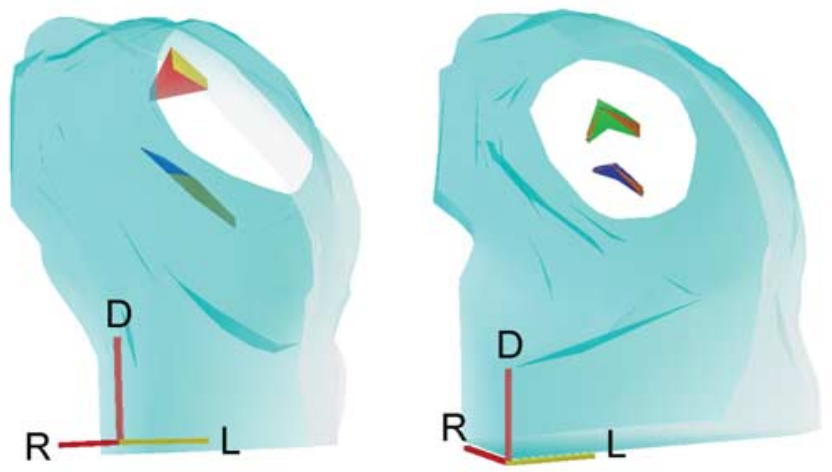

\section{Medial view}

Figure 7. 3-D reconstructions to show the mutual relationship and orientation of the $3 \mathrm{kHz}$ (red), $8 \mathrm{kHz}$ (green), and $30 \mathrm{kHz}$ (blue) laminae based on the tracks and lesions (dots) shown on the corresponding cases. Each lamina was reconstructed from four lesions equally spaced. R, Rostral; D, dorsal; L, lateral, C; caudal.

(6.3 and $29 \mathrm{kHz}$ ). A 3-D reconstruction (Fig. 8C) shows the full extent of three axonal laminae in the CNIC at 1.7, 1.8 (same as Fig. $8 \mathrm{~A}$ ), and $4.5 \mathrm{kHz}$ and their relationship to the angle of the recording electrode in the tonotopic mapping experiments, nearly orthogonal to the laminae. The higher-frequency laminae are somewhat more oblique to the angle of the electrode than the lower-frequency ones. The orientation of these anatomical laminae is similar to the segments of the frequency-band laminae shown in Figure 7.

We estimated the minimum cross-sectional diameter of the 

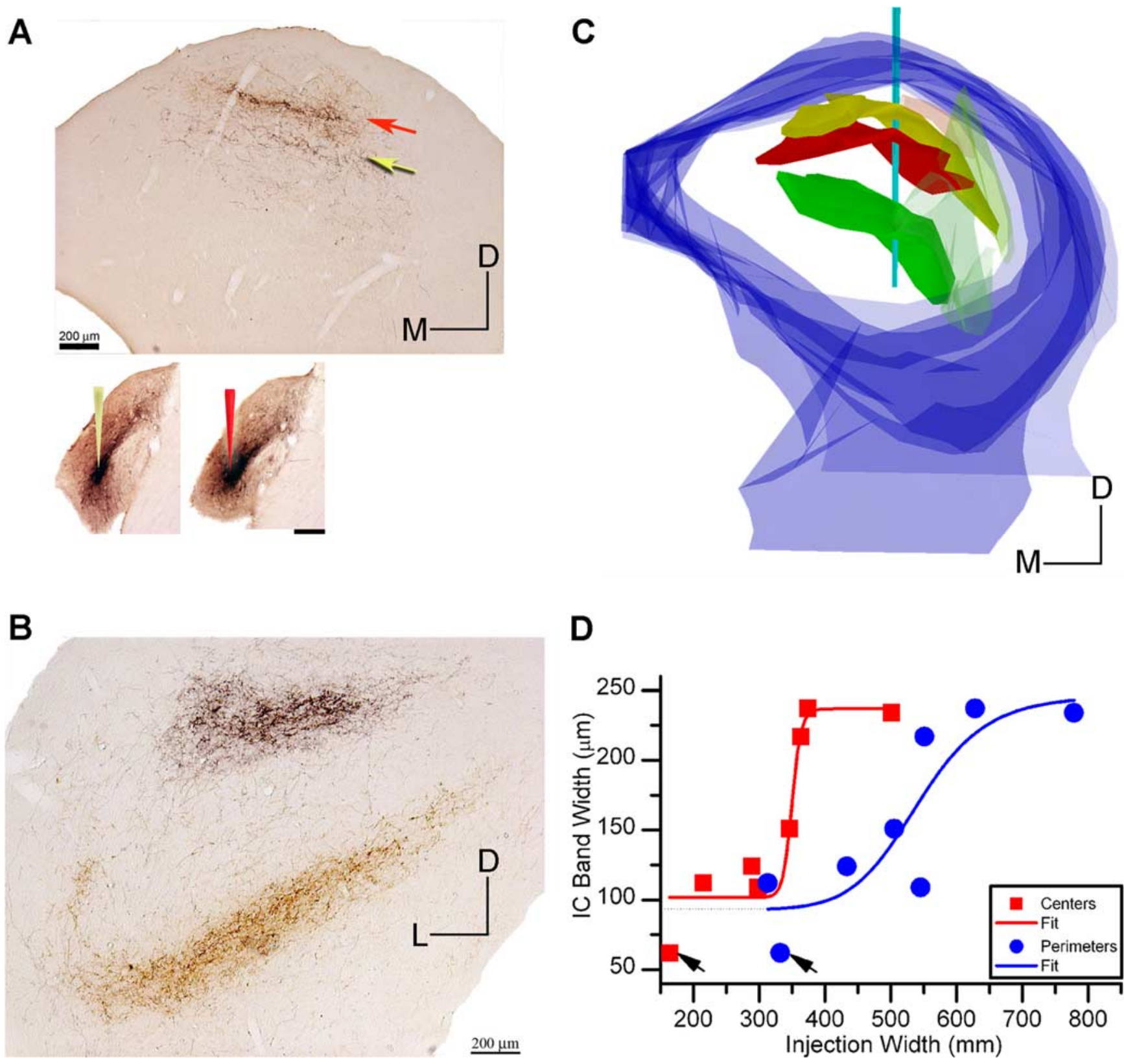

D

Figure 8. $\quad \boldsymbol{A}$, Axonal laminae in IC (case 121) after two injections in DCN (see inset in $A$ at the bottom of the IC with injection sites) at 1.7 and $1.8 \mathrm{kHz}$ (BDA, black-yellow arrow; TDR, red arrow). Arrows indicate injection in DCN. Note, BDA labeled two laminae. B, Case 231 shows widely spaced laminae (3 octaves) in IC from a BDA (black axons) injection in DCN at $6.3 \mathrm{kHz}$ and a TDR (red axons) injection at $29 \mathrm{kHz}$ in DCN. C, 3-D reconstruction of IC shows the full extent of the axonal bands in the CNIC and their relationship to the angle of the recording electrode. Note that higher-frequency laminae are more oblique to the angle of the electrode. Laminae after 4.5 and 1.8 -1.7 kHz injections. Case 117 (green lamina, 4.5); case 121 (red and yellow laminae, 1.7-1.8). D, The size of the band of axons is related to the size of the injection site, and the mean width of the lamina is $\sim 100 \mu \mathrm{m}$ in diameter. D, Dorsal; L; lateral; M, medial.

anatomical laminae in eight cases in which tracers had been injected into the DCN. To do this, we had to take into account the size of the injection site. Larger injections result in more extensive labeling in CNIC presumably because multiple laminae are labeled. The relationship between the thickness of the axonal laminae and the size of the injection site in DCN was estimated as shown in Figure $8 D$. The injection size was measured using the outer diameter of the center and the outer perimeter of the injection site. The cross-sectional diameter was measured at multiple sites in each section as published previously (Malmierca et al., 2005). This diameter is perpendicular to the longest axis of the laminae running ventrolateral to dorsomedial in the sections. The relationship between in- jection size and laminar width is described by a sigmoidal function (Fig. $8 D$ ) that is similar regardless of whether the center or the outer diameter of the injection is used. In either case, these data suggest that the minimum thickness of the axonal laminae approaches $100 \mu \mathrm{m}$ after the smallest injections.

The thinnest axonal laminae are presumed to represent single fibrodendritic laminae. Seven axonal laminae from the four cases with the thinnest laminae have a mean diameter of $104 \pm 21 \mu \mathrm{m}$ (Table 1). In one case, the two laminae in the low-frequency CNIC were narrower, $55-84 \mu \mathrm{m}$ in diameter, but most laminae ranged from 100 to $134 \mu \mathrm{m}$ in diameter. After an adjustment for $10-12 \%$ shrinkage during histology, these measurements match 
the 140-150 $\mu \mathrm{m}$ mean step size, resulting in a stair-step jump in BF during multiunit mapping.

\section{Discussion}

The present study shows a discontinuous tonotopic organization in the CNIC. Multiunit mapping reveals that the rat IC possesses a distinct stepwise organization in the order in frequency representation. Data from single units reinforces the idea that the BFs of neurons in the IC are distributed in a discontinuous manner. Together, both types of data argue against the general view that the tonotopic organization in the CNIC forms a continuous frequency gradient. Rather, it seems that there is a defined space of collicular tissue devoted to a given frequency bandwidth.

A key methodological issue is whether or not the stepwise progression of BF that we observed could be an artifact of methodology. We think not because it was observed in all penetrations through the CNIC with electrode steps as small as $25 \mu \mathrm{m}$ and regardless of whether the recordings were performed while advancing the electrode downward or upward along the same track (Figs. 3, 4). Electrode steps of $50 \mu \mathrm{m}$ or less were necessary to observe the stepwise organization because the changes in frequency occurred at $\sim 150 \mu \mathrm{m}$. Previous studies (Rose et al., 1966; Clopton and Winfield, 1973; Merzenich and Reid, 1974) used larger steps in their electrode mapping and thus are likely to have sampled across the stepwise organization. Another important question is whether or not the recorded BF remains constant over time for both single-unit and multiunit recordings. We recorded up to 21 different single-unit FRAs repeatedly (three to seven repeated FRAs) to check the variability of their BF over time for $23 \mathrm{~min}$ up to $80 \mathrm{~min}$. We found that BF remains virtually constant, changing on average 0.006 octaves (i.e., 50 times smaller than the jumps of BF, 0.34), with a variance of 0.0002 .

Our observations are based on two independent datasets that yielded very similar results, one from multiunit mapping and the other from single units. The multiunit mapping of the tonotopic organization was specifically collected for this study, but the single-unit data were collected in previous experiments with different aims unrelated to tonotopic organization (Hernández et al., 2005; Pérez-González et al., 2005, 2006). Moreover, the single-unit data were collected in two different laboratories with different sound equipment and loudspeakers. The finding of stepwise tonotopic organization using different methods suggests a robust organizational principle.

\section{Previous tonotopic mapping studies}

A single previous study with multiunit recordings has shown a similar stepwise tonotopic organization in the CNIC of the cat (Schreiner and Langner, 1997). They demonstrated that frequency organization is characterized by constant-frequency ratios (on average, 0.278 octaves per frequency step) corresponding to a spatial distance of $175 \mu \mathrm{m}$ within the IC. These steps were larger than those found in the present study of the rat, and the size differences may be related to species differences and the larger brain of the cat.

Tonotopic maps are found throughout the auditory system from cochlear nucleus to auditory cortex (Ryan et al., 1988; Kaltenbach and Lazor, 1991; Friauf, 1992; Spirou et al., 1993; Malmierca et al., 1998; Bajo et al., 1999; Doron et al., 2002). Some appear to be continuous, whereas others are stepwise. For exam-
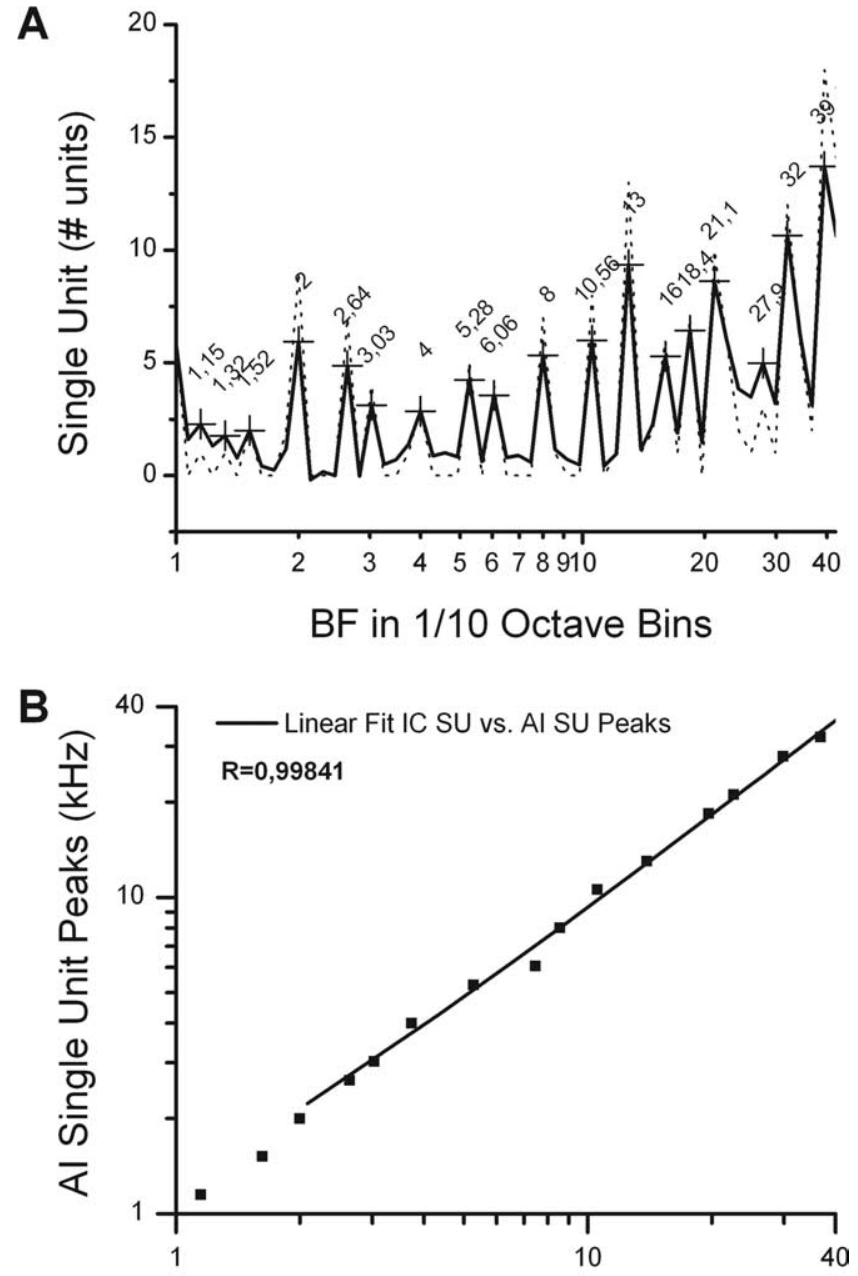

IC Single Unit Peaks (kHz)

Figure 9. BFs of single-unit sample from auditory cortex. $A$, Logarithmic histogram of the pooled BF data (discontinuous line) from rat auditory cortex [Doron et al. (2002), their Fig. 2] shows a multimodal distribution with $10-12$ peaks occurring at $0.31 \pm 0.10$ octave intervals. Fast Fourier transform smoothing (continuous line) in $1 / 10$ octave bins. B, BFs of single-unit data from the CNIC and AC matches similar single-unit peak sets are strongly correlated $(r=$ 0.99841). SU, Single unit; Al, primary auditory cortex.

ple, in the dorsal cochlear nucleus of the cat, Spirou et al. (1993) found a continuous tonotopic progression despite the complex FRAs with multiple, discontinuous islands of excitation surrounded by inhibition (Young and Voigt, 1982; Young, 2008). In contrast, Cetas et al. (2001) reported a distinct stepwise progression in the tonotopic organization of the ventral division of the auditory thalamus (MGV) in the rabbit. 
In most studies of single units, it is not clear whether there is a discontinuous distribution of best frequency. To determine whether the BFs of single units in the primary auditory cortex of the rat follow a stepwise progression, we analyzed the BF of 198 cortical single units from a previous study (Doron et al., 2002, their Fig. 2) using the same approach that we used for our 604 IC single units. The cortical units showed a similar multipeaked distribution (Fig. 9B), with the peaks occurring at $0.31 \pm 0.10$ octave intervals. The frequency distribution in the cortex is very similar to that of the distribution in the IC (Fig. 9B) $(r=0.99841)$. These findings suggest that there is a discontinuous tonotopic organization that begins in the IC and continues through the cortex.

\section{Relationship of tonotopic organization to anatomy}

There may be a relationship between tonotopic organization and dendritic morphology. Cetas et al. (2001) found a distinct stepwise progression in the tonotopic organization of the MGV in the rabbit. The steps in the rabbit MGV ( $\sim 1$ octave) were larger than those reported in the IC of the cat $[\sim 0.28$ octaves (Schreiner and Langner, 1997)] or rat $[\sim 0.29$ octaves (present data) $]$. Besides possible species differences, this discrepancy might be attributable to different organizations in MGV and IC. A comparison of dendritic fields suggests that the larger step size is positively correlated with a larger dendritic field width (Cetas et al., 2003).

Previous anatomical studies in the rat have shown that highfrequency laminae in IC contain flat disk-shaped neurons separated by interlaminar compartments made of less flat neurons (Malmierca et al., 1993, 1995). The intralaminar compartments are absent in the low-frequency region. Our data in the rat show that the axonal laminar thickness and the frequency step changes are similar across frequency $(140-150 \mu \mathrm{m})$. The dendritic arbors of flat cells are $\sim 50 \mu \mathrm{m}$ thick and less flat cells are $\sim 100 \mu \mathrm{m}$ thick on average (Malmierca et al., 1993, 1995), suggesting that two to three flat neurons organized side-by-side may form a functional unit in low-frequency regions (Fig. 8) (Malmierca et al., 2005). At the high-frequency region, a lamina might include a flat neuron and a less flat neuron side-by-side (Malmierca et al., 1993, 1995).

\section{Functional significance}

How does the discontinuous distribution of the single-unit data relate to the physical-anatomical laminae? The data in the IC and cortex suggest groupings of neurons in units of $\sim 0.3$ octaves. At the IC level, best frequencies may be organized as partially overlapping bandpass filters with a center-to-center separation of one-third octave. Thus, near threshold, frequencies at the center of the filters are favored over those at the overlapping regions, and it results in the multi-modal, saw-toothed pattern of frequency distribution. These midbrain bandpass filters have broader bandwidth than those conceived at the periphery to model the output of the cochlea (Moore, 1986; Moore et al., 1999; Moore and Glasberg, 2007). The auditory filters are usually estimated to be $10-17 \%$ of the center frequency in human studies, a bandwidth of $0.14-0.23$ octaves. If the auditory filters in the rat are similar, the midbrain filters may be approximately double those at the periphery.

Critical band filters have been postulated to originate at the midbrain level (Ehret and Merzenich, 1985; Ehret and Merzenich, 1988; Ehret and Schreiner, 2005) in which inhibitory processing produces level-tolerant neurons (narrow FRA types) (LeBeau et al., 2001; Hernández et al., 2005). Schreiner and Langner (1997) suggested that the IC consists of a stack of 30-40 critical bands, each equal in size to the frequency-band laminae defined by the changing steps in the tonotopic map. The number of crit- ical bands in the rat is not known, but a rough estimate can be based on two assumptions: (1) the basilar membranes of mammals are scale models of each other and critical bands cover equal distances on the basilar membrane (Greenwood, 1990); and (2) one critical band is thought to cover $\sim 1 \mathrm{~mm}(0.7-1.3 \mathrm{~mm})$ on the basilar membrane. Based on the $8 \mathrm{~mm}$ length of the rat's basilar membrane, rats have $\sim 8-12$ critical bands (Ehret and Schreiner, 2005). Interestingly, our data in the IC suggest that there may be $8-12$ laminae, each covering $0.29-0.36$ octaves. This separation is similar to critical bands of $0.333-0.375$ octaves suggested for the mouse (Egorova et al., 2006). Moreover, this grouping is also compatible with studies on the frequency separation needed to activate independent neuronal populations in the IC (Yang et al., 2003, 2004; Oliver, 2005). Two pure tones 0.5 octaves apart activate two laminae in the IC, whereas tones 0.25 octaves apart activate a single lamina.

Thus, our anatomical and physiological data suggest that the tonotopic map in the CNIC in the rat is composed of discrete physiological laminae that correspond to the anatomical fibrodendritic laminae of the CNIC. The groupings of neurons with $\sim 0.3$ octaves separation represent separate arrays of neurons with a discontinuous frequency representation near threshold. Such a discontinuous frequency representation has interesting functional implications for hearing because it implies unequal thresholds for closely adjacent frequencies.

\section{References}

Bajo VM, Merchan MA, Malmierca MS, Nodal FR, Bjaalie JG (1999) Topographic organization of the dorsal nucleus of the lateral lemniscus in the cat. J Comp Neurol 407:349-366.

Cetas JS, Price RO, Velenovsky DS, Sinex DG, McMullen NT (2001) Frequency organization and cellular lamination in the medial geniculate body of the rabbit. Hear Res 155:113-123.

Cetas JS, Price RO, Crowe J, Velenovsky DS, McMullen NT (2003) Dendritic orientation and laminar architecture in the rabbit auditory thalamus. J Comp Neurol 458:307-317.

Clopton BM, Winfield JA (1973) Tonotopic organization in the inferior colliculus of the rat. Brain Res 56:355-358.

Doron NN, Ledoux JE, Semple MN (2002) Redefining the tonotopic core of rat auditory cortex: physiological evidence for a posterior field. J Comp Neurol 453:345-360.

Egorova M, Vartanyan I, Ehret G (2006) Frequency response areas of mouse inferior colliculus neurons. II. Critical bands. NeuroReport 17:1783-1786.

Ehret G, Merzenich MM (1985) Auditory midbrain responses parallel spectral integration phenomena. Science 227:1245-1247.

Ehret G, Merzenich MM (1988) Complex sound analysis (frequency resolution, filtering and spectral integration) by single units of the inferior colliculus of the cat. Brain Res 472:139-163.

Ehret G, Schreiner CE (2005) Spectral and intensity coding in the auditory midbrain. In: The inferior colliculus (Winer JA, Schreiner CE, eds), pp 312-345. New York: Springer.

Evans EF (1979) Neuroleptanesthesia for the guinea pig. An ideal anesthetic procedure for long-term physiological studies of the cochlea. Arch Otolaryngol 105:185-186.

Faye-Lund H, Osen KK (1985) Anatomy of the inferior colliculus in rat. Anat Embryol (Berl) 171:1-20.

Friauf E (1992) Tonotopic order in the adult and developing auditory system of the rat as shown by c-fos immunocytochemistry. Eur J Neurosci 4:798-812.

Greenwood DD (1990) A cochlear frequency-position function for several species-29 years later. J Acoust Soc Am 87:2592-2605.

Hernández O, Espinosa N, Pérez-González D, Malmierca MS (2005) The inferior colliculus of the rat: a quantitative analysis of monaural frequency response areas. Neuroscience 132:203-217.

Irvine DRF (1992) Physiology of the auditory brainstem. A review of the structure and function of auditory brainstem processing mechanisms. In: The mammalian auditory pathway: neurophysiology (Popper AN, Fay RR, eds), pp 153-231. New York: Springer. 
Kaltenbach JA, Lazor J (1991) Tonotopic maps obtained from the surface of the dorsal cochlear nucleus of the hamster and rat. Hear Res 51:149-160.

LeBeau FE, Malmierca MS, Rees A (2001) Iontophoresis in vivo demonstrates a key role for $\mathrm{GABA}_{\mathrm{A}}$ and glycinergic inhibition in shaping frequency response areas in the inferior colliculus of guinea pig. J Neurosci 21:7303-7312.

Lenarz T, Lim HH, Reuter G, Patrick JF, Lenarz M (2006) The auditory midbrain implant: a new auditory prosthesis for neural deafness-concept and device description. Otol Neurotol 27:838-843.

Lim HH, Anderson DJ (2006) Auditory cortical responses to electrical stimulation of the inferior colliculus: implications for an auditory midbrain implant. J Neurophysiol 96:975-988.

Lim HH, Anderson DJ (2007) Spatially distinct functional output regions within the central nucleus of the inferior colliculus: implications for an auditory midbrain implant. J Neurosci 27:8733-8743.

Lim HH, Lenarz T, Joseph G, Battmer RD, Samii A, Samii M, Patrick JF, Lenarz M (2007) Electrical stimulation of the midbrain for hearing restoration: insight into the functional organization of the human central auditory system. J Neurosci 27:13541-13551.

Malmierca MS (2003) The structure and physiology of the rat auditory system: an overview. Int Rev Neurobiol 56:147-211.

Malmierca MS, Blackstad TW, Osen KK, Karagülle T, Molowny RL (1993) The central nucleus of the inferior colliculus in rat: a Golgi and computer reconstruction study of neuronal and laminar structure. J Comp Neurol 333:1-27.

Malmierca MS, Seip KL, Osen KK (1995) Morphological classification and identification of neurons in the inferior colliculus: a multivariate analysis. Anat Embryol (Berl) 191:343-350.

Malmierca MS, Leergaard TB, Bajo VM, Bjaalie JG, Merchan MA (1998) Anatomic evidence of a three-dimensional mosaic pattern of tonotopic organization in the ventral complex of the lateral lemniscus in cat. J Neurosci 18:10603-10618.

Malmierca MS, Merchan MA, Henkel CK, Oliver DL (2002) Direct projections from cochlear nuclear complex to auditory thalamus in the rat. J Neurosci 22:10891-10897.

Malmierca MS, Saint Marie RL, Merchan MA, Oliver DL (2005) Laminar inputs from dorsal cochlear nucleus and ventral cochlear nucleus to the central nucleus of the inferior colliculus: two patterns of convergence. Neuroscience 136:883-894.

Merryll EG, Ainswoth A (1972) Glass-coated platinum coated tungsten microelectrodes. Med Biol Eng 10:662-672.

Merzenich MM, Reid MD (1974) Representation of the cochlea within the inferior colliculus of the cat. Brain Res 77:397-415.

Moore BC (1986) Parallels between frequency selectivity measured psychophysically and in cochlear mechanics. Scand Audiol Suppl 25:139-152.

Moore BC, Glasberg BR (2007) Modeling binaural loudness. J Acoust Soc Am 121:1604-1612.

Moore BC, Vickers DA, Plack CJ, Oxenham AJ (1999) Inter-relationship between different psychoacoustic measures assumed to be related to the cochlear active mechanism. J Acoust Soc Am 106:2761-2778.
Oliver DL (2005) Neuronal organization of the inferior colliculus. In: The inferior colliculus (Winer JA, Schreiner CE, eds), pp 69-114. New York: Springer.

Oliver DL, Morest DK (1984) The central nucleus of the inferior colliculus in the cat. J Comp Neurol 222:237-264.

Oliver DL, Beckius GE, Bishop DC, Kuwada S (1997) Simultaneous anterograde labeling of axonal layers from lateral superior olive and dorsal cochlear nucleus in the inferior colliculus of cat. J Comp Neurol 382:215-229.

Pérez-González D, Malmierca MS, Covey E (2005) Novelty detector neurons in the mammalian auditory midbrain. Eur J Neurosci 22:2879-2885.

Pérez-González D, Malmierca MS, Moore JM, Hernández O, Covey E (2006) Duration selective neurons in the inferior colliculus of the rat: topographic distribution and relation of duration sensitivity to other response properties. J Neurophysiol 95:823-836.

Rees A, Sarbaz A, Malmierca MS, Le Beau FE (1997) Regularity of firing of neurons in the inferior colliculus. J Neurophysiol 77:2945-2965.

Rose JE, Gross NB, Geisler CD, Hind JE (1966) Some neural mechanisms in the inferior colliculus of the cat which may be relevant to localization of a sound source. J Neurophysiol 29:288-314

Ryan AF, Furlow Z, Woolf NK, Keithley EM (1988) The spatial representation of frequency in the rat dorsal cochlear nucleus and inferior colliculus. Hear Res 36:181-189.

Schreiner CE, Langner G (1997) Laminar fine structure of frequency organization in auditory midbrain. Nature 388:383-386.

Semple MN, Aitkin LM (1979) Representation of sound frequency and laterality by units in central nucleus of cat inferior colliculus. J Neurophysiol 42:1626-1639.

Snyder RL, Sinex DG (2002) Immediate changes in tuning of inferior colliculus neurons following acute lesions of cat spiral ganglion. J Neurophysiol 87:434-452.

Snyder RL, Sinex DG, McGee JD, Walsh EW (2000) Acute spiral ganglion lesions change the tuning and tonotopic organization of cat inferior colliculus neurons. Hear Res 147:200-220.

Spirou GA, May BJ, Wright DD, Ryugo DK (1993) Frequency organization of the dorsal cochlear nucleus in cats. J Comp Neurol 329:36-52.

Sutter ML, Schreiner CE (1991) Physiology and topography of neurons with multipeaked tuning curves in cat primary auditory cortex. J Neurophysiol 65:1207-1226.

Yang Y, Saint Marie RL, Oliver DL (2003) Frequency resolution in the auditory brainstem determined by sound-induced expression of Fosprotein. Soc for Neurosci Abstr 29:592.11.

Yang Y, Saint Marie RL, Oliver DL (2004) The effect of binaural stimulation on frequency resolution in the rat inferior colliculus (IC). Assoc Res Otolaryngol Abs 27:1565.

Young ED (2008) Neural representation of spectral and temporal information in speech. Philos Trans R Soc Lond B Biol Sci 263:923-945.

Young ED, Voigt HF (1982) Response properties of type II and type III units in dorsal cochlear nucleus. Hear Res 6:153-169. 


\title{
Mecanismos de plasticidad (funcional y dependiente de actividad) en el cerebro auditivo adulto y en desarrollo
}

\author{
M.A. Izquierdo ${ }^{\text {a,b }}$, D.L. Oliver $^{\text {a,c }}$, M.S. Malmierca ${ }^{\text {a,b }}$ \\ MECANISMOS DE PLASTICIDAD (FUNCIONAL Y DEPENDIENTE DE ACTIVIDAD) \\ EN EL CEREBRO AUDITIVO ADULTO Y EN DESARROLLO
}

\begin{abstract}
Resumen. Introducción y desarrollo. Los sistemas sensoriales poseen una representación topográfica del epitelio sensorial en el sistema nervioso central. En la vía auditiva, esta representación da lugar a mapas tonotópicos. Durante las últimas cuatro décadas se han estudiado los cambios originados en estos mapas tonotópicos tras lesiones mecánicas periféricas o mediante la exposición de animales en desarrollo a un ambiente acústico enriquecido. Tales manipulaciones sensoriales inducen una reorganización plástica del mapa tonotópico de la corteza auditiva. Por el contrario, el trauma acústico no parece generar plasticidad funcional en núcleos subcorticales. Los mecanismos que producen estos cambios difieren tanto en su base molecular como en el curso temporal durante el cual acontecen y, a grandes rasgos, pueden diferenciarse dos tipos: los que implican un proceso activo de reorganización y los que sencillamente suponen un reflejo pasivo de la eliminación de aferencias periféricas. Sólo los primeros implican un proceso de reorganización plástico genuino. Así pues, la plasticidad neuronal es de importancia vital para el desarrollo correcto y funcional del sistema nervioso auditivo y para el subsiguiente tratamiento y rehabilitación tras la implantación de prótesis auditivas. Sin embargo, el desarrollo de plasticidad también puede generar sensaciones anormales como los acúfenos. En la actualidad, además de los estudios de plasticidad, ha surgido un nuevo concepto en neurobiología denominado 'estabilidad neuronal', cuyas implicaciones y bases conceptuales pueden ayudar a mejorar el tratamiento de las patologías auditivas. Conclusión. La combinación de plasticidad y estabilidad neuronal se plantea como una estrategia de futuro muy prometedora para diseñar nuevos tratamientos de las patologías auditivas. [REV NEUROL 2009; 48: 421-9]
\end{abstract}

Palabras clave. Estabilidad. Frecuencia óptima. Mapa tonotópico. Período crítico. Plasticidad dependiente de actividad. Plasticidad funcional. Trauma acústico.

\section{INTRODUCCIÓN}

Los sistemas sensoriales poseen una representación topográfica del epitelio sensorial en el sistema nervioso central. Esta característica fundamental también está presente en el sistema auditivo en forma de mapas tonotópicos de los receptores auditivos, en prácticamente todos los niveles de la vía auditiva [1]. Durante muchos años se ha pensado que estos mapas sensoriales sólo podían modificarse durante el desarrollo, especialmente a lo largo de determinados 'períodos críticos' que poseen una duración limitada [2]. También se creía que esta propiedad del sistema nervioso se perdía en el cerebro adulto [2,3]. Sin embargo, en la actualidad, sabemos que los mapas topográficos tienen una gran capacidad de reorganización si el sistema sensorial maduro se ve privado de sus aferencias normales de forma crónica, por ejemplo, a consecuencia de una lesión periférica [4-6] o como resultado de las experiencias sensoriales adquiridas a lo largo de la vida del individuo [7]. Además, se sabe que las propiedades de respuesta básicas de neuronas corticales aisladas se modifican a consecuencia de diferentes paradigmas de condicionamiento [8-10].

\footnotetext{
Aceptado tras revisión externa: 19.01.09.

${ }^{a}$ Unidad de Neurofisiología de la Audición. Instituto de Neurociencias de Castilla y León. ${ }^{b}$ Departamento de Biología Celular y Patología. Facultad de Medicina. Universidad de Salamanca. Salamanca, España. ${ }^{c}$ Department of Neuroscience. University of Connecticut Health Center. Farmington, Connecticut, Estados Unidos.

Correspondencia: Dr. Manuel S. Malmierca. Laboratorio 1: Unidad de Neurofisiología de la Audición. Instituto de Neurociencias de Castilla y León. Pintor Fernando Gallego, 1. E-37007 Salamanca. Fax: +34 923294750. E-mail:msm@usal.es

Estudio financiado por MICINN (BFU2006-00572) y JCYL-UE (GR221 y SAN673/SA20/08) para M.S.M., y por NIH (grant R01 DC00189) para D.L.O.

(C) 2009, REVISTA DE NEUROLOGÍA
}

Esta revisión se centra en los cambios plásticos inducidos en los mapas sensoriales auditivos a consecuencia de una modificación en sus aferencias y se hace hincapié, de manera especial, en los posibles mecanismos subyacentes a esa reorganización, que ha sido objeto de estudio en los últimos 40 años.

\section{QUÉ ENTENDEMOS POR 'PLASTICIDAD FUNCIONAL'}

Antes de profundizar en el estudio de las alteraciones en los mapas tonotópicos conviene definir el término 'plasticidad' porque en el lenguaje científico se abusa de él considerablemente y porque implica numerosos procesos cuyo origen está aún por determinar. El término 'plasticidad' se aplica a una gran cantidad de fenómenos, como la recuperación funcional tras una lesión, la neurogénesis en adultos, la reorganización de mapas corticales en función de las distintas experiencias sensoriales, los cambios sinápticos asociados al aprendizaje, etc. Todos estos fenómenos, y otros, suponen una modificación de la respuesta neuronal, pero no todos implican un cambio persistente en las propiedades funcionales de las neuronas [11]. Para que un cambio se considere una manifestación de 'plasticidad funcional' debe expresar algún tipo de mecanismo o proceso activo, que se inicia por un cambio en las aferencias y que no refleja una mera pérdida de aferencias sensoriales [12,13], sino que supone un proceso activo de readaptación frente a las condiciones cambiantes del medio (para una discusión detallada sobre la definición de plasticidad, véanse $[8,13,14])$. Este proceso activo podría implicar cambios en el número o eficacia de las sinapsis o cambios en las características neuronales intrínsecas de una o varias neuronas de la vía a través de la cual llegan las aferencias [13]. Dichos cambios en la eficacia sináptica están, en parte, mediados por la acción de neurotrofinas -entre las que destaca el factor 
neurotrófico derivado del cerebro (BDNF) [15]- o por la acción del factor de crecimiento similar a la insulina de tipo I (IGF-I) [16]. Además, los cambios en la eficacia sináptica estabilizan las conexiones de una determinada vía aferente una vez que éstas alcanzan su 'diana' [17] y pueden constituir un sustrato morfológico para el aprendizaje y la memoria. En concreto, existe un tipo de plasticidad sináptica asociativa, o hebbiana [18], basada en correlaciones temporales de aferencias. Las conexiones sinápticas que presentan correlaciones positivas se potencian y estabilizan, mientras que aquellas que muestran una correlación negativa o nula se desestabilizan o se eliminan [19]. Este fenómeno se fundamenta en que las aferencias procedentes de áreas sensoriales vecinas muestran, en general, más correlación entre sí de la que muestran con áreas no adyacentes. Por tanto, las áreas corticales adyacentes deberían representar regiones sensoriales vecinas, estableciendo de este modo un mapa topográfico [20].

Una de las causas de los mecanismos de plasticidad es la alteración del equilibrio entre aferencias excitatorias e inhibitorias, que puede desenmascarar aferencias latentes al núcleo deprivado [21]. Hoy día se sabe que esta alteración no sólo puede afectar a diferentes porciones dentro del campo receptivo [22], sino también a las bandas laterales que 'esculpen' el campo receptivo neuronal. La consecuencia final de los cambios en la inhibición es una expansión del campo receptivo [23-25] y, en última instancia, un cambio plástico del mapa tonotópico en el núcleo afectado. Esta alteración puede persistir de manera crónica [14,26].

En esta revisión se realiza una exposición detallada sobre plasticidad funcional en la representación sensorial en el cerebro auditivo, teniendo siempre presente que los cambios plásticos en dicha representación pueden deberse, en gran medida, a mecanismos de plasticidad que operan en la célula (plasticidad sináptica). Se centrará la atención en estudios clave sobre este fenómeno, desarrollados principalmente en la corteza auditiva [6,12,27-29], y en otros más recientes, llevados a cabo por nuestro grupo de investigación en el colículo inferior [30], un centro de procesamiento, integración y redistribución de la información auditiva subcortical del tronco del encéfalo [1,31].

\section{ESTUDIOS SOBRE PLASTICIDAD EN EL SISTEMA AUDITIVO}

Las cortezas sensoriales primarias, incluida la corteza auditiva de mamíferos adultos, muestran una gran capacidad plástica tras la alteración de sus patrones de aferencias por denervación periférica [12,13,32]; sin embargo, no está claro si existe o no y, en su caso, cuál es la contribución de los núcleos sensoriales subcorticales a dicha capacidad. Muchos de los modelos experimentales basados en lesiones mecánicas de la cóclea se han realizado en núcleos inferiores de la vía auditiva y no han encontrado pruebas de la existencia de plasticidad funcional troncoencefálica $[33,34]$ o han puesto de manifiesto la existencia de dicho fenómeno en determinadas zonas o 'parches' en el colículo inferior [35]. Sin embargo, estudios morfológicos han demostrado que en los núcleos cocleares se puede observar crecimiento axonal y de botones sinápticos tras lesiones por trauma acústico [36-38]. Por otro lado, Kamke et al [39] revelaron la existencia de cambios plásticos en el tálamo (cuerpo geniculado medial) similares a los que ocurren a nivel cortical. Estos resultados sugieren que los fenómenos de plasticidad funcional aparecen por primera vez y de manera evidente en el tálamo.
Un tercer tipo de estudios, desarrollados por el grupo de Merzenich [27-29,40], se basa en la exposición de animales de experimentación a un ambiente acústico enriquecido durante el desarrollo. Este modelo conduce a la modificación plástica de la representación auditiva cortical. Dicha alteración depende del desarrollo de las aferencias sensoriales e incluso puede determinarse de manera muy exquisita un breve período ("período crítico'), durante el cual el desarrollo de dichas aferencias determina la reorganización plástica cortical [27,28], que es más limitada en la corteza auditiva adulta. Los mecanismos que originan este tipo de modificaciones plásticas son diferentes a los que aparecen en la plasticidad funcional, y ello se refiere como 'plasticidad dependiente de actividad' [27-29,41-44].

Así pues, la plasticidad es un proceso adaptativo muy deseable que permite la reparación neuronal tras un traumatismo cerebral, el aprendizaje a lo largo de la vida y la adaptación a cambios medioambientales [45].

Por todo ello, resulta muy conveniente y útil revisar la existencia de plasticidad en el cerebro auditivo adulto y durante el desarrollo como consecuencia de la modificación periférica de sus aferencias, ya sea fomentando su actividad o eliminándolas. De esta manera podremos entender los posibles mecanismos de recuperación que operan tras una lesión en los receptores, determinar las consecuencias centrales de una alteración en el desarrollo o comprender las bases que regulan el aprendizaje y la memoria.

\section{PLASTICIDAD INDUCIDA POR LESIONES MECÁNICAS DEL ÓRGANO DE CORTI}

Muchos de los estudios sobre plasticidad funcional en el sistema auditivo han sido llevados a cabo por el grupo de investigación de Irvine [6,8,12,13,34,35,39,46]. El modelo utilizado por este grupo se basa en lesionar mecánicamente una zona restringida de la cóclea de animales adultos. Para ello, utilizan una micropipeta de vidrio con la cual destruyen parte del órgano receptor y producen así una pérdida restringida en la sensibilidad auditiva [12]. Posteriormente, realizan registros electrofisiológicos para elaborar un mapa tonotópico del núcleo auditivo objeto de su estudio.

A nivel cortical, este tipo de lesiones provoca una reorganización en el mapa tonotópico. Esta reorganización cumple los requisitos antes descritos para un cambio plástico funcional [6], es decir, implica un proceso activo porque, como veremos, los umbrales de respuesta en la zona reorganizada son normales. El resultado es una resintonización, o cambio en la frecuencia óptima de respuesta, de las neuronas corticales que representan la zona lesionada de la cóclea (la frecuencia óptima es aquella frecuencia del sonido a la que una neurona responde con un umbral más bajo; el campo receptivo o mapa de frecuencias de las neuronas tiene forma de $\mathrm{V}$, con el pico indicando la frecuencia óptima y una 'cola' de respuesta a bajas frecuencias).

Esta reorganización afecta a la corteza auditiva primaria donde proyecta la cóclea lesionada, es decir, afecta a la corteza contralateral a la lesión (Fig. 1). La región cortical que se ve privada de sus aferencias normales tras la lesión no permanece silente, sino que pasa a ser ocupada por una representación expandida de las zonas adyacentes de la cóclea y, por lo tanto, de las frecuencias que estos lugares representan [12]. Este tipo de estudios posee la ventaja de que la corteza auditiva ipsilateral a la lesión se puede utilizar como autocontrol, ya que los recepto- 


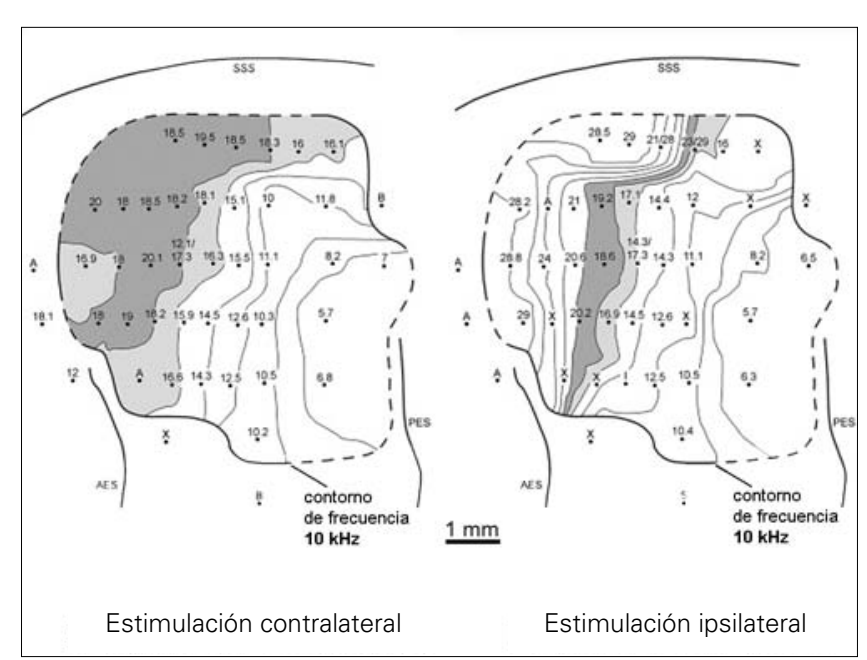

Figura 1. Mapa tonotópico de la corteza auditiva primaria. Las líneas finas delimitan áreas de isofrecuencia (zonas que responden a la misma frecuencia). El área representada en gris claro corresponde a la frecuencia a la que se realizó la lesión coclear. El panel de la derecha ilustra la representación de las frecuencias (tonotopía) en la corteza control (ipsilateral a la lesión mecánica de la cóclea), y el de la izquierda muestra la reorganización sufrida por el mapa tonotópico tras la lesión. Las frecuencias adyacentes a la lesión (representadas en gris oscuro) sufren una expansión, es decir, están más representadas que en la corteza auditiva control (modificado de [77]).

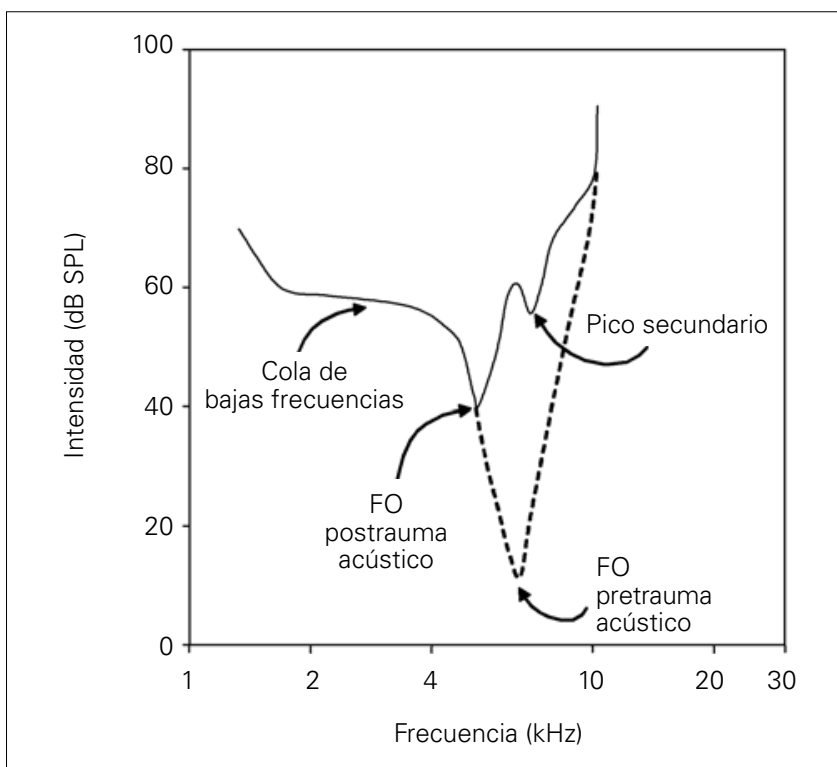

Figura 2. Esquema de un mapa de frecuencias (campo receptivo) de una neurona antes (línea discontinua) y después (línea continua) de sufrir un trauma acústico. La zona más sensible -frecuencia óptima (FO)-previa al trauma acústico desaparece a consecuencia de la eliminación de aferencias desde la zona lesionada de la cóclea. La 'nueva' frecuencia óptima de respuesta tras el trauma acústico se desplaza a la izquierda, hacia la cola de bajas frecuencias -FO postrauma acústico-, dando la impresión errónea de que se ha producido una 'resintonización' en la frecuencia de respuesta. En muchas neuronas se observa un pico secundario que representa un residuo de la respuesta previa a la lesión (modificado de [78]).

res que proyectan a esa corteza no han sufrido daño alguno porque la lesión coclear que provocan al animal es mecánica y unilateral. De manera análoga, se ha visto una reorganización de características similares, provocada por lesiones periféricas restringidas, en la corteza somatosensorial (donde se describió es- te tipo de alteración por primera vez [4]), así como en las cortezas visual y motora de animales adultos [47].

Estas lesiones, que también provocan una reorganización plástica similar en el tálamo, no producen el mismo efecto en niveles inferiores de la vía auditiva. En el colículo inferior se ha descrito una plasticidad 'en parches' [35], con zonas en las que existe un cambio de naturaleza plástica en la respuesta de sus neuronas. Este cambio plástico podría contribuir de forma activa a la generación de la plasticidad que se observa a nivel cortical.

En los núcleos cocleares, en cambio, hay una ausencia de plasticidad funcional tras una lesión coclear restringida [34] que limita el desarrollo de plasticidad en la representación sensorial de la vía auditiva al colículo inferior y núcleos superiores de la vía. Por ello, el colículo inferior constituye una pieza clave en investigaciones futuras sobre plasticidad en el sistema nervioso auditivo porque representa el primer núcleo de la vía en el que se han observado indicios de plasticidad como consecuencia de este tipo de lesiones periféricas. Sin embargo, como ya mencionamos con anterioridad, estudios morfológicos recientes contradicen esta idea [36-38].

Robertson e Irvine formularon una teoría que explica la reorganización, de naturaleza 'no plástica', observada en los mapas sensoriales de los núcleos cocleares y determinadas porciones del colículo inferior [6,34]. Dicha hipótesis, a la cual denominaron hipótesis de la 'respuesta residual', plantea que las consecuencias de una lesión periférica sobre la representación central de los receptores es tal que los mapas sensoriales reflejan únicamente la pérdida de aferencias, sin dar lugar a ningún proceso activo de reorganización que pueda considerarse plasticidad. Aparecen 'nuevas' frecuencias óptimas de respuesta, que corresponden a la porción del campo receptivo original cuyas aferencias no han sido eliminadas por la lesión periférica, es decir, son el 'residuo' de la respuesta previa a la lesión. Por tanto, la neurona no resintoniza su frecuencia de respuesta, sino que el cambio en frecuencia que se observa en los campos receptivos de las neuronas se debe a las aferencias 'sanas' que llegan a la neurona tras la lesión y que, en condiciones normales, constituían la 'cola' de bajas frecuencias de los campos receptivos. Esta hipótesis se ilustra en el esquema de la figura 2, donde podemos observar que, tras una lesión periférica, la parte más sensible a la estimulación es la porción de la cola de bajas frecuencias (Fig. 2, línea continua), con umbrales más bajos que los correspondientes a la frecuencia de respuesta 'original' -la frecuencia que ha resultado lesionada- (Fig. 2, línea discontinua) y una frecuencia más baja -por su posición en la cola-, dando la 'falsa' impresión en el mapa tonotópico de que la zona de repuesta a bajas frecuencias ha 'invadido' la zona de representación de la lesión periférica (o zona de proyección de la lesión [33]), aunque en realidad, se produce un fuerte incremento de los umbrales de respuesta a la o las frecuencias lesionadas. Dicho incremento de los umbrales provoca que, tras la lesión, la frecuencia más sensible sea más baja que la frecuencia previa a la lesión. La similitud con la reorganización del mapa tonotópico que tiene lugar tras un cambio plástico (invasión de la zona de representación de la lesión por frecuencias adyacentes) ha provocado que este modelo se conozca también como modelo de "pseudoplasticidad' [33]. La respuesta a la frecuencia óptima original sigue presente, pero con un umbral muy elevado (Fig. 2) y en muchas ocasiones constituye un pico de respuesta secundario o residual, que es el vestigio del pico de respuesta del campo receptivo original [48]. Este reflejo pasivo de la lesión, con bajas 
frecuencias artefactuales, también se ha descrito en fibras del nervio auditivo y de una forma análoga se ha explicado por la pérdida del pico de respuesta original [49], de manera que el efecto de la lesión parece transmitirse a lo largo de la vía. En algunos casos, además, la cola de bajas frecuencias puede presentar cierta hipersensibilidad, es decir, sus umbrales de respuesta son más bajos de lo esperable. Este hecho provoca la sensación de que el campo receptivo ha sufrido una resintonización a una frecuencia más baja, tanto en el nervio auditivo $[48,49]$ como en centros superiores, incluida la corteza auditiva [5,12,39], y que podría deberse al desenmascaramiento de aferencias latentes preexistentes, como se discutirá más adelante.

Por ello, los umbrales de respuesta en la zona de proyección de la lesión constituyen el 'dato' fundamental para diferenciar entre cambios plásticos genuinos y respuestas residuales no plásticas.

\section{PLASTICIDAD INDUCIDA POR TRAUMA ACÚSTICO}

El trauma acústico (o daño acústico inducido por ruido) es una lesión del oído interno que causa una pérdida auditiva neurosensorial, a consecuencia de la exposición prolongada a un sonido de alta intensidad. Esta afección es cada día más frecuente debido a la sobreexposición sonora típica de las sociedades modernas. Por ello, la probabilidad de sufrir una lesión acústica es mucho mayor que la probabilidad de sufrir una lesión mecánica de la cóclea. Aunque los trabajos basados en lesiones mecánicas de la cóclea han contribuido, significativamente, a esclarecer los mecanismos básicos de plasticidad que operan a nivel cortical tras una lesión periférica, es necesario el estudio de las lesiones producidas tras un trauma acústico. Todo ello ayudará a entender mejor los cambios que ocurren en el sistema auditivo tras lesiones del órgano de Corti, pues en realidad este mecanismo de lesión es más frecuente y, en cierto modo, la causa más 'natural' de lesión auditiva.

El modelo de lesión mecánica provoca una lesión localizada y restringida en el órgano de Corti (órgano receptor auditivo), mientras que el trauma acústico afecta a un área más amplia de frecuencias, dependiendo de la intensidad y duración del estímulo utilizado [36-38,50-53]. Además, los efectos entre animales son muy variables [30,50-54]. Todo ello dificulta, en gran medida, la interpretación de los resultados obtenidos tras un trauma acústico.

A nivel central, este tipo de pérdida auditiva produce una reorganización persistente del mapa tonotópico del colículo inferior en animales adultos [55]. Dicha modificación consiste en expansiones en la representación de determinadas frecuencias a lo largo del colículo inferior. No obstante, en la mayoría de casos, esa reorganización se acompaña de un incremento muy notable de los umbrales de respuesta (> $20 \mathrm{~dB}$ ), demostrando así su naturaleza pseudoplástica. Este incremento en los umbrales de respuesta a determinadas frecuencias observado en los mapas tonotópicos (elaborados a partir de las respuestas de pobla-
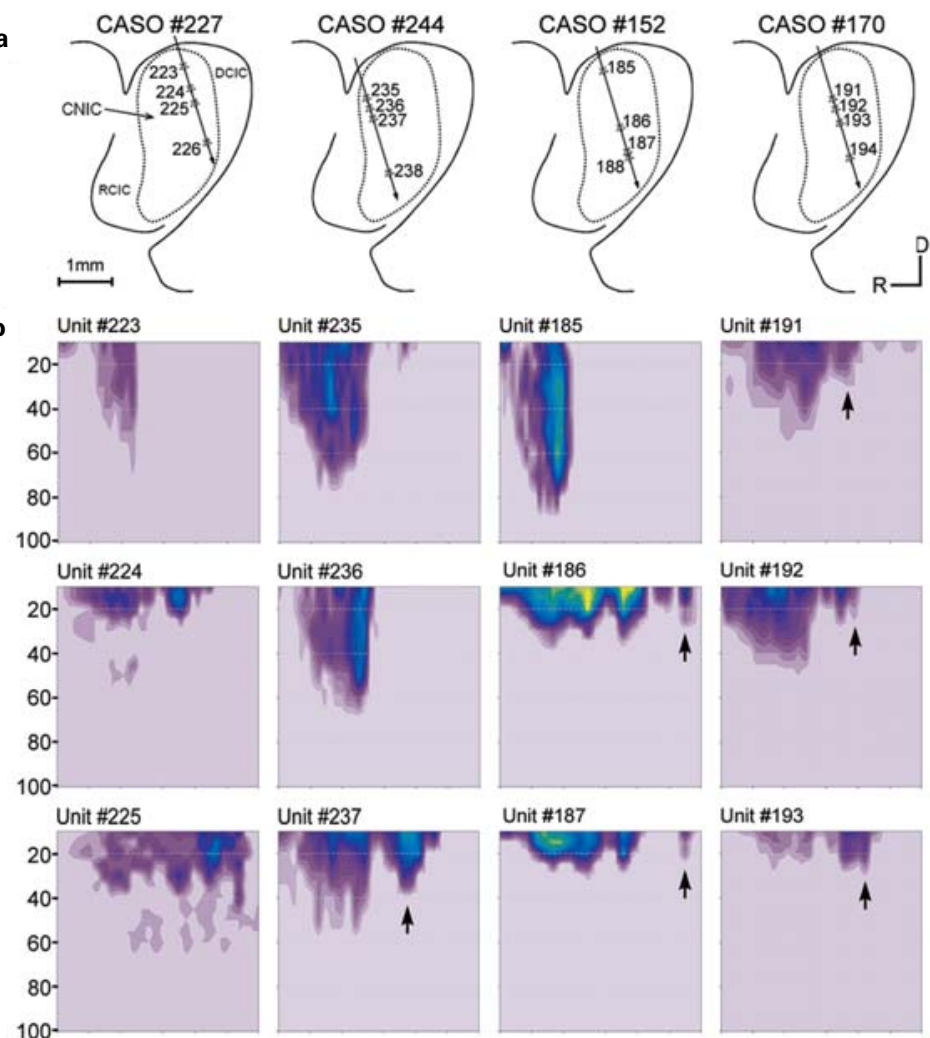

Unit \#192
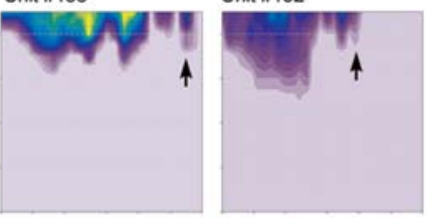

Unit \#237

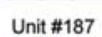

Unit \#193
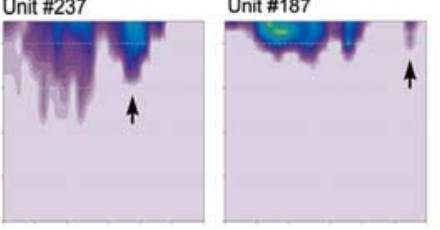

Un:
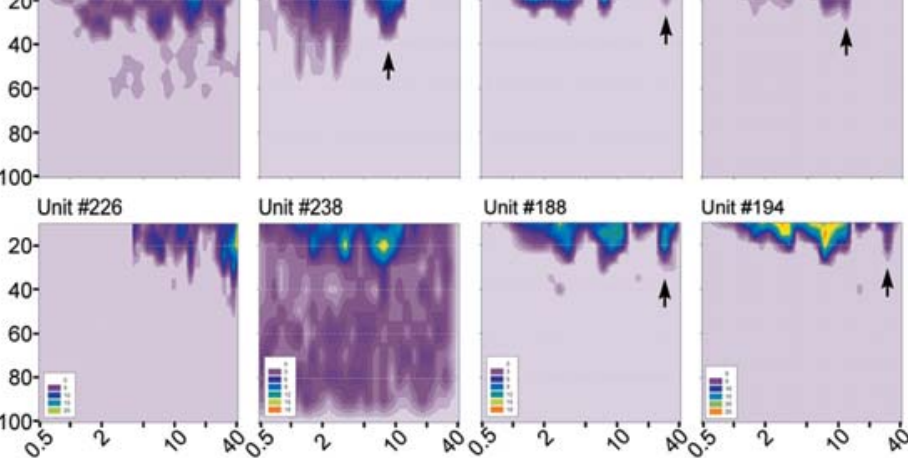

Unit \#238

Unit \#188

Unit \#194
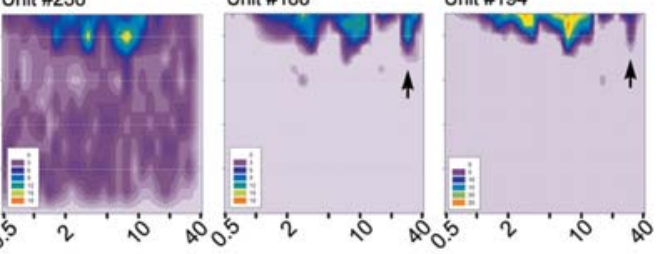

Frecuencia $(\mathrm{kHz})$

Figura 3. Respuesta neuronal tras un trauma acústico. a) Recorrido del electrodo de registro a través del colículo inferior, indicando con una estrella la posición en la que se registraron unidades neuronales aisladas. b) Mapas de frecuencia de dichas neuronas. Cada onas registradas en el mismo tracto. La escala de colores covo. El nivel de intensidad sonora se expresa en decibelios (dB) de atenuación. Se puede observar un fuerte aumento en los umbrales de respuesta a medias y altas frecuencias, acompañado de un incremento en la tasa de actividad espontánea y picos secundarios a altas frecuencias (flechas verticales) (tomado de [30]).

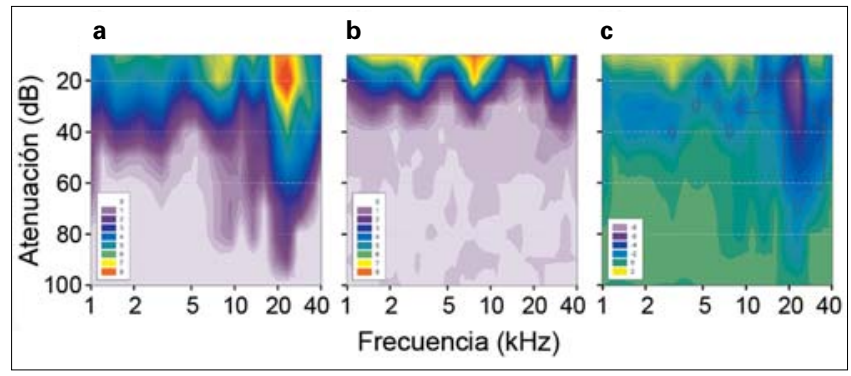

Figura 4. Diferencia en la respuesta entre un grupo control (a) de neuronas del colículo inferior ( $n=20)$ y un grupo de neuronas (b) tras un trauma acústico $(n=31)$. Los mapas de frecuencias en a y b representan, respectivamente, la suma de la respuesta para cada una de las poblaciones neuronales. El mapa de frecuencias (c) resulta de la sustracción de b menos a; muestra diferencias estadísticamente significativas en la respuesta tras un trauma acústico (área delimitada por la línea de puntos). Estas diferencias se centran en el 'pico' o zona de máxima sensibilidad del campo receptivo de la neurona (tomado de [30]). 


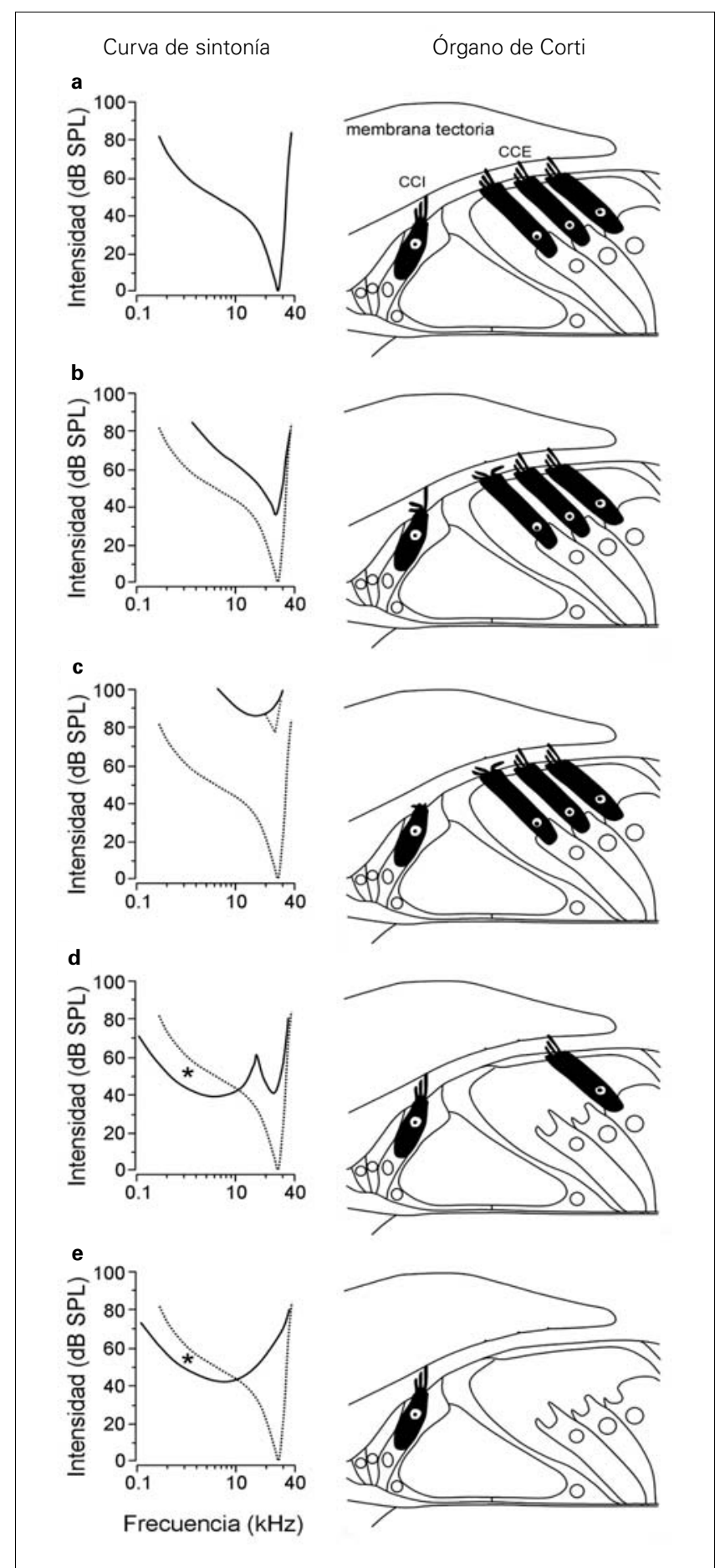

Figura 5. Representación esquemática de la curva de sintonía (curva de respuesta) y del órgano de Corti normal (a) y de cuatro situaciones diferentes de daño coclear (b, $c, d, e)$. Cada caso se muestra con su correspondiente curva de sintonía, procedente de las fibras radiales que inervan esa región. En b y c se muestra un aumento de los umbrales provocado por lesiones en los estereocilios de las células ciliadas internas (CCI) y externas (CCE). En b se produce una desorganización de los estereocilios en las CCI y CCE; los umbrales aumentan, pero se mantiene la sintonía neuronal (respuesta específica a determinadas frecuencias). En c se pierde la sintonía neural por una pérdida de estereocilios en las $\mathrm{CCl}$. En d y e se representa un aumento de los umbrales con pérdida de la sintonía neuronal, causada por una pérdida total de las CCE (e), aunque puede subsistir un pico de respuesta residual a la frecuencia óptima original si no se pierden todas las CCE (d). En ambos casos (d, e) se observa hiperactividad en la cola de bajas frecuencias (asterisco) originada, en parte, por el desacoplamiento entre las células ciliadas y la membrana tectoria (modificado de [48]). ciones neuronales) se corresponde con un aumento generalizado en los umbrales de respuesta al sonido de neuronas individuales [30] (Fig. 3b) y se acompaña de un incremento en la tasa de actividad espontánea, a consecuencia del trauma acústico. La lesión se centra en la zona más sensible (aquella que posee un umbral de respuesta más bajo) del campo receptivo de las neuronas, el pico de su mapa de frecuencias, y no sólo afecta a las neuronas que responden media octava por encima de la frecuencia del estímulo traumático [56], sino que abarca casi todo el rango auditivo del animal, excepto para la zona de frecuencias bajas. Ello se debe a que los receptores para bajas frecuencias del órgano de Corti reciben una menor vibración de la membrana basilar como consecuencia de la onda de presión sonora [57] (Figs. 3 b y 4). Esas aferencias, que forman la porción de bajas frecuencias del campo receptivo de las neuronas del colículo inferior, son las que constituyen el residuo de la respuesta previa a la lesión y reflejan lo que sucede periféricamente en el nervio auditivo, como se puede observar en el esquema de la figura 5. En dicha figura se ilustra cómo, dependiendo del daño provocado en las células receptoras (células ciliadas), la curva de respuesta del nervio auditivo se ve alterada en mayor o menor medida [48].

La reorganización de naturaleza 'no plástica' observada como consecuencia del trauma acústico, así como los estudios llevados a cabo por Irvine et al [35] que hemos descrito en el apartado anterior, ponen de manifiesto que el colículo inferior posee una capacidad limitada de generar plasticidad a largo plazo. Desgraciadamente, no existen estudios detallados sobre las consecuencias del trauma acústico en los mapas auditivos en todos los niveles de la vía auditiva similares a los obtenidos por nuestro grupo de investigación en el colículo inferior [30], por lo que, en este momento, concretar el nivel de la vía en el que emerge el fenómeno de plasticidad funcional (en el caso de que exista tras un trauma acústico) resulta tremendamente especulativo.

Por otro lado, diversos estudios [58,59] en los que se lesionan las células del ganglio espiral han demostrado una reorganización rápida y dinámica en los campos receptivos de neuronas del colículo inferior inmediatamente después de provocar la lesión. Sin embargo, esta capacidad de generar plasticidad posee una duración muy limitada de, aproximadamente, entre unos pocos minutos y una hora [58,59]. Este hecho hace pensar en la posible existencia de una ventana temporal, de duración limitada, en la que se produciría la reorganización plástica de los mapas tonotópicos, fuera de la cual no es posible observar dichos cambios (p. ej., en experimentos con animales crónicos) o la reorganización que se produce no es tan evidente.

Otra posibilidad a contemplar es que este tipo de plasticidad funcional para la codificación de la frecuencia emerge en centros superiores de la vía auditiva [39,60,61], iniciándose en el colículo inferior [30,35]. Esto puede suceder tras una lesión mecánica de la cóclea, pero contrasta con el hecho de que no se ha demostrado aún la generación de plasticidad en los mapas tonotópicos a ninguno de los niveles de la vía auditiva, como consecuencia de un trauma acústico en animales crónicos. Una posible explicación a dicha limitación en el desarrollo de plasticidad es el grado de lesión inducido en los receptores. Una lesión muy amplia en frecuencia (como la que ocurre tras un trauma acústico) podría impedir la generación de plasticidad o limitar una posible recuperación en la respuesta funcional de las neuronas auditivas en el colículo inferior [30], así como en otros núcleos de la vía auditiva tras la lesión. Por tanto, la res- 
puesta de dichas neuronas tras la lesión sería de tipo residual. Por ello, no podemos descartar que sea necesario conservar un determinado porcentaje de las aferencias sensoriales para que pueda generarse un fenómeno de plasticidad funcional.

\section{PLASTICIDAD INDUCIDA POR EXPOSICIÓN A UN AMBIENTE ACÚSTICO ENRIQUECIDO}

Las experiencias vitales a edad temprana tienen un impacto muy importante y duradero sobre la percepción del cerebro adulto. Desde hace más de 40 años sabemos que existe una etapa posnatal breve de elevada receptividad para el sistema nervioso, conocida comúnmente como 'período crítico' [2]. Aunque el aprendizaje a lo largo de la vida es posible, la plasticidad neuronal durante este período crítico resulta máxima, facilitando la adaptación del cerebro en desarrollo a su medio ambiente y proporcionándole una experiencia basal estable y duradera [27-29]. La increíble facilidad con la que los niños criados y educados en diferentes culturas pueden adquirir de forma natural el lenguaje de su entorno supone una de las múltiples manifestaciones de esta plasticidad cerebral tan intensa; de hecho, resulta muy difícil adquirir un habla normal sin una retroalimentación auditiva y la capacidad de aprendizaje [62]. La actividad provocada por el sonido es importante para el desarrollo auditivo normal y para los cambios sinápticos dependientes de actividad que tienen lugar en el sistema auditivo durante el desarrollo [41,43, 44]. Sin embargo, la existencia de ese período limitado de plasticidad cerebral puede resultar potencialmente problemático cuando se asocia a un medio ambiente prematuro empobrecido o distorsionado; por ejemplo, el desarrollo normal de los mapas tonotópicos resulta enormemente alterado en animales sometidos a estimulación con tonos [28] y se degrada profundamente cuando los animales se crían durante el período crítico en un ambiente con ruidos modulados o continuos [29,40]. Estudios similares sobre el desarrollo de la localización del sonido muestran resultados similares [41]. Este ambiente retarda enormemente la aparición de la representación topográfica 'adulta' y el refinamiento de la selectividad en la respuesta de la corteza auditiva, en comparación con el patrón de desarrollo normal. Por otro lado, la exposición continua a ruido provoca una prolongación del período crítico, de tal forma que si esos animales se someten posteriormente a estimulación con pulsos de tonos puros, la corteza auditiva se reorganiza rápidamente, demostrando que la plasticidad inducida por exposición a estímulos sonoros, característica del período crítico, se mantiene activa [40].

Un estudio más reciente demuestra que la exposición a tonos puros induce alteraciones profundas y persistentes en la representación cortical del sonido sólo si la exposición se produce durante un breve período comprendido entre P11 y P13 [27,28], demostrando la existencia y duración del período crítico en ratas. La figura 6 muestra un mapa de la superficie de la corteza auditiva en animales control y en animales expuestos a un tono puro durante el período crítico. Podemos observar cómo la superficie de la corteza auditiva que responde a la frecuencia de exposición $(7 \mathrm{kHz})$, en animales estimulados a dicha frecuencia, aumenta en extensión, abarcando un área más amplia de la corteza auditiva (en detrimento del área cortical dedicada a fre-

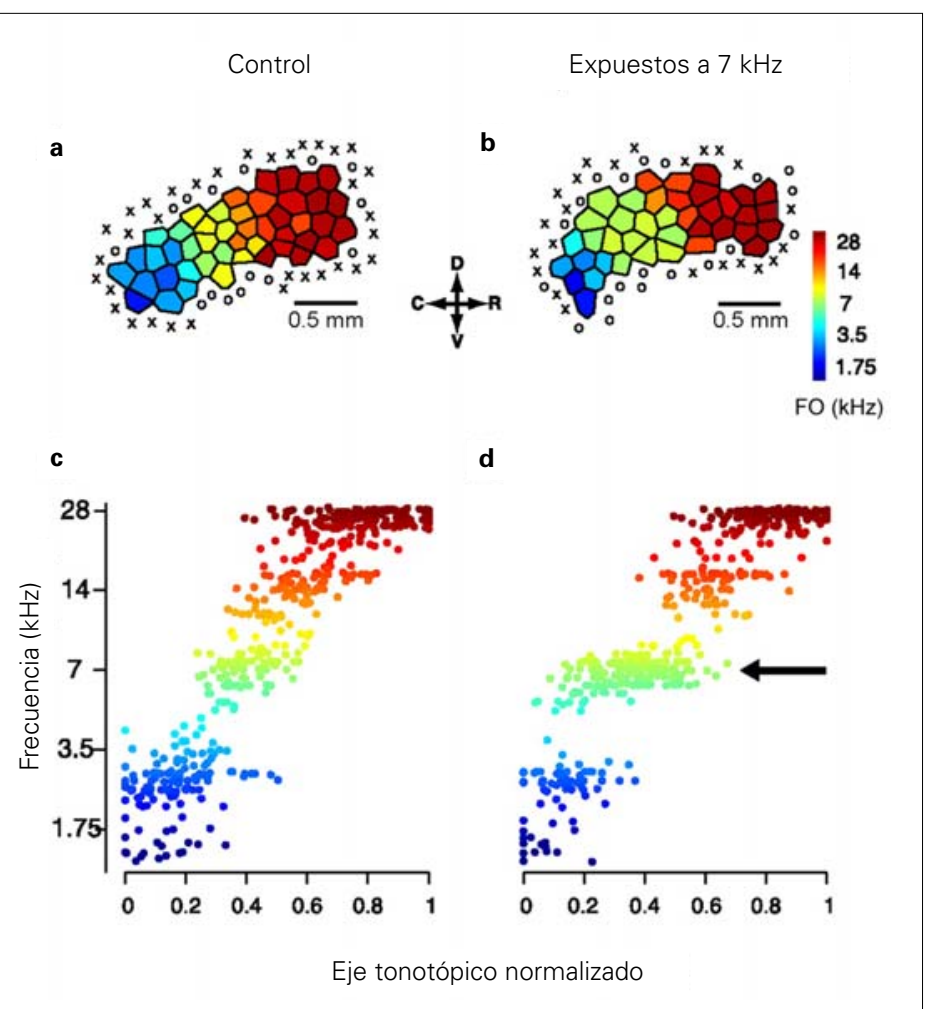

Figura 6. Efectos de la exposición a un sonido durante el período crítico sobre los mapas tonotópicos de la corteza auditiva. a) Mapa tonotópico de la corteza auditiva de una rata control a P18. b) Mapa tonotópico de la corteza auditiva a P18 de una rata sometida a estimulación con tonos puros de $7 \mathrm{kHz}$ durante el período crítico; se observa un incremento en el área de respuesta a $7 \mathrm{kHz}$ en el mapa tonotópico de la corteza auditiva de animales estimulados. c, d) Distribución de las frecuencias óptimas de respuesta en función de un eje tonotópico normalizado en animales control (c) y en animales estimulados durante el período crítico (d): se aprecia un incremento del número de sitios de registro que responden a la frecuencia de estimulación (7 kHz) en los animales del grupo experimental (flecha) y una disminución en la respuesta a las frecuencias adyacentes a dicha frecuencia de estimulación (modificado de [27]).

cuencias adyacentes), es decir, incrementa el número de neuronas que responden a la frecuencia de estimulación. Esta reorganización supone un fenómeno de plasticidad genuina y dependiente de actividad, ya que los umbrales de respuesta en el área expandida no difieren significativamente de los umbrales normales para esa frecuencia en lo que sería su ubicación normal y surge como consecuencia de una actividad aumentada o estimulación enriquecida [27]. Sin embargo, no está claro si este tipo de plasticidad se genera a nivel cortical o se transmite a la corteza desde el colículo inferior [63-65], a través de un proceso de codificación jerárquico 'de abajo hacia arriba' desde centros subcorticales.

\section{POSIBLES APLICACIONES TERAPÉUTICAS}

La reorganización plástica de los mapas tonotópicos se ha relacionado con sensaciones anormales, como los acúfenos o tinnitus $[42,66]$. El acúfeno es una sensación auditiva 'fantasma' [67] que acompaña con frecuencia a la pérdida auditiva, aunque también se manifiesta como consecuencia de la hipersensibilidad a determinados fármacos (salicilatos, quinina, antibióticos aminoglicósidos y cisplatino [68]). Esta patología es más propia de la vejez, pero también puede darse en niños. Se pien- 
sa que en el futuro esta afección será cada vez más frecuente, debido al incremento de las pérdidas auditivas a consecuencia del ocio (p. ej., por escuchar música con un volumen muy elevado) y la contaminación acústica medioambiental, combinado con un aumento en la esperanza de vida [68]. Los mecanismos de plasticidad que producen este fenómeno se han estudiado ampliamente $[66,68]$. La exposición a un sonido de alta intensidad, así como la administración de fármacos, no afecta o disminuye la tasa de actividad espontánea de las fibras del nervio auditivo. Por el contrario, los mismos tratamientos producen un incremento en la actividad espontánea de diversas estructuras del sistema nervioso central, incluyendo el núcleo coclear dorsal, el colículo inferior y la corteza auditiva. Este incremento de la actividad espontánea se atribuye a un descenso en los niveles de inhibición central (probablemente gabérgica) en dichas estructuras auditivas, que se traduce en hiperactividad neuronal [26,69-71]. Por ello, la reorganización plástica de los mapas tonotópicos y el consiguiente aumento en la actividad espontánea de sus neuronas puede resultar más perjudicial que beneficioso $[66,68]$.

En el desarrollo de futuros tratamientos para la sordera puede ser más efectivo buscar un método basado en mantener la 'estabilidad' de las respuestas neuronales, en lugar de centrarse en inducir plasticidad como mecanismo de reparación de la lesión acústica, ya que la plasticidad puede conducir, como se ha descrito, a una alteración en el procesamiento de la información auditiva. Por contra, la estabilidad neuronal emerge como un concepto de vital importancia a la hora de entender los mecanismos que operan tras una lesión periférica y sus posibles implicaciones clínicas. A lo largo del desarrollo, los factores proapoptóticos disminuyen, mientras que los mecanismos de neuroprotección se incrementan. Como resultado, las neuronas maduras se hacen menos dependientes de las aferencias que reciben para su supervivencia [72,73]. En estos trabajos se han encontrado numerosas neuronas que sobreviven, evitando una ruta apoptótica, a pesar de haber sufrido una gran deaferentación. Así pues, en respuesta a un daño periférico, el cerebro adulto debe afrontar dos retos importantes y supuestamente paradójicos: estabilidad y plasticidad. Por un lado, debe preservar los circuitos y la organización sináptica necesarios para mantener la conducta y la memoria a largo plazo, y por otro, debe permitir que dichos circuitos se adapten a los cambios ambientales, el aprendizaje o las lesiones. Por ello, mientras que la plasticidad es claramente relevante, la estabilidad debe suponer una propiedad emergente por sus implicaciones conceptuales y clínicas [72-74].

El desarrollo de plasticidad en el sistema nervioso auditivo desempeña un papel muy importante en los pacientes con implantes cocleares. Las probabilidades de éxito de un implante coclear aumentan si la operación se realiza a una edad temprana. Asimismo, el rendimiento clínico de los usuarios de implantes mejora con la experiencia auditiva. Se producen determinados cambios en el sistema auditivo que inducen esas mejoras en la percepción del lenguaje con el uso de los implantes (plasticidad). En la actualidad no sabemos si esas mejoras son el resultado exclusivamente de modificaciones corticales o involucran cambios en núcleos previos de la vía auditiva. Así pues, resulta evidente que se precisan estudios futuros para esclarecer los detalles de estos mecanismos, aunque investigaciones preliminares sugieren que la mejoría observada en pacientes con implantes cocleares que han sido tratados con rehabilitación, así como el éxito de los implantes realizados en el colículo inferior, podrían deberse a una reorganización plástica de los mapas corticales, a consecuencia de la estimulación 'artificial' de las fibras aferentes [75,76].

\section{CONCLUSIONES}

Esclarecer los mecanismos de plasticidad, así como los factores que los controlan, proporcionará datos fundamentales para entender cómo el cerebro se desarrolla y mantiene sus propiedades funcionales en condiciones óptimas. Esta información también orientará el abordaje clínico a la hora de mejorar o revertir los efectos de las enfermedades, lesiones o disfunciones del sistema auditivo.

Entre los modelos animales usados para el estudio de la plasticidad neuronal auditiva destacan los modelos de lesión periférica de receptores, que permiten entender los mecanismos de plasticidad funcional (sea por lesión mecánica o por trauma acústico), y la exposición a un ambiente acústico enriquecido durante el desarrollo, que permite estudiar los mecanismos de plasticidad dependiente de actividad. La exposición a un ambiente acústico enriquecido durante el desarrollo ha posibilitado determinar y modificar la duración del período crítico necesario para la ocurrencia de plasticidad. No obstante, los mecanismos responsables de esa breve etapa posnatal de intenso desarrollo de plasticidad no se conocen aún con claridad, por lo que este modelo animal puede contribuir de forma notable a su esclarecimiento.

\section{BIBLIOGRAFÍA}

1. Malmierca MS. The structure and physiology of the rat auditory system: an overview. Int Rev Neurobiol 2003; 56: 147-211.

2. Hubel DH, Wiesel TN. The period of susceptibility to the physiological effects of unilateral eye closure in kittens. J Physiol 1970; 206: 419-36.

3. Blakemore C, Van Sluyters RC. Reversal of the physiological effects of monocular deprivation in kittens: further evidence for a sensitive period. J Physiol 1974; 237: 195-216.

4. Merzenich MM, Kaas JH, Wall J, Nelson RJ, Sur M, Felleman D. Topographic reorganization of somatosensory cortical areas $3 \mathrm{~b}$ and 1 in adult monkeys following restricted deafferentation. Neuroscience 1983; 8: 33-55.

5. Merzenich MM, Kaas JH, Wall JT, Sur M, Nelson RJ, Felleman DJ. Progression of change following median nerve section in the cortical representation of the hand in areas $3 \mathrm{~b}$ and 1 in adult owl and squirrel monkeys. Neuroscience 1983; 10: 639-65.

6. Robertson D, Irvine DR. Plasticity of frequency organization in auditory cortex of guinea pigs with partial unilateral deafness. J Comp Neurol 1989; 282: 456-71.
7. Recanzone GH, Schreiner CE, Merzenich MM. Plasticity in the frequency representation of primary auditory cortex following discrimination training in adult owl monkeys. J Neurosci 1993; 13: 87-103.

8. Irvine DR, Wright BA. Plasticity of spectral processing. Int Rev Neurobiol 2005; 70: 435-72.

9. Ryugo DK, Weinberger NM. Differential plasticity of morphologically distinct neuron populations in the medical geniculate body of the cat during classical conditioning. Behav Biol 1978; 22: 275-301.

10. Weinberger NM. Associative representational plasticity in the auditory cortex: a synthesis of two disciplines. Learn Mem 2007; 14: 1-16.

11. Tsukahara N. Synaptic plasticity in the mammalian central nervous system. Annu Rev Neurosci 1981; 4: 351-79.

12. Rajan R, Irvine DR, Wise LZ, Heil P. Effect of unilateral partial cochlear lesions in adult cats on the representation of lesioned and unlesioned cochleas in primary auditory cortex. J Comp Neurol 1993; 338: $17-49$.

13. Calford MB. Dynamic representational plasticity in sensory cortex. Neuroscience 2002; 111: 709-38. 
14. Calford MB, Rajan R, Irvine DR. Rapid changes in the frequency tuning of neurons in cat auditory cortex resulting from pure-tone-induced temporary threshold shift. Neuroscience 1993; 55: 953-64.

15. Gómez-Palacio Schjetnan A, Escobar-Rodríguez ML. Codificación y retención de la memoria: el factor neurotrófico derivado del cerebro (BDNF) en la plasticidad sináptica. Rev Neurol 2007; 45: 409-17.

16. Rodríguez-De la Rosa L, Contreras-Rodríguez J, Cediel-Algovia R, León Y, Sánchez-Calderón H, Murillo-Cuesta S, et al. Acciones neurotróficas del factor de crecimiento similar a la insulina de tipo I en el oído interno. Rev Neurol 2007; 45: 245-50.

17. Morales B, Rozas C, Pancetti F, Kirkwood A. Períodos críticos de plasticidad cortical. Rev Neurol 2003; 37: 739-43.

18. Hebb DO. The organization of behavior. New York: John Wiley; 1949.

19. Singer W. Development and plasticity of cortical processing architectures. Science 1995; 270: 758-64.

20. Merzenich MM, Nelson RJ, Kaas JH, Stryker MP, Jenkins WM, Zook $\mathrm{JM}$, et al. Variability in hand surface representations in areas $3 \mathrm{~b}$ and 1 in adult owl and squirrel monkeys. J Comp Neurol 1987; 258: 281-96.

21. Rajan R. Receptor organ damage causes loss of cortical surround inhibition without topographic map plasticity. Nat Neurosci 1998; 1: 138-43.

22. Palombi PS, Caspary DM. GABA inputs control discharge rate primarily within frequency receptive fields of inferior colliculus neurons. J Neurophysiol 1996; 75: 2211-9.

23. Scholl B, Wehr M. Disruption of balanced cortical excitation and inhibition by acoustic trauma. J Neurophysiol 2008; 2: 646-56.

24. Hernández O, Espinosa,N, Pérez-González D, Malmierca MS. The inferior colliculus of the rat: a quantitative analysis of monaural frequency response areas. Neuroscience 2005; 132: 203-17.

25. LeBeau FE, Malmierca MS, Rees A. Iontophoresis in vivo demonstrates a key role for GABA(A) and glycinergic inhibition in shaping frequency response areas in the inferior colliculus of guinea pig. J Neurosci 2001; 21: 7303-12.

26. Wang J, Salvi RJ, Powers N. Plasticity of response properties of inferior colliculus neurons following acute cochlear damage. J Neurophysiol 1996; 75: 171-83.

27. De Villers-Sidani E, Chang EF, Bao S, Merzenich MM. Critical period window for spectral tuning defined in the primary auditory cortex (A1) in the rat. J Neurosci 2007; 27: 180-9.

28. Zhang LI, Bao S, Merzenich MM. Persistent and specific influences of early acoustic environments on primary auditory cortex. Nat Neurosci 2001; 4: 1123-30.

29. Bao S, Chang EF, Davis JD, Gobeske KT, Merzenich MM. Progressive degradation and subsequent refinement of acoustic representations in the adult auditory cortex. J Neurosci 2003; 23: 10765-75.

30. Izquierdo MA, Gutiérrez-Conde PM, Merchan MA, Malmierca MS. Nonplastic reorganization of frequency coding in the inferior colliculus of the rat following noise-induced hearing loss. Neuroscience 2008; 154: 355-69.

31. Loftus WC, Malmierca MS, Bishop DC, Oliver DL. The cytoarchitecture of the inferior colliculus revisited: a common organization of the lateral cortex in rat and cat. Neuroscience 2008; 154: 196-205.

32. Buonomano DV, Merzenich MM. Cortical plasticity: from synapses to maps. Annu Rev Neurosci 1998; 21: 149-86.

33. Kaltenbach JA, Czaja JM, Kaplan CR. Changes in the tonotopic map of the dorsal cochlear nucleus following induction of cochlear lesions by exposure to intense sound. Hear Res 1992; 59: 213-23.

34. Rajan R, Irvine DR. Absence of plasticity of the frequency map in dorsal cochlear nucleus of adult cats after unilateral partial cochlear lesions. J Comp Neurol 1998; 399: 35-46.

35. Irvine DR, Rajan R, Smith S. Effects of restricted cochlear lesions in adult cats on the frequency organization of the inferior colliculus. J Comp Neurol 2003; 467: 354-74.

36. Kim JJ, Gross J, Potashner SJ, Morest DK. Fine structure of long-term changes in the cochlear nucleus after acoustic overstimulation: chronic degeneration and new growth of synaptic endings. J Neurosci Res 2004; 77: 817-28.

37. Bilak M, Kim J, Potashner SJ, Bohne BA, Morest DK. New growth of axons in the cochlear nucleus of adult chinchillas after acoustic trauma. Exp Neurol 1997; 147: 256-68.

38. Kim JJ, Gross J, Morest DK, Potashner SJ. Quantitative study of degeneration and new growth of axons and synaptic endings in the chinchilla cochlear nucleus after acoustic overstimulation. J Neurosci Res 2004; 77: 829-42.

39. Kamke MR, Brown M, Irvine DR. Plasticity in the tonotopic organization of the medial geniculate body in adult cats following restricted unilateral cochlear lesions. J Comp Neurol 2003; 459: 355-67.

40. Chang EF, Merzenich MM. Environmental noise retards auditory cortical development. Science 2003; 300: 498-502.

41. Seidl AH, Grothe B. Development of sound localization mechanisms in the Mongolian gerbil is shaped by early acoustic experience. $\mathrm{J}$ Neurophysiol 2005; 94: 1028-36.

42. Muhlnickel W, Elbert T, Taub E, Flor H. Reorganization of auditory cortex in tinnitus. Proc Natl Acad Sci U S A 1998; 95: 10340-3.

43. Kandler K. Activity-dependent organization of inhibitory circuits: lessons from the auditory system. Curr Opin Neurobiol 2004; 14: 96-104.

44. Kandler K, Gillespie DC. Developmental refinement of inhibitory soundlocalization circuits. Trends Neurosci 2005; 28: 290-6.

45. Lomber SG, Eggermont JJ. Reprogramming the cerebral cortex: adaptive plasticity following central and peripheral lesions. Oxford: Oxford University Press; 2006.

46. Irvine DR. Auditory cortical plasticity: does it provide evidence for cognitive processing in the auditory cortex? Hear Res 2007; 229: 158-70.

47. Gilbert CD. Adult cortical dynamics. Physiol Rev 1998; 78: 467-85.

48. Liberman MC, Dodds LW. Single-neuron labeling and chronic cochlear pathology. III. Stereocilia damage and alterations of threshold tuning curves. Hear Res 1984; 16: 55-74.

49. Liberman MC. Single-neuron labeling and chronic cochlear pathology. I. Threshold shift and characteristic-frequency shift. Hear Res 1984 16: 33-41.

50. Bohne BA, Harding GW, Nordmann AS, Tseng CJ, Liang GE, Bahadori RS. Survival-fixation of the cochlea: a technique for following time-dependent degeneration and repair in noise-exposed chinchillas. Hear Res 1999; 134: 163-78.

51. Holme RH, Steel KP. Progressive hearing loss and increased susceptibility to noise-induced hearing loss in mice carrying a Cdh23 but not a Myo7a mutation. J Assoc Res Otolaryngol 2004; 5: 66-79.

52. Wang J, Ding D, Salvi RJ. Functional reorganization in chinchilla inferior colliculus associated with chronic and acute cochlear damage. Hear Res 2002; 168: 238-49.

53. Yoshida N, Hequembourg SJ, Atencio CA, Rosowski JJ, Liberman MC. Acoustic injury in mice: $129 / \mathrm{SvEv}$ is exceptionally resistant to noiseinduced hearing loss. Hear Res 2000; 141: 97-106.

54. Cody AR, Robertson, D. Variability of noise-induced damage in the guinea pig cochlea: electrophysiological and morphological correlates after strictly controlled exposures. Hear Res 1983; 9: 55-70.

55. Malmierca MS, Izquierdo MA, Cristaudo S, Hernández O, Pérez-González D, Covey E, et al. A discontinuous tonotopic organization in the inferior colliculus of the rat. J Neurosci 2008; 28: 4767-76.

56. Cody AR, Johnstone BM. Acoustic trauma: single neuron basis for the 'half-octave shift'. J Acoust Soc Am 1981; 70: 707-11.

57. Le Page EL, Johnstone BM. Nonlinear mechanical behaviour of the basilar membrane in the basal turn of the guinea pig cochlea. Hear Res 1980; 2: 183-9.

58. Snyder RL, Sinex DG, McGee JD, Walsh EW. Acute spiral ganglion lesions change the tuning and tonotopic organization of cat inferior colliculus neurons. Hear Res 2000; 147: 200-20.

59. Snyder RL, Sinex DG. Immediate changes in tuning of inferior colliculus neurons following acute lesions of cat spiral ganglion. J Neurophysiol 2002; 87: 434-52.

60. Harrison RV. Age-related tonotopic map plasticity in the central auditory pathways. Scand Audiol Suppl 2001; 53: 8-14.

61. Kral A. Unimodal and cross-modal plasticity in the 'deaf' auditory cortex. Int J Audiol 2007; 46: 479-93.

62. Jusczyk PW, Hohne EA. Infants' memory for spoken words. Science 1997; 277: 1984-6.

63. Oliver DL, Izquierdo MA, Malmierca MS. Early sound exposure modifies function in the inferior colliculus (IC) of the rat. Annual Meeting Society for Neuroscience. Atlanta, EE. UU., octubre de 2006.

64. Izquierdo MA, Malmierca MS, Oliver DL. Early sound exposure alters frequency coding in the inferior colliculus (IC) of the rat. ARO MidWinter Meeting. Denver, EE. UU., febrero de 2007.

65. Oliver DL, Izquierdo MA, Malmierca MS. Early sound exposure alters frequency coding in the inferior colliculus. The Auditory Brain -a tribute to Dexter Irvine. Lorne, Australia, julio de 2007.

66. Eggermont JJ. The role of sound in adult and developmental auditory cortical plasticity. Ear Hear 2008; 29: 819-29.

67. Jastreboff PJ, Brennan JF, Coleman JK, Sasaki CT. Phantom auditory sensation in rats: an animal model for tinnitus. Behav Neurosci 1988; 102: 811-22.

68. Eggermont JJ. Tinnitus: neurobiological substrates. Drug Discov Today 2005; 10: 1283-90.

69. Bauer CA, Brozoski TJ, Holder TM, Caspary DM. Effects of chronic salicylate on GABAergic activity in rat inferior colliculus. Hear Res 2000; 147: 175-82.

70. Milbrandt JC, Holder TM, Wilson MC, Salvi RJ, Caspary DM. GAD levels and muscimol binding in rat inferior colliculus following acoustic trauma. Hear Res 2000; 147: 251-60.

71. Abbott SD, Hughes LF, Bauer CA, Salvi R, Caspary DM. Detection of 
glutamate decarboxylase isoforms in rat inferior colliculus following acoustic exposure. Neuroscience 1999; 93: 1375-81.

72. Harris JA, Hardie NA, Bermingham-McDonogh O, Rubel EW. Gene expression differences over a critical period of afferent-dependent neuron survival in the mouse auditory brainstem. J Comp Neurol 2005; 493: 460-74.

73. Harris JA, Rubel EW. Afferent regulation of neuron number in the cochlear nucleus: cellular and molecular analyses of a critical period. Hear Res 2006; 216-217: 127-37.

74. Turrigiano GG, Nelson SB. Homeostatic plasticity in the developing nervous system. Nat Rev Neurosci 2004; 5: 97-107.

75. Rauschecker JP, Shannon RV. Sending sound to the brain. Science 2002; 295: 1025-9.
76. Lenarz M, Lim HH, Lenarz T, Reich U, Marquardt N, Klingberg MN, et al. Auditory midbrain implant: histomorphologic effects of longterm implantation and electric stimulation of a new deep brain stimulation array. Otol Neurotol 2007; 28: 1045-52.

77. Kamke MR, Brown M, Irvine DR. Basal forebrain cholinergic input is not essential for lesion-induced plasticity in mature auditory cortex. Neuron 2005; 48: 675-86.

78. Kaltenbach JA, Meleca RJ, Falzarano PR. Alterations in the tonotopic map of the cochlear nucleus following cochlear damage. In Salvi RJ, Henderson D, Fiorino F, Colleti V, eds. Auditory system plasticity and regeneration. New York: Thieme Medical Publishers; 1996. p. 317-32.

\section{FUNCTIONAL AND ACTIVITY-DEPENDENT PLASTICITY MECHANISMS IN THE ADULT AND DEVELOPING AUDITORY BRAIN}

Summary. Introduction and development. Sensory systems show a topographic representation of the sensory epithelium in the central nervous system. In the auditory system this representation originates tonotopic maps. For the last four decades these changes in tonotopic maps have been widely studied either after peripheral mechanical lesions or by exposing animals to an augmented acoustic environment. These sensory manipulations induce plastic reorganizations in the tonotopic map of the auditory cortex. By contrast, acoustic trauma does not seem to induce functional plasticity at subcortical nuclei. Mechanisms that generate these changes differ in their molecular basis and temporal course and we can distinguish two different mechanisms: those involving an active reorganization process, and those that show a simple reflection of the loss of peripheral afferences. Only the former involve a genuine process of plastic reorganization. Neuronal plasticity is critical for the normal development and function of the adult auditory system, as well as for the rehabilitation needed after the implantation of auditory prostheses. However, development of plasticity can also generate abnormal sensation-like tinnitus. Recently, a new concept in neurobiology so-called 'neuronal stability' has emerged and its implications and conceptual basis could help to improve the treatments of hearing loss. Conclusion. A combination of neuronal plasticity and stability is suggested as a powerful and promising future strategy in the design of new treatments of hearing loss. [REV NEUROL 2009; 8: 421-9]

Key words. Acoustic trauma. Activity-dependent plasticity. Best frequency. Critical period. Functional plasticity. Stability. Tonotopic map. 
APÉNDICE II:

Summary 



\section{INTRODUCTION}

A distinct feature of sensory systems is the topographical representation of the sensory epithelium in the central nervous system. In the auditory system, the sensory epithelium in the cochlea is organized according to frequency. Receptor cells are maximally stimulated by different frequencies of sound depending on their position along the basilar membrane. The resulting gradient in frequency tuning gives rise to a topographic representation of sound frequency, or tonotopic organization, a representation that is maintained in a point-to-point fashion from the first auditory relay centre, the cochlear nucleus, up to the cortex (Malmierca, 2003; Malmierca et al., 2008).

For many years it was thought that topographic maps could be modified by experience only during development, notably during 'sensitive' or 'critical' periods of limited duration (Zhang et al., 2001; Nakahara et al., 2004; de Villers-Sidani et al., 2007), and that this organization was fixed in the adult brain. However, it is now well-established that topographical maps have the capacity to reorganize if the mature sensory system is chronically deprived of its normal input through damage of the sensory receptors or if an increased stimulation by a patterned acoustic stimulus during development is performed.

Cortical plasticity is well-documented (Zhang et al., 2001; Chang and Merzenich, 2003; de Villers-Sidani et al., 2007; Irvine, 2007); however, it is unclear to what extent subcortical nuclei contribute to cortical reorganization because of the wide variety of experimental models and the controversial results obtained. Studies carried out in the cochlear nucleus after mechanical lesions of the receptors have failed to demonstrate plastic changes in frequency reorganization (Kaltenbach et al., 1992; Rajan and Irvine, 1998); however, a single study of the auditory thalamus has shown evidence for genuine plastic reorganization of the tonotopic map similar to that seen in the auditory cortex (Kamke et al., 2003). On the other hand, there are no detailed studies regarding the chronic effect of acoustic trauma on the neuronal responses of the inferior colliculus (IC).

The IC is the major processing center in the auditory midbrain. Anatomically, the central nucleus of the IC (CNIC) is composed of fibrodendritic laminae (Oliver and Morest, 1984; Malmierca et al., 1993, 2005). This laminar organization is made up of flat, diskshaped neurons and axonal afferents that originate in lower auditory centers (Malmierca et al., 1993). 
This study proposes the analysis of physiological consequences of acoustic trauma and exposure to an augmented acoustic environment during development in the inferior colliculus. Since the inferior colliculus is an obligatory relay center for most inputs from lower auditory centers en route to the cortex, understanding its contribution to thalamic and cortical plasticity in frequency coding is essential. The present study aimed to shed light on the issue of subcortical plasticity in the auditory system with special emphasis on the role of the midbrain in frequency coding and the consequences of a traumatic or an augmented acoustic environment on frequency coding.

The auditory system is an excellent model to study these effects, because sounds can be delivered to the animal in a well-controlled manner due to its tonotopic organization. 
This hypothesis leads us to consider these major goals:

1. Study the normal tonotopic organization in the rat inferior colliculus.

2. Analyze changes in the tonotopic organization induced by the exposure to an altered acoustic environment, both after an acoustic trauma and after exposure to an augmented acoustic environment.

3. Determine cellular changes due to the exposure to an altered acoustic environment.

4. Analyze if over-exposure to a given sound in neonates alters the development of auditory function. 


\section{EXPERIMENTAL PROCEDURES}

Experiments were performed on a total of 66 healthy young-adult rats (Rattus norvegicus, Rj: Long Evans) free from any signs of external- or middle-ear pathology of either sex (B.W. 130-430 g). Rats age range 43-371 days old. The care and use of animals reported on in this study were approved by the University of Salamanca Animal Care and Use Committee and conformed to the guidelines of the EU directive 2003/65/CE and the Spanish RD 1201/2005.

\section{EXPERIMENTAL GROUPS AND EXPERIMENTAL DESIGN}

Animals were randomly assigned to one of three groups: 1$)$ control animals ( $n=32$, 3-7 months old) were used to make a detailed study of the normal auditory function and the tonotopic map in the IC; 2$)$ animals exposed to intense pure tone stimuli $(\mathrm{n}=17$, see table 1 for parameters); and 3) animals exposed to an augmented acoustic environment during the critical period $(\mathrm{n}=17$, table 2$)$.

\section{Acoustic trauma}

Animals in group 2 were exposed to continuous pure tones of either 5 or $8 \mathrm{kHz}$, at intensities between 110-121 dB SPL (table 1). Throughout the exposure, the animals were unanesthetized and unrestrained within individual cages which were suspended inside a small reverberant sound-exposure box with non-parallel sides (e.g. Liberman and Gao, 1995; Yoshida et al., 2000; Izquierdo et al., 2008). The exposure stimulus was generated by a custom-made noise source, amplified (Magnat Audio-Produkte GmbH, Germany) and delivered to four free-field speakers (Mac Audio Electronic GmbH \& Co. KG, Germany) placed on the walls of the sound box. Sound exposure levels were measured at the position equivalent to the top of the rat's head before and after each exposure, using a $1 / 2$ inch condenser microphone (Brüel and Kjær 4191, Nærum, Denmark) coupled to a DI-2200 spectrum analyzer (Diagnostic Instruments. Livingston, Scotland, UK).

Animals were allowed to recover for $>35$ days since little if any temporary threshold shift occurs after this period (Yoshida et al., 2000; Miller et al., 1963).

\section{Exposure to an augmented acoustic environment}

Four litters of animals and their mothers were exposed to an augmented acoustic environment (AAE, table 2) during the first postnatal month. Two litters were exposed 
from P9-P28 to an AAE consisting of $14 \mathrm{kHz}$ pure tone pips $(25 / 250 \mathrm{~ms}, 60-70 \mathrm{~dB})$ for 14-18 hours per day.

One litter ( $\mathrm{n}=4$ animals) was exposed to AAE of tones with a $4 \mathrm{kHz}$ carrier and 14 Hz modulation frequency $(60-70 \mathrm{~dB}, 1000 / 2600 \mathrm{~ms})$ from P9-P28 and a fourth litter $(\mathrm{n}=4$ animals) was exposed to AAE of tones with a $7 \mathrm{kHz}$ carrier and $40 \mathrm{~Hz}$ modulation frequency $(70 \mathrm{~dB}, 250 / 750 \mathrm{~ms})$ from P9-P17. Animals were housed in a sound attenuation chamber at all times.

Sounds were generated by a PC-based system and custom software (Malmierca et al., 2008) and delivered with a loudspeaker (Realistic, Fort Worth, TX 76102).

\section{SURGICAL PROCEDURES}

On the day of recording, surgical anesthesia was induced with urethane $(1.5 \mathrm{~g} / \mathrm{kg}$, $20 \%$ solution, i.p. $)$ and maintained with supplementary doses $(0.5 \mathrm{~g} / \mathrm{kg}$, i.p. $)$ to preserve an areflexive state. Surgical and experimental procedures were performed in an electrically shielded, sound-attenuating room. The trachea was cannulated and atropine sulfate $(0.05$ $\mathrm{mg} / \mathrm{kg}$, s.c.) was administered to reduce bronchial secretions. Body temperature was monitored with a rectal probe and maintained at $38 \pm 1{ }^{\circ} \mathrm{C}$ by a thermostatically controlled electric blanket. The animal was placed in a stereotaxic frame in which the ear bars were replaced by hollow specula that accommodated the sound delivery system (Rees et al., 1997; Malmierca et al., 2005, 2008). A craniotomy was performed to expose the cerebral cortex and the cerebellum overlying the IC. A tungsten electrode was placed through the cortex and used to record extracellular single unit (SU) and multiunit (MU) responses in the IC in response to pure tone stimulation.

\section{MEASURING THE COCHLEAR ACTION POTENTIAL AUDIOGRAM}

Auditory function in animals was assessed by measuring the compound action potential (CAP) of the auditory nerve. The tympanic bulla was exposed and the middle ear cavity was opened. A silver wire serving as the recording electrode was placed on the round window through a hole made in the bulla. The response was amplified (100000x), filtered $(0.1-3 \mathrm{kHz})$ and averaged offline. CAP thresholds were measured under computer control in response to tone pips ( $5 \mathrm{~ms}$ duration with $1 \mathrm{~ms}$ rise-fall time), delivered at a $10 \mathrm{~Hz}$ repetition rate through a closed and calibrated sound system. The stimulus intensity was varied in $1 \mathrm{~dB}$ steps. CAP thresholds were determined for 20 frequencies between 0.5 and $39 \mathrm{kHz}$ (Rajan et al., 1991; Izquierdo et al., 2008). 
Stimuli were generated on a System II workstation (Tucker- Davis Technologies. Gainesville, FL, USA) using custom software and delivered using two electrostatic loudspeakers (TDT EC1) driven by two TDT ED1 modules. The output of the system was calibrated in situ using a Brüel and Kjær 4136 1/4 inch condenser microphone. The electrode was advanced using a microdrive (Burleigh 6000). Action potentials were amplified (10000-90000x) with a Bioamp amplifier (TDT) and filtered (0.5-3 kHz, TDT DB4) before being processed by a spike discriminator (TDT SD1). Spike times were logged by feeding the output of the spike discriminator into an event timer (TDT ET1) synchronized to a timing generator (TDT TG6). Stimulus generation and on-line data visualization were controlled with custom software.

Monaural stimuli were used to generate frequency response areas (FRAs) from wellisolated SU using pure tones $(75 \mathrm{~ms}, 5 \mathrm{~ms}$ rise/fall time, $4 \mathrm{~Hz}$ repetition rate). The frequency of each stimulus was varied randomly and intensity was modified in a pseudorandom fashion, in steps of $10 \mathrm{~dB}$ attenuation. The data obtained were analyzed and plotted using commercial software (Microsoft Excel, SigmaPlot and SPSS).

For the tonotopic mapping studies we made penetrations from anterodorsal to posteroventral through the IC at an angle $10^{\circ}$ from the frontal plane. This angle is approximately orthogonal to the predominant orientation of isofrequency laminae (Malmierca et al., 1993). The electrode was advanced in steps of 25 or $50 \mu \mathrm{m}$ and recordings were made at each site, thus determining the best frequency (BF, the sound frequency that elicits a minimal neuronal response with the minimum intensity) and response threshold of MU.

The BF distribution was analyzed as a function of depth along the electrode track using an automated Microsoft Excel spread sheet. The distance in micrometers and frequency change in octaves was calculated for any change in $\mathrm{BF}$ with respect to the previous $\mathrm{BF}$ recorded and for any change in $\mathrm{BF}>0.1$ octaves. We have considered changes $>0.1$ octaves as different isofrequency laminae.

\section{HISTOLOGICAL VERIFICATION OF RECORDING SITES}

At the end of each experiment, electrolytic lesions (5-10 $\mu \mathrm{A}, 5-10 \mathrm{~s})$ were made using the tungsten recording electrode. The animal was given a lethal dose of sodium pentobarbitone (Nembutal) and perfused intracardially with Ringer's solution followed by fixative (1\% paraformaldehyde and $1 \%$ glutaraldehyde in $0.1 \mathrm{M}$ phosphate buffer). The brains were immersed in a 30\% sucrose solution for 2-3 days. Sagittal sections $(40 \mu \mathrm{m})$ were cut on a freezing microtome and stained with Cresyl Violet to facilitate identification of cytoarchitectural boundaries. All sites from which we recorded single and MU activity 
were in the CNIC as defined in the rat by Malmierca et al. (Malmierca et al., 1993; Loftus et al., 2008). 


\section{RESULTS}

To assess the effects of noise-exposure on the functional organization of the IC we will first present 1) CAP audiograms, 2) detailed tonotopic maps of the IC derived from MU responses and 3) SU FRAs recorded from normal control animals. We will then compare these normal data with data recorded from noise-exposed animals (animals exposed to acoustic trauma and augmented acoustic environment).

\section{GROUP 1: CONTROL ANIMALS}

\section{Normal CAP audiogram}

The CAP audiogram was measured from seven control animals (Fig. 9A). The most sensitive region occurred around $20-30 \mathrm{kHz}$. From $30 \mathrm{kHz}$, thresholds increased gradually up to the highest frequency tested $(39 \mathrm{kHz})$. We calculated the mean and SD from these seven control cases, and used the derived function (Fig. 9A; red line) as the control CAP audiogram for comparison with noise exposed animals.

\section{Mapping of tonotopic organization}

Recorded tracks had an average length of $2180 \pm 460 \mu \mathrm{m}$ (mean $\pm \mathrm{SD}$ ), which corresponds well with the dimensions of the IC in the rat (Faye-Lund and Osen, 1985; Malmierca et al., 1993; Malmierca, 2003). When the BF was recorded every 25-50 $\mu \mathrm{m}$ (Fig. 11), we found a distinct stair-step pattern in every penetration $(\mathrm{n}=16$ animals, 45 penetrations). In 12 penetrations, no clear tonotopic organization was found (Fig. 11C, black symbols) or the tonotopic progression was incomplete. Histological location of these tracks showed that they were outside the central nucleus. For the 33 penetrations that were considered complete and located within the central nucleus, we plotted BF versus recording depth. The frequency of these penetrations ranged from 0.5 to $40 \mathrm{kHz}$. Each showed a distinct staircase pattern (Fig. 11). The BF remained nearly constant (changing $<0.1$ octaves) for an average of $151 \pm 41 \mu \mathrm{m}$ (mean \pm SD) and then jumped $0.34 \pm 0.11$ octaves ( $n=460$ steps). On average, there were $14 \pm 3.7$ steps per track (Malmierca et al., 2008). 
In order to study the cellular basis of the tonotopic organization, we recorded 120 FRAs from 32 normally hearing adult rats. As expected, the BF of the individual FRAs progressively increases with recording depth within the IC. Most of the FRAs recorded from this group of control animals were of the V-shaped type. Our sample also contained some non-V-shaped FRAs, but they were less abundant. The majority of neurons in this control group lacked spontaneous activity.

In a separate set of experiments, we analysed 604 FRAs from well isolated single units that belong to the auditory neurophysiology lab data collection (Hernández et al., 2005; Pérez-González et al., 2006). When the BFs of all 604 units in this sample were pooled and displayed as a histogram with 0.1 octave bins, we observed a multimodal distribution with 16 peaks occurring at $0.32 \pm 0.11$ octave intervals (Fig. 12A). In the distribution of the multiunit recordings, 14 peaks match 12 of the single-unit peaks (Fig. 12B). The 12 matched peaks from these two independent datasets are strongly correlated ( $\mathrm{r}$ $=0.99855)$ in a linear regression analysis. The combined sequence of peaks from the two distributions suggests that there are 18 peaks that occur at $0.29 \pm 0.1$ octave intervals. 


\section{CAP audiogram}

To ensure a permanent threshold shift (PTS), we waited 35-296 days after the exposure before recording physiological responses from the noise-exposed animals. Regardless of the acoustic trauma experienced (table 1), 10/17 cases showed a PTS of $>20$ $\mathrm{dB}$ (Fig. 14, arrow) at 3-4 kHz (Fig. 14, vertical dashed line) and above. Of the remaining 7 cases, 4 (cases \# 107, 147, 148 and 150) also exhibited a PTS at lower frequencies (Fig. 14, dotted lines), i.e. an even broader PTS including virtually all frequencies tested.

\section{Tonotopic map of the inferior colliculus after an acoustic trauma}

We recorded MU BF maps from the 17 rats that had been exposed to an acoustic trauma at $5 \mathrm{kHz}(\mathrm{n}=6)$ and $8 \mathrm{kHz}(\mathrm{n}=11$; table 1$)$. We examined a total of 29 tracks across the CNIC (10 from animals exposed to $5 \mathrm{kHz}$ traumatic tone and 19 tracks to $8 \mathrm{kHz}$ ). Figs. 15 and 16 show 12 of the tracks and their corresponding CAP audiograms. They are fully representative of the entire sample. Noise induced hearing loss resulted in a reorganization of the normal tonotopic organization map of the IC. The distinct staircase pattern observed in normal cases was clearly altered and became more or less blurred (Fig. 15) or significantly distorted (Fig. 16). In these experimental cases the BF remained constant for an average of $218.5 \pm 113 \mu \mathrm{m}$ (vs. $151 \pm 41$ observed in the control cases; $t$ test, $\mathrm{P}<0.01$ ) and then jumped by $0.49 \pm 0.40$ octave (vs. $0.34 \pm 0.11$ in the control cases). Thus, the number of steps was significantly reduced ( $\mathrm{n}=287$ steps, $9.9 \pm 4.4$ on average/ track; t-test, $\mathrm{P}<0.05$ ) as can be seen from Figs. 15 and 16 (Izquierdo et al., 2008).

We have divided the individual cases of tonotopic map reorganization into two main patterns: 1) the first pattern showed minimal alteration of the tonotopic map. Most of the frequency steps that occurred in normal animals were present (Fig. 15), the missing frequencies corresponded to the hearing loss seen in the CAP audiogram and were flanked by expansions of adjacent frequencies. 2) The second pattern showed a profound reorganization across the whole CNIC (Fig. 16) and an absence of the characteristic normal stepwise frequency progression. This alteration led to a significant expansion in the size of one or two steps corresponding to the frequencies represented at the edge of the loss in cochlear sensitivity as judged from the CAPs. Both patterns showed a marked increase in the response thresholds. There appeared to be a correlation between the CAP audiogram and the degree of reorganization exhibited in the CNIC. Those cases that showed the least alteration in tonotopic mapping corresponded to those whose CAPs exhibited the least loss in cochlear sensitivity. 


\section{Frequency response areas in chronically lesioned animals}

We examined 142 SU FRAs from animals with an acoustic trauma at $5 \mathrm{kHz}(\mathrm{n}=84)$ or $8 \mathrm{kHz}(\mathrm{n}=58)$. Fig. 18A shows the recording sites in the CNIC for 16 SUs in four different animals and their corresponding FRAs (Fig. 18B). SUs located at the beginning of the tracks, i.e. superficially within the IC $(0-1000 \mu \mathrm{m})$, possessed V-shaped FRAs in most cases with a clear peak indicating their BF $(1.5-2.9 \mathrm{kHz})$ and thresholds around $20-40 \mathrm{~dB}$ SPL. These FRAs were similar to those found in control animals for this frequency range. As the recording electrode progresses ventrally, i.e. recording depth increases $(>1000 \mu \mathrm{m})$ broader SU FRAs were observed and response thresholds were markedly increased. FRAs in this region usually had one or more additional frequency peaks at frequencies above BF (e.g. Fig. 18B, arrows). The frequency of these peaks gradually increased as a function of depth. The most ventrally located neurons showed complex, non-V-shaped FRAs, with two or three frequency peaks and high thresholds (40-60 dB SPL). A large proportion of FRAs recorded after an acoustic trauma showed an increase in spontaneous activity rate $(55.6 \%)$. The neuronal response thresholds can be obtained from the SU FRAs. Fig. 19B shows a histogram of mean thresholds at BF in $1 / 2$ octave bins for the control and traumatized SUs. The range of frequencies between $8.1-32 \mathrm{kHz}$ exhibits the most sensitive thresholds. We observed a statistically significant increase in thresholds from the 5.71 to $32 \mathrm{kHz}$ as a consequence of the acoustic insult. From $32 \mathrm{kHz}$ up to the highest frequency tested (40 $\mathrm{kHz}) \mathrm{SU}$ thresholds did not show a significant increase.

In order to determine whether the acoustic trauma mainly damages the most sensitive region of the FRA, i.e. the BF region, we analysed two pool of FRAs, 1) a group of normal and 2) a group of traumatized high frequency $(>20 \mathrm{kHz})$ FRAs. The pathologic group of FRAs was subtracted from the control FRA pool (Fig. 20C). The BF region of the normal FRAs disappears, so only the less sensitive region of the 'low frequency tails' is maintained. 


\section{CAP audiogram}

Physiological responses from these early exposed animals did not show significant changes after the exposure. Thresholds for the whole frequency range lie into the normal threshold range because the level of the tone employed ( $\sim 60-70 \mathrm{~dB}$ SPL) did not reach a dangerous level that could induce a PTS.

\section{Tonotopic map of the inferior colliculus after exposure to an augmented acoustic environment}

Our results from the IC demonstrate that this AAE alters the neurons in CNIC tuned to a BF of $14 \mathrm{kHz}$. The length of the step at the AAE stimulus of $14 \mathrm{kHz}$ was longer in the neonatally exposed animal.

Furthermore, we compared the average length of the step at $\mathrm{BF}=14 \mathrm{kHz}$ to the length of the next lowest frequency step. These are displayed in Fig. 22, showing a trend in the experimental animals for the $14 \mathrm{kHz}$ region of the CNIC track to be lengthened. However, there was no difference between experimental and control tracks for the frequency steps in the electrode track to either side of the $14 \mathrm{kHz}$ region. We also measured the threshold for each multiunit recording site. The $14 \mathrm{kHz}$ region and the steps to either side had significantly lower thresholds in control tracks than in experimental tracks (Fig. 22). This suggested that the neonatal sound exposure has a profound and overall effect of raising the thresholds of the system.

Analysis of all MU recording sites in the IC of neonates exposed to $14 \mathrm{kHz}$ showed another effect of AAE exposure, regardless of whether they were in the CNIC or other parts of IC. In experimental animals, there was a small and consistent increase in the number of units responding around $14 \mathrm{kHz}(11.4-16 \mathrm{kHz}$; Fig. 23). This suggests that neurons outside of the central nucleus also may have been influenced by the early sound exposure.

\section{Frequency response areas after neonatal sound exposure}

We studied the effects of early sound exposure on the FRAs of well isolated single neurons from the CNIC. We also used two-tone stimulation, often called two-tone suppression (TTS; Fig. 24). In $68 \%$ of the units (19/28) with BF $>14 \mathrm{KHz}$, there was a peak of activity at the BF and often a second higher threshold peak around $14 \mathrm{kHz}$. This was especially evident in 10/28 cases (35\%). However, the two-tone FRA also revealed that 
the second peak of activity was accompanied by a lower threshold inhibitory area also at 14 kHz. In summary, the FRA and TTS FRA results suggest that early sound exposure to 14 $\mathrm{kHz}$ altered the balance of excitatory and inhibitory responses at that frequency in the CNIC.

In order to study an affect on the receptive field, we compared SU FRA (normalized and pooled) data, from littermates exposed to the three different neonatal conditions, to identical SU FRA data from control animals. There was no statistical difference in the mean of the BF of control or AAE groups in each comparison that follows.

In all cases, differences between experimental and control were best seen in units with the $\mathrm{BF}$ above the AAE frequency. In all three cases, the units in AAE animals showed enhanced excitation relative to control at frequencies above the AAE stimulus frequency but unrelated to the BF of the units (Fig. 25). 


\section{DISCUSSION}

The work of my doctoral thesis demonstrates a number of important features in the functional organization of the IC, including a discontinuous tonotopic organization in the CNIC. MU mapping and SU recordings revealed that the rat IC possesses a distinct stepwise organization in the order in frequency representation. These results contrast the general view that the tonotopic organization in the CNIC forms a continuous frequency gradient.

We also demonstrate that noise-induced hearing loss produces a persistent reorganization of the tonotopic map in the IC of adult rats. This reorganization shows expansions of frequency representations across the IC. At the single cell level, FRAs also show a significant increase in their thresholds and spontaneous activity following acoustic trauma. These results suggest that the changes may be passive and not attributable to a dynamic frequency reorganization similar to that seen in auditory cortex after restricted mechanical lesions of the cochlea.

In addition, this work reveals that early sound exposure alters the tonotopic map in CNIC, most often by increasing the size of the lamina and increasing the number of neurons tuned to the BF of the AAE stimulus. This was despite an overall increase of the threshold in the AAE animals. At the single cell level, FRAs reflect complex changes that may be due to an alteration in the balance between excitation and inhibition as a consequence of the sound exposure.

\section{METHODOLOGICAL CONSIDERATIONS AND LIMITATIONS}

A key methodological issue is whether or not the stepwise progression of BF that we observed in the normal IC could be an artefact of methodology. We think not because it was observed in all penetrations through the CNIC with electrode steps as small as $25 \mu \mathrm{m}$ and regardless of whether the recordings were performed while advancing the electrode downward or upward along the same track (Malmierca et al., 2008).

We did not perform histological examinations of the cochleae to assess the resulting structural damage of the hair cells and adjacent tissues after an acoustic trauma. However, the acoustic trauma that we employed is very similar (or longer) to that used in previous studies (Liberman and Dodds, 1984; Heinz and Young, 2004) including those using rats as experimental model (Fechter et al., 2000; Chen and Fechter, 2003); therefore, it is reasonable to suggest that the levels of structural hair cell damage resulting from this study would be similar (or even more dramatic) to previously reported cases.

The intensity level of the traumatizing tone used here almost always resulted in much more profound damage over a wider frequency area than in the case of the mechanical lesions. This damage was not restricted to a frequency range of approximately half octave 
above the frequency of the trauma (Cody and Johnstone, 1981). The net result was that we obtained a very severe ( $>30 \mathrm{~dB}$ PTS) and broadband frequency lesion in most of our cases.

With identical animal exposures we observed a high degree of interanimal variability (even within the same litter). Unpredictable functional and structural changes of the cochlea after acoustic overexposures have also been noted in previous studies (Yoshida et al., 2000; Holme and Steel, 2004). This variability may be due to the normal genetic diversity that occurs across individuals, and could result in the markedly different susceptibility among animals observed in the control and experimental groups.

\section{FUNCTIONAL SIGNIFICANCE OF DISCONTINUOUS FREQUENCY REPRESENTATION}

The data in the IC suggest groupings of neurons in units of $\sim 0.3$ octaves. At the IC level, BFs may be organized as partially overlapping bandpass filters with a center-tocenter separation of one-third octave. Thus, near threshold, frequencies at the center of the filters are favored over those at the overlapping regions, and it results in the multi-modal, saw-toothed pattern of frequency distribution. Critical band filters have been postulated to originate at the midbrain level (Ehret and Merzenich, 1985; Ehret and Schreiner, 2005) in which inhibitory processing produces level-tolerant neurons ('narrow' FRA types; LeBeau et al., 2001; Hernández et al., 2005). Schreiner and Langner (1997) suggested that the IC in the cat consists of a stack of 30-40 critical bands, each equal in size to the frequency-band laminae defined by the changing steps in the tonotopic map.

The number of critical bands in the rat is not known, but a rough estimate can be based on two assumptions: (1) the basilar membranes of mammals are scale models of each other and critical bands cover equal distances on the basilar membrane (Greenwood, 1990); and (2) one critical band is thought to cover $\sim 1 \mathrm{~mm}(0.7-1.3 \mathrm{~mm})$ on the basilar membrane. Based on the $8 \mathrm{~mm}$ length of the rat's basilar membrane, rats have $\sim 8-12$ critical bands (Ehret and Schreiner, 2005). Interestingly, our data in the IC suggest that there may be 12 18 laminae in the rat, each covering $0.29-0.36$ octaves. This separation is similar to critical bands of $0.333-0.375$ octaves suggested for the mouse (Egorova et al., 2006). Moreover, this grouping is also compatible with studies on the frequency separation needed to activate independent neuronal populations in the IC (Oliver, 2005). Two pure tones 0.5 octaves apart activate two laminae in the IC, whereas tones 0.25 octaves apart activate a single lamina.

Thus, our physiological data suggest that the tonotopic map in the CNIC in the rat is composed of discrete physiological laminae that correspond to the anatomical fibrodendritic laminae of the CNIC (Malmierca et al., 2008). The groupings of neurons with $\sim 0.3$ octaves separation represent separate arrays of neurons with a discontinuous frequency representation near threshold. Such a discontinuous frequency representation has 
interesting functional implications for hearing because it implies unequal thresholds for closely adjacent frequencies.

\section{REORGANIZATION OF THE TONOTOPIC MAP IN THE INFERIOR COLLICULUS AFTER AN ACOUSTIC TRAUMA}

Previous results are controversial. While the chronic studies based on mechanical lesions of the cochlea (Irvine et al., 2003) showed a limited capacity for plasticity with a patchy reorganization of the tonotopic map of the IC in cat, lesions of the spiral ganglion cells demonstrated that the FRAs in the IC undergo a rapid dynamic reorganization shortly after the lesion was produced (Snyder and Sinex, 2002). If we define plasticity in terms of retuning or the unmasking of inputs leading to a near normal response in the damaged area (for a detailed discussion on the definition of plasticity see Calford et al., 1993; Rajan, 2001), our results reveal the absence of plasticity in the auditory midbrain (in a way analogous to that seen in auditory cortex), in either the general tonotopic map of the IC or at the level of the individual FRAs (Izquierdo et al., 2008). Most of the changes seen in the IC after an acoustic trauma can be explained by the 'residual-response hypothesis' (Rajan et al., 1993) and do not seem to reflect a genuine plastic phenomenon. Thus, this phenomenon may be largely lost in the mature animal compared with developing animals (Harrison et al., 1998).

However, our data cannot rule out other forms of plasticity such as synaptic or molecular plasticity (Potashner et al., 1997; Mossop et al., 2000; Brozoski et al., 2002; Kim et al., 2004; Suneja et al., 2005; D'Sa et al., 2007) and further studies will be necessary to fully address the effect of noise-induced hearing loss on IC responses. Furthermore, other molecular plastic changes may occur immediately after the lesion and/or for longer periods than those examined in our study (Snyder and Sinex, 2002).

\section{EFFECTS OF AN AUGMENTED ACOUSTIC ENVIRONMENT ON THE NEURONAL RESPONSES OF THE INFERIOR COLLICULUS}

There are several studies demonstrating activity-dependent plasticity in the auditory system (Zhang et al., 2001; Chang and Merzenich, 2003; de Villers-Sidani et al., 2007). One of these studies showed plastic modifications in the regions of the IC responding to the stimulation frequency (Yu et al., 2007). In our study, we also demonstrate similar changes; the AAE alters the neurons in IC tuned to a BF of $14 \mathrm{kHz}$. In exposed animals, the electrode recorded neurons at the frequency of the early sound exposure $(14 \mathrm{kHz})$ over a longer distance than in control animals. This effect involves a retuning of frequencies, that is to say, an activity-dependent plastic mechanism that affects neurons in adjacent laminas. 
However, the effect of the exposure is not only focused on the response to the exposure frequency. We observed complex changes in the FRAs of neurons with BF higher that the exposure frequency. These changes affect mainly the response to frequencies above exposure frequency, leading to an increase in excitability. We could explain this because development of sound evoked activity in the central auditory system depends on the development of the cochlea. In the immature cochlea, only the base responds to sound, and it does so only to low-frequencies. During maturation, the same point on the cochlear partition responds to successively higher frequencies (Fig. 3) until the cochlea responds to the full range of frequencies (Lippe and Rubel, 1983). Thus, the stimulation of a given frequency during development induces a long term potentiation effect at a higher frequency in the adult animal.

These results indicate that developmental plasticity occurs on a much greater scale than previously appreciated in the mammalian auditory midbrain.

\section{FUNCTIONAL SIGNIFICANCE AND SPECULATIONS ON CLINICAL IMPLICATIONS}

Electrical stimulation using cochlear implants after long-term deafness results in significant increases in thresholds and marked degradation in spatial selectivity in the IC. This may explain the poor speech discrimination performance in cochlear implant users with congenital or very early-acquired deafness that are implanted as adults (Vollmer et al., 2007). These data are in general agreement with our findings.

As a consequence of the changing and potentially harmful environment, the adult brain usually faces two ostensibly paradoxical challenges: stability and plasticity. It must preserve the circuitry and synaptic organization necessary to maintain behaviour and longterm memories while allowing circuits to adapt to environmental changes, learning and injury. The study of structural and functional plasticity has captivated and even obsessed the attention of neurobiologists over the past 50 years (Harris and Rubel, 2006), but it is now clear that an entire group of genes that promote neuronal stability is upregulated and occurs during the initial development of hearing (Harris et al., 2005). Thus, while behavioral plasticity is clearly important, stability may be an emerging property important for both conceptual and clinical reasons.

The results we present here also suggest that it may be important to maintain the stability of the neuronal circuitry in the IC since plasticity for frequency coding (at least after an acoustic trauma) seems to be limited at the midbrain level. In fact, it is not clear what perceptual advantages are provided by plasticity. Plastic reorganization of the tonotopic map in cortex has been related to abnormal sensations (Eggermont and Komiya, 2000) including tinnitus (Muhlnickel et al., 1998) and has been suggested to be more problematic than beneficial (Eggermont, 2005). In the future, it may be more effective to 
look for a treatment of noise-induced hearing loss that emphasizes stability rather than focusing solely on plasticity. 


\section{CONCLUSSIONS}

1. The tonotopic map of the central nucleus of the inferior colliculus is composed of discrete physiological laminae. These laminae are the physiological substrate for the anatomical fibrodendritic laminae.

2. Best frequency in the inferior colliculus is represented in a discontinuous stepwise manner, forming groups of neurons with $\sim 0.3$ octaves separation.

3. Acoustic trauma produces a persistent reorganization of the tonotopic map in the inferior colliculus and disrupts the normal stepwise representation of sound frequency.

4. Most of the changes seen in the inferior colliculus after an acoustic trauma can be explained by the 'residual-response hypothesis' and do not seem to reflect a genuine plastic phenomenon.

5. Early sound exposure alters the tonotopic map in the inferior colliculus, most often by increasing the size of the lamina and increasing the number of neurons tuned to the BF of the AAE stimulus. 


\section{ABBREVIATIONS}

AAE, augmented acoustic environment

$\mathrm{BF}$, best frequency

CAP, compound action potential

CNIC, central nucleus of the inferior colliculus

$\mathrm{dB}$, decibels

FRA, frequency response area

IC, inferior colliculus

MU, multiunit

PTS, permanent threshold shift

SPL, sound pressure level

SU, single unit

TTS, two-tone suppression 


\section{REFERENCES}

Brozoski, T. J., Bauer, C. A. and Caspary, D. M., 2002. Elevated fusiform cell activity in the dorsal cochlear nucleus of chinchillas with psychophysical evidence of tinnitus. J Neurosci. 22, 23832390 .

Calford, M. B., Rajan, R. and Irvine, D. R., 1993. Rapid changes in the frequency tuning of neurons in cat auditory cortex resulting from pure-tone-induced temporary threshold shift. Neuroscience. 55, 953-964.

Chang, E. F. and Merzenich, M. M., 2003. Environmental noise retards auditory cortical development. Science. 300, 498-502.

Chen, G. D. and Fechter, L. D., 2003. The relationship between noise-induced hearing loss and hair cell loss in rats. Hear Res. 177, 81-90.

Cody, A. R. and Johnstone, B. M., 1981. Acoustic trauma: single neuron basis for the "half-octave shift". J Acoust Soc Am. 70, 707-711.

de Villers-Sidani, E., Chang, E. F., Bao, S. and Merzenich, M. M., 2007. Critical period window for spectral tuning defined in the primary auditory cortex (A1) in the rat. J Neurosci. 27, 180-189.

D'Sa, C., Gross, J., Francone, V. P. and Morest, D. K., 2007. Plasticity of synaptic endings in the cochlear nucleus following noise-induced hearing loss is facilitated in the adult FGF2 overexpressor mouse. Eur J Neurosci. 26, 666-680.

Eggermont, J. J., 2005. Tinnitus: neurobiological substrates. Drug Discov Today. 10, 1283-1290.

Eggermont, J. J. and Komiya, H., 2000. Moderate noise trauma in juvenile cats results in profound cortical topographic map changes in adulthood. Hear Res. 142, 89-101.

Egorova, M., Vartanyan, I. and Ehret, G., 2006. Frequency response areas of mouse inferior colliculus neurons: II. Critical bands. Neuroreport. 17, 1783-1786.

Ehret, G. and Merzenich, M. M., 1985. Auditory midbrain responses parallel spectral integration phenomena. Science. 227, 1245-1247.

Ehret, G., Schreiner, C. E., 2005. Spectral and intensity coding in the auditory midbrain. In: The inferior colliculus (Winer JA, Schreiner CE, eds), pp 312-345. New York: Springer.

Faye-Lund, H. and Osen, K. K., 1985. Anatomy of the inferior colliculus in rat. Anat Embryol (Berl). 171, 1-20. 
Fechter, L. D., Chen, G. D., Rao, D. and Larabee, J., 2000. Predicting exposure conditions that facilitate the potentiation of noise-induced hearing loss by carbon monoxide. Toxicol Sci. 58, $315-323$.

Greenwood, D. D., 1990. A cochlear frequency-position function for several species--29 years later. J Acoust Soc Am. 87, 2592-2605.

Harris, J. A., Hardie, N. A., Bermingham-McDonogh, O. and Rubel, E. W., 2005. Gene expression differences over a critical period of afferent-dependent neuron survival in the mouse auditory brainstem. J Comp Neurol. 493, 460-474.

Harris, J. A. and Rubel, E. W., 2006. Afferent regulation of neuron number in the cochlear nucleus: cellular and molecular analyses of a critical period. Hear Res. 216-217, 127-137.

Harrison, R. V., Ibrahim, D. and Mount, R. J., 1998. Plasticity of tonotopic maps in auditory midbrain following partial cochlear damage in the developing chinchilla. Exp Brain Res. 123, 449-460.

Heinz, M. G. and Young, E. D., 2004. Response growth with sound level in auditory-nerve fibers after noise-induced hearing loss. J Neurophysiol. 91, 784-795.

Hernández, O., Espinosa, N., Pérez-González, D. and Malmierca, M. S., 2005. The inferior colliculus of the rat: a quantitative analysis of monaural frequency response areas. Neuroscience. $132,203-217$.

Holme, R. H. and Steel, K. P., 2004. Progressive hearing loss and increased susceptibility to noiseinduced hearing loss in mice carrying a Cdh23 but not a Myo7a mutation. J Assoc Res Otolaryngol. 5, 66-79.

Irvine, D. R., 2007. Auditory cortical plasticity: does it provide evidence for cognitive processing in the auditory cortex? Hear Res. 229, 158-170.

Irvine, D. R., Rajan, R. and Smith, S., 2003. Effects of restricted cochlear lesions in adult cats on the frequency organization of the inferior colliculus. J Comp Neurol. 467, 354-374.

Izquierdo, M. A., Gutierrez-Conde, P. M., Merchan, M. A. and Malmierca, M. S., 2008. Nonplastic reorganization of frequency coding in the inferior colliculus of the rat following noiseinduced hearing loss. Neuroscience. 154, 355-369.

Kaltenbach, J. A., Czaja, J. M. and Kaplan, C. R., 1992. Changes in the tonotopic map of the dorsal cochlear nucleus following induction of cochlear lesions by exposure to intense sound. Hear Res. 59, 213-223.

Kamke, M. R., Brown, M. and Irvine, D. R., 2003. Plasticity in the tonotopic organization of the medial geniculate body in adult cats following restricted unilateral cochlear lesions. J Comp Neurol. 459, 355-367. 
Kim, J. J., Gross, J., Morest, D. K. and Potashner, S. J., 2004. Quantitative study of degeneration and new growth of axons and synaptic endings in the chinchilla cochlear nucleus after acoustic overstimulation. J Neurosci Res. 77, 829-842.

LeBeau, F. E., Malmierca, M. S. and Rees, A., 2001. Iontophoresis in vivo demonstrates a

key role for $\mathrm{GABA}(\mathrm{A})$ and glycinergic inhibition in shaping frequency response areas in the inferior colliculus of guinea pig. J Neurosci. 21, 7303-7312.

Liberman, M. C. and Dodds, L. W., 1984. Single-neuron labeling and chronic cochlear pathology. III. Stereocilia damage and alterations of threshold tuning curves. Hear Res. 16, 55-74.

Liberman, M. C. and Gao, W. Y., 1995. Chronic cochlear de-efferentation and susceptibility to permanent acoustic injury. Hear Res. 90, 158-168.

Lippe, W. and Rubel, E. W., 1983. Development of the place principle: tonotopic organization. Science. 219, 514-516.

Loftus, W. C., Malmierca, M. S., Bishop, D. C. and Oliver, D. L., 2008. The cytoarchitecture of the inferior colliculus revisited: a common organization of the lateral cortex in rat and cat. Neuroscience. 154, 196-205.

Malmierca, M. S., 2003. The structure and physiology of the rat auditory system: an overview. Int Rev Neurobiol. 56, 147-211.

Malmierca, M. S., Blackstad, T. W., Osen, K. K., Karagulle, T. and Molowny, R. L., 1993. The central nucleus of the inferior colliculus in rat: a Golgi and computer reconstruction study of neuronal and laminar structure. J Comp Neurol. 333, 1-27.

Malmierca, M. S., Hernández, O. and Rees, A., 2005. Intercollicular commissural projections modulate neuronal responses in the inferior colliculus. Eur J Neurosci. 21, 2701-2710.

Malmierca, M. S., Izquierdo, M. A., Cristaudo, S., Hernández, O., Pérez-González, D., Covey, E. and Oliver, D. L., 2008. A discontinuous tonotopic organization in the inferior colliculus of the rat. J Neurosci. 28, 4767-4776.

Miller, J. D., Watson, C. S., Covell, W. P., 1963. Deafening effects of noise on the cat. Acta Otolaryngol (Stockh) 176:1-91.

Mossop, J. E., Wilson, M. J., Caspary, D. M. and Moore, D. R., 2000. Down-regulation of inhibition following unilateral deafening. Hear Res. 147, 183-187.

Muhlnickel, W., Elbert, T., Taub, E. and Flor, H., 1998. Reorganization of auditory cortex in tinnitus. Proc Natl Acad Sci U S A. 95, 10340-10343. 
Nakahara, H., Zhang, L. I. and Merzenich, M. M., 2004. Specialization of primary auditory cortex processing by sound exposure in the "critical period". Proc Natl Acad Sci U S A. 101, 71707174.

Oliver, D. L., 2005. Neuronal organization of the inferior colliculus. In: The inferior colliculus (Winer JA, Schreiner CE, eds), pp 69-114. New York: Springer.

Oliver, D. L. and Morest, D. K., 1984. The central nucleus of the inferior colliculus in the cat. J Comp Neurol. 222, 237-264.

Pérez-González, D., Malmierca, M. S., Moore, J. M., Hernández, O. and Covey, E., 2006. Duration selective neurons in the inferior colliculus of the rat: topographic distribution and relation of duration sensitivity to other response properties. J Neurophysiol. 95, 823-836.

Potashner, S. J., Suneja, S. K. and Benson, C. G., 1997. Regulation of D-aspartate release and uptake in adult brain stem auditory nuclei after unilateral middle ear ossicle removal and cochlear ablation. Exp Neurol. 148, 222-235.

Rajan, R., 2001. Plasticity of excitation and inhibition in the receptive field of primary auditory cortical neurons after limited receptor organ damage. Cereb Cortex. 11, 171-182.

Rajan, R. and Irvine, D. R., 1998. Absence of plasticity of the frequency map in dorsal cochlear nucleus of adult cats after unilateral partial cochlear lesions. J Comp Neurol. 399, 35-46.

Rajan, R., Irvine, D. R. and Cassell, J. F., 1991. Normative N1 audiogram data for the barbiturateanaesthetised domestic cat. Hear Res. 53, 153-158.

Rajan, R., Irvine, D. R., Wise, L. Z. y Heil, P., 1993. Effect of unilateral partial cochlear lesions in adult cats on the representation of lesioned and unlesioned cochleas in primary auditory cortex. $\mathrm{J}$ Comp Neurol. 338, 17-49.

Rees, A., Sarbaz, A., Malmierca, M. S. and Le Beau, F. E., 1997. Regularity of firing of neurons in the inferior colliculus. J Neurophysiol. 77, 2945-2965.

Schreiner, C. E. and Langner, G., 1997. Laminar fine structure of frequency organization in auditory midbrain. Nature. 388, 383-386.

Snyder, R. L. and Sinex, D. G., 2002. Immediate changes in tuning of inferior colliculus neurons following acute lesions of cat spiral ganglion. J Neurophysiol. 87, 434-452.

Suneja, S. K., Yan, L. and Potashner, S. J., 2005. Regulation of NT-3 and BDNF levels in guinea pig auditory brain stem nuclei after unilateral cochlear ablation. J Neurosci Res. 80, 381-390.

Vollmer, M., Beitel, R. E., Snyder, R. L. and Leake, P. A., 2007. Spatial selectivity to intracochlear electrical stimulation in the inferior colliculus is degraded after long-term deafness in cats. $\mathrm{J}$ Neurophysiol. 98, 2588-2603. 
Yoshida, N., Hequembourg, S. J., Atencio, C. A., Rosowski, J. J. and Liberman, M. C., 2000. Acoustic injury in mice: $129 / \mathrm{SvEv}$ is exceptionally resistant to noise-induced hearing loss. Hear Res. 141, 97-106.

Yu, X., Sanes, D. H., Aristizabal, O., Wadghiri, Y. Z. and Turnbull, D. H., 2007. Large-scale reorganization of the tonotopic map in mouse auditory midbrain revealed by MRI. Proc Natl Acad Sci U S A. 104, 12193-12198.

Zhang, L. I., Bao, S. and Merzenich, M. M., 2001. Persistent and specific influences of early acoustic environments on primary auditory cortex. Nat Neurosci. 4, 1123-1130. 